\title{
When the whole is more than the sum of its parts: Investigating ways that advanced skills for VET teachers are conceptualised and how they are developed.
}

\section{Teressa Schmidt}

Advanced Diploma Business Administration with Distinction (USQ)

Associate Degree Further Education and Training with Distinction (USQ)

Bachelor Further Education and Training with Dean's Commendation (USQ)

School of Education and Professional Studies

Arts, Education and Law

Griffith University

Submitted in fulfilment of the requirements of the degree of Doctor of Philosophy

February, 2019 


\section{ABSTRACT}

This thesis reports on an interpretive inquiry undertaken to understand the way that advanced skills for Australian VET teachers are conceptualised and how they are developed. This is an important topic which may help to inform contemporary discourse in the sector, and which examines the quality of Australian VET provision, particularly the quality VET teaching (see for example, Griffin, 2017; Harris, 2015; Smith \& Yasukawa, 2017).

There is a large body of work which focuses on quality teaching, however it is difficult to find agreement on the skills, knowledge, behaviours and characteristics of expert VET teachers. Considerably diverse and often conflicting conceptualisations of teaching and teachers' work are represented in the literature on teaching in general, and while the volume is so large that it is almost overwhelming, two basic approaches have been discerned and discussed in the thesis. On the one hand, there are the conceptualisations arrived at through a 'reductionist' approach, which seek to reduce or atomise teaching into its various parts to arrive at a requisite list of skills, knowledge and attributes, and particular behaviours, methods or practices teachers must implement to teach well. On the other hand, there exists a more 'holistic' approach which seeks to understand teaching by focussing on the personal an essential, yet somewhat intangible and often individualist quality that a teacher may bring to his/her work. It recognises the importance of the teacher as central to teaching, 'the distinctive, irreproducible human being who inhabits the role of the teacher' (Hansen, 2001, p. 1).

In the Australian VET sector, the discourse on quality teaching has been dominated by a reductionist approach, resulting in what Mulcahy (2011) may describe as a 'standards movement', and which is characterised by multiple attempts to atomise VET teachers' work into a comprehensive framework of essential, reproducible capabilities and behaviours (see for example, Innovation and Business Skills Australia, 2013; LH Martin Institute, 2016; Mitchell \& Ward, 2010). This work reflects similar activity internationally and across education sectors which has resulted in the development of professional standards proceeding at 'remarkable speed' (Mulcahy, 2003, p. 3), triggered by neo-liberal education policy reform. The standards movement in VET is closely aligned to a debate about professionalism and the VET workforce (Atkins \& Tummons, 2017; Guthrie \& Clayton, 2012). It is also representative of the contemporary turn in the sector which attempts to conceptualise teaching as a competency, 
in which the elements of teaching practice are atomised into lists of reproducible and measurable skills and knowledge.

The research project employed a multiple case study methodology involving three case studies, each a large public VET provider in Queensland, Australia. Data to develop each case was collected through individual, semi-structured interviews with managers and teachers from each organisation. Key findings suggest divergent views between VET managers and VET teachers about the nature of advanced skills. While VET teachers with advanced skills are likely to conceptualise these holistically, their managers are more likely to express an atomised view which is highly influenced by context. It is suggested that VET teachers develop advanced skills by accessing a wide range of activities, and take personal responsibility for their own continuing professional development needs. Their development may be negatively impacted by insufficient access to necessary resources and by unbalanced organisational approaches to professional development which emphasise the capabilities needed to comply with regulatory requirements and overlook other aspects of the VET teacher's personal and professional learning needs.

Despite the small scale and situated nature of the project, it presents implications likely to be relevant sector-wide. The research suggests that, while the reductionist approaches which dominate contemporary discussions may help to identify some of the relevant capabilities of VET teachers, they largely overlook the importance of the teacher's personal, ethical and moral character and the features that stem from this. The thesis calls on the sector to interrogate assumptions that generate ever more lists and frameworks, and to explore alternative 'holistic' conceptualisations which place the being of the teacher at its core and which recognise the moral, ethical and relational aspects of teaching. Further, it proposes that developing the language to conceptualise and describe a more 'holistic' view of VET teaching may complement existing frameworks, to provide an even more insightful and comprehensive understanding of 'good' VET teaching, which may in turn help to inform strategies for the education and development of VET teachers to ensure quality teaching into the future. 


\section{Statement of Originality}

This work has not previously been submitted for a degree or diploma in any university. To the best of my knowledge and belief, the thesis contains no material previously published or written by another person except where due reference is made in the thesis itself. 


\section{ACKNOWLEDGEMENTS}

There are many people who deserve thanks and acknowledgement for their contribution to this thesis. Firstly, I must thank the research participants who so enthusiastically and generously gave of their time so that I could explore their views on a topic which is undoubtedly close to their hearts.

A genuine, heartfelt thanks must also go to my Principal Supervisor, Dr. Steven Hodge, who patiently - and with good humor - listened, countered, discussed, and importantly, encouraged me to see things from different perspectives and to journey down some frustratingly meandering but enlightening paths which I may not have encountered on my own. I feel blessed to have had such a unique, authentic and genuinely committed individual to guide my research and my studies. The significance of this happy fact was not lost on me while I explored the importance of such qualities in 'good teaching'. Thankyou also to Dr. Raymond Smith, Associate Supervisor, whose sage words and advice were offered exactly at the time they were most needed.

I must not forget to mention my partner Ray and daughter Anna who, for many weeks, months and years, were regularly woken by the very loud grind of the coffee machine during obscenely early hours of the morning - hours which, I admit, most others would likely refer to as the middle of the night. They also endured the closed office door, the distracted gaze and the fragmented and unfinished conversations, as I had embarked on a very personal journey, and not one that I could easily share with them.

Finally, I must thank my friends and colleagues who continued to ask after my progress, even when I forbade them from doing so. To find them all waiting at the end to celebrate my completion brought a most unexpected and humbling joy. 


\section{TABLE OF CONTENTS}

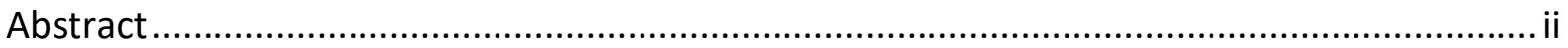

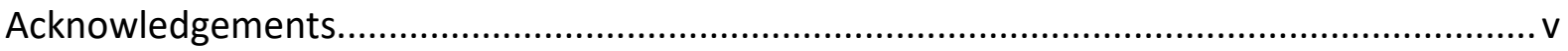

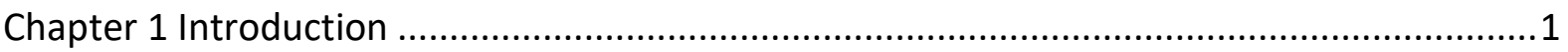

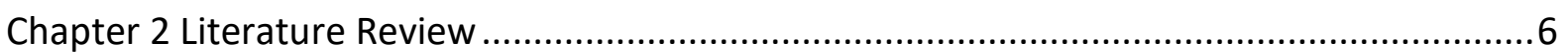

How are advanced teaching skills understood? .......................................................... 6

The reductionist approach to conceptualisations of teaching .....................................

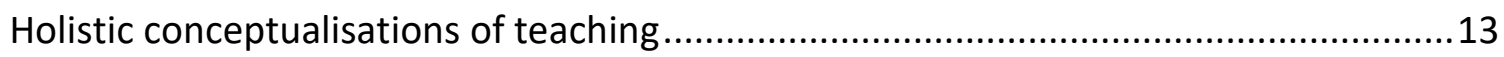

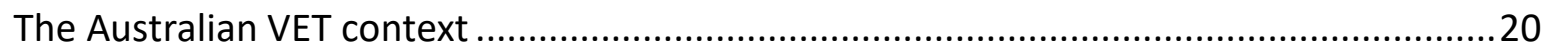

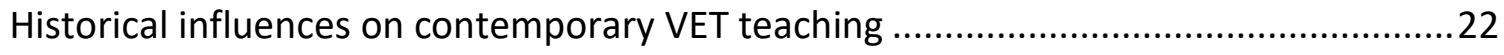

From VET teacher to VET practitioner: the impact of CBT, neoliberalism and new

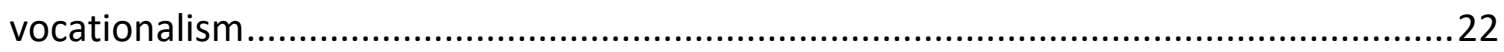

The contemporary VET environment: a focus on VET teaching ...................................28

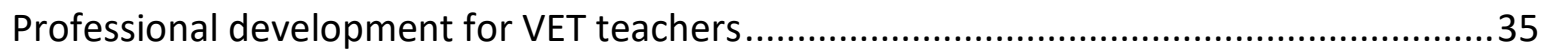

Professional development relating to vocational pedagogical skills ...............................36

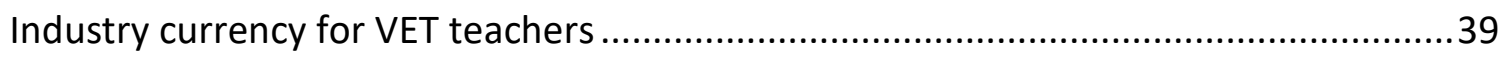

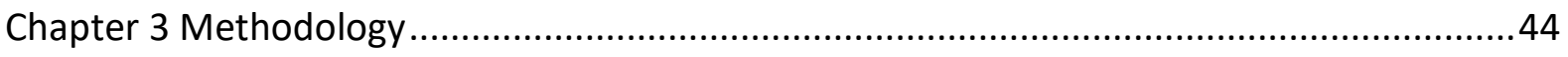

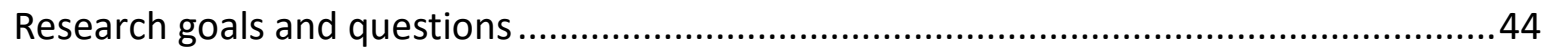

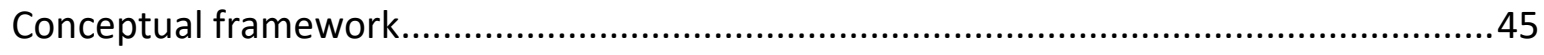

Ways of meaning making - social constructionism and the individual ..........................46

Secret, sacred and cover stories: ways of managing epistemological dilemmas ...........48

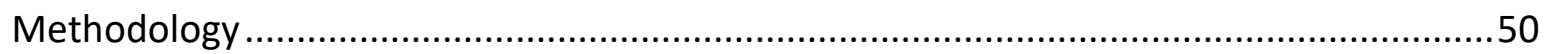

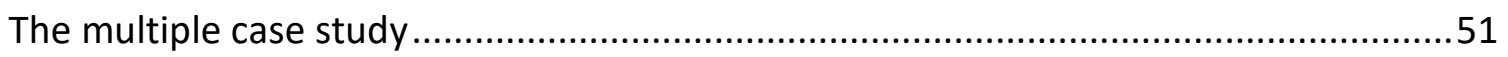

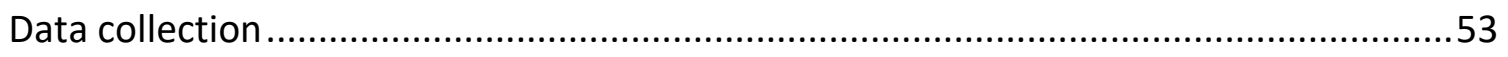

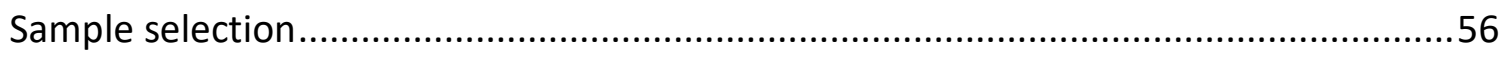

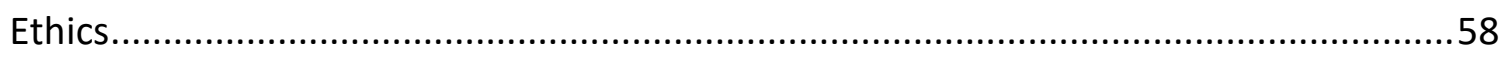


Data analysis .59

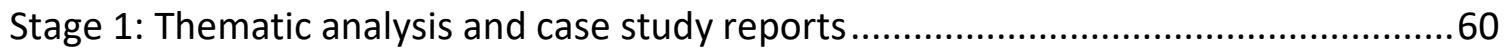

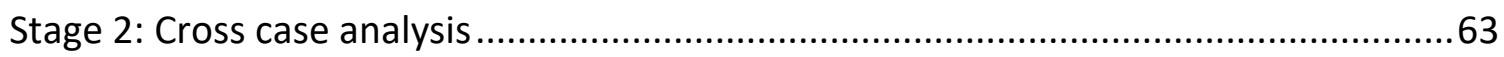

Validity, trustworthiness and the qualitative multiple case study methodology................65

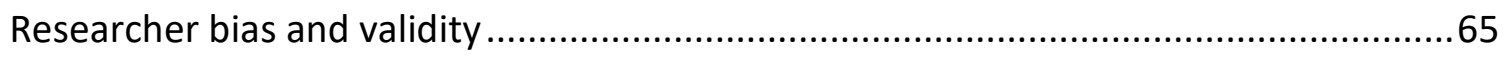

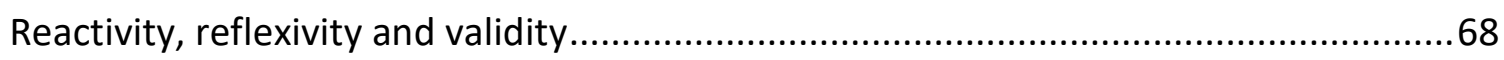

Case studies, transferability and usefulness of the findings .........................................69

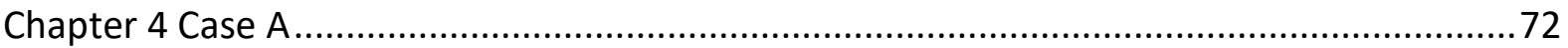

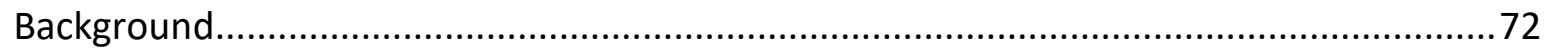

Data collection, participants and the case study context .......................................... 72

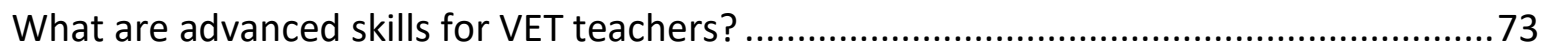

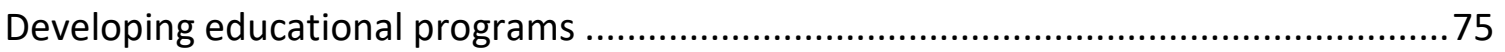

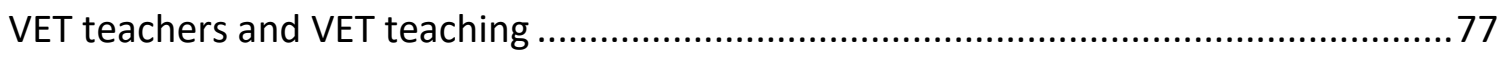

Passion, communication and connectedness in VET teaching.......................................80

Development of advanced skills for VET practitioners ................................................ 85

Formal education and the development of advanced skills ........................................86

The relationship between time, experience and advanced skills ..................................89

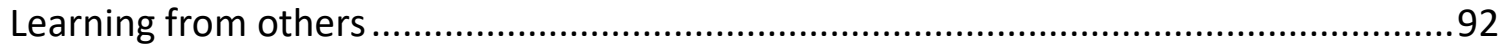

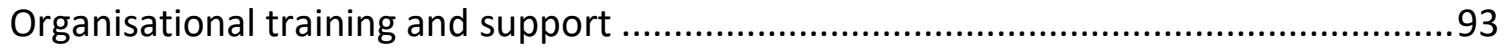

Personal attributes and development of advanced skills ..........................................95

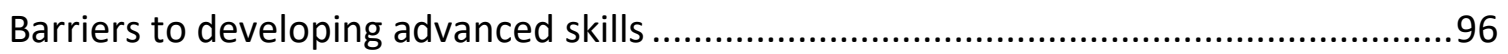

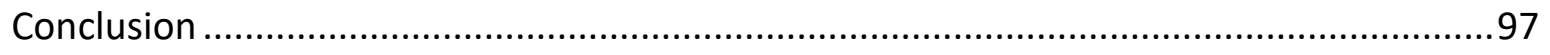

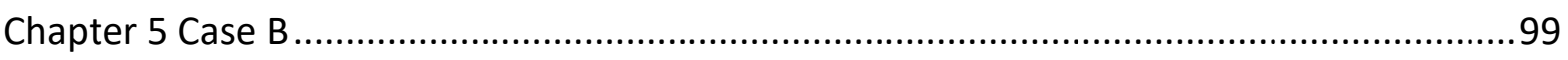

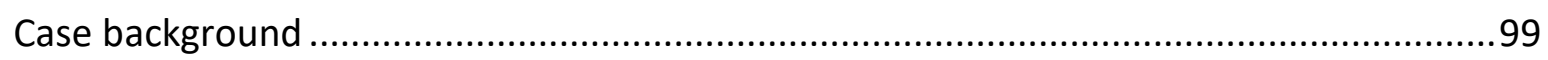

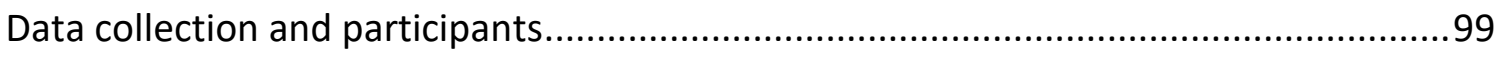

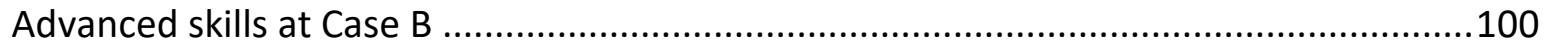


Curriculum, assessment and compliance .103

Teaching in different contexts: technology and advanced skills...............................106

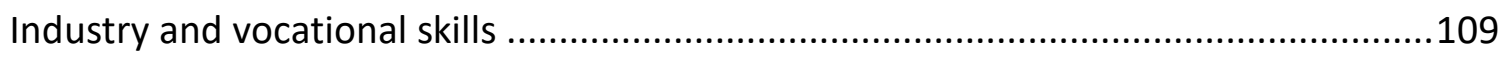

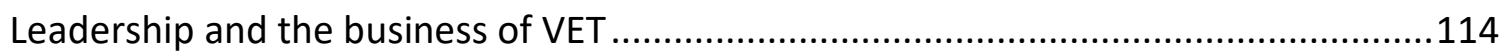

Personal attributes, relationships and the individual VET teacher .............................116

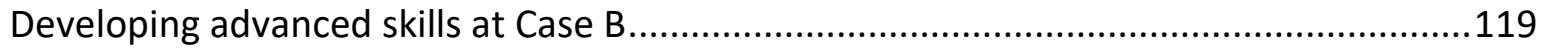

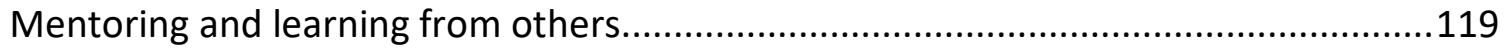

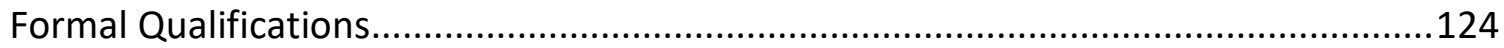

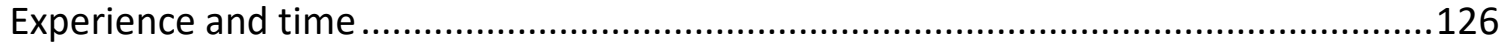

Barriers to developing advanced skills at Case B ...................................................128

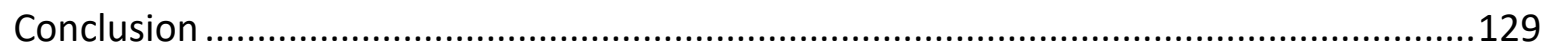

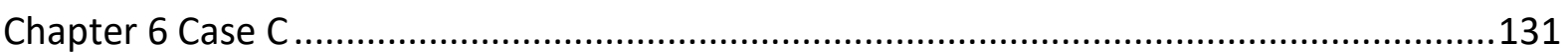

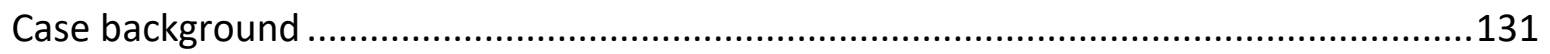

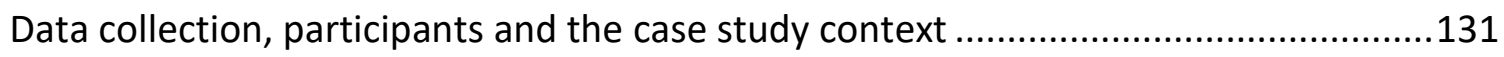

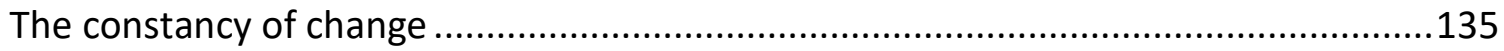

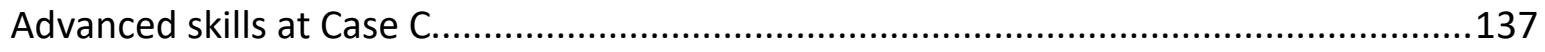

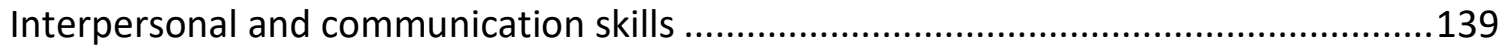

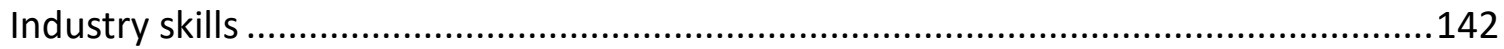

Managing the requirements of the job, the organisation and the VET sector ..............144

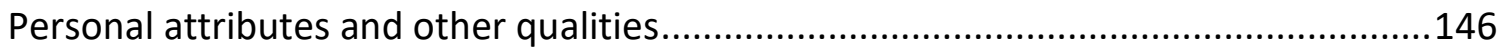

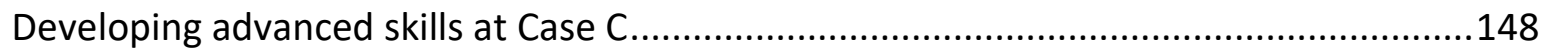

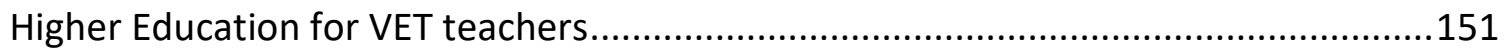

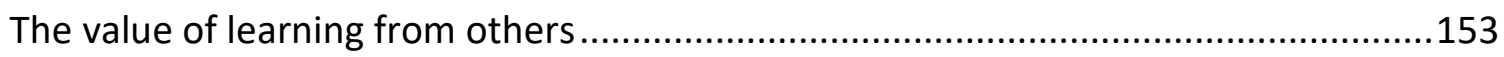

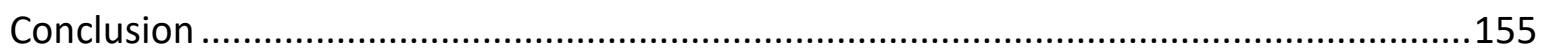

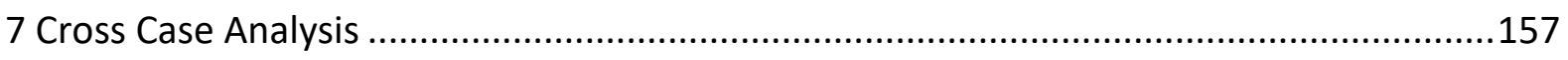

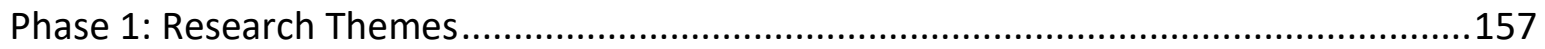


Phase 2: Individual Case Analysis and Findings.

Case A Analysis and Findings 159

Case B Analysis and Findings 162

Case C Analysis and Findings .165

Phase 3: Merged Findings .167

Theme 1: Can advanced skills be described as a list of skills, knowledge and capabilities? .168

Theme 2: Is there an aspect of advanced skills which is related to the individual character of the teacher? 168

Theme 3: Are there differences between the way that managers and teachers understand advanced skills? 169

Theme 4: What factors contribute to the development of advanced skills?..... 170

Theme 5: What are the barriers to the development of advanced skills? .171

Phase 4: Assertions .172

Chapter 8 Discussion. .173

Assertion 1 .174

VET managers' conceptualisations of advanced skills .175

VET teachers' conceptualisations of advanced skills .181

Managing Epistemological Dilemmas: Secret, Sacred and Cover Stories. .189

Assertion 2 .191

Higher level study and the development of advanced skills..... 193

Learning from others and the development of advanced skills. 196

The importance of the individual and personal agency in developing advanced skills.200

Assertion 3 .203

The barrier of limited resources 203

Unbalanced approaches to professional development and the impact on advanced skills 


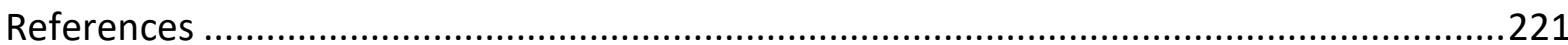

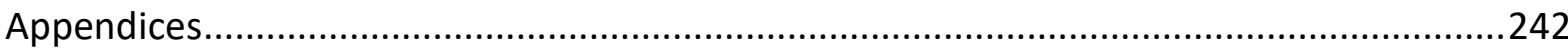

Appendix A: Plain Language Information Statement and Informed Consent ...................243

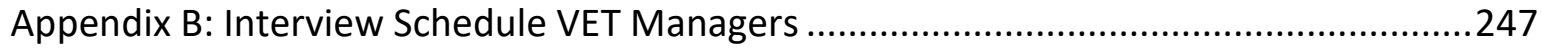

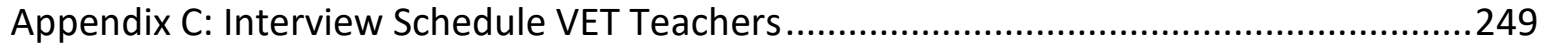

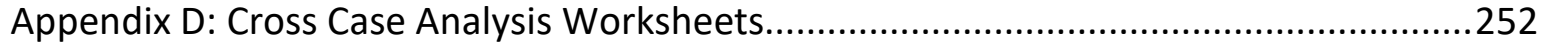




\section{CHAPTER 1 INTRODUCTION}

Conceptions of teaching have consequences. They influence how teachers think about and conduct their work. They shape what researchers investigate. They guide how teacher educators prepare new candidates. They play a role in what students come to expect from their teachers. And they underlie how administrators, policy makers, politicians, businesspersons, and parents perceive and judge teachers. In short, conceptions of what teaching is, and of what it is for, make a difference in educational thought and practice. (Hansen, 2001, p. 1)

This research project shines a light on teachers in Australia's Vocational Education and Training (VET) sector. In particular, it explores the attributes of the 'good teacher' in VET by asking the question 'How are advanced skills for VET teachers understood and how are they developed?' This is an important topic for contemporary VET, given the current discourse in the sector which focuses on VET quality (Griffin, 2017; Harris, 2015; Smith \& Yasukawa, 2017) and the questionable sufficiency of the Certificate IV in Training and Assessment, the mandated teaching qualification required by VET teachers (Billett, Choy, \& Smith, 2013; Smith \& Grace, 2011). While not a new topic in Australian VET literature, the discussion of VET quality and VET teaching has now reached 'fever pitch' (Griffin, 2017, p.7), undoubtedly fuelled by the reputational damage the sector has suffered post-2012 (Braithwaite, 2018; Griffin, 2017; Guthrie, Smith, Burt, \& Every, 2014), due to the introduction of competitive funding models and the activities of training providers who prioritised profit over quality (Toner, 2014), and in some cases, employed unethical and unscrupulous recruitment, teaching and assessment practices (Braithwaite, 2018; Buchanan, 2012; Harris, 2015; Nakar, Bagnall, \& Hodge, 2018; Toner, 2014).

While the lens on Australian VET quality has focused on the effectiveness of its regulator or on the relevance, consistency and interpretation of its curriculum (Hodge, 2014; Smith, Smith, Hampson, \& Junor, 2015), it has also turned towards the quality of teachers and teaching in the sector. Wheelahan and Moodie (2011) reported an 'unprecedented level of attention' (p. 13) being paid to VET teachers and VET teaching in Australia, a situation which has continued unabated. There is an established link between VET teaching quality and student outcomes (Braithwaite, 2018; Walker, 2012; Wheelahan \& Moodie, 2011) and according to Harris $(2015$, p. 16), the 'quality of the VET system is only as good as its teachers and trainers'. 
My curiosity for this topic began in 2008, upon my appointment to a management role in TAFE Queensland with supervisory responsibility for more than 40 vocational teachers. Prior to this appointment I had been a teacher at the same TAFE Institute for more than 10 years. During that time I had developed a close network of fellow teachers, who, despite coming from diverse industry backgrounds and teaching in different vocational areas, shared a passion for vocational education. These teachers were the 'good teachers' in VET, respected by their students, other teachers and industry, motivated by successful outcomes for those that they taught and confident in the power of VET to change lives. Soon after being appointed to my new supervisory role, the TAFE Institute became involved in Mitchell and Ward's (2010) research project which intended to identify the capabilities of VET teachers and to develop a 'comprehensive model of VET professional practice' (p. 9). The Institute's teachers voluntarily completed an online survey to self-assess their skills, knowledge and capabilities in vocational education and training. I soon noticed that the organisation's participation in this project had a significant influence on the way that VET teachers' roles were conceptualised and the language used in relation to teaching and teachers. Managers began to refer to teachers as 'practitioners', while beginning teachers became known as 'novices'. Exceptional teachers who were considered to have business acumen and who therefore contributed to the organisation's commercial business targets were revered as 'Advanced VET Practitioners'.

The influence of Mitchell and Ward's research project also began to permeate the organisations' annual Performance and Professional Development Planning (PPDP) process for VET teachers. PPDP meetings were intended to be a discussion between the teacher and the manager to determine whether the teacher's overall performance in the organisation was satisfactory (or whether improvement was required), and to identify short and long term developmental goals dependent upon the individual teacher's professional development requirements and the organisation's strategic needs. This largely discursive style of PPDP became more structured following the Institute's participation in Mitchell and Ward's (2010) research project, as a teacher's performance and capability development requirements were now meticulously analysed against the nine skill sets articulated in the model of VET teacher capabilities, and professional development goals became focused on ensuring that teachers moved as efficiently as possible from Mitchell and Ward's (2010) novice practitioner level 
towards that of an Advanced VET Practitioner. Personally, as a manager, I encountered problems implementing the new PPDP approach. While the model distilled the requirements of VET teachers' work to a discrete set of capabilities and therefore provided a relatively objective means by which one could evaluate a teacher's performance or prescribe appropriate remedial developmental activities, it didn't necessarily capture the unique qualities or essence of the passionate, committed and dedicated VET teachers who had made up the professional network I had inhabited when I myself was a teacher. I felt that there was something missing or misunderstood from the model, despite the rigorous process used to develop it and the comprehensive list of skills and capabilities that it addressed, and soon afterwards I embarked upon this research project to further explore the qualities of the 'good' VET teacher. The reference to 'advanced skills' for VET teachers in the research question is a nod to its origins from this period and to the language which became commonplace in the VET sector during the time of Mitchell and Ward's (2010) pervasive study.

Other VET teaching capability frameworks were developed in the wake of Mitchell and Ward's (2010) model, each one aiming to provide a more comprehensive and complete articulation of VET teachers' required skills, knowledge and capabilities. Innovation and Business Skills Australia (IBSA) developed the 'VET Practitioner Capability Framework', intended to provide a 'common language for the knowledge, skills, behaviours and attitudes that practitioners will display if they are working well in their roles' (Innovation and Business Skills Australia, 2013, p. 6). Soon after, in 2015, the Queensland College of Teachers (QCT) developed the Professional Standards for Further Education and Training Practitioners, claimed to describe the 'gold standard' for VET teachers (Queensland College of Teachers, 2015, p. 1). TAFE Queensland, although involved in the research study that informed Mitchell and Ward's Model of VET Practice (Mitchell \& Ward, 2010), and in the consultation process undertaken for the development of IBSA's VET Practitioner Capability Framework (Innovation and Business Skills Australia, 2013) and QCT's Professional Standards for Further Education and Training (Queensland College of Teachers, 2015), identified a need to develop its own framework, the TAFE Queensland Educator Capability Framework (TAFE Queensland, 2016). The most recent framework to be developed is the LH Martin Institute's (2016) VET Teaching Capability Framework, which to date, is still in draft.

Each of the VET teacher capability frameworks described have been arrived at through an approach which I have termed 'reductionist'. This is a way of understanding and describing 
teaching and teachers' work by distilling it to an atomised list of requisite skills, knowledge and attributes teachers must develop and behaviours, methods or practices they must implement, in order to teach well. A review of the relevant capability frameworks and other conceptualisations of teaching which have been arrived at through reductionist approaches are discussed in Chapter 2, Literature Review. In Chapter 2 I have also discussed alternative conceptualisations of teaching which can be seen to be more 'holistic' in their approach. Rather than seeking an itemised list of requisite skills, knowledge, characteristics and behaviours, holistic conceptualisations tend to focus on the personal, individual and somewhat intangible quality that a teacher may bring to his/her work. This is a way of understanding teachers' work which recognises the importance of the teacher as central to teaching, described by Hansen (2001, p.1) as 'the distinctive, irreproducible human being who inhabits the role of the teacher'. To situate the discussion on teaching in the context of Australian VET, a background discussion on the significant milestones and changes in the sector has also been provided in Chapter 2, along with an analysis of how these sector-wide contextual changes have impacted upon VET teachers' work, conceptualisations of VET teaching and on initial education and continuing professional development for VET teachers.

In order to explore conceptualisations of VET teachers' work and to answer the question 'How are advanced skills for VET teachers understood and how are they developed?' a methodology was required which would allow the exploration of conceptualisations arrived at through both reductionist and holistic approaches and the developmental implications associated with these divergent approaches. In Chapter 3, Methodology, I have explained and justified a qualitative research design which utilises a multiple case study approach, in which each case is a large Queensland public VET provider. The design was structured according to Maxwell's (2005) interactive model which requires that all aspects of the design, from the conceptual framework to the methods used to collect and analyse data, are logically related and interconnected. Recognising the impact of the already existing conceptualisations of teachers' work in the context of the VET sector, I have framed the study according to an overarching worldview of social constructionism. I have, however, also acknowledged the existential elements evident in the individual, authentic decisions made by VET teachers about teaching and the epistemological dilemmas that they may face when their individual choice is in conflict with the expectations constructed and communicated within the VET landscape in which they teach. Chapter 3 also provides an explanation and 
justification of the narrative interviews used to collect data for each case study, and the process used to analyse and interpret the data using both thematic and cross-case analysis methods. Issues of validity and transferability raised by the research methodology have been addressed in this chapter.

The report produced for each of the three case studies (Case A, Case B and Case C) are provided in chapters 4,5 and 6 respectively. This is followed by Chapter 7, Cross Case Analysis, which considers the project's empirical data and presents the findings that are unique to each Case and those which are shared across the Cases. The findings suggest there are divergent views between VET managers and VET teachers on the nature of advanced skills and that managers' conceptualisations were more likely to be reductionist in their approach and highly contextual, influenced by the organisation's business goals at a particular time. VET teachers' conceptualisations of advanced skills, on the other hand, were more holistic and less influenced by context, focusing primarily on teaching, learners and learners' achievements. The research also indicates that VET teachers develop advanced skills through a range of different activities, and that they demonstrate a personal commitment to their own continuing professional development. Further, the development of advanced skills may be negatively impacted by resourcing issues, or by an organisation's unbalanced approach to professional development which prioritises activities relating to regulatory or compliance requirements over those relating to other aspects of the teachers' personal and professional development needs. Chapter 8, Discussion, draws upon the empirical data and relevant literature to discuss and support the project's findings and to address the research question. Finally, in Chapter 9, Conclusion, the implications of the research outcomes are discussed and suggestions for its application in the VET sector are made. 


\section{CHAPTER 2 LITERATURE REVIEW}

The way in which teachers' work is conceptualised and understood is an important topic, for as Hansen (2001) points out, 'conceptions of teaching have consequences' (p. 1). For example, the conceptions held by teachers and others about what teaching is and the role of the teacher, in turn influence how teachers carry out their work, how they are perceived and judged by others, how aspiring teachers are prepared for teaching and what is researched about teaching (Hansen, 2001, p. 1). Perhaps unsurprisingly then, there exists an abundant body of work which seeks to understand good teaching, albeit one which focuses predominantly on the compulsory education sector rather than on VET. While there are, unarguably, differences between the work undertaken by teachers in VET and their counterparts in the compulsory sector, the purpose of teaching and the intention of teachers are likely more similar between sectors than they are contrasting. It would be, according to Robertson (2008, p. 8), 'unwise' to disregard the research undertaken in relation to the compulsory school sector, therefore I will begin the review by analysing the different ways in which good teaching has been conceptualised generally, before focussing more specifically on the contemporary Australian VET context. I have identified two contrasting and somewhat conflicting approaches that have been employed to understand teachers' work and teaching, and will use these to frame the discussion. The first approach is essentially reductionist, in that it seeks to analyse and atomise good teaching to a technical activity with a definable and reproducible set of specific skills, knowledge or behaviours. The other approach is more holistic, and rather than seeking reproducibility and conformity, it represents teaching as a personal activity by recognising and celebrating the individual teacher as central to good teaching. Finally, I will discuss contemporary views on VET teaching and VET teacher development and examine the turn towards a predominantly reductionist approach in the way that these important concepts are dealt with in the sector.

\section{How are advanced teaching skills understood?}

There is a large body of work which focuses on the teachers who stand apart from their peers, those variously described as the 'good teacher' (Palmieri, 2004), the 'excellent teacher' (Corben \& Thomson, 2001), the 'expert teacher' (Turner-Bisset, 2001), the 'accomplished' teacher (Shulman, 1987), the 'authentic teacher' (Hodge, 2015; Laursen, 2005), or even, in the case of 1990's Australian Vocational Education and Training, the 
'advanced VET practitioner' (Mitchell, 2008). It is difficult however, to find agreement in the literature on the skills, knowledge, behaviours and characteristics that expert teachers demonstrate, and just as there are many different terms used to describe the outstanding teacher, there are also multiple perspectives on what is required to be one. This is unsurprising, considering, as Turner-Bisset (2001) points out, judgments on teaching expertise are often subjective, 'coloured by the observer's own classroom experience, knowledge of teaching and learning, and subject knowledge' (p. XI). Adding to the complexity of the argument, are the multiple and sometimes conflicting conceptualisations on the nature of teaching and teachers' work and the results that effective teaching should yield. There is no question, according to Noddings (2003) that teaching is 'conceptually and practically dependent on learning' (p. 242). Dewey (1910), for example, likened teaching to a somewhat transactional relationship between teacher and student, comparable to buyer and seller. While acknowledging the responsibility of the student in the teaching-learning relationship, Dewey's (1910, p. 30) perspective was that if the student had not learned, then the teacher cannot claimed to have taught.

While it is accepted that teaching is inextricably linked to learning, the literature abounds with varying views on how teachers influence learning, and on how teaching should best be conceptualised. Teachers have been compared to artists who bring creativity, intuition and individual talent to the classroom, with learning occurring as part of the process rather than as a direct result (Eisner, 1994), or alternatively as craftspeople who skilfully apply technical expertise to produce an intended outcome (Lortie, 1975; Tom, 1980). They have been considered the 'knowers', with knowledge of themselves, their students, the content and of teaching and learning (Connelly \& Clandinin, 1999, p. 1), or viewed as applied scientists and psychologists who apply a formulaic approach to teaching with the expectation of predictable and reproducible results (Gage, 1989; Gage \& Travers, 1973). Some apportion teachers the responsibility to uphold societal norms, ethics and values (Dewey, 1966; Noddings, 2016; Van Manen, 1994), while yet others challenge them to be the emancipators charged with empowerment of individuals towards self-efficacy and the ability to think for themselves (Freire, 1972; Greene, 1973; Rancière, 1991).

While the volume of literature and the diversity of views it presents is so large as to seem almost overwhelming, there appears to be two distinctly different approaches used to understand and describe teaching and teachers' work. On the one hand, there is the 
conceptualisation of teaching which is arrived at through a 'reductionist' approach, which seeks to reduce or atomise teaching into its various parts, to arrive at a requisite list of skills, knowledge and attributes that teachers require and particular behaviours, methods or practices that they must implement in order to teach well. On the other, there exists a more holistic approach which seeks to understand teaching by focussing on the personal - an essential, yet somewhat intangible and often individualist quality that a teacher may bring to his/her work. It recognises the importance of the teacher as central to teaching - 'the distinctive, irreproducible human being who inhabits the role of the teacher' (Hansen, 2001, p. 1). The review of the literature in this section will begin with an analysis through the reductionist lens before going on to explore the holistic perspective of teaching.

\section{The reductionist approach to conceptualisations of teaching}

The reductionist approach to conceptualisations of teaching is one which deconstructs teachers' work into its discrete parts, aiming to reveal the specific skills, knowledge, attributes and behaviours that a teacher must demonstrate for 'good teaching'. It seeks a tangible measure of teaching quality and reproducible uniformity, and is an instrumental way of conceptualising teaching which focuses on the 'means' - what the teacher should be able to do, and how he/she should do it; and the 'ends' - what the outcome of teaching should be (Hansen, 2001, pp. 2-3). The literature presents numerous representations of teaching derived through a reductionist approach, each with a unique perspective, sometimes conflicting and often overlapping with each other. For example, teaching has been 'unpacked' to reveal it as an applied science, a system, a reflective process or as a competency. Even the esteemed and popularly cited knowledge-base models of teaching produced by eminent researchers Lee Shulman (1987) and Rosie Turner-Bissett (2001) can be categorised as essentially reductionist, with each aiming to produce the most complete and comprehensive description of the knowledge, skills and behaviours the good teacher requires. Each of these iterations will be dealt with in turn in this section. Firstly though, I will address the concept that good teaching practice can be regarded as a common-sense activity, and is something that we can all do because we have all experienced being taught (Squires, 1999, p. 3).

The idea that good teaching can be attributed to common sense has its theoretical basis in social learning theories which assume sharing and learning knowledge to be an everyday, ordinary event attained through participation in society (see for example, Berger \& 
Luckmann, 1966) and in communities of like-minded or similarly engaged people (Brown, Collins \& Duguid, 1989, Lave \& Wenger, 1991). We have all conceivably had experience doing the things that teachers do, such as planning and resourcing activities, encouraging or giving feedback to others, showing others how to do things and explaining things to others. We have all been teachers and we have all been taught (Squires, 1999, p. 4). Although not widely articulated as a model of teaching, Hargreaves (1993, p. 90) asserted that the development of common sense knowledge, and in particular, what he termed 'professional common sense knowledge', relating specifically to teaching, is the foundation to good teaching practice and an essential component of teacher education. Objections to the conceptualisation of teaching as a common sense activity centre on the argument that a profession cannot simply be reduced to a common sense activity, as it relies upon specialised forms of knowledge (Squires, 1999). It also infers a pragmatic approach to teaching - doing the best with what is available at the time - which essentially limits opportunity for analysis and development of teaching practice (Turner-Bisset, 2001).

An alternative conceptualisation, and one which starkly contrasts the view of teaching as 'common sense', is the idea that it should be regarded as an applied science, and that by applying a learned formula or prescriptive series of actions, teachers can expect predictable and reproducible results on student learning (Gage, 1989; Gage \& Travers, 1973). This conceptualisation of teaching is primarily derived from psychology, and while many contemporary learning theories and pedagogical principles have emerged from it (Squires, 1999), it has largely been discredited as a model of teaching, (Turner-Bisset, 2001, p. 2). The problem is that it does not take into account the many contingencies that arise when interacting with humans, contingencies which will alter the result of any application of formula or theory to a human subject in order to produce an outcome of learning (Squires, 1999). The idea that teaching could be conceptualised as an applied science was controversial, and opponents to the idea sought to find an alternative and what they considered to be a more suitable representation of teaching. From these tensions, the conceptualisation of teaching as a craft emerged.

Teaching as a craft is a paradigm which assumes that similarly to silversmithing, pottery or woodwork, the process and act of teaching can be imitated, practiced, refined and mastered (Squires, 1999, p. 8). Lortie (2002, p. 135), for example, held that an expert teacher approaches his/her work as a craftsperson, applying considerable technical expertise and 
judgment to produce an intended (or hoped-for) outcome, monitoring progress and making corrections as required. Similarly, Tom (1980) likened teaching to the craft of fishing, an activity which also requires considerable knowledge, skill and experience to succeed. He differentiated teaching as a 'moral craft' though, due to the normative value and expectations placed upon the relationship between teacher and student, which requires the teacher to also apply 'analysis, judgement and moral sensitivity' to the role (Tom, 1980, p. 321). This represents a shift by Tom towards a more holistic approach to conceptualising teaching, and so will be dealt with in more detail in the following section. According to Squires (1999) the conceptualisation of teaching as a craft is most likely to resonate with the vocational, technical and further education sector due to its origins from the apprenticeship system and its continuing remit for reproduction of largely practical and skills-based work. It does have limitations however. Turner-Bisset $(2001$, p. 2$)$ for example, is critical of its focus on only the 'concrete in teaching' i.e. teachers' knowledge which can be codified. Further, and by Lortie's own admission, the analogy is fraught due to the 'intangible' nature of teaching in a context which is characterised by 'the absence of concrete models for emulation, unclear lines of influence, multiple and controversial criteria, ambiguity about assessment timing, and instability in the product' (Lortie, 2002, p. 136).

A view of teaching which enjoyed brief popularity, is described by Squires (1999, p. 13) as the 'teaching as a system paradigm'. Proponents apply a generalist view of work processes and decision making to teaching, based upon the assumption that teaching (and other kinds of professional work) can be rationalised and reduced to a somewhat administrative flow of defined decision making processes and associated consequential actions (Squires, 1999). As this is a generalist paradigm, it is limited in that it does not specifically identify or acknowledge the functions of teachers or the work that they do; it is merely a process ends-means model (Squires, 1999, p. 14). Further, according to TurnerBisset $(2001$, p. 3), it does not account for the unpredictable nature of teaching and the variety of contexts in which it takes place.

An alternative to the systems conceptualisation of teachers' work is the view of teaching as reflective practice, emerging from the work of Schön (1983) and Argyris (e.g. Argyris \& Schön, 1974). Focusing on the way that teachers develop and apply their teaching expertise, the reflective practice paradigm argues that, rather than follow a formulaic process, effective teachers must learn to respond to and solve problems and contingencies that arise 
in the process of teaching by reflecting on what is happening (reflection in action) and on what has happened (reflection on action) (Schön, 1983). Squires (1999, pp. 16-17) and Turner-Bisset (2001, p. 3) are critical of the conceptualisation, as it focuses only on the notion of reflective practice as an element of good teaching, neglecting the other functions of teaching work and the knowledge, skills or processes required to perform them. Brookfield (1995) for example, portrays critically reflective teaching not as a practice per se, but rather as a means of identifying and scrutinizing 'the assumptions that undergird how we work' (Brookfield, 1994, p. xii). He depicts such reflective practice to be both developmental and essential to 'good' teaching, explaining that while 'we teach to change the world' (Brookfield, 1994, p. 1), such a sense of innocent, well intentioned hopefulness alone is not enough:

One of the hardest things teachers have to learn is that the sincerity of their intentions does not guarantee the purity of their practice. (Brookfield, 1994, p. 1)

Each of the conceptualisations of teaching presented thus far apply a reductionist approach, atomising the idea and practice of good teaching to arrive at a particular behaviour or approach. They do not however, specify what a good teacher should know and what he/she should do, paving the way for another conceptualisation of teaching, that which Squires $(1999$, p. 17) terms the 'teaching as competence' paradigm. The teaching as competence approach applies functional analysis to atomise teacher's work into a set of discrete tasks and the underpinning skills and knowledge required to perform each of the tasks. Emerging from vocational education and teacher education in the 1960s and 1970s (Squires, 1999, p. 17), it still dominates the contemporary Australian education landscape. The teaching as competence influence can be seen in the compulsory education sector, which prescribes its desired teacher attributes in the Australian Professional Standards for Teachers (Australian Institute for Teaching and School Leadership, 2011), and also in VET, as evidenced by the numerous frameworks developed by the sector to articulate teachers' requisite skills and knowledge. These frameworks, which will be expanded upon in a later section of the review, include: The JMA Analytics Model of VET Capability Development (Mitchell \& Ward, 2010); the VET Capability Framework (Innovation and Business Skills Australia, 2013); and TAFE Queensland's Educator Capability Framework (TAFE Queensland, 2016). There are also two frameworks currently in draft: the Queensland College of Teachers' Professional Standards for Vocational Education and Training Practitioners (Queensland College of Teachers, 2015); and LH Martin Institute's VET Teaching Capability Framework (LH Martin 
Institute, 2016). The appeal of the competence model may lie in its offering of a logical and pragmatic approach by which teaching practice may be consistently and homogenously defined, evaluated and recreated. There are however, a number of criticisms of the approach. According to Squires (1999), it does not adequately articulate the relationship between what is done and how it is done. It also does not adequately account for the contingent and contextual nature of teaching work (Squires, 1999, p. 20). Further, Turner-Bissett (2001, p. 3) argued that not only is the competence approach 'unmanageable', it 'atomises what should be seen as a whole entity'. Turner-Bissett subsequently developed another paradigm, one which characterises teaching as a 'knowledge-based profession', with a suite of knowledge, skills and processes that make up the professional work of the expert teacher.

Turner-Bissett's (2001) model builds upon the significant and influential work of influential educational theorist, Shulman (1987) who contends that expert teachers demonstrate a 'wisdom of practice' drawn from a knowledge base that includes: content knowledge; pedagogical knowledge; pedagogical content knowledge; curricular knowledge; knowledge of learners; knowledge of educational contexts; and knowledge of educational goals (p. 8). Turner-Bissett $(2001$, p. 13) felt that Shulman's list of knowledge bases did not adequately articulate how they relate to and interact with each other, and expanded upon them by differentiating knowledge of learners into the categories of cognitive and empirical knowledge, and by adding three additional knowledge bases: knowledge/models of teaching (also described as beliefs about teaching); knowledge of self; and beliefs about subject (Turner-Bissett, 2001). Unlike Shulman, Turner-Bisset (2001) also described how the knowledge bases interact in all phases of the teacher's professional work (p. 13).

It seems plausible to assume that the reductionist view of teaching seeks to create order and measurable certainty to the practice of teaching and to teacher education by explicating the capabilities and attributes that must be learned and demonstrated. Certainly, as evidenced by the numerous teaching capability frameworks described previously, contemporary conceptualisations of educational practice appear to be keenly influenced by the reductionist approach, the competency paradigm, and the work of theorists in the field such as Shulman and Turner-Bissett. The literature also reveals an alternative way of understanding and investigating teaching however, one which focuses less on dissecting, categorising and itemising the skills, knowledge and attributes required to teach, and instead explores teaching from an holistic, more philosophical perspective. 


\section{Holistic conceptualisations of teaching}

The holistic conceptualisation of teaching is one which views it as more than simply the engagement of the sum of its parts; that is, it assumes that expert teaching cannot be explained only in terms of the skills, knowledge and attributes that a teacher employs through the process, practice or act of teaching. The holistic view of teaching appears to have emerged from philosophical, rather than instrumental origins and recognises that there is an individual and potentially irreproducible quality that good teachers bring to the work of teaching. As pointed out by Day (2004):

Teaching and learning at its best is not, then, an entirely rational set of processes. High quality input does not always result in high-quality output. Good teaching can never be reduced to technique or competence. (Day, 2004, p. 12)

While all who examine teaching through the holistic, humanist lens place the teacher at the core of the work, the literature reveals some differences. For example, while holistic conceptualisations of teaching predominantly explore teaching by examining the teacherstudent relationship and in particular, the ethical and moral consequences of that relationship (see for example, Freire, 1972; Macmurray, 1964; Noddings, 2003; Rancière, 1991; Van Manen, 1991a), there are others, such as Connelly and Clandinin (1995) who examine the interface between the teacher and the educational landscape that they navigate. There are also those who consider the relationship that the teacher has with teaching itself, exploring his/her identity and embodiment as a teacher (Hansen, 1995), and yet others who challenge teachers towards critical introspection, and to investigate the relationship that the teacher has with him/her self (Greene, 1973).

The nature of the teacher-student relationship is a prominent topic in the discourse on expert teaching and particularly in the literature relating to holistic conceptualisations of teaching. Macmurray (1964, p. 17), for example, regarded it as one of the foremost of personal relations and the most important component of successful teaching. While having 'no objection' to teachers learning techniques of teaching, and recognising that they needed to learn discipline-specific knowledge, Macmurray (1964) held that this alone would not lead to successful teaching. 
Teaching is not, and in the nature of things, however much you try to make it so, never can be a business, an industry, in which you can be successful by learning the technique. (Macmurray, 1964, p. 22)

Some liken the teacher-student relationship to that of performer and audience, with the teacher taking centre stage as an artist. The 'teaching as an art paradigm' conceptualises teaching as an artistic practice, an 'elaboration of style' (Squires, 1999, p. 6), enacted by a teacher gifted with the personal qualities, abilities and characteristics befitting the artistic and creative expression required for the teaching performance. Highet (1951) for example, felt that even a 'mediocre scholar' could be an excellent teacher if he possessed the skill of communication, required for 'transmission of thought from one mind to another' (p.97), entreating teachers to rehearse their instruction as one would a speech or public performance. While the conceptualisation of teaching as an art has a long history, it persists even in contemporary settings. Eisner (1994) for example, describes teaching as an act which is performed with skill and grace, which requires qualitative judgements to manage its contingent rather than routine nature, and one in which the outcomes are often emergent, unexpected and created through the process, rather than being 'preconceived and efficiently attained' (p. 155). Critics of the paradigm argue that it romanticises teaching as a practice which, like the arts, is 'intuitive, personal, mysterious and typically the province of the gifted few' (Squires, 1999, p. 8).

The conceptualisation of teaching as an art alludes to a teacher-student relationship which is entertaining, enjoyable and somewhat light-hearted. Other conceptualisations however, attribute to the teacher a great deal more responsibility in the relationship, arguing that the role of teacher should be accompanied by a significant moral and ethical duty. Tom (1980) for example, tasks teachers with the moral responsibility to ensure what is taught is of value, and to avoid exploiting the nature of the essentially unbalanced teacher-student relationship. This is a similar view to Macmurray (1964) who demands that the essential teacher-pupil relationship is one of genuine care, and also to Noddings (2003) who regards teaching as a relational practice based upon the development of a 'culture of care and trust', and one which entrusts every teacher to be a 'moral educator' (Noddings, 2012, p. 777). According to Noddings (2003, p. 244), 'the teacher as person is centrally important in teaching'. She charges the teacher with the responsibility of setting an example with 'her 
whole self, her intellect, her responsiveness, her humour, her curiosity . . . her care'. Rather than the prescriptive list of skills and knowledge required by proponents of the reductionist approach, the best teachers according to Noddings (2012, p. 777), have an 'unusually broad intellectual competence', developed from a richer, broader education that enables them to draw upon 'literature, history, politics, religion, philosophy, and the arts' (Noddings, 1999, p. 215).

Like Noddings and Macmurray, Van Manen (1991a; 1991b) also examined teaching through a relational lens, concerning himself with ensuring education continued as a 'rich human and cultural activity', conceived of a 'living process of personal engagement' between the teacher and student (Van Manen, 1991b, p. 4). While the focus of Noddings' and Macmurray's teacher-student relationship is on care and caring, Van Manen emphasises the teacher's demonstration of 'pedagogical thoughtfulness and tact' (Van Manen, 1991a). Tact, in Van Manen's sense, refers to what is termed 'mensen-kennis' in Dutch, which translates to 'people-knowledge' (Van Manen, 1994, p. 137). Those with tact have a certain kind of interpersonal sensitivity and perceptiveness towards others, 'a kind of wisdom about how people are and how they tend to act or react in specific situations' (Van Manen, 1994, p. 138). Van Manen alludes to the notion that good teachers are born, not made, conceding that 'there is a hint that the quality of tact is somewhat like talent' (Van Manen, 1991a, p. 526) and that some people possess more than others (Van Manen, 1994). While conceding that Shulman's work to identify the professional knowledge bases of expert teachers may be seen as comprehensive and impressive, Van Manen holds that Shulman's expert teachers may 'nevertheless lack the qualities that are essential to good teaching (Van Manen, 1994, p. 142) which include, along with tactful sensitivity, a deep sense of responsibility and morality combined with an interpretive intelligence and a passion for learning (Van Manen, 1991b, p. 8).

While Macmurray, Noddings and van Manen describe the ideal teacher-student relationship as a positive, ethical and moral one with care and trust at its heart, Freire (1972) interrogated the relationship to expose an alternative but prevalent relationship between teacher and student, which at its extreme, is characterised by oppression and power. In particular, he challenged the typically didactic and 'fundamentally narrative character' of traditional teaching practice which positions the teacher in a role as the expert 'narrating subject' and students as 'patient, listening objects' and as receptacles to be filled (Freire, 
1972, pp. 57-58). At first glance, Freire does little to elucidate the qualities of the good or expert teacher. He does however, highlight the criticality of the teacher-student relationship and provoke a call to action for an alternative, one in which the teacher becomes emancipator instead of oppressor. Freire's (1972) position, and that of other critical theorists such as Giroux (1992, 1997), is underpinned by an assumption that education systems serve as political levers to replicate existing social, economic and power structures through a 'banking', reproductive model of education - a model which facilitates continued oppression of the already disadvantaged and which enables the perpetuation of economic and social power for the already privileged. Freire also holds however, that education may be transformational and emancipatory, and his views on such potential egalitarian outcomes have been influential in the development of critical pedagogy (Brookfield, 1995). Critical pedagogy assigns the role of emancipator to the teacher, and tasks him/her with a responsibility to 'expose and resist' the political structure of education which would otherwise enable the legitimisation of power and control of the socially and economically dominant (Brookfield, 1995, p. 208).

Freire's view is somewhat reminiscent of Heidegger, who believed that teachers should challenge the establishment's expectations of their role in order to make authentic decisions about how they engage with learners, attesting that teachers should not be 'mere dispensers of information but 'let' learning take place by being ahead of student in quest of learning' (Hodge, 2015, p. 63). Donnelly (1999), who examined teaching through Heidegger's philosophical lens, and in particular, his major work 'Being and Time', found that as teaching is essentially a social activity and therefore resistant to theoretical ways of knowing, teachers are likely to experience a tension between the instrumentality which is somewhat a necessity of teaching (e.g. teaching the required curriculum) and a 'concernful being-with' their students (Donnelly, 1999, p. 933). The 'concernful being-with', Donnelly regards as the foundation of teaching, and one which, according to Hodge (2015), 'underpins an understanding relationship that, through the "clearing" action of being-in-the-world, opens an ongoing and unproblematic space for teacher and learner to share discoveries and build competence' (p. 65).

In a similarly provocative and challenging style, Rancière (1991) challenged traditional teaching conceptualisations in his tale of $18^{\text {th }}$ Century French teacher, Jacotot, who was exiled to teach in Belgium with no knowledge of the Flemish language. According to Rancière (1991, 
p. 7), the relationship which positions the teacher as explicator, a role similar to Freire's narrating subject, results in 'enforced stultification' of the student. Ranciere's alternative to enforced stultification, revealed through the story of Jacotot's teaching, is an ethos which focuses on emancipation of the student, guided by the belief that 'all men are of equal intelligence' and that to learn, the student needs only the motivation and opportunity, with the teacher's role that of a discreet guide (Rancière, 1991, p. 29). The key to unlocking the student's capacity to learn, according to Rancière $(1991$, p. 101) is to enable him/her to learn, initially, just one thing, upon which everything else can be learned and understood. The impact of such emancipation is so great, that the learner can learn even when the teacher does not know the topic, or in Jacotot's case, even when he does not know the language (Rancière, 1991, p. 15).

Freire and Ranciere, like Heidegger, recognised that their views on teaching would likely be controversial and perceived as a threat to the espousers of the traditional teaching establishment with its focus on conformity, structure and order. The teachers that seek to challenge traditional teaching roles and expectations, such as Ranciere's Jacotot or Heidegger's 'authentic' teachers, then, must find ways to recognise and avoid these threats. According to Hodge $(2015$, p. 70$)$, Heidegger's philosophy suggests that the authentic teacher understands and is alert to the threat of conformist, instrumentalist thinking and will seek to ensure learners also identify and avoid such threats. Narrative educational researchers Connelly and Clandinin (1995) also identified the tension between teaching practice and the expectations of others, and shed light on some of the ways in which teachers managed this tension through the stories that they constructed and told about their practice.

Connelly and Clandinin (1995) examined teachers work as they navigated the educational landscape inside and outside of the classroom. They studied the impact of contextual factors on teachers' behaviour and the expectations of those who seek to change the way that teachers work (such as researchers and policy makers). While describing teachers as 'knowers of themselves, of their situations, of children, of subject matter and of teaching and of learning', (Connelly \& Clandinin, 1999, p. 1), they recognised that teaching and teaching work is both individual and contextual; influenced by the teachers' individual identity and experience, but also linked to their experiences between the borders of space, identity and time (Connelly \& Clandinin, 1988). Rather than seeking to identify specific and discrete kinds of knowledge and skills required for a teachers' work, they perceived teachers' 
knowledge as a professional knowledge landscape, one which is 'composed of relationships among people, places, and things' (Connelly \& Clandinin, 1995, p. 5). Further, and similarly to Van Manen and Donnelly, they recognised the underlying and embedded assumption of ethicality and morality in the teacher's role, viewing the teachers' knowledge landscape as both an intellectual and moral one (Clandinin \& Connelly, 1996, p. 25), and one which may lead to what Connelly and Clandinin (1995, p. 4) refer to as 'epistemological dilemmas'; dilemmas that occur as teachers find that their view of appropriate and best teaching practice is in conflict with views outside of their safe and autonomous space in the classroom. According to Clandinin and Connelly (1996), teachers develop 'secret stories' in this safe classroom space, responding to the needs of learners according to their own professional, intellectual and moral judgement, even when their practices do not align to the often changing policies and mandates that seek to exert an influence on classroom practice from outside of its boundaries.

The professional landscape that teachers work in is often changing, shaped by 'sacred stories', a term used by Clandinin and Connelly (1996) to describe 'what is coming down the pipe' (p. 25); that is, the information, research and policy about other's views on how teachers should teach which is funnelled into the school to change practice. The sacred stories often shape the school's goals and focus, and so in order to continue teaching according to their own judgement, teachers may develop 'cover stories' - alternative narratives told to others about their classroom practice. Secret or cover stories are neither good nor bad according to Clandinin and Connelly (1996), and as demonstrated by Schmidt (2017, p. 12), teachers may construct them to ensure that their professional practice is responsive to the needs of learners, rather than tailored to the views and policies of those outside the classroom who seek to have an influence within it.

While Clandinin and Connelly (1996) studied teachers' work and knowledge through the relationships that they experience within and outside of the classroom, some, such as Hansen (1995) and hooks ${ }^{1}$ (2009) explored the unique relationship that teachers have with the role itself and challenged an alternative conceptualisation of teaching as a profession. For Hansen (1995), teaching is a vocation or calling, 'a summons, a bidding, an invitation' to a

\footnotetext{
${ }^{1}$ hooks is displayed in lower case throughout the thesis, replicating the cited author's preferred naming conventions.
} 
particular way of life (Hansen, 1994, p. 259). The conceptualisation of teaching as a vocation, he contends, infers that the teacher derives a sense of 'identity', 'personal fulfilment' and 'enduring personal meaning' from the work (Hansen, 1995, p. 8) which like Day (2004), Hansen (1995) regards as being 'larger than fulfilling its discrete requirements' (p. 15). For Hansen, the vocation of teaching involves a sense of duty and public service as well as moral and personal commitment (Hansen, 1994, 1995, 1998); and while Hansen does not imply that by 'being called' the teacher has no need to develop additional intellectual knowledge and skills for teaching, he does presume that those who feel the call the teach will quickly discover the moral qualities embedded in the role, such as patience, attentiveness and fairness (Hansen, 1998, p. 649). hooks (2009), also refers to the vocational aspect of teaching, but takes the implied virtuous and moral responsibilities further, charging the role with an almost evangelistic quality and labelling it a 'prophetic vocation' (p. 181) which demands of teachers 'allegiance to integrity of vision and belief in the face of those who would either seek to silence, censor, or discredit our words' (hooks, 2009, p. 181). hook's ideal pedagogical practice is the 'practice of freedom', a practice she says, which is easier for teachers to learn if they already believe that there is an aspect of their vocation which is sacred (hooks, 1994, p. 13).

A review of the literature on holistic conceptualisations of teaching would not be complete without a reference to Maxine Greene, who while sympathetic to some of the necessarily pragmatic aspects of teachers' work, unapologetically applied a phenomenological existentialist approach to understand it. While others have focused on the outward relationships that teachers develop (e.g. with their students), Greene turned the focus inwards, challenging teachers to know themselves, to critically question their thoughts, actions and beliefs, and to find ways to enable students to 'choose intelligently and authentically' for themselves (Greene, 1973, p. 272). The teacher's task according to Greene, is to equip students with the conceptual tools and self-respect to think, choose and act in a way that they consider is right (Greene, 1973, p. 272), thus presenting a challenge to those who charge teachers with prescriptive views and a rigid curriculum. She urges teachers to resist conformance with predefined roles, calling upon them to 'struggle against unthinking submergence in the social reality that prevails' and not to accept 'ready-made standardised schemes at face value' (Greene, 1973, p. 269). 
Greene is not alone in challenging teachers to throw down the gauntlet, and to resist those who seek to constrain their teaching according to a certain paradigm or view of best practice. Those who share the holistic view are unerringly resistant to and critical of the reductionist view, or conceptualisations that seek to instrumentalise the practice of teaching as a means to an end, or who seek a formulaic description of teaching. Donnelly (1999) for example, urges teachers to 'look very hard and critically at demands for an increased emphasis on instrumentality' (p. 947), while Hansen (2001) portrays activity and outcome based (i.e. reductionist) conceptions of teaching as almost fad-like, declaring that they 'come and go', with lifespans as transient as the that of the concern, interest or reform from which they were generated (p. 7).

\section{The Australian VET context}

To this point, this review has dealt with the various conceptualisations of teaching in the literature in a general sense without referring specifically to the teaching that happens in the Australian VET sector. This is both intentional and justified, partly because there is a wealth of research to draw from which discusses the idea of good teaching in the compulsory schooling sector, but very little which focuses specifically on VET. Further, few would argue that, regardless of the sector, curriculum or the subject, teachers and teaching exist for the same reason - so that students can learn. Despite the similarities however, there are some differences between teaching in VET and teaching in other sectors which warrant special consideration due to their impact on VET teachers' work. The most significant considerations are those relating to: the mandatory requirements for entry to the VET teaching role; the diversity of the VET student cohort; and the unique challenges precipitated by the sector's close alignment with the economic and workforce development agendas of government.

VET is positioned obliquely in the Australian educational landscape between the compulsory schooling and higher education sector and its primary purpose is to provide industry relevant training for a wide range of vocations. Unlike other sectors and due to its close connection to industry's needs, VET sector's regulatory requirements mandate that VET teachers establish themselves in a vocational occupation prior to becoming a teacher. While it may be argued that teachers in other sectors also experience this challenge to some extent as they must develop deep knowledge of the subjects they teach, only VET teachers have a regulatory requirement to maintain their vocational skills and knowledge throughout their 
teaching career (Schmidt, 2017). This has led to VET teachers being described as 'dual professionals', recognising that they must maintain a 'dual identity' as both vocational expert and teacher (McDonald, 2011; Palmieri, 2004). It has also led to a VET teaching workforce which is arguably more diverse than in other sectors, as VET teachers are drawn from vocational backgrounds as diverse as the industry-specific qualifications that they teach (Tyler \& Dymock, 2017). According to Brennan Kemmis and Green (2013), the complexity of the VET teacher's work is also arguably misunderstood:

...the work of the VET teacher is complex, multi-faceted and much more than the narrow definitions of competency that are at the basis of many of the training reforms in Australia and internationally. (Brennan Kemmis \& Green, 2013, p. 118)

It is not only the VET sector's workforce which is diverse. The VET student cohort also varies widely in age, cultural background, socio-economic status, literacy and numeracy skills and prior knowledge and experience - all factors which may impact upon their needs in relation to learning, and in turn increase the demands placed upon the VET teacher (National Skills Standards Council, 2013; Productivity Commission, 2011; Skills Australia, 2011). Many argue that VET teachers are insufficiently prepared for these demands, given that the mandatory educational qualification for VET teaching, the Certificate IV in Training and Assessment, has been criticised for being inadequate (Darwin, 2007; National VET Equity Advisory Council, 2011; Simons \& Smith, 2008; Smith \& Grace, 2011), 'lean’ preparation for the job role (Billett, Choy, \& Smith, 2013; Clayton, Meyers, Bateman, \& Bluer, 2010), or at best, and if delivered well, a preliminary qualification which is suitable for initial entry to VET teaching but which would require additional capability development for the development of advanced teaching skills (Guthrie, McNaughton, \& Gamlin, 2011; Productivity Commission, 2011; Robertson, 2008; Williams, 2010).

The economic and political environment in which the VET sector operates also adds to the complexity of the VET teacher's role. Its close alignment to industry labour needs, its peculiar and unique link to the economic development agendas of governments and its sensitivity to policy changes (Harris, 2017) present additional challenges to VET teachers. This is particularly evident in the contemporary VET environment as teachers grapple with the demands associated with increased marketization, competition and regulation of the sector (Smith \& Yasukawa, 2016). Given these differences, complexities and challenges then, in order to understand VET teaching in a contemporary sense, it is helpful to first understand 
the historical background as well as the evolution of the sector and the teacher's role alongside the key policy changes and reforms which have shaped their work and contemporary perceptions of 'good teaching' in VET.

\section{Historical influences on contemporary VET teaching}

Vocational Education and Training first emerged in Australia in the 1820 s as a replica of Britain's apprenticeship and adult and technical training systems (Goozee, 2001; Whitelock, 1974). Developed as a response to increasing labour shortages, VET's close alignment to industry and its expected contribution to workforce needs and the economic agendas of governments has seen it 'tossed to and fro by the winds of many changing influences' ever since (Harris, 2015, p. 16). The 1974 release of the Kangan Report marked a period remembered fondly by the sector. Described as a 'watershed' (Smith \& Keating, 2003, p. 9) for Australian VET and a 'milestone of great and enduring significance' (Kearns \& Hall, 1994, p. 1), the Kangan report is credited with the development of a broader and more liberal concept of vocational education, establishing TAFE as the Australian public provider for the sector, and significantly, defining TAFE's role as an alternative to other education sectors (Australian Committee on Technical and Further Education \& Kangan, 1974; Kearns \& Hall, 1994; Smith \& Keating, 2003). It is hailed for providing the sector with 'an identity, philosophy, increased status and much-needed funding' (Rushbrook \& Mackinnon, 1998, p. 159).

While the recommendations of the Kangan Report undoubtedly had an impact upon the sector's teachers, it wasn't until 1978 and the release of the Fleming Report (Fleming \& Tertiary Education Council, 1978) that the focus turned specifically to them and their work. The Fleming Report, for the first time, attempted to differentiate VET teaching from that which occurs in other sectors and proposed a model of teacher preparation which 'centred on a career shift from [industry] practitioners to teachers' (Chappell, Gonczi, \& Hager, 1994, pp. 184-185). Significantly, it noted the increasing demands made on vocational teachers and marked 'the first systemic effort at improving the quality and standing of TAFE teachers' (Harris, 2017, p. 7).

From VET teacher to VET practitioner: the impact of CBT, neoliberalism and new vocationalism

A decade on from the Kangan report, in the late 1980s, Competency Based Training (CBT) was introduced to the VET sector, marking yet another particularly significant period of change 
for VET teachers. Described by Harris and Hodge (2009, p. 123) as the linchpin and most enduring feature of reforms in Australian VET, the emergence of CBT into Australian VET was typical of the neoliberalism reforms occurring across the Western world at the time (Hodge, 2016). Borne out of the Dawkins Report into industry training in Australia (Dawkins, 1988), the reforms were triggered by an agenda to increase the global competitiveness of the Australian workforce (Billett et al., 1999). Smith and Keating (2003) report some confusion in the sector about CBT, what it is, and what it isn't (p. $122-125)$. In Australia, however, they consider CBT to be characterised by a number of key features (Smith \& Keating, 2003). With a modularised curriculum comprised of competency 'standards' drawn from industry input, CBT is typically focussed on outcomes rather than on inputs. Assessment in CBT is ungraded and criterion-referenced rather than norm-referenced and is based on demonstration of skill rather than on knowledge. CBT also assumes a competency-based rather than a time-based approach to training and assessment and is characterised by recognition of prior learning and a more flexible and self-paced approach (Smith \& Keating, 2003, pp. 125-126). CBT reforms introduced a top-down model of curriculum development which saw a 'tightening of the formula for curriculum developing and implementation' (Billett et al., 1999, p. 1), and which was widely criticised for its lack of input by educators, a narrowing of the focus for vocational education and an increased emphasis on assessment outcomes over educational input (Billett et al., 1999; Hodge \& Harris, 2012; Misko, 1999). Further reforms to the curriculum occurred with the introduction of Training Packages in 1997 (Smith \& Keating, 2003). Described as an 'administrative innovation' by Hodge (2016, p. 172), this reform created the system of curriculum that exists in Australian VET today, with competencies grouped into 'packages' according to industry disciplines and dispensed according to prescribed combinations of modularised competencies to form a range of qualifications (Smith \& Keating, 2003). To support the government's ambitious economic and productivity goals for the VET sector, the Australian National Training Authority (ANTA), was established in 1992 as a statutory authority to develop, manage and promote the national training framework. ANTA was later abolished in 2005, with its responsibilities transferred to the Government Department of Education, Employment and Workplace Relations (DEEWR).

The CBT reforms marked the advent of a new era in VET teaching and a dramatic shift in VET teachers' work. It transformed the VET teacher into a 'facilitator of learning' (Smith \& Keating, 2003, p. 231) who, according to Harris (1995), assumed the role of liaison person, 
adviser, mentor, facilitator, information dispenser, skills demonstrator, assessor, materials developer and evaluator (pp. 270-271). CBT reforms and the reconfiguring of the VET teacher's role triggered the first suite of research to identify skills and competencies required by VET teachers, the corresponding 'gaps', and the recommended strategies to 'equip teachers with the enhanced skills' they required (Hall, Hayton, Mageean, \& Scarfe, 1990, pp. 7-8), setting a trend that has continued unabated throughout the remainder of the twentieth and twenty-first centuries. This foray into the reductionist approach and its continuation into contemporary VET has contributed to the development of numerous instruments and frameworks, each intended to articulate, evaluate and inform the development of VET teachers' skills.

CBT reforms and the associated changes to VET coincided with a turn towards 'new vocationalism' in education (Chappell \& Johnston, 2003, p.6), a global shift precipitated by the effects of neoliberalism and an increased emphasis on the instrumental and economic purpose of education and its role in developing the human capital required to meet labour skills shortages (Ball, 1994; Chappell \& Johnston, 2003; Grubb, 1996; Pring, 2004; Skilbeck, Connell, Lowe, \& Tait, 1994). The Australian Government's microeconomic reforms during this period initiated the development of an open training market for VET and the entry into the marketplace of privately owned, for-profit RTOs, which in turn created a new environment of market competitiveness for the public provider (TAFE) (Anderson, 1997). Under these influences the VET teacher's role diversified and expanded further, becoming increasingly commercially focused in a process referred to by Chappell and Johnston (2003, p. 10) as the 'businessing' of VET. VET teachers became, according to Seddon (2001), active agents in the agenda for these reforms which demanded 'changes in their work, their identities and their commitments' (Seddon, 2001, p. 62), a shift reflected in all areas of the VET sector, according to Anderson, Brown and Rushbrook (2004):

Within the new market paradigm, VET administrators have become business managers, VET teachers have been recast as training entrepreneurs, and VET students have been reframed as customers, rather than learners. (Anderson, Brown \& Rushbrook, 2004, p. 238)

Renewed perceptions of VET teachers' roles and expectations of their productivity and performance influenced a shift towards a more technical view of VET teaching, a further diversification and expansion of the role and a change in title from VET teacher to 'VET practitioner'. It also triggered a debate (which is ongoing) on the professionalism of the VET 
teaching workforce, with some arguing that $\mathrm{CBT}$ and neo-liberalism reforms had the effect of de-professionalising and devaluing VET teaching (Harris, Simons, \& Clayton, 2005).

Despite the discourse around the VET teacher's role during this period, there was a scarcity of research on what constituted 'good teaching' in VET. According to Palmieri (2004), the discussion on VET teaching was most often related to the teacher's ability to meet industry needs and ensuring that they had the technical skills to use new technology, apply new methods of teaching, and to manage the impact of organisational change. This led Palmieri (2004), to wonder whether the teacher's role in the learning process had been 'disregarded or under-valued' (p. 2), since little had been said about the 'intrinsic nature' of the good VET teacher, nor the importance of the teacher-student relationship. One study which did focus specifically on the VET sector during this period and which highlighted the centrality of the teacher and the teacher-student relationship, was a small scale project conducted by Corben and Thomson (2001) which involved 18 TAFE teachers in the North Coast Institute of TAFE in New South Wales. They found good teaching in the VET sector to extend 'far beyond competence in a set of practical skills', and that expert teachers draw upon a 'rich and complex knowledge base', and share certain 'attributes of excellence' (Corben \& Thomson, 2001, p.p. 1-2). These attributes include the basic skills and knowledge required to teach in VET - the technical/vocational skills related to their occupational discipline and expertise in teaching and learning methodologies. Corben and Thomson's (2001) study also found that excellent VET teachers shared skills and attributes not dissimilar to excellent teachers from other sectors, ascribing them high level communication skills, a learner focused approach which respected diverse backgrounds and needs, and certain 'personal attributes, beliefs and values' which compel them to help others learn and reach their potential (Corben \& Thomson, 2001, pp. 1-3). Despite these similarities, the discourse which sought to differentiate the VET teacher's role from that of other sectors continued with a particular focus on the skills required by the VET teacher to meet the demands of the VET reforms and the changing VET environment.

Chappell and Johnston (2003) announced the emergence of the 'new VET practitioner'. They used the term to describe VET teachers who had developed new skills to meet the demands of an increasingly complex role, a changing scope of work and new expectations which extended 'beyond traditional teaching or training' (p. 8) to include 
marketing, entrepreneurial and management responsibilities. Mitchell, Chappell, Bateman, and Roy (2006) later expanded the definition of the 'new VET practitioner' to refer to VET teachers who had developed a 'hybrid mix of educational and business thinking' in response to the VET market changing from being predominantly supply to demand driven (Mitchell et al., 2006, p. 24). According to Mitchell et al. (2006), the new VET practitioner would be a 'strong educator with an equally strong appreciation of business' (p.24). While they provided a detailed list of attributes required of the new VET practitioner, Mitchell et al. (2006) also conceded that these attributes 'may not reside within one individual', but would ideally be evident within a team (p. 24). Mitchell developed a considerable body of work around 'VET practitioners' and their skills, knowledge and attributes, even describing the evolution of the 'Advanced VET Practitioner', an 'exceptional' version of the VET practitioner with a range of skills and knowledge acquired over considerable years, who demonstrated 'a deeper knowledge of both education and industry, and the skills to customise training and develop business solutions to a wider range of clients' (Mitchell, 2008, p. 8). Mitchell's work was pervasive, and terminology such as 'VET Practitioner' and 'Advanced VET Practitioner' became widely adopted by Australian RTOs, particularly TAFE. The focus of research into VET teaching during this period, and in Mitchell's work particularly, was on the skills required for VET teachers to respond to the commercial, demand driven, business shift in VET. Students and employers became known as 'customers' and 'clients', and those revered as 'Advanced VET Practitioners' demonstrated 'extraordinary capabilities for building client relationships, ensuring customer responsiveness and supporting flexible delivery' (Mitchell, 2008, p. 6).

Building upon Mitchell's previous work, Mitchell and Ward (2010) conducted a nationwide quantitative research study to analyse the skills encompassed by 'VET professional practice' and to enable the VET sector to implement appropriate capability building strategies for its VET practitioners (p. 6). From this research, Mitchell and Ward developed the JMA Analytics model of VET practice which specified the skills required of VET practitioners and described three different categories of VET practitioners: the Foundation VET practitioner; the Specialist VET Practitioner; and the Advanced VET practitioner. Established Foundation VET practitioners were proficient in five foundation skills: learning theories; learning styles; foundation learning facilitation; foundation assessment; and organisation and student management (Mitchell \& Ward, 2010, p. 11). The term 'Novice' was 
applied to describe those not yet proficient in these skills. Mitchell and Ward's (2010) study also identified two broad types of Specialist VET Practitioners: the VET commercial specialist; and the VET learning and assessment specialist. The VET learning and assessment specialists were regarded as experts in facilitation, organisation and management of learning and assessment including e-learning, online assessment, distance learning and off-shore delivery (Mitchell \& Ward, 2010, p. 12). Commercial specialists on the other hand, were those with the skills to personalise training for organisations, to contextualise and adapt training packages for commercial purposes and to manage commercial relationships (Mitchell \& Ward, 2010, p. 12). The Advanced VET Practitioner, according to the JMA Analytics model, had the skills and capabilities of both the commercial specialist and the learning and assessment specialist (Mitchell \& Ward, 2010). The skills that Mitchell and Ward (2010) attribute to VET learning and assessment specialists are mostly representative of traditional conceptions of teaching. The commercial specialist skills set however, appears to represent the VET teacher's move away from teaching altogether to a role more appropriately aligned to a business development unit. Indeed, this appeared to be the case for at least one Queensland TAFE, which introduced a new job role for 'Enterprise Learning Consultants', appointing a number of 'highly skilled VET practitioners' to the role (Piccardi, 2013, p. 12), and assigning them the responsibility to assist industry with their business and educational needs by developing workforce development solutions (Piccardi, 2013, p. 7). While the Enterprise Learning Consultants were initially employed according to their existing industrial award and conditions (i.e. as VET teachers), the intention was to assign the role 'its own unique classification to keep pace with the demands of industry' (Piccardi, 2013, p. 12), thus potentially representing an absolute shift from VET teacher to a VET business development role.

The commercialisation of VET and the shift to a demand driven, industry led VET sector has generated significant criticism (Anderson, 1998, 2005; Robinson, 1998; Robinson \& Kenyon, 1998; Toner, 2014). Peoples (1998), for example, lamented the development of an 'education and training system designed by business to meet narrow economic objectives and run along clinically commercial lines' (p. 201), while Hetherington and Rust (2014, p. 8) described the impact of unintended but damaging consequences of the increasingly commercialised VET model, which have included government budget blow-outs, variable educational quality and reduced confidence in the sector. Guthrie, Smith, Burt, and Every 
(2014) found that a number of strategies implemented by RTOs in order to remain viable in the competitive VET marketplace presented 'a risk to the quality of training delivery' (p. 7). The sector has suffered reputational damage (Braithwaite, 2018; Griffin, 2017; Guthrie et al., 2014), as the increasingly commercial and competitive training marketplace became a fertile landscape for unscrupulous operators with lean models of education provision who prioritised profit over quality (Toner, 2014) and in some cases, employed unequivocally unethical and unscrupulous practices (Braithwaite, 2018; Buchanan, 2012; Harris, 2015; Nakar, Bagnall, \& Hodge, 2018; Toner, 2014).

Against this backdrop, the sector has sought a solution through its legislated standards and the activities of its regulator. National compliance standards were outlined in the Australian Quality Training Framework (AQTF) and first implemented in 2002. They were subsequently revised in 2005, 2007 and 2010. In 2012, the standards became Commonwealth legislation as 'Standards for NVR RTOs 2012', before being replaced by the current legislative instrument, Standards for Registered Training Organisations (RTOs) 2015 (Commonwealth Government of Australia: Department of Education and Training, 2015). The Australian Skills Quality Authority (ASQA) was established in 2011 as the Australian Government's national VET regulator to 'make sure that the sector's quality is maintained through the effective regulation of providers and accredited courses' (Australian Skills Quality Authority, 2018). Prior to 2011, regulation was undertaken by individual State and Territory regulatory bodies (Braithwaite, 2018). Despite efforts to strengthen the regulatory framework of the sector however, the quality of VET has remained a prominent theme of discourse in contemporary VET discourse.

\section{The contemporary VET environment: a focus on VET teaching}

The dominant theme in contemporary Australian VET discourse is unquestionably that of quality. While this is not a new topic in VET literature, the discussion has now reached 'fever pitch', according to Griffin (2017, p. 7). Some of the debate has focused on the effectiveness of the sector's regulator or on the relevance, consistency and interpretation of the VET curriculum (Hodge, 2014; Smith, Smith, Hampson, \& Junor, 2015). The spotlight has also however, very acutely turned to focus on VET teachers and the quality of VET teaching. Wheelahan and Moodie (2011), reported an 'unprecedented level of attention' being paid to 
VET teachers and VET teaching in Australia (p. 13), and this level of interested has continued unabated. Harris (2015) noted that the 'quality of the VET system is only as good as its teachers and trainers' (p. 16), echoing the established link between VET quality, student outcomes and the quality of VET teaching expressed by others including (for example) Braithwaite (2018), Walker (2012), and Wheelahan and Moodie (2011). Work has been undertaken in an effort to understand and articulate what constitutes quality VET teaching and to develop (in a similar fashion to Mitchell and Ward's 2010 model of VET practice), a set of standards, a model or a framework which comprehensively expresses VET teaching competencies, capabilities and standards. This work reflects similar activity internationally and across education sectors which has seen the development of professional standards proceeding at 'remarkable speed' (Mulcahy, 2003, p. 3), triggered by neo-liberal education policy reform and an agenda to improve quality of teaching, enable greater accountability of schools and teachers, provide a mechanism for performance appraisal and a framework for the continuing professional development (CPD) of teachers (Mulcahy, 2003, 2011). The standards movement in VET is also closely aligned to a parallel debate around professionalism and the vocational education teaching workforce (Atkins \& Tummons, 2017; Guthrie \& Clayton, 2012; Mulcahy, 2003). Further, it is representative of the contemporary turn in Australian education which attempts to conceptualise teaching as a competency - an atomisation and instrumentalisation of teaching which has been presented in this review as a product of the reductionist approach.

The framework of standards which underwrites the mandatory (and minimum) professional entry requirements of Australian VET teachers is the TAE (Training and Education) Training Package and the Certificate IV in Training and Assessment (TAE40116) qualification. It will be dealt with in this section, along with a number of other frameworks developed for the Australian VET context, namely: the VET Practitioner Capability Framework (Innovation and Business Skills Australia, 2013); Professional Standards for Vocational Education and Training Practitioners (Queensland College of Teachers, 2015); TAFE Queensland Educator Capability Framework (TAFE Queensland, 2016) and the VET Teaching Capability Framework (LH Martin Institute, 2016) ${ }^{2}$.

\footnotetext{
${ }^{2}$ Still in draft $23 / 2 / 17$
} 
The Training and Education Training Package is comprised of a series of units intended to outline the skills and knowledge required of educators in Australia's VET sector. Different combinations of specific units are required to achieve the various qualifications articulated by the package. In addition to the Certificate IV in Training and Assessment (TAE40116) - the minimum requisite requirement for VET teachers - the Training Package specifies the requirements for completion of a Diploma of Education and Training (TAE50116), Diploma of Training Design and Development (TAE50216), Graduate Diploma of Adult Language, Literacy and Numeracy (TAE80113), Graduate Diploma of Adult Language, Literacy and Numeracy Leadership (TAE80213) and a Graduate Certificate in Digital Education (TAE80316). Each qualification described within the package is intended to relate to a different role within the training and education industry sector. For example, the Certificate IV in Training and Assessment (TAE40116) 'reflects the roles of individuals delivering training and assessment services in the vocational education and training (VET) sector' (PWC's Skills for Australia, 2017, p. 7), while the Diploma of Education and Training (TAE50116) is intended for those involved in vocational education leadership and mentoring roles in training organisations (PWC's Skills for Australia, 2017, p. 10). A VET teacher who has completed the Certificate IV in Training and Assessment is deemed to have achieved competency in ten different units relating to the design, delivery and evaluation of training and assessment as well as addressing adult language, literacy and numeracy skills (PWC's Skills for Australia, 2017, p. 8).

The current Training and Education Training Package is the most recent version of a curriculum document which has been updated many times since the inception of CBT into Australian VET. The package, and in particular the various iterations of the Certificate IV qualification, have been subject to intense review and criticism for providing an inadequate or incomplete preparation for VET teaching (Darwin, 2007; National VET Equity Advisory Council, 2011; Simons \& Smith, 2008). It makes no claims however, other than to provide a framework of competencies which relate to specific roles within the sector, and as such, describes only the skills, knowledge and behaviours of a competent or novice VET teacher, rather than an expert or good teacher (Robertson, 2008; Williams, 2010). As a curriculum document, the Training Package also does not provide guidance on CPD pathways for VET teachers, a gap which the sector has sought to fill through the other frameworks discussed here. 
Innovation and Business Skills Australia (IBSA) developed the 'VET Practitioner Capability Framework', to provide a 'common language for the knowledge, skills, behaviours and attitudes that practitioners will display if they are working well in their roles' (Innovation and Business Skills Australia, 2013, p. 6). This project was funded by the Australian Commonwealth government, and at the time, IBSA was the body responsible for the Vocational Training and Assessment curriculum (the TAE Training Package) which specified the competency requirements for the VET teachers' mandatory Certificate IV in Training and Assessment. IBSA's framework describes sixteen capabilities required by VET teachers, grouped into four domains: systems and compliance; teaching; industry and community collaboration; and assessment (Innovation and Business Skills Australia, 2013, p. 8). While the domains are intended to articulate what is 'fundamental' to VET teaching and assessment, the framework also specifies a number of generic skills that VET teachers need in order to 'function effectively' and to 'deal with the changing demands of work' (Innovation and Business Skills Australia, 2013, p. 9). These skills are: leadership; ethics; cultural competence; innovation; teamwork and collaboration; and evidence based practice and research (Innovation and Business Skills Australia, 2013, p. 9). IBSA's framework articulates the capabilities and skills requirements according to three hierarchical levels based upon the VET teacher's experience and expertise, with the intention of providing a basis for specifying work role responsibilities, for evaluation of required performance and capability gaps, and to facilitate professional development planning according to individual needs and capability gaps (Innovation and Business Skills Australia, 2013).

In 2015, the Queensland College of Teachers (QCT) developed a framework entitled the Professional Standards for Further Education and Training Practitioners to articulate the 'gold standard' for VET teachers (Queensland College of Teachers, 2015, p. 1). Modelled on the nationally recognised standards for the compulsory school sector, the Australian Professional Standards for Teachers (Australian Institute for Teaching and School Leadership, 2011), QCT's framework is intended to be 'aspirational and developmental' in nature, and to represent 'what practitioners should aspire to know and do as professionals in Vocational Education and Training' (Queensland College of Teachers, 2015, p. 1). There are seven standards listed, grouped according to three domains: professional knowledge; professional practice; and professional engagement. Within each standard there are a number of statements which define what VET teachers should be able to know and do (Queensland 
College of Teachers, 2015, p. 2). Unlike IBSA's VET Practitioner Capability Framework, QCT's Professional Standards does not differentiate performance at different levels. Rather, it describes 'behaviours and qualities' at the advanced level, 'beyond the expectations of the current legislated minimum qualification', the Certificate IV in Training and Assessment (Queensland College of Teachers, 2015, p. 2).

TAFE Queensland, although involved in the research study that informed Mitchell and Ward's Model of VET Practice (Mitchell \& Ward, 2010) and in the consultation processes for IBSA's VET Practitioner Capability Framework (Innovation and Business Skills Australia, 2013) and QCT's Professional Standards for Further Education and Training (Queensland College of Teachers, 2015), identified a need to develop its own framework, the TAFE Queensland Educator Capability Framework (TAFE Queensland, 2016). Modelled upon IBSA's framework, but aligned to TAFE Queensland's organisational goals, the TAFE Queensland Educator Capability Framework is intended to serve evaluative, recognition and developmental purposes, ascribed as providing opportunities to 'identify and recognise educational excellence' and to guide the professional development and career pathways for educators in the organisation (TAFE Queensland, 2016, p. 3). Similarly to IBSA's framework, TAFE Queensland's Educator Capability Framework articulates 'skills, abilities and knowledge' that VET teachers are expected to demonstrate, grouped into domains, and described at different (hierarchical) levels of capability (TAFE Queensland, 2016, p. 3). The eight domains are: professionalism and core values; learning and teaching; assessment; innovative product and practices; technology for learning; learner, industry and community engagement; quality and compliance; and educational leadership. The four hierarchical levels of capability are: transitioning (at the lowest level); proficient; highly accomplished; and, at the highest level, leading (TAFE Queensland, 2016, p. 5). According to TAFE Queensland (2016, p. 7), the framework's levels are aligned to 'qualification pathways'. For example, the lowest level of expertise, 'transitioning', is aligned to achievement of the Certificate IV in Training and Assessment, while the 'highly accomplished' level of expertise aligns to Diploma level units of competency and the 'leading' level to achievement at advanced diploma, bachelor and masters qualification levels (TAFE Queensland, 2016, p. 7). Only the 'proficient' level is not aligned directly to a qualification level, instead describing "behaviours which demonstrate evidence of applied knowledge within educational practice' (TAFE Queensland, 2016, p. 7). 
The most recent VET Teaching Capability Framework has been developed (in draft form) by LH Martin Institute. At first glance, the model appears similar to the other frameworks dealt with in this section, listing a number of capabilities grouped into the domains of professional knowledge, professional practice and professional learning, and articulated according to four different levels of performance and expertise (LH Martin Institute, 2016). According to Schubert (2017) however, the difference between this framework and the others is that it focuses not on the broader context of the VET teacher's role, but on the capabilities directly related to teaching and learning. The framework's developers have drawn from the concepts of 'visible learning', a model of teaching developed and popularised by Hattie (2012) which challenges teachers to see themselves as evaluators of student learning - to make learning visible - in order to measure their impact or effectiveness and adjust behaviours as needed for maximum impact. The link to Hattie's work is evidenced in the language used within the framework which describes VET teaching capabilities in terms of the impact that they have on student learning. Hattie's research, while widely accepted and applied by many in the compulsory education sector, has also been criticised by others, primarily in relation to the accuracy and validity of the statistical analysis used to arrive at the model's recommendations (e.g. Arnold, 2011). It has also not been applied in the VET sector as vigorously as it has in the compulsory education sector. The VET Teaching Capability Framework is, at this time, yet to be finalised and published, and the potential for yet another framework to be developed in the interim seems possible, given that there are still studies being undertaken to determine what constitutes 'good teaching' in VET, such as Smith \& Yasukawa, 2017.

The contemporary 'standards movement' in Australian VET has not yet reached agreement on a framework or model which might be applied universally to the sector. The usefulness of such an approach has also not been rigorously critiqued in Australia, perhaps because a compulsory framework has not yet been implemented. It would be pragmatic however, to note the response to a similar period within the United Kingdom's Further Education (FE) sector (largely equivalent to Australian VET) which resulted in the development of compulsory standards to describe the expectations of the sector's teachers and to provide a standardised framework to align an elevation of status as a teacher with the completion of relevant qualifications. The implementation of the standards were accompanied by a compulsory CPD requirement of at least 30 hours per year (Lifelong Learning UK, 2007, p. II). 
Criticising the model and standards as an artefact of the 'managerial approach' to education which accompanied the neo-liberalism reforms of the 1990's, Bathmaker (2000, p. 9) cautioned that they would likely provide an 'additional means of monitoring and control, rather than the basis for the development of an innovative and forward-looking profession' (Bathmaker, 2000, p. 9). Similarly, Lucas (2002, p. 459) cited the 'dangers of adopting an overregulatory approach' to teaching, highlighting the risk that implementation of the standards would result in a mechanical and uncritical application to teacher training and development which focused on meeting regulatory requirements rather than meeting the developmental needs of the sector's teachers. Three different versions of the standards were released over a fifteen year period from 1999 and later abandoned altogether, leading to further criticism for creating an additional layer of change in a sector already dominated by shifting policy, regulatory requirements and market conditions (Tummons, 2014). Adding to the cautionary advice gleaned from the UK experience is that provided by Mulcahy (2011, p.109) who argues that:

...no version of professional standards - neither the well-established version where teaching standards assume the form of statements of teachers' knowledge, skills and dispositions, nor the now less visible version where they take the form of 'wisdom of practice' performed in the everyday and embodied work of teachers-needs to and ought to prevail. (Mulcahy, 2011, p.109)

Similarly to Australian VET, the UK's FE sector has been subjected to increasing economic and competitive pressures due to neo-liberalist educational reforms. Changes to the Government Act and the 'incorporation' of the sector in the 1990s removed FE colleges from local government control 'to introduce markets and competition' (Lucas \& Crowther, 2016 , p. 583). More than 25 years on from the reforms, the FE sector is now faced with what Elliott (2017, p. xxiii) describes as 'perilous times', characterised by closures and mergers of FE colleges across the UK. While reforms to Australia's VET sector have ultimately resulted in concerns about the quality of VET and a response dominated by an increased focus on regulation and teachers' skills, the reaction from the UK's FE sector has developed somewhat differently. From the economically-driven and politically designed backdrop of what Biers $(2009$, p. 35$)$ describes 'as a culture of performativity in education - a culture in which means become ends in themselves so that targets and indicators of quality become mistaken for quality itself', a neo-marxist, social justice movement has emerged, which positions Further Education teachers as not only dual professionals with the role of industry expert and teacher, 
but as emancipators and 'triple professionals' with an additional responsibility of political agency, active citizenship and advocacy (Hodgson \& Spours, 2015, p.12). The resistance of FE teachers to the reforms, which many view as precipitating a devaluation of the sector and further disadvantage to those who access it (particularly young people) (Atkins, 2010, Tomlinson, 1997), has resulted in the development of a social movement persuasion and a renewed interest in the potential of critical pedagogy and transformative teaching and learning to create social change (see for example, Duckworth \& Smith, 2018; Maxted, 2015).

While there are similar concerns about the devaluation of the Australian VET sector and its potential to perpetuate the challenges of the already socioeconomically disadvantaged (see for example, Billett, 2014; Polesel, 2010; Wheelahan, 2017), the dominant issue to emerge from neo-liberalist reforms and the subsequent commercialisation of vocational education is not social justice, but VET quality and the ambition to provide a means to measure quality teaching. Aside from the Training and Education Training package, each of the teacher capability frameworks discussed in this section claim to serve a developmental purpose; that is, to guide the professional development of vocational teachers beyond their entry as novices. This is likely no coincidence, given the debate about the sufficiency of the Certificate IV in Training and Assessment for VET teacher preparation and the fact that VET teachers' CPD is both a regulatory requirement and a topic inextricably linked to the contemporary discourse on the quality of VET teaching. The following section will deal with the literature which discusses the topic of professional development for VET teachers.

\section{Professional development for VET teachers}

Given the literature's agreement that the Certificate IV in Training and Assessment, the minimum educational qualification required for VET teaching, provides only entry level preparation for the role at best, it seems reasonable to assume that 'good' VET teachers develop additional skills and knowledge as part of their CPD. Further, undertaking continual professional development is a regulatory requirement for VET teachers, outlined in the Standards for Registered Training Organisations (RTOs) 2015 (Commonwealth Government of Australia: Department of Education and Training, 2015) (referred to as 'the Standards' throughout this review). As dual professionals, they must balance the need to maintain 'current industry skills' (Commonwealth Government of Australia: Department of Education and Training, 2015, Clause 1.13) with continued development of vocational pedagogical skills 35 
(Commonwealth Government of Australia: Department of Education and Training, 2015, Clause 1.16). Despite considerable debate on the topic over the past decade, there is still no agreement on how this balance is best achieved (Schmidt, 2019 in print) and discussion on the topic remains relatively dichotomous. On the one hand is a body of work which focuses on the VET teacher's requirement to develop pedagogical knowledge and skills, while on the other is a discussion centred on issues relating to industry currency. This section will deal with each in turn from both an historical and contemporary context.

\section{Professional development relating to vocational pedagogical skills}

VET teachers undertake a variety of different professional development activities to develop their pedagogical skills and knowledge. These include (for example), formal training programs which lead to an accredited vocational or tertiary qualification, structured professional development training programs which do not lead to a qualification and informal professional development activities which occur as learning opportunities at work (Henry, 2001; Lowrie, Smith, \& Hill, 1999; Simons \& Harris, 2001; Simons, Harris, Pudney, \& Clayton, 2009). Historically, professional development strategies and activities were coordinated at national, state, RTO and individual teacher level, or as a combination of these (Smith, 2009; Smith \& Keating, 2003), however the increasing delegation of responsibility for VET from Commonwealth to State governments since the 1990s has seen a greater emphasis on activities coordinated and funded by the individual and the employing RTO. Nationally coordinated professional development activities were usually aligned to national training priorities and changes to VET policies or systems, such as (for example) CBT, the introduction of Training Packages and the technologically driven shift towards online training provision (Smith, 2000). Other nationally coordinated and funded activities included initiatives such as sponsored VET teacher training and the Reframing the Future program.

The sponsored VET teacher training program provided an opportunity for beginning VET teachers to gain a relevant tertiary teaching qualification fee free, and supported through a release from teaching duties. This program ceased in the 1990s for a number of reasons. Due to VET market and policy reforms of that period, each state and territory gained greater autonomy and financial responsibility for VET and in the resulting landscape of increasing economic pressures, sponsored VET teacher training became too expensive to support at the state or institute level. At the same time, the first iteration of the Certificate IV in Training 
and Assessment was developed as an alternative and more economical, competency based framework for VET teaching qualifications (Smith, 2009; Smith \& Keating, 2003). ANTA (Australian National Training Authority, 1997, p. 5) reported on a number of different federally funded VET development initiatives which were implemented during this period which included projects relating to CBT and industry currency (including a funded return to industry program) as well as a national professional development program for VET teachers. LearnScope and Reframing the future are both examples of significant nationally led projects of this period.

LearnScope was a national staff development program funded and led by ANTA. According to Harris et al. (2001), it was 'widely used, well-received and appropriately evaluated' (p. 44). The program focused on providing CPD for VET teachers relating to new learning technologies and flexible delivery. Reframing the Future (known as 'Framing the Future' in its first iteration) began in 1997. An initiative of Commonwealth, State and Territory Governments, the program was funded from 1997 - 2008 to build 'capacity of the Australian vocational education and training (VET) system to support the implementation of the national training system and the aims of the Council of Australian Governments (COAG) and its national reform agenda' (Reframing the Future, 2008). The program's goals were to provide VET teacher developmental opportunities aligned to improving the quality of CBT, responding to the needs of students and industry, and increasing productivity of the VET workforce (Reframing the Future, 2008). The impact of Reframing the Future on the VET workforce was quite likely significant, considering its website's claims that more than 66,000 practitioners and enterprise partners participated in its activities, which included funded projects, national forums and the development of a range of publications (Reframing the Future, 2008). The Reframing the Future program, along with all nationally-led professional development initiatives ended following a 2008 Council of Australian Governments (COAG) meeting in which a new National Skills Workforce Development Agreement was reached, devolving responsibility for VET workforce development from the Commonwealth government to the States and Territories (Council of Australian Governments, 2008).

The shift of responsibility for vocational education (including development of its workforce) provided states and territories with greater autonomy to develop professional development strategies for VET teachers which aligned to the specific needs and priorities of each state's jurisdiction. At the time, the Queensland VET Development Centre (QVDC) was 
responsible for the design and implementation of that state's VET professional development strategy. QVDC's professional development activities, provided free or at minimal cost to participants, were intended to align to the state's policies and priorities for the VET sector. For example, their $2012-2015$ strategy was built upon the skills development in four priority areas, described as 'pillars': teaching, learning and assessment; leadership; industry experience and engagement; and business development (Queensland VET Development Centre, 2012). In March 2014, the QVDC was abolished and state-led VET teacher development ceased in Queensland, leaving the responsibility for CPD to RTOs and the individual teachers. The gap left by QVDC has been somewhat filled by Velg Training, a private, for-profit membership-based organisation, which claims to be 'Australia's leading provider of Vocational Education and Training (VET) professional development and consulting services' (Velg Training, 2018). Similarly, Victoria's VET Development Centre, while primarily addressing the professional development needs of VET teachers in its own state through state government funding, also provides fee for service professional development activities to the sector Australia-wide (VET Development Centre, 2016).

It is difficult to determine how well the national and state-based professional development programs achieved their aims, or the extent to which VET teachers have developed skills and knowledge as a result of the programs. Evaluation of participant outcomes were conducted for projects conducted under the Reframing the Future initiative and a number of publications have been developed as a result of the program, however it is not clear which activities and programs yielded the most effective developmental results. The Queensland VET Development Centre claims that the 2012-2015 strategy 'builds upon the success of the 2007 - 2010 Strategy' (Queensland VET Development Centre, 2012, p. 5), however the evaluation of the previous strategy was broad, and not specifically focused on the relative efficacy of particular activities. An evaluation of the professional development activities provided by the Victoria's VET Development Centre by Billett et al. (2013) emphasised the value of non-accredited professional development activities for VET teachers.

In the absence of national or even state-based strategies relating to ongoing CPD for VET teachers, responsibility has now fallen on providers and individuals to meet CPD needs, related not only to regulatory requirements, but also to the improvement of VET quality (Braithwaite, 2018; Productivity Commission, 2011; Wheelahan \& Moodie, 2011). Despite these factors, which might reasonably imply a compelling need to monitor and evaluate the 
effectiveness of VET teacher's CPD, Tyler and Dymock (2017, pp. 3-4) reported a paucity of data on the topic, and found that regulatory audits only collected evidence of compliance or non-compliance, not on the types of activities undertaken, nor their effectiveness. They also noted that CPD 'is often undertaken to fulfil obligations and meet certification requirements', rather than to have a specific impact upon the quality of VET teaching (Tyler \& Dymock, 2017, p. 46) and that no single approach to CPD will meet the needs of every industry, organisation or teacher (Tyler \& Dymock, 2017, p. 46).

The ongoing CPD debate in Australian VET is dominated by a call for a national professional development strategy which leads to higher qualifications and greater teaching expertise (Corbel, Wheelahan, Forward, \& Darwin, 2014; Guthrie et al., 2011; Hodge, 2014; Jones, Pitard, \& McClusky, 2011; Rasmussen, 2016; Skills Australia, 2011; Smith \& Grace, 2011; Wheelahan \& Moodie, 2011) and to establish an accountable professional association to register VET teachers and track their CPD (Guthrie \& Clayton, 2012; Skills Australia, 2010; Tyler \& Dymock, 2017), however the sector has not yet established or agreed on any guidelines to support the implementation of either approach. Further, the requirement for VET teachers to maintain industry currency must also be considered in the development of strategies for CPD.

\section{Industry currency for VET teachers}

Despite entering VET teaching with the requisite industry-specific qualifications and experience, VET teachers must continue to develop and maintain current industry skills throughout their teaching career. This is a regulatory requirement (Commonwealth Government of Australia: Department of Education and Training, 2015, Clause 1.13), but is also linked to the provision of quality vocational education and training. According to Australia's VET regulator, the Australian Skills Quality Authority (ASQA), quality training and assessment depends upon VET trainers and assessors holding current skills and knowledge in both their industry area and in vocational education and training (Australian Skills Quality Authority, 2017, p. 61). This view is shared by VET teachers, their managers and VET students who regard current industry knowledge as an essential component of good VET teaching practice (Schmidt, 2017; Smith \& Yasukawa, 2017), and by industry who consider it necessary to ensure graduates of VET programs have the skills and knowledge required for work (Clayton, Jonas, Harding, Harris, \& Toze, 2013). Despite agreement on the importance of 
industry currency however, the literature reports confusion and inconsistent views on what is needed to fulfil the requirement (Clayton et al., 2013; Dickie et al., 2004; Wheelahan \& Moodie, 2011), as well as issues associated with non-compliance (Australian Skills Quality Authority, 2017; Guthrie, 2010; Tyler \& Dymock, 2017), access to suitable activities (Toze \& Tierney, 2010) and achieving an appropriate balance between industry currency CPD activities and those which enable the development of pedagogical skills for VET teaching (Schmidt, 2019 in print).

The Standards define current industry skills as: 'the knowledge, skills and experience required by VET trainers and assessors and those who provide training and assessment under supervision to ensure that their training and assessment is based on current industry practices and meets the needs of industry' (Commonwealth Government of Australia: Department of Education and Training, 2015, p. 8). They include, for example: knowledge and/or experience in using the latest techniques, processes and products; understanding relevant legislation; holding formal relevant industry qualifications; and providing relevant and current training content (Commonwealth Government of Australia: Department of Education and Training, 2015 , p. 8). ASQA describes a variety of activities that may contribute to VET teachers' industry currency. These include:

...volunteering or working part-time in the industry area; undertaking accredited training relevant to the industry area; belonging to industry associations; engaging with industry (for example, through discussions with employers or attending industry networking events); reading industry journals and subscriptions; staying informed about changes to technology; and keeping up to date with changes to legislation. (Australian Skills Quality Authority, 2017, p. 63)

While there appears to be an extensive variety of activities that VET teachers might undertake to maintain currency, not all, it seems, are ascribed equal value. ASQA, for example, cautions that what is considered relevant will vary according to the industry area (Australian Skills Quality Authority, 2017), while Clayton et al. (2013, p. 21) reported that the regulatory body's auditors place the greatest value on activities which involve direct interactions with industry employers such as: consulting with industry representatives; participating in industry led training; undertaking paid work in industry; and participating in industry release, an activity which allows the VET teacher to engage in a work role in industry while being paid by the RTO (Clayton et al., 2013, p. 22). Other activities, such as participation in industry networks and associations, attending trade exhibitions and conferences, 
conducting research or reading industry journals, though industry related and perceivably providing a legitimate method for VET teachers to maintain industry currency, may be viewed by auditors as less valuable as they involve less direct engagement with industry (Clayton et al., 2013, pp. 21-24). Interestingly, industry employers on the other hand, are likely to consider such activities highly effective, enabling VET teachers to engage with industry and remain abreast of new industry developments (Clayton et al. 2013).

In addition to the diverse and somewhat conflicting views on what constitutes a legitimate, relevant or valuable industry currency activity, there also appears to be confusion around sufficiency; that is, the duration and frequency of participation in relevant activities which is required in order for a VET teacher to be considered 'current'. Such requirements are not made explicit by the Standards or by the regulator, leaving the responsibility for interpretation to VET teachers, RTOs and auditors, with Tyler and Dymock (2017, p. 22) reporting 'considerable variation' in their views on the appropriate volume, duration and frequency of industry currency activities for VET teachers. Those employed by TAFE Queensland must work according to the Queensland TAFE Educators Agreement, which calls for VET teachers to undertake 'a minimum of 10 days professional development and release to industry' (Queensland Industrial Relations Commission, 2016, p. 24). The agreement asserts that professional development activities should be 'prioritised' according to those which 'develop and extend an Educator's vocational competency and currency of skills and knowledge relevant to vocational training, learning and assessment and current industry skills' (Queensland Industrial Relations Commission, 2016, p. 24), but it doesn't state how many of the ten days should be apportioned to industry currency or how many to other types of CPD, such as those undertaken to develop vocational pedagogical skills. The absence of clear or mandated guidelines around sufficiency, nor the legitimacy of different types of industry currency activities has created additional issues for VET teachers. Some find it difficult to source appropriate, meaningful and productive activities which align to the RTO's policies and procedures, the views of supervisors who are required to approve the activity and the regulatory body's auditors (Schmidt, 2019 in print; Toze \& Tierney, 2010, p. 8). They also face workload and timing issues associated with scheduling industry currency activities, with the literature reporting incidences of VET teachers maintaining currency requirements by working part time in industry while also engaged full time as a VET teacher (Schmidt, 2019 in print; Toze \& Tierney, 2010, p. 13). 
In this section of the literature I have demonstrated the literature's interrogation of professional development needs and activities for VET teachers. Arguably, and perhaps for pragmatic reasons, it more often positions professional development activities as something undertaken for compliance reasons or to facilitate sector-wide reforms, rather than to achieve any particularly useful gains in teaching expertise. The literature also reveals a progressive shift in responsibility for VET teaching and VET teachers' development from federal and state government to RTOs and individual teachers, largely precipitated by political and market driven funding reforms. Although there are calls in the VET sector for a national professional development strategy and higher level qualifications for its teachers, it has not yet agreed on the VET teachers' developmental needs, as can be evidenced by the number of different capability frameworks produced by the sector between 2009 and 2019 . This is a landscape dominated and created by a reductionist and instrumental approach to conceptualising VET teaching, which views the role as means to an end, and which espouses a belief that to achieve the sector's role as an instrument to realise economic and social policies (often frequently changing), its teachers must uniformly possess a comprehensive and specific range of capabilities - knowledge, skills and behaviours - even if the sector has not yet been able to agree on what these are.

A sympathetic review of the literature which presents a more holistic view of teaching, the views of Noddings, Greene, Hansen and van Manen, for example, might urge a change in tack for the VET sector, a deviation from its current overwhelmingly lineal, instrumental, prescriptive and reductionist path. A view of VET teaching which emphasises the importance of the teacher as an individual, with a broader responsibility than that which can be described in a capability framework, no matter how detailed, would recommend a vastly different professional development pathway. Certainly, the holistic view of teaching presented in this literature review is not a conceptualisation that should be reserved only for other education sectors, as pointed out by Brennan Kemmis and Green (2013):

The moral, social and personal dimensions of teaching, and the recognition of the importance of these dimensions, survive in the expressions of praxis that come from those who have day to day responsibility for their students. (Brennan Kemmis \& Green, 2013, p. 118)

To answer the question 'How are advanced skills for VET teachers understood and how are they developed?' a methodology will be required which enables examination of conceptualisations arrived at through both reductionist and holistic approaches and the 
developmental implications associated with these divergent approaches. It is also important to understand the impact of perceptions communicated within the VET teacher's working environment as well as those derived by the individual and personal meaning making of VET teachers themselves. In Chapter 3 the design of the project's research methodology will be explained and justified as an appropriate way of achieving these aims. 


\section{CHAPTER 3 METHODOLOGY}

An effective research design, according to Maxwell $(2005$, p.2) is 'one in which the components work harmoniously together'. To achieve this, there must be an interconnection between the philosophical worldview (beliefs) of the researcher, the strategy of inquiry (methodology) and the research methods (Creswell, 2009). Maxwell (2005) developed an interactive model of research design to structure the 'interconnected and flexible' (p.3) relationship between five key components of a study. These components are: the goals of the research; the conceptual framework which will guide and inform the research; the questions that the research seeks to answer; the methods that will be used to conduct the research; and consideration of the study's validity (Maxwell, 2005, p. 4). In this chapter I will apply Maxwell's model to describe and justify the research design employed, illustrating the alignment between the research questions, the qualitative multiple case study methodology, the methods employed to collect and analyse the data and the conceptual framework which scaffolds the inductive inquiry. I will begin however, by outlining the importance of the research project, its goals and purpose.

\section{Research goals and questions}

For a research project to be meaningful, it must be worth doing. According to Maxwell (2005, p. 4) the purpose and goals of the study, the issues that the researcher seeks to understand and the policies or practices that he/she intends to influence should be clearly outlined at the beginning. Clarifying these will help to guide important decisions about the research design and provide a basis for justifying and demonstrating relevance of the project. The purpose of this study was to understand advanced skills for VET teachers and how they are developed. Its significance as a topic was established through an analysis of the literature (Chapter 2) which found that the quality of VET and in particular, the quality of VET teaching, is an important and prominent topic of contemporary discourse in the sector and that there is an established link between the quality of VET teaching and learner outcomes (see for example: Harris, 2015; Walker, 2012; Wheelahan \& Moodie, 2011). While some recent studies (Rasmussen, 2016; Schubert, 2017; Smith \& Yasukawa, 2017) have investigated the skills and knowledge required for 'good' VET teachers (described as 'advanced skills' in this study), and a number of frameworks have been developed in an attempt to articulate these (Innovation and Business Skills Australia, 2013; LH Martin Institute, 2016; Mitchell \& Ward, 2010; TAFE 
Queensland, 2016), there is still no agreement in the sector on what these advanced skills are or how they are best developed.

This research project is expected to contribute important knowledge to help inform policies and practices relating to quality in VET teaching, VET teacher preparation and VET teacher professional development. To achieve this, I sought a greater understanding of advanced skills for VET teachers by focusing on the following two questions:

- How are advanced skills for VET teachers understood?

- How are they developed?

In Maxwell's interactive model, the research design centres around the research questions they are at the heart of the design and connect all of the other components (Maxwell, 2005, p. 4). They also serve a number of functions. As well as explaining what the research project seeks to understand, they help to focus the study and provide 'guidance on how to conduct it' (Maxwell, 2005, p. 75). Also focusing and informing the research study's design is the conceptual framework which underpins it. The following section will provide an explanation of the study's framework and how it supported and informed the research project.

\section{Conceptual framework}

The conceptual framework is 'the system of concepts, assumptions, expectations, beliefs, and theories that supports and informs' a research project (Maxwell, 2005, p. 39). In this research project I explored conceptualisations of advanced skills for VET teachers through the lens of social constructionism, assuming that knowledge and meaning are not discovered, but developed and transmitted through our social interactions with others and the world around us (Crotty, 1998). While social constructionism provided the overarching framework for the study which was situated within the context of three different training organisations, two other theories provided useful scaffolding for the project. Sartre's (1977) theory of existentialism was used to frame an exploration of the importance of the individual teacher and the moral and ethical choices he/she makes within the social constructs of the VET teaching environment, while Connelly and Clandinin's (1995) theory of secret, sacred and cover stories provided a structure to understand how teachers manage the sometimes conflicting expectations of the socially constructed VET landscape and the implications of the 
individual, authentic decisions that they themselves make about teaching. This section will explain how these theories have been used to frame the project.

The literature review (Chapter 2), presented two different ways of conceptualising good teaching and advanced skills for VET teachers. On the one hand, there are essentially reductionist conceptualisations which seek to distil the various components of 'good teaching' to a specific capability, practice or set of skills and knowledge. On the other, there are conceptualisations which are more holistic and which emphasise the importance of the individual teachers' personal character and attributes. The influence of the social component of constructionism is most evident in the reductionist conceptualisations of teaching, as the contemporary frameworks and lists of skills meant to articulate 'good teaching' by proponents of this view are strongly grounded and influenced by the context and norms of the RTO and the VET sector. The more holistic perspectives of teaching however, tend to place a greater importance on the individual activity of meaning making within the social context. Indeed some, such as Greene (1973) and Van Manen (1991) for example, embrace an existentialistic point of view, presuming that VET teachers with advanced skills possess qualities that are 'pre-social', individual and unique, and that they assume a responsibility for making moral and ethical decisions based upon critical and conscious analysis and thought. Tensions may arise as VET teachers critically question or practice teaching in an 'authentic' way, according to their own belief in what is right in a particular situation (exercising what Jean-Paul Sartre referred to as their 'existential choice') if these beliefs do not align to those constructed within the context of the organisation or VET sector. The way in which VET teachers deal with these tensions was examined according to Connelly and Clandinin's (1995) theory, which explains teachers' ways of managing similar epistemological dilemmas through the narratives of secret, sacred and cover stories.

\section{Ways of meaning making - social constructionism and the individual}

Social constructionism is a world view which assumes that 'all reality, as meaningful reality, is socially constructed' (Crotty, 1998, p. 54). Importantly, it does not premise that meaning is completely subjective and individual; rather it emphasises the influence of pre-existing, inherited and socially communicated meanings, culture, environment, society and institutions - the things described by Heidegger $(1962$, p. 65$)$ as the 'world always already there'. Viewed through this lens, VET teachers' and managers' perceptions of VET teaching skills and their 
development are likely to be influenced by pre-existing understandings and culture within multiple social contexts, including: the organisation in which the VET teacher carries out his/her work; the vocational sector in which VET teachers' work is situated and regulated; and the broader community and the shared views on good teaching which exist within it. The social constructionist worldview provides a helpful framework for understanding the reductionist approaches, which seek to understand 'good teaching' by atomising it to a definable and reproducible set of skills, knowledge and behaviours, a conceptualisation which is constructed upon pre-existing social, historical and regulatory structures. The literature review also identified an alternative way of conceptualising teaching, which presumes that advanced teaching skills are essentially pre-social and non-contextual, and which emphasises the importance of the individual teacher's character and characteristics, making visible the subtle moral, ethical, personal and relational dimensions of teaching described by (for example): Brennan Kemmis and Green (2013); Freire (1972), Greene (1973); Hansen (1995, 2001); Noddings (1999, 2012, 2016a); and Van Manen (1991). While not all of these authors would describe themselves as 'existentialists', their alternative conceptualisation of teaching is at least somewhat representative of existentialist themes.

Existentialism, according to Noddings (2016b, p. 61), cannot be properly described as a philosophical school due to the varied and often contradictory positions held by its proponents, who usually reject systematic philosophy and schools of thought. Daigle (2006), instead describes it as a 'philosophical movement articulated on the basis of fundamental criticisms of philosophical theories and systems' (p.4). A key theme in existentialism is attributable to Sartre (1977); that 'existence precedes essence' (p. 41) and that as humans, we are 'self-conscious, self-interpreting, and world-interpreting beings', free to create ourselves rather than being a product of a creator's preconceived design (Braddock, 2006, p. 94). Existentialists emphasise individual meaning making and the freedom of individual choice, so rather than assuming the socially constructed and culturally defined perception of a teacher, an existentialist view would see teachers choosing their identities as teachers for themselves and taking full responsibility for their choices, even when those choices are in conflict with policy or pre-defined conceptions of how a teacher should teach.

No outside factor or force, no science or set of rules or moral law, can make decisions for him. The only significant choices are those that involve him totally and project his existence into a future still unknown. (Greene, 1973, p. 256) 
Importantly, while existentialism emphasises the choice of the individual, according to Sartre (1977), it is also concerned with the responsibility of the individual towards others:

And when we say that a man is responsible for himself, we do not only mean that he is responsible for his own individuality, but that he is responsible for all men. (Sartre, 1977, p. 36)

Thus, while a social constructionist worldview has been applied due to the influence of culture and social context on the way that 'good teaching' is conceptualised, the existentialist themes observed in the exploration of the moral and ethical dimensions of teaching must be acknowledged. According to Noddings (2016b), existentialism has also influenced contemporary discussions on the relational aspects of teaching and on the unintended, untaught, non-curricular influences that teachers have on their students, described by Jackson (1992) as the things we learn from our teachers about ourselves and others, and about life in general' (p. xi). The existentialist perspective may be inherently fraught for teachers however, who find that critically questioning, or railing against standardised expectations of teaching, teachers and what should be taught, leads to tensions and disquiet.

\section{Secret, sacred and cover stories: ways of managing epistemological dilemmas}

The holistic conceptualisations which focus on the individual character of the teacher somewhat emancipate teachers with the freedom and courage of individual choice. It also tasks them with tremendous responsibility for their choices. Greene (1973) for example, encourages teachers to question presumptions about teaching and the teachers' role, to '...struggle against unthinking submergence in the social reality that prevails' (Greene 1973, p. 269), and to take nothing for granted, instead developing their engagement in 'critical thinking and authentic choosing' (Greene, 1973, p. 269). It is conceivable that the 'struggle' described by Greene may lead to tensions for VET teachers when critical questioning of presumptions and enactment of authentic choice conflicts with the conformist approach required by the systems and socially constructed context of the VET sector and the RTO in which they work. To understand these tensions and the way that VET teachers manage them, I have applied the metaphorical framework developed by Connelly and Clandinin (1995) in their study of teachers' 'professional knowledge landscapes' and their theory of 'secret, sacred and cover stories' (p. 4). 
Teachers, according to Connelly and Clandinin (1995), inhabit and cross to and fro between the boundaries of two fundamentally different places on the professional knowledge landscape: the special, safe, somewhat secret place behind the classroom door and the professional place outside of it, which is largely constructed by others and influenced by 'sacred stories', the stories funnelled into the school and to teachers with a goal of shaping teacher practice (Clandinin \& Connelly, 1996, p. 25). They assert that teachers make authentic, independent choices about the teaching that happens in the classroom, even though these choices may be at odds with the policies, procedures and understandings - the sacred stories - prescribed by the educational setting and context that exists beyond the classroom door. This situation, according to Connelly and Clandinin (1995) may lead to teachers experiencing 'moral and epistemological dilemmas' (p. 5). To manage the tension arising from such dilemmas, teachers may develop 'secret stories', stories lived in practice in the safe space of the classroom (Connelly \& Clandinin, 1995, p. 12); and 'cover stories', alternative narratives about their classroom practice which are told in the professional knowledge landscape outside of the classroom (Connelly \& Clandinin, 1995, p. 15). Clandinin and Connelly's metaphorical framework provides a useful basis for understanding and explaining how teachers manage the boundary crossing required and the tensions that arise as they navigate between the their individual and authentic perceptions of 'good teaching' and the sometimes conflicting expectations and requirements of their managers, the RTO and the VET sector (Schmidt, 2017).

Within this conceptual framework, in order to understand advanced skills for VET teachers and the way that they are developed it was important to learn about the perceptions and experiences of individual VET teachers, but also of the VET managers who may influence the way that VET teaching skills are understood, recognised, rewarded and developed. Social constructionism assumes that meaning making is contextual and developed from the understanding and meaning that is already constructed, inferring a highly contextual aspect to knowledge. VET teachers' work and their professional development is situated both locally (within the context of the RTO in which they work) and sectoral (within the context of the VET sector, including its regulatory frameworks, policies and systems). To understand conceptualisations of advanced skills through the lens of social constructionism then, the study would ideally be situated within the context of the RTO and the sector. Social constructionism also requires a focus on individual meaning making, illuminating the 
importance of studying the personal characteristics, beliefs and understanding of individual VET teachers about advanced skills and their development. For this reason, it was necessary to seek individual experiences and perceptions of VET teachers with advanced skills. These requirements inevitably led to a research design comprised of a qualitative multiple case study methodology in which each case is a large public VET provider in Queensland, with data collected through interviews with VET managers and teachers with advanced skills from each of the organisations. In the following section I will elaborate on this methodology and justify it as appropriately suited to the project's goal and purpose.

\section{Methodology}

Though representing somewhat contending ways of understanding meaning making, social constructionism and existentialism provide complementary epistemological perspectives for what is essentially an inductive, interpretive, research project, best suited to investigation using a qualitative approach. As pointed out by Merriam (2009, p. 5):

Qualitative researchers are interested in understanding how people interpret their experiences, how they construct their worlds, and what meaning they attribute to their experiences. (Merriam, 2009, p.5)

In this project, I sought to understand how those who work in the VET sector, VET managers and teachers, understand advanced skills, and the experiences that enable VET teachers to develop advanced skills, making the choice of a qualitative design inherently sound. Selecting this methodology however, also required rejection of the alternative quantitative or mixed method approaches. Where qualitative research 'relies primarily on human perception and understanding' (Stake, 2010, p. 11), quantitative research is grounded in scientific methods, bounded by the notion of absolute truth and a reality that is most probable and measurable (Creswell, 2009; Merriam, 2009). This aligns most closely to a positivist worldview which is incompatible with the social constructionist and existentialist theory underpinning the study's conceptual framework. Qualitative research on the other hand, assumes a subjective view of reality, with the aim of studying things in their natural settings to make sense of or interpret the meanings people bring to them (Denzin \& Lincoln, 2011, p. 3). Quantitative research is also most often a deductive process in which researchers objectively test theories by collecting and analysing primarily numerical data (Creswell, 2009), while qualitative research is most appropriate to use for inductive studies such as this one, which are based upon nonnumerical data. 
There is a third strategy of inquiry which incorporates both qualitative and quantitative methodologies. This is the mixed methods approach, appropriate to use when 'results need to be explained, exploratory findings need to be generalized, a primary experimental design needs to be expanded or enhanced, multiple cases need to be compared or contrasted, the participants need to be involved in the research, and/or a program needs to be evaluated' (Creswell \& Plano Clark, 2018, p. 8). The aim of this research project however, is to conduct a detailed and rich exploration of advanced skills for VET teachers and how they are developed. Rather than seeking to prove or disprove a theory, evaluate a program or to argue for generalisation of findings, the findings are intended to be inductive, exploring the views and experiences of VET teachers and managers relating to advanced skills and their development, a purpose which is appropriately aligned to a purely qualitative methodology.

\section{The multiple case study}

The term 'qualitative research' (or alternatively, 'qualitative inquiry') is generally regarded as an umbrella term which encompasses a variety of qualitative and interpretive approaches, such as (for example) ethnographic research, phenomenological research, grounded theory research, narrative research and case study research (Creswell, 2013; Merriam, 2009; Van Maanen, 1983). Each of these approaches have a central purpose or focus. Narrative studies, for example, focus on the life of one particular individual, while phenomenology focuses on the lived experiences of individuals regarding a concept or phenomenon, grounded theory uses systematic procedures bound by scientific rigor and credibility to develop a theory, and ethnography focuses on the behaviours of a particular culture-sharing group (Creswell, 2013). Case study research on the other hand, is an approach which provides the opportunity to develop 'an in-depth description and analysis of a bounded system' (Merriam, 2009, p. 40), by studying in detail 'the particularity and complexity of a single case' (Stake, 1995, p. xi). The bounded system refers to an individual, an organisation, or an institution; it must be 'a specific, a complex and functioning thing' (Stake, 1995, p. 2). Case study research may be conducted using a single case, however for this research project, I employed a multiple case study approach involving three cases.

The case study methodology has a number of strengths, particularly in the field of education research. Merriam (2009, p. 51) cites its value in 'studying educational innovations, 
evaluating programs and informing policy', and in enabling understanding that can 'affect and improve practice'. Wellington (2000, p. 97) describes well written case studies as illustrative, insightful, disseminable, accessible, attention-holding, strong on reality, vivid and of value in teaching. Case study research and in particular, multiple case study research, is also useful for generating theory which may help structure future research, thus significantly adding to the body of knowledge about a subject (Bassey, 1999; Eisenhardt \& Graebner, 2007; Merriam, 2009). In multiple case study research, the focus is still on the individual case, however it is analysed in comparison to a collection of cases which share a common phenomenon, object or condition which Stake $(2006$, p. 6) refers to as the 'quintain'. While the researcher studying a single case may seek to understand the case, in multicase studies, the researcher seeks to understand the quintain, and the cases are studied for what they can tell us about it (Stake, 2006). In this study the quintain was 'advanced skills for VET teachers and how they are developed', and each individual case has been studied for the insights, understanding and meaning that it could contribute to this phenomenon.

This study will focus on three cases, each one a unique, separate, bounded system, but also, as recommended by Stake (2006), somewhat similar. All three are large public VET providers in Queensland which provide a comprehensive range of VET programs and which have originated from TAFE Queensland with similar systems, policies and procedures. They operate in the same state-funded training market and employee wages and conditions are prescribed by similar industrial agreements. Further, as RTOs, their operations must comply with the same regulatory and legislative requirements which govern activity in the VET sector. While similar, the cases are also separate bounded systems by virtue of their geographical boundaries and the contextual differences which this creates. They also have separate performance and reporting obligations, and different region-specific projects and goals which impact upon the experiences of the VET teachers and managers and create different contexts in which they carry out their work.

Individual narrative interviews were conducted to collect data for each case report and to gain a greater understanding of the quintain. Conducting a number of individual interviews within each site enabled an exploration of the way in which advanced skills for VET teachers are understood within the social context of the sector and the organisational setting, while also exploring the individually constructed and potentially divergent meanings unique to each participant. This is an appropriate approach given the project's theoretical framework 
which juxtaposes the contextual and socially situated lens of social constructionism with the uniquely individual understanding permitted from the existentialist's perspective. It also provided the opportunity to identify tensions which might arise when the individual's meaning and understanding differs from that which is socially constructed and situated within the context of VET teachers' work.

\section{Data collection}

Research data was collected using narrative interviews with VET managers and VET teachers from the organisation. This is a strategy of inquiry which allows the researcher to capture, through discussion, personal and human dimensions of experience over time, and which takes into account the relationship between individual experience and cultural context (Clandinin \& Connelly, 2000). Narrative interviews were considered a particularly relevant method of data collection for this study, given the insight of Connelly and Clandinin's (1995) theoretical framework of secret, sacred and cover stories which holds that the narratives told by teachers about teaching are likely to vary according to whom the story is told. The secret stories of teaching - the practice which occurs behind the closed doors of the classroom - can only be extracted from the teachers themselves (Connelly \& Clandinin, 1995), and it is likely that the stories of teaching reported by their managers will reflect the sacred stories influenced by research, policy and organisational goals and the cover stories told to them by teachers.

The focus of narrative interviews is on the representation of participants' stories as told by them (Kvale \& Brinkmann, 2015), and the interview practice and techniques required to collect this narrative data varies considerably from the traditional, standard interview approach. Traditional interview practice is a highly structured activity intended to collect data in a relatively uniform format so that it can be 'categorised, codified and generalised' (Borer \& Fontana, 2012, p. 47). It is also largely a transactional interaction characterised by clearly demarcated roles and led by an interviewer who asks questions which the participant answers (Chase, 2011; Gubrium \& Holstein, 2012; Mishler, 1986). This traditional interview approach is more aligned to a positivist philosophy which assumes that knowledge exists as facts and feelings held by the participant and must be discovered through the use of structured interviews and careful questioning (Brinkmann \& Kvale, 2015; Gubrium \& Holstein, 2011). The conceptual and theoretical framework of this research study however, required a shift in practice towards the collaborative, discursive style recommended by Mishler (1986, p ix) in 
which the dialogue and meanings are 'contextually grounded' and jointly constructed by the interviewer and the participant.

The shift from a traditional interview to a narrative interview style represented a reconceptualisation of the roles which would usually be played by myself as researcher and the participants. Gubrium and Holstein (2012) describe the shift as one in which the participants move from a position of passive subjectivity to one of active subjectivity. In this role they become 'constructive practitioners' (Gubrium \& Holstein, 2012, p. 33). The shift in power and roles is emphasised by Mishler (1986) who cites the need to empower interview respondents by lessening the control and domination of the interviewer. Similarly, Chase (2011, p. 423) describes the relationship shift from that of 'interviewee-interviewer' to 'narrator and listener'. To achieve this shift it is necessary to change the traditional methods of structuring, conducting and organising interviews. While traditional structured or semistructured interviews require the development of a detailed interview schedule to ensure that interviews are conducted systematically and uniformly with all participants, this format was not suitable for the dialogical style and aims of the narrative interview. Instead, I developed an 'interview guide', using the format suggested by Patton (2002, p. 343). The interview guide outlined the topics and subject areas to be raised with each participant, but allowed myself as the researcher and the participant, as the empowered interviewee, the freedom to explore and probe more deeply into areas of particular importance or interest to the topic. I developed two different guides, one for VET managers and one for VET teachers with advanced skills. While the purpose of the interviews was the same, to develop the case study which would help me to better understand the quintain (advanced skills for VET teachers and how they are developed), I asked VET teachers with advanced skills questions which encouraged them to reflect upon their own skills and experiences but asked VET managers questions about their observations and understanding of VET teachers whom they believed to have advanced skills. Interview guides for VET managers and VET teachers with advanced skills are included in Appendices $B$ and $C$ respectively.

Each interview was of 45-90 minutes duration, and true to the narrative style, I used the questions from the interview guide as a prompt to trigger discussion from the interviewee rather than to elicit short, direct responses. This approach allowed further exploration of interesting issues raised by interviewees and resulted in interviews in which the participant's voices dominated rather than my own. If however, the discussion stalled or veered too 
broadly off the main topic of advanced skills for VET teachers, I referred to the interview guide to ask another question and bring it back on track.

I followed the advice provided by Bogdan and Biklen (2007, p. 70), completing all interviews for one case before moving onto the next. This process helped to avoid confusion between the cases, but it also allowed me to improve my interviewing technique and to identify exploratory themes to focus on for the other cases. For example, once I completed the interviews for Case A, I noticed divergent views between VET managers and teachers about advanced skills, so when collecting data for Case B and C, I was interested to find out if similar phenomenon existed in those settings. I also wanted to explore possible contextual influences in the way that advanced skills were understood which might reveal divergent views between cases. I followed the same approach to data collection for each case, conducting interviews with VET managers first before moving on to interviews with VET teachers with advanced skills. Teachers with advanced skills were identified and invited to participate in the research by professional recommendation from managers and peer nomination. All interviews were recorded and transcribed verbatim. The transcripts were then provided to participants for review, confirmation or amendment. Once all interviews for a case had been completed, transcribed and approved by participants, I developed the report for that case before moving onto the next.

While narrative interviews provided the dominant means of data collection, the case studies were informed through other aspects of the project's design. As Stake (1995, p. 49) points out, 'there is no particular moment when data gathering begins', and in this project, data gathering legitimately included the development of the literature review, and my own previous acquaintance with the cases and the context in which VET teaching takes place. Stake (1995, p. 49) holds that 'a considerable proportion of all data is impressionistic, picked up informally as the researcher first becomes acquainted with the case.' My initial impressions were undoubtedly reflexively observed and interpreted due to my status as an 'insider' as well as researcher in this case. These impressions were tested and refined, however through the detailed analysis provided in the Literature Review, which served to provide a contextual grounding for the cases in the highly reported setting of Australia's VET sector.

While it is important to choose a research methodology appropriate to the research purpose, question and theoretical framework, it is also important to select cases and 
interview questions which will yield interesting theoretical findings relevant to the quintain and the research questions. In the following section I discuss the sample selection process used to identify cases and participants appropriate to the project.

\section{Sample selection}

In qualitative research, samples are unlikely to be regarded as statistical, probabilistic or representative of an entire population (Wellington, 2000, p. 60). According to Maykut and Morehouse (1994, p. 56), the strategy used to select a research sample for qualitative research purposes should depend upon the researcher's judgement and the focus of the research study, so with this in mind I applied a purposive sampling approach to select the cases. Purposive sampling involves the selection of participants or cases with a specific purpose in mind (Wellington, 2000) and can be applied to select individuals and/or organisations with certain characteristics relevant to the study. For a multiple case study methodology it is important to select cases that can help us to understand the 'quintain' (Stake, 2006, p. 6), so for this project, it was necessary to ensure that each case would provide access to VET teachers with advanced skills, and to managers who supervise VET teachers and have influence on their work and the learning activities they undertake to develop VET teaching skills. I selected three Cases, with each Case representing a large public VET provider. All three Cases originated from TAFE Queensland, the state-based public provider. Two Cases (Cases A and B) were existing regions of TAFE Queensland, and the other (Case C) was a University which merged with a TAFE Queensland region to create a 'dual sector' institution approximately three years prior to data collection.

I considered a number of factors before selecting the Cases. Firstly, I decided to situate the study in Queensland. This decision was made for pragmatic reasons, but also because there are a number of contextual factors which may affect VET teachers' work, and which vary between states. While legislative and regulatory requirements are applied nationally, funding and the industrial instruments that frame VET teaching practice are largely state based. I then selected three VET providers which were somewhat similar, and in which VET teachers with advanced skills might typically be found, but with sufficient differences to yield theoretically interesting findings. The cases have a shared history as regions of TAFE Queensland, and each provides a wide range of VET courses in multiple locations throughout Queensland. While VET is the core business for Cases A and B, they also offer a small number 
of Bachelor courses through a partnership with a university. Case $C$, on the other hand, was previously a university providing only Higher Education programs, but now also delivers VET programs as a dual sector university. VET teachers from Cases A and B are employed according to the TAFE Queensland Certified Agreement 2016, while Case C's VET teachers are subject to a different enterprise agreement, negotiated with their employer, the university.

There were also contextual, organisation-specific differences between the cases which may influence teachers' and managers' views on VET teaching skills and how they are developed. Although the cases were RTOs of a similar size which operated in similar market conditions in the same state, each had different strategic business goals which in turn influenced the managers' performance goals and focus. These contextual differences are significant in any discussion about VET teachers' skills and professional development, as they have been found to have an impact on the context in which VET teachers carry out their work, the activities that are recognised and rewarded and the developmental opportunities available to them (Schmidt, 2017a). At the time of data collection, Case A's managers were focused on an internal recruitment and selection process undertaken to appoint teaching team leaders. This initiative was intended to devolve some of the responsibility for compliance and mentoring of VET teaching teams from their managers and other relevant organisational departments to the teachers appointed to the newly created Team Leader position. Case B on the other hand, was involved in a large project to develop online learning and assessment resources for use in all regions of TAFE Queensland. This project required a significant investment of time and financial resources and as a result, Case B's managers were focused on ensuring that VET teachers had the technological skills and knowledge to use the newly developed online resources. For Case $C$, the focus was very much on navigating the challenges associated with integrating the merged VET organisation (including its employees, students and products) into an existing Higher Education organisational structure. There were also differences between the Cases in the way that VET teachers' participation in professional development activities was guided, managed and monitored, and the associated organisational policies and procedures.

Deciding upon the number of Cases to study was just as important as selecting the particular Cases. According to Yin (2014), the number of Cases to be included in a multiple case study methodology should depend on the type of phenomenon being studied and the questions to be answered. While Stake (2006) and Eisenhardt (1989) argue that fewer than 
four cases or greater than ten will limit the benefits of the research and make theory generation difficult, according to Yin (2014), even a two-case study will strengthen a research study's findings. In this instance, more than three Cases would prove unwieldy, given the constraints of a PhD project and considering that the data collection to develop the Cases would require between 30 - 36 separate interviews.

To develop each case study, I planned to recruit and interview 10-12 participants from each case. To understand potential differences in the way that managers and teachers understand advanced skills and how they are developed, my goal was to interview 2-4 managers and 7-10 teachers from each case. I used a snowball strategy to recruit participants, a strategy which involved seeking professional recommendations for suitable participants from 'well-situated' people in each organisation (Gall, Gall, \& Borg, 2007, p. 185). To implement this approach, I initially sought approval to conduct the research project from the most senior VET manager in each organisation. For case $A$ and $B$, this approval was provided by the respective General Managers, while for Case C, approval was gained from the Pro ViceChancellor for VET. I provided information about the research project to each of the approving managers and sought recommendations from them for suggested participants for the first phase of interviews, specifically seeking those with a responsibility for managing VET teachers and who have a role to play in approving and planning their professional development (refer to the Plain Language Information Sheet and Request for Approval provided in Appendix A). Implementing the snowball strategy, I asked each of these participants to identify one or more VET teachers whom they considered to have advanced skills, so that I could invite them to participate in the research project. I repeated this process of recruiting participants throughout the interviews with VET teachers, until I had no new recommendations of participants to interview and had achieved the sample size intended for the project. Before commencing the data collection process however, it was necessary to consider ethical implications associated with the research and gain ethical clearance, important aspects of the research design and implementation which will be addressed in the following section.

\section{Ethics}

This project was conducted in accordance with the guidelines provided by the National Statement on Ethical Conduct in Human Research (National Health and Medical Research 
Council, Australian Research Council, \& Universities Australia, 2007) and ethical clearance provided for the project by Griffith University. Ethics approval was received from on the $5^{\text {th }}$ August, 2015, with a valid protocol period until 31 ${ }^{\text {st }}$ December, 2017 (GU Ref No: EDN/64/15/HREC). Data collection did not commence until ethics clearance was received, and was completed within the protocol's stated timeframes.

All ethical requirements were met during the conduct of the research project. Permission was obtained from the relevant senior personnel of each participating organisation prior to data collection. Each participant was provided with the Plain Language Information Statement (included as Appendix A) and required to provide informed consent prior to interview. Participants were reminded that they could retract their consent at any time, and were provided with a transcript of their interview and asked to edit, amend (if required) and to approve the transcript before data analysis was undertaken. All participants approved their transcripts, and none withdrew their consent for their participation in the project. Pseudonyms were used to protect the identity of participants throughout the research project, in Case reports and published works. Audio files sent to an external transcription service were given de-identified naming conventions. Due to the small sample size, participants were advised in the Plain Language Information Sheet that identification may be possible. Transcripts, audiotapes and any documents related to the project were stored in a locked filing cabinet only available to myself as the researcher and will be destroyed five years after the thesis is published. Electronic files relating to the research project have been stored on my own personal computer which is password protected, and backed up on an external hard drive which is also password protected and stored in a locked filing cabinet only accessible to myself. Participants will be provided a copy of the final thesis if requested.

\section{Data analysis}

As Wolcott (1994, p. 1) points out, 'the real mystique of qualitative inquiry' lies not in the way the data is gathered, but in the way that it is used. In this section I will describe the thematic and cross case analysis methods used to develop the project's findings. Due to the data collection method employed (narrative interviews) and the research methodology applied (a qualitative multiple case study approach), I undertook data analysis in two stages. In the first stage, I applied thematic analysis to interpret interview data and develop each case report, 
completing this process for each case in turn before moving onto the next case. Once each case study report had been developed, I used cross-case analysis to determine similarities and differences between cases, and to interpret them to develop the study's findings. I will elaborate on the two stages, thematic analysis and cross case analysis, in this section.

\section{Stage 1: Thematic analysis and case study reports}

Thematic analysis is a method used to identify, analyse and report themes or patterns within the data (Braun \& Clarke, 2006, p. 79) and a way of 'encoding qualitative information' (Boyatzis, 1998, p. 1). A theme, according to Braun and Clarke (2006, p. 82) 'captures something important about the data in relation to the research question and represents some level of patterned response or meaning with the data set'. The method of thematic analysis, according to Boyatzis $(1998$, p. 1) is a 'way of seeing' - looking for and identifying these themes. For this project, thematic analysis was also important as a way to determine the data to be related in each case study report.

Braun and Clarke $(2006$, p. 87$)$ describe six phases in the process of thematic analysis: familiarising yourself with the data; generating initial codes; searching for themes; reviewing themes; defining and naming themes; and producing the report. I applied these phases to each of the three case data sets (i.e. the interviews collected for each case) in turn, in order to produce the case study reports provided in Chapters 4,5 and 6. While Braun and Clarke's (2006) phases provide a useful framework to underpin the thematic analysis, they do not assume that the process would be linear. Certainly this was indeed my experience in this research project in which the analysis process, just as Braun and Clarke (2006) described, was 'recursive', requiring a 'constant moving back and forward' between the data set, extracts of data and analysis of the data (Braun \& Clarke, 2006, p. 86).

I commenced the first phase - familiarising myself with the data - during the data collection process, while conducting interviews. During this period, I recorded each interview and listened to each recording a number of times, before interviews were transcribed verbatim. I completed some of the transcriptions myself, a necessary process which was also an effective means of familiarisation with the data (Riessman, 1993). Due to time constraints, however, I also employed a reputable data transcription service, but proof-read and edited each transcribed interview (listening again to the audio while doing so) to familiarise myself with the transcription while also checking accuracy. Each transcription, once completed, was 
emailed to the respective interview participant to check accuracy and clarify interpretations where required. The familiarisation process, listening and re-listening to audio recordings, reading and re-reading transcripts was time-consuming, but necessary, providing the 'bedrock' for the remainder of the analysis process (Braun \& Clarke, 2006, p. 87).

The second phase of thematic analysis began after I had familiarised myself with the data, and involved producing the initial codes (Braun \& Clarke, 2006, p. 88). The coding process is a way of organising, reducing and classifying the data by identifying, tagging and extracting a feature which is interesting, or relevant to the research question (Boyatzis, 1998; Braun \& Clarke, 2006; Leavy, 2017). Coding can be undertaken manually, or by using computer-assisted qualitative data analysis software (CAQDAS) (Bazeley \& Jackson, 2013; Gibbs, 2002). Given that Braun and Clarke's (2006) advice for this process is to: code as many potential themes or patterns as possible; to maintain the context of the text by including a little of the surrounding data where relevant; and to code individual extracts of data into as many themes as they relate to, I chose to facilitate the process using CAQDAS in the form of QRS International's NVivo program. The program provided a database function which allowed me to upload the full set of data for each case as a separate 'project' before undertaking the systematic coding process. Using NVivo, I worked methodically through the data set for each case (i.e. all transcribed interviews for a case), looking for each 'codable moment' (Boyatzis, 1998, p. 3) before highlighting and coding the text and enough of the surrounding text to provide context, at a 'node'. A node provides a way of organising similar ideas and thoughts from the entire data set (Gibbs, 2002, p. 31). Each node was assigned a relevant name or phrase to readily identify the theme to which it applied, using the research questions as a starting point. For example, I identified and coded extracts relating to the different capabilities, knowledge and attributes participants considered to be advanced skills for VET teachers, and responses indicating beliefs about how advanced skills are developed, adding new nodes as I identified each new idea relating to the research questions. I used the functionality of NVivo to define the node and the ideas that would be coded to it (Bazeley \& Jackson, 2013; Gibbs, 2002), ensuring consistency of the information organised within each node. I also coded specific data excerpts to multiple nodes where it was relevant and appropriate to do so. During this phase I reviewed each interview transcript on more than one occasion, returning to check that all relevant excerpts were coded, only completing the process when I was satisfied that coding was comprehensively completed. 
Braun and Clarke (2006) describe three separate phases which should be undertaken following the initial coding process: searching for themes; reviewing themes; and defining and naming themes. In this project however, I found that the identifying, refining and finalising themes was a more holistic, organic process. I started by analysing the long list of codes (nodes) produced in phase two identifying those that might be combined to form overarching themes, and those that should be regarded as sub-themes due to their relevance to an identified overarching theme (Braun \& Clarke, 2006, p. 89). While Braun and Clarke provide some guidelines about frequency and proportion to determine what should count as a theme, it was also necessary to apply my own judgement to the process (Braun \& Clarke, 2006, p. 82). For example, while there would ideally be 'a number of instances of the theme across a data set' (Braun \& Clarke, 2006, p. 82), the frequency of instances does not equate to the relative importance or significance of a theme. For this project, I identified as themes, related responses that were relevant to the research questions and occurred on a number of occasions across the data set. I also noted outlying responses - those that did not align to the predominant representation of views across the data set. While Braun and Clarke (2006) recommend the manual development of a 'thematic map' to illustrate the relationship between themes and coded sub-themes, using NVivo I developed a hierarchy of nodes and sub-nodes, where themes were represented as nodes and the related coded data organised as sub-nodes within each theme (Gibbs, 2002). During this process I refined, reviewed and defined the themes, returning often to the data to clarify context as needed and to search for and code any relevant text that may have been previously missed.

Finally, once the coding and analysis process was complete for a particular Case, I wrote the case study report, using themes and sub-themes to structure the discussion, and using extracts from the text to illustrate key points. The writing process was not separate to the analysis; rather it was part of it, and throughout the process it was important to refer back to the research questions to determine what was relevant and what was not. As Wolcott (2009, p. 19), points out 'writing is thinking'. The writing process also helps us to 'discover what we are thinking' and to reveal gaps in our argument (Wolcott, 2009, p. 19), and during this process I frequently returned to the data, reviewing the coded text, looking for missed codable moments or alternative meanings of coded responses. My goal was to produce a logical and interesting report on each case which was interpretative, rather than simply descriptive (Braun \& Clarke, 2006), and which provided enough rich data to be relatable to 
the reader (Wellington, 2000), with sufficient extracts from the data included to support and illustrate key points and interpretations. It was important to emphasise the voice of the participants throughout the Case reports, so to facilitate this, and to differentiate their quotes from citations of other published works, all participant quotes (apart from large block quotes) made in-text were italicised. I applied this formatting style consistently throughout all three Case reports and in Chapter 8 Discussion. When all Case reports were completed (refer to Chapters 4,5 and 6), I undertook the project's final analytical stage, cross-case analysis.

\section{Stage 2: Cross case analysis}

Cross case analysis is a process which identifies what is common across cases and what is unique in relation to the themes and the topic of the research study (Stake, 2006). While the focus of a multiple case study project is on the quintain it is not so much a study of the quintain as it is a study of cases for what they tell us about the quintain' (Stake, 2006, p. 7). For this project, the quintain is 'advanced skills for VET teachers and how they are developed' and the focus of cross-case analysis was to identify what the 'situated experience' of the case reports could tell us about it (Stake, 2006, p. 7). The findings developed through cross case analysis are referred to as Assertions by Stake (2006, p. 41), who describes a number of steps which must be taken in order to derive them: identifying themes to be comparatively analysed across the cases; analysing the utility of cases for each theme; identifying findings from each case; merging multicase findings; and finally, developing assertions relevant to the merged findings and themes (Stake, 2006). I will expand upon each of these steps in this section.

The first step in Stake's (2006) method of cross case analysis is to determine the Themes upon which the analysis will be based. In thematic analysis, a theme refers to an important or patterned response in the data. In Stake's (2006) method of cross case analysis however, the term refers to the questions or 'primary information about the quintain that the researchers seek' (Stake, 2006, p. 43). I followed Stake's (2006) recommended process of reading and re-reading each case study to determine five Themes relevant to this study. This was essentially an inductive process in which I determined information about the quintain which remained unanswered by a review of the literature and through interaction and analysis of the Cases to identify the information they were likely to reveal. It was also a somewhat reflexive process, influenced by my 'insider' relationship with the topic as a 
researcher with lengthy experience as a VET teacher and manager. After determining the Themes, I returned to the case study reports in order to determine and rank their expected utility (or usefulness) in relation to each Theme. I did this by analysing the quantity and quality of relevant evidence each Case contained against each of the Themes, ranking them as ' $L$ ' if expected to provide limited evidence in relation to a particular Theme, ' $M$ ' if expected to be moderately useful in addressing the Theme, and ' $\mathrm{H}$ ' if expected to be highly useful and relevant to the Theme.

With the Themes in mind I returned to the Case reports once again to identify situated findings - what each Case could tell me about the quintain. In this process, the 'situationality' of each case is preserved (Stake, 2006, pp. $40-41$ ), and Case Findings are ranked according to their importance to each of the five Themes. Case Findings and their importance to each Theme are provided in Appendix D, Table 2. From the individual Case Findings, I identified clusters of similar topics and findings across cases, and refined these to develop 14 'Merged Findings'. Some findings were not able to be merged, and following Stake's (2006) advice, I recorded these as 'Special Findings'. Merged Findings and Special Findings have been listed and ranked according to their relative importance to each of the five Themes in Table 3 (Appendix D).

The final step in cross case analysis is to develop Assertions from the Merged Findings. Assertions are the final findings of the analysis, and according to Stake (2006, p. 71), each 'should have a single focus, an orientation for understanding the quintain and evidence to support it'. I have developed three Assertions from the cross case analysis:

Assertion 1: Teachers with advanced skills are more likely to conceptualise these holistically and recognise the importance of the teacher's individual qualities, while managers are more likely to express an atomised and contextual interpretation of advanced skills.

Assertion 2: Teachers develop advanced skills through a variety of activities and those with advanced skills take personal responsibility for their own continued learning and development. 
Assertion 3: The development of advanced skills may be negatively affected by insufficient resources and an unbalanced approach to professional development

A Table of Assertions which maps each Assertion to the relevant Merged Findings and Themes is provided in Appendix D (Table 4). The cross case analysis process will be presented in more detail in Chapter 7, and each of the Assertions and the evidence to support them will be discussed in Chapter 8.

\section{Validity, trustworthiness and the qualitative multiple case study methodology} In qualitative research, the concept of 'validity' may be controversial (Maxwell, 2005, p. 122). Traditionally, and when applied in the positivist sense, the measure of validity assumed the existence of 'objective truth' (Maxwell, 2005, p. 122), and was defined as 'the degree to which a method, a test or a research tool actually measures what it is supposed to measure' (Wellington, 2000, p. 30). It was also often associated with the concept of 'reliability', referring to 'the extent to which a research fact or finding can be repeated' (Bassey, 1999, p. 75). The position of many contemporary researchers (particularly qualitative researchers) has changed, and it is argued that validity cannot be guaranteed when applied only to methods. Instead, and importantly, in the case of qualitative research, the concept of validity should be applied to the evaluation of results and the interpretation of a study's findings. In this sense, validity refers to the correctness or credibility of a study's description, conclusion, explanation and interpretation (Maxwell, 2005, p. 122); that is, it focuses on the validity and 'trustworthiness' of a study's conclusions rather than the validity of the methods which were used to collect the data. The greatest threats to validity, according to Maxwell (2005), are researcher bias and reactivity.

\section{Researcher bias and validity}

Researcher bias refers to the issues that may be associated with the subjective nature of qualitative data analysis and interpretation. The validity of a study's conclusions may be compromised if the researcher focuses only on data that confirms his/her pre-existing assumptions about the topic, or which stands out to him/her because of personal interest. As pointed out by Miles and Huberman (1994, p. 263): 
...people as information seekers - and as processors - are far more likely to see confirming instances of original beliefs or perceptions than to see disconfirming instances, event when disconfirmations are more frequent. (Miles \& Huberman, 1994, p. 263)

In case study research, the issue lies not only in the data which is selected to analyse or the conclusions that are drawn, it can also affect what is reported. Qualitative case studies are intended to produce detailed, rich data. While this is the desired outcome, the researcher must make decisions about how to report the data and how much should be reported, as a product which is too lengthy, detailed or involved may not be useable by the intended audience (Merriam, 2009). While it is important to develop a written account of each case which focuses on the data most relevant to the research questions, it is also necessary to provide enough detail to ensure that the report is honest and ethical, which takes the reader 'into the case situation and experience' (Patton, 2002, p. 450), for as Guba and Lincoln (1981, p. 378) point out, a case writer can selectively report from the data in order to illustrate 'virtually anything he wished'. While according to Maxwell (2005) it is impossible to eliminate my own bias from the research, I have implemented three recommended strategies at different stages of the project to ensure the integrity and validity of the findings and my interpretations and conclusions: respondent and peer validation; comprehensive case reporting; and identification of discrepant evidence and outliers (Maxwell, 2005).

The first strategy, respondent validation, was implemented at data collection and throughout the analysis phase. The process, also referred to as 'member checks' (Lincoln \& Guba, 1985, p. 314), played a critical role in ensuring the integrity and trustworthiness of the research.

This [respondent validation] is the single most important way of ruling out the possibility of misinterpreting the meaning of what participants say and do and the perspective they have on what is going on. (Maxwell, 2005, pp. 126-127)

In the first instance, I applied the strategy to ensure the integrity and accuracy of data collected from interviews with participants. For example, as the data to produce the case studies was collected through individual interviews with VET teachers and managers, I recorded all interviews and transcribed them verbatim (as suggested by Maxwell, 2005), before sending each participant his/her interview transcript for verification, clarification and editing as required. During analysis and interpretation of the data I undertook a further process of respondent validation to identify potential researcher bias in the project's findings 
and conclusions. In a strategy which also included peer review, I sought feedback on interim findings and my interpretation of emergent themes by presenting at relevant research conferences, including the annual conferences of the Australian Vocational Education and Training Research Association (AVETRA) (Schmidt 2017a, 2018) and the Australian Council of Deans of Education Vocational Education Group (ACDEVEG) (Schmidt 2016, 2017c). VET managers and teachers from each case and other researchers with experience in the field were well represented at each of these conferences, providing an opportunity to gain valuable insights into the plausibility of the emergent findings, how well they represented the views of the participants, and alternative ways in which the data might be interpreted. I also sought peer academic review by submitting papers about the project's emerging findings to peer reviewed journals (Schmidt 2017b, 2019 in print)

The second strategy employed to ensure validity and integrity of the research was comprehensive case reporting, implemented when preparing the report on each Case. In this process of collating, sorting and analysing data, and during the writing and rewriting of each Case, I aimed to develop a case study report that was transparent, relevant and comprehensive, rather than selective and narrow in its approach. This strategy aligns with Patton's (2002) recommendations that each case study would include enough detail to 'illuminate the focus of inquiry without becoming boring and laden with trivia' (Patton, 2002, p. 450), and to enable the reader to assess the evidence in order to make his/her own interpretations (Merriam, 2009, p. 258).

The third strategy was implemented during the analysis phase of the project. While collating, sorting and analysing the data to prepare each case study, and during the process of cross case analysis, I looked for and reported on both convergent and divergent themes, actively seeking discrepant data or examples of what Miles and Huberman (1994, p. 269) describe as 'outliers' - evidence that seemed contradictory to emergent findings, or examples which varied considerably from common themes in the data. The strategy, described by Maxwell (2005, p. 127) as 'a key part of the logic of validity testing in qualitative research', was particularly helpful in this project. The outliers, views on advanced skills for VET teachers which did not align to the dominant views in the literature or the data, alerted me to one of the key findings to emerge from the research: that there is a distinctly individual nature to 
advanced teaching skills, evidence of which I could have overlooked if I had focused only on data that could be coded to dominant themes and views.

\section{Reactivity, reflexivity and validity}

While dealing with validity threats posed by researcher bias is important, it is also necessary to account for 'reactivity', described by Maxwell (2005, p. 124) as 'the influence of the researcher on the setting or individuals studied', and referred to by Miles and Huberman (1994, p. 265) as 'researcher effect'. Reactivity is impossible to avoid when data is collected through interviews as the discussion (and hence, the participants' responses) is always led, at least in part, by the questions that the interviewer asks. According to Maxwell (2005), it is possible to avoid 'negative consequences' of reactivity by avoiding leading questions, however the goal of qualitative research is not to minimise the researcher's influence, but to understand the effect of the influence, acknowledging and accepting that 'the researcher is part of the world that he or she studies' (Maxwell, 2005, p. 125). Understanding the impact of reactivity is particularly important in qualitative case study research which is, by its design, a 'product of the interaction between respondents, site, and researcher' in which 'the construction is rooted in the person, character, experience, context, and philosophy' of the researcher (Lincoln \& Guba, 1990, p. 54). While positivist approaches typically require personal detachment of the researcher and minimisation of subjectivity, contemporary interpretive researchers recognise the 'impossibility of the neutral stance' (Wellington, 2000, p. 42) and consider how to position themselves in the research through a process referred to as 'reflexivity' (Creswell, 2013, p. 216).

Reflexivity is described by Lincoln, Lynham and Guba (2011, p. 124) as 'the process of reflecting critically on the self as researcher'. Far from being regarded as a risk to validity, contemporary opinion regards reflexivity as a valuable part of the research process. Wolcott (1994, p. 186) for example, describes the process as 'entry-level theorising' and Duncan and Watson (2010, p. 51) argue that reflexivity 'lies at the heart of critical research'. In contemporary qualitative studies then, the positivist goal of achieving objectivity and detachment of the researcher is acceptably and necessarily replaced by 'reflexive subjectivity and the politics of position' (Grbich, 2013, p. 113).

The researcher cannot be separated from his/her background, life experiences and memories (frames), which inevitably filter impressions of the actions and behaviour of others. (Grbich, 2013, p. 13) 
While reflexivity has assumed a place of relative importance in the contemporary qualitative project, the 'trustworthiness' of the research relies upon honesty and openness (Wellington, 2000). Trustworthiness requires researchers to critically reflect upon their personal stance and position on a topic, and to identify how their personal experience influences this stance and the way that the project is conducted, analysed and reported (Cousin, 2010). Undoubtedly, my own experience in the VET sector as a teacher, manager and researcher has had a significant influence on the project's topic, its design, conclusions and on the theory which has underpinned it. In many ways, my 'insider' status was advantageous, as it facilitated access to appropriate project participants and to gain permissions required to undertake the project within each of the three organisations. It also helped to establish the trust required for an effective interview process. My experience as a manager in the sector was respected by the managers who participated in interviews, and likewise, VET teachers appreciated that I had considerable experience as a teacher myself, and would more likely understand their views and the contextual sector-specific issues that impacted upon them and their work. As Cousin (2010, p. 15) points out: 'If you have experienced a problem, you can speak with greater authority on it'. Despite these advantages, it was still important to ensure the project and its outcomes were not singularly representative of my own preexisting views and beliefs about advanced skills for VET teachers and how they are developed. The validation strategies described previously, that is, respondent and peer validation, comprehensive case reporting, and identification of discrepant evidence and outliers, helped to ensure the trustworthiness and integrity of the project in this regard.

\section{Case studies, transferability and usefulness of the findings}

Transferability is a term often used to describe generalisability, referring to 'the extent to which research findings in one context can be transferred or applied to other contexts or settings' (Wellington, 2000, p. 197). The application of transferability and generalisation to case study research is a contentious issue, often raised by critics who reject the idea that transferability can be achieved when there is a small sample size (or indeed, a sample size of one), thus questioning the value of case study research in developing a field's knowledge (Flyvbjerg, 2006). While many qualitative researchers accept that generalisability (in the scientific, positivist sense at least) is not possible in case study research (see for example: Bassey, 1999; Lincoln \& Guba, 1990; Stake, 1995; Wellington, 2000; Wolcott, 1994), Flyvbjerg 
(2006) highlights the advancements made in science through single cases and experiments, citing the contributions of Galileo, Darwin, Newton, Einstein and Marx which were based upon a single case or a few carefully selected cases and experiments. It is reasonable to propose then, that outside of the positivist criteria, there is an opportunity for the research project to contribute to the body of knowledge on VET teaching, advanced skills for VET teachers and how they are developed. There is also a sense of transferability which rests with the interpretation of the individual reader.

In alignment with the social constructionist worldview which frames the study, the richness of the data reflected in each case study report will enable multiple interpretations based upon the reader's personal experience and the meaning making influence of the social context in which they are situated. Stake $(1978,1995)$ described this process as naturalistic generalisation, a means of transferability by which readers construct their own conclusions and interpret a case study based upon individual, personal experience. While naturalistic generalisations 'seldom take the form of predictions, but lead regularly to expectation', they are nonetheless valuable as they influence and guide the actions of the reader (Stake, 1978, p. 6). This view is shared by Wellington (2000) who espoused the value of the 'relatability' of case studies, recognising the influence of the reader's experience, knowledge and biases in the way that case study data is interpreted (Wellington, 2000) and by Eisner (1991), who likened a qualitative case study to a 'guidebook' which sensitises readers to 'what is likely to be found, if they know where and how to look' (Eisner, 1991, p. 207). Similarly, Bassey (1999), while supporting the view that scientific or statistically based generalisation from case study research is not possible, recommends the dissemination of 'fuzzy generalisations'. Fuzzy generalisations infer or predict the possibility of something happening, but without providing any measure of its probability. They invite the reader to investigate the data further, and to interpret the usefulness or transferability of the research based upon their own context and experience (Bassey, 1999).

While I have applied caution not to overstate claims of transferability for this study, Yin (2014) would argue that the project's design - the investigation of multiple cases at different sites - could somewhat justify generalisations. I have presented and discussed the project's findings - the Assertions developed through cross case analysis - and supported them with evidence derived from the data, the relevant literature and transcribed responses 
from the study's participants. I have also provided a detailed report for each Case, enabling readers the opportunity to delve deeper and to find insights particularly relevant to their context.

In this chapter I have explained the research methodology and conceptual framework underpinning the study's design. The following chapters will articulate the results of its implementation, providing the data, findings, analysis and conclusions. In Chapters 4, 5 and 6, I will provide reports for Case A, Case B and Case $C$ respectively. This will be followed by a Chapter 7, Cross Case Analysis, and discussion of the findings in relation to the research question in Chapter 8. 


\section{CHAPTER 4 CASE A}

\section{Background}

Case $A$ is one of six regions within the TAFE Queensland network. At the time of data collection, the region had been relatively newly established following a restructure of TAFE Queensland in which thirteen TAFE Institutes were variously amalgamated to become six 'regions'. Case A has a geographic footprint which spans approximately 300 kilometres from north to south, and includes six campus locations. The region delivers a range of courses, including accredited and non-accredited short courses and qualifications from Certificate I to Advanced Diploma across a broad range of industry training areas including: trades; community services; health; creative industries; digital and information technologies; fitness and recreation; hospitality and cookery; tourism and events; justice and security; education and business. Courses are available to students on campus and in distance mode (primarily online), or as a blend of the two. In many cases students can study full time or part time, and some programs offer flexible enrolment and completion points. Workplace delivery and assessment modes are also available, however this option is most often offered to those participating in training as an apprentice or trainee.

\section{Data collection, participants and the case study context}

Data to prepare the case study was collected through interviews with twelve participants: three managers and nine teachers with advanced skills. The managers invited to participate (Roslyn, Graeme and Catherine) were responsible for direct supervision of VET teachers work and development in the organisation. Each had significant experience in the VET sector: Roslyn and Graeme had each more than 20 years of experience, and Catherine, more than 10. Roslyn had previously worked only in TAFE administrative and management roles, while Catherine and Graeme had experience as VET teachers prior to becoming VET managers.

The nine teachers invited to participate were those identified by managers or peers as teachers with advanced skills. They taught vocational students in the diverse disciplines of health, hospitality, education, hairdressing, trades, creative industries and language, literacy and numeracy (LLN). Their teaching experience varied from less than 10 years for Anita, Maxine and Tony, to more than 15 years for Astrid and Sandra, and more than 20 for Fran, Louise, Nerida and Josie. Nerida, Astrid and Fran had gained teaching experience in the 
compulsory education sector prior to commencing their career in VET. Data was collected through semi-structured interviews with each participant. The questions asked of managers and teachers varied, however all were required to reflect upon and discuss their views on what advanced skills for VET teachers were, and how they were developed.

\section{What are advanced skills for VET teachers?}

At the beginning of each interview, participants were asked the question, 'What are advanced skills for VET teachers?' Some, such as managers Roslyn and Graeme, found this a difficult question to answer, at least initially. Roslyn, for example, described it as a 'vexed question's, explaining that advanced skills were highly contextual, and that a person might be considered 'advanced' in one setting but not advanced in another.

So I think, you know, the question is a vexed one for me about, do I have any advanced teachers. There are definitely people with the technical skills and that's sort of to me, it's a core, I mean, fundamentally we've got to have that, but the other part of that question is really about the environment they're in and their level of comfort in dealing with the scenario that they're currently in. I think that is quite a significant thing. (Roslyn, Manager, Case A)

Manager Graeme felt that advanced skills were difficult to define due to the fact that teachers who demonstrate them are ostensibly quite scarce.

...so when I talk about the advanced skills in VET practitioners in our region, probably within the 110, 111 people that I'm responsible for, probably only a handful are people that I would define as being advanced practitioners. (Graeme, manager, Case A)

Both managers and teachers had difficulty identifying and describing advanced skills for VET teachers, at least initially. As each interview progressed however, all were able to identify a number of capabilities, attributes and behaviours demonstrated by those with advanced skills. Interestingly, though, the discussion revealed a divergence of views between managers and teachers, a situation which teacher Josie summed up by stating:

What I think as being advanced and what management sees as advanced or values, are two different things. (Josie, teacher, Case A)

\footnotetext{
${ }^{3}$ In-text quotes from participants have been italicised for emphasis and to differentiate them from citations of published works
} 
Certainly, while Case A teachers generally referred to advanced skills in relation to teaching and the influence of teaching on student outcomes, their managers more often described advanced skills in relation to leadership and communication.

To me, and my experience in the VET sector, the advanced skills are around the leadership of teams, mentoring of other teachers, being able to work across vocational areas, certainly having an accountability. (Graeme, manager, Case A)

Manager Roslyn shared Graeme's view that those with advanced skills provided leadership, mentoring and coaching for other teachers. She also emphasised the importance of business and communication skills.

This [advanced skills for VET teachers] is about something else, it's about more than that, the capacity to actually teach others, a teacher of teachers, a teacher and mentor guide, a coach, a person who can defend a position that we might have on a particular matter and one who can deal with the multifaceted business that we're dealing with. (Roslyn, manager Case A)

Manager Catherine, while agreeing that teachers with advanced skills acted as mentors in the organisation, also felt that they were innovators, and initiators and supporters of change. In particular, Catherine felt that teachers with advanced skills in Case A supported others to adapt to the recent restructure of TAFE Queensland which resulted in the amalgamation of two previously separate Institutes.

They'll come to me and have a conversation about what new ideas they want to implement. So it's sort of about that communication that we see, their participation across the organisation, particularly now that we've amalgamated from two organisations to one, and how quickly they've adapted that change and mentored others or supported others to take on that change. (Catherine, Case A)

This does not mean however, that TQEC managers do not value teaching skills. Rather, as Roslyn pointed out, they viewed skills related to teaching as 'fundamental' skills, 'core' to the teacher's role and advanced skills as additional skills that the individual teacher employed which added value to the organisation.

Case A teachers were also asked to answer the question: 'What are advanced skills for VET teachers', but were encouraged to reflect upon their own skills, knowledge and experience as a teacher in doing so. Each identified a range of skills, knowledge and capabilities which he/she considered to be advanced. These have been broadly grouped and addressed according to the themes of: educational design skills; teaching skills; interpersonal 
and relational skills; industry skills; and knowledge of the VET context, or the 'big picture'. As well as specific skills and capabilities though, Case A teachers also described some personal attributes and qualities that VET teachers with advanced skills brought to the role. Each of these themes will be explored in more details in the next section.

\section{Developing educational programs}

Case A participants described a range of capabilities utilised by VET teachers with advanced skills to plan educational programs, interpret curriculum documents, design assessment and manage and organise knowledge. Case A'S VET teachers are required to develop planning documents which describe the course structure and the learning and assessment activities that take place - referred to as a Training and Assessment Strategy (TAS). The TAS provides the overall plan for the course to be delivered, and becomes a key source document for many other administrative activities including student enrolment, the creation of timetables and the allocation of resources. The information contained in the Training and Assessment Strategy must be accurate and comprehensive, as it is required to meet compliance and regulatory requirements by describing the way in which each unit in the course will be delivered and assessed. This extensive planning activity is regarded as an advanced skill by some Case A teachers as it requires knowledge of the organisation's policies, practices and systems as well as knowledge of compliance, reporting and regulatory requirements, described by teacher Fran as 'the bigger picture'.

I'd have to say things like knowledge of the bigger picture [are advanced skills], like the strategic organisational information and the registered training organisation standards, knowledge and skills in the procedures and policies of our organisation, an extensive knowledge of the training packages, you know, mapping the training and assessment strategy plans that we have to do, all of that kind of thing. (Fran, teacher, Case A)

To design and plan educational programs, VET teachers must also develop a thorough understanding of the curriculum for their particular vocational training area. In the Australian VET context, the curriculum is referred to as a Training Package. Case A's VET teachers referred to 'unpacking' the Training Package, a process in which they interpret the requirements of a qualification and each of the relevant Units of Competency that make up the qualification. Each Unit of Competency describes the skills and knowledge that are required to perform a particular task or aspect of a job role, and a qualification is comprised 
of a number of these. The number and type of Units that make up a qualification vary according to the individual Training Package. To understand the curriculum - to 'unpack the Training Package' - the VET teacher must develop an understanding not only of each unit to be delivered, but its relationship to other units, the qualification and the industry outcomes a complex raft of knowledge which, according to Fran, takes some time and practice to develop.

You're not going to take it on board the first time because there's so much information, but just referring back to it almost, that becomes the Bible, so to speak. So I think it's just using it all the time, understanding it by referring to it all the time. (Fran, teacher, Case A)

Teacher Sandra described the need to "know every single Unit [in the Training Package]', also pointing out that to be considered advanced, VET teachers needed to understand not only the Training Package, but 'all the assessments that go with it', as assessing the performance of students against the standards outlined in the Training Package is key part of the VET teacher's role. While this may suggest that designing compliant assessment tasks is a core requirement for VET teachers, half of the Case A's participants (manager Catherine and teachers Maxine, Sandra, Josie, Louise and Astrid ) deemed it an advanced skill which some teachers develop over time, and which others will never achieve. Maxine explained that she had frequently been asked to 'help people to write assessments, review assessments', explaining, 'What I've discovered is that [assessment] writing skills aren't something that everybody has' (Maxine, teacher, Case A). According to Case A participants, assessment design is a complex process which requires specialised knowledge to achieve. Assessment tasks must be, according to teacher Sandra, 'relevant' and 'related to industry'. They must also, as pointed out by Maxine, meet the requirements of the Training Package to ensure compliance with regulatory requirements.

Ensuring that all of our training and assessment materials meet the requirements of the training package or accredited course, you know, it's all those things that make us compliant that are really important. (Maxine, teacher, Case A)

To design compliant assessment tasks, VET teachers must understand the curriculum and the regulatory requirements legislated by the Standards for Australian Training Organisations 2015. Teacher Louise, however, believes that designing relevant assessment relies upon the teacher's industry knowledge and 'instinct'. 
I think assessment comes back to a little bit of instinct in terms of, instinct and industry knowledge. I guess those two go hand-in-hand. In the VET sector it is really about "What does a student need to know to be effective as an employee after they leave a two year program?" (Louise, teacher, Case A)

From the perspective of Case A's managers and teachers, effective application of educational design skills to plan educational programs, interpret curriculum documents and to design assessment requires a depth and breadth of knowledge which must be continually added to and updated. The way that the individual teacher manages, organises and uses knowledge of this volume and complexity may also be an advanced skill according to teacher Fran, who explained:

I think the way that we store knowledge, expert teachers kind of, they develop better systems for storing, organising and accessing information. (Fran, teacher, Case A)

While the skills to develop sound educational programs and assessments are important, not all regarded them as advanced. Rather, they were regarded as a requirement of the job role, and skills that needed to be developed over time and with experience. Similarly, some (such as manager Roslyn) regard teaching skills as 'core' to the VET teachers' job role, while others regard them as a skill which differentiates VET teachers with advanced skills from others. According to teachers Sandra, Nerida, Astrid, Louise and Josie, advanced skills for VET teachers are related to teaching - teaching which ensures the best outcomes for students. This theme which will be explored in the next section.

\section{VET teachers and VET teaching}

Teaching is an inherent component of the VET teachers' job role, but according to many Case A participants, those with advanced skills are more effective and ensure better outcomes for students. Teacher Sandra, for example, felt that while completing a higher educational qualification (to Masters degree level) certainly helped her to develop knowledge and skills which improved her teaching practice, there is an aspect of advanced teaching which is inherent to the individual teacher.

Some people can do it, some people can't. I know what a learner looks like. I know how to teach a specific learner, I actually know the student...know is there something they're not learning, do they need other things? (Sandra, teacher, Case A) 
According to a number of Case A participants, teachers with advanced skills are also likely to be confident teaching in different contexts, including online. Two of the three managers interviewed, indicated that different skills are required to teach effectively in more than one mode. For example, a teacher who primarily teaches in a classroom may require different skills to teach students effectively in the workplace or using an online platform. VET teachers with skills to teach effectively in different modes and contexts are considered advanced by these managers. Such teachers are scarce however, according to Graeme.

Mostly teachers are specialists in one area or another, and they will dabble in other areas of delivery, but those that can actually work very easily across those range of modes are few and far between. (Graham, manager, Case A)

Some Case A participants felt that teachers with advanced skills managed the classroom differently as they had the ability to multi-task and manage a number of different student and classroom activities at once. Teachers Sandra and Tony for example, train apprentices (albeit in different industry areas). The training programs they teach require a flexible approach, as student cohorts come together for training for often short periods of time and with varying levels of skills, knowledge and ability (depending upon the apprenticeship stage they have reached). In order to manage the different skills and knowledge levels and to ensure that each apprentice gains maximum value from the release to training, classroom activities may need to be set up in a way which allows apprentices to work on different tasks and activities concurrently. As teacher Sandra explained, to manage this environment effectively the teacher must 'know every single Unit, know all the assessments that go with it, and be able to group them [students] together according to the stage [of their apprenticeship]'. Teacher Tony for example, described the way that he managed this by setting up and monitoring an open learning area containing several different specialist learning stations which students moved through depending upon their stage of progression through the course.

These days I might be teaching four or five different units to apprentices in different stages. And how we get around that, I've got the workshop set up with specialist areas, so electronical area, or underbody area, or brake area. And l've got all projects already developed that the students have to do, so all the parts and tools and everything are there, instructions. Once they do their theory I can move them off into different areas and also be hovering around the classroom; I've got a classroom with all 
glass out into the workshop, so I can keep an eye on them while I'm working with other students. (Tony, teacher, Case A).

In addition to teaching skills, VET teachers must have current industry qualifications and skills. These requirements are legislated by the Standards for Registered Training Organisations 2015, which state that VET teachers must hold vocational competencies at or above the qualification level they teach as well as relevant current industry skills (Commonwealth Government of Australia: Department of Education and Training, 2015, p. Clause 1.13). To meet the regulatory requirements, they must have been employed in a prior occupation before becoming a VET teacher, and are required to maintain current industry skills and knowledge throughout their VET teaching career. Teacher Tony explained that maintaining industry currency was essential to ensure that teachers remained 'credible' and able to teach students relevant and accurate industry knowledge and skills.

You really have to be up on your trade area, otherwise you're not credible with your students. So it's very important to be up-to-date because they will be asking you questions all the time. (Tony, teacher, Case A)

Most Case A participants (both managers and teachers) raised the importance of current and relevant industry knowledge and skills, however it was also widely recognised that this type of knowledge on its own will not produce an advanced VET teacher.

It's great to have awesome currency, but unless you balance that out with great educational [knowledge and skills], I don't believe that's the making of a good teacher. You've got to have education with industry. (Sandra, teacher, Case A)

VET teachers' work has changed over time, as the sector is subjected to frequent change due to political and market influences and funding and regulatory changes. Keeping abreast of these changes and the changing organisational priorities that result from them has also influenced the perception of advanced skills, according to Case A managers Roslyn, Graeme and Catherine. VET teachers must maintain a sound knowledge of the VET system and policy as it is a sector which is constantly changing. For example, the curriculum is reviewed regularly by a range of stakeholders. These reviews may result in minor changes as part of a continuous improvement process, or significant changes which require the release of a new version of the curriculum and redevelopment of teaching and assessment materials. Regulatory requirements are subject to change, bringing new requirements for compliance. 
The market in which VET operates is also shifting, with new funding models creating greater commercial competition for both TAFE and private providers. These changes present significant challenges to VET teachers in their endeavour to design and teach high quality educational programs which are not only compliant but which also meet the needs of industry and individual students. Changes to the broader VET context also result in changes to the organisation's goals, and to the contribution that the VET teacher is expected to make to ensure that organisation meets these goals. For example, according to manager Graeme, changes to the way that funding for vocational education is allocated has resulted in changes to Case A's organisational goals and to the work priorities of its managers and VET teachers.

With the increased competition in the VET space, there's a lot more reliance and focus on delivering to international students both on and offshore, whilst we chase that work and have that commercial focus. (Graeme, manager, Case A)

To be regarded as a VET teacher with advanced skills in such a complex and rapidly changing environment, manager Roslyn acknowledges, is no small achievement:

Their [VET teachers with advanced skills] capacity to actually teach is really critical, it's just critical, and that, the broadness of the skills required to do that well, are really quite extraordinary in a changing world. (Roslyn, manager, Case A)

Regardless of the complexity of the environment in which they carry out their work, to teach well and to be regarded as a VET teacher with advanced skills, according to Case A participants, relies somewhat upon an individual quality that lies within the VET teacher. The next section will explore the personal attributes that VET teachers with advanced skills bring to the role, including a passion for teaching, and the ability to communicate with others to build relationships, and to engage and connect with students.

\section{Passion, communication and connectedness in VET teaching}

According to Case A participants, VET teachers with advanced skills use interpersonal skills to motivate, engage and communicate with diverse cohorts of students. Manager Graeme, for example, described a teacher with advanced skills as 'somebody who is culturally aware and sensitive to the needs of their students'. Student diversity however, is not limited to cultural differences. According to teacher Maxine, VET teachers with advanced skills could relate to students from diverse age groups, with different personalities, and from varying educational 
and cultural backgrounds. They use their interpersonal skills to identify individuals who require assistance, even if they don't ask for help themselves.

You're working across different age groups, different cultures, often there's language barriers, there is the attributes of the learners themselves; you get some that are quite proactive and outgoing and, you know, they ask questions, whereas others will hide in the corner and you think they're going okay, whereas in actual fact they're not. (Maxine, teacher, Case A)

The importance of engaging and connecting with students was also highlighted by teachers Nerida, Astrid, Josie and Sandra. Nerida for example, felt that she was able to quickly develop connections and relationships with students, and that this personal strength was pivotal to her achieving success and recognition as a teacher with advanced skills.

It's all about engagement with students. I can say that I know my colleagues would say that is a strength of mine, that ability to engage and have those relationships with students. (Nerida, teacher, Case A)

This was also the case for teacher Astrid:

Yeah, I mean I think I'm pretty comfortable with planning and creating the learning experiences, also building relationships with the students is a big part of it, the ability to connect with students and make them feel like valued. (Astrid, teacher, Case A)

Josie felt that interpersonal and communication skills were necessary personal attributes that teachers with advanced skills brought to the teaching role.

I've a bit of a theory that [as a teacher with advanced skills] you are naturally good with students and people anyway. So I feel like I came with, sort of, well developed interpersonal skills, communication skills, people skills, empathy. (Josie, teacher, Case A)

For Sandra, the ability to connect and build a relationship with students enabled her to provide the optimal environment for learning.

I think the major thing is, I can actually sit with a student for just five or 10 minutes, and actually, really identify how that student actually learns. And pin point it. And gear my whole lesson, every single time that student comes in, to specifically get the best out of that student in the shortest space of time. I think that's the difference. (Sandra, teacher, Case A)

According to teacher Louise, teachers with advanced skills understand not only how to communicate, engage and connect with students, but to motivate them to 'want to discover more or to be critical thinkers'. Manager Graeme expressed a similar view, pointing out that he considered motivating and connecting with students difficult, and therefore advanced. 
Understanding what motivates people to learn and what motivates different cohorts of students - being able to understand that and being able to connect with the students is a difficult thing to achieve (Graeme, manager, Case A)

Communication and interpersonal skills are used by VET teachers with advanced skills not only for effective interaction and engagement with students, but with colleagues, industry and others. Manager Roslyn, for example, felt that VET teachers with advanced skills were those with '...the capacity to engage with people very calmly, the capacity to be very articulate about things which are not necessarily about teaching and the capacity to communicate ideas and thoughts very coherently'. The ability to connect and communicate with others also enables VET teachers with advanced skills to lead and mentor others in the organisation. The contribution of those who do so, was noted by both managers and teachers. Josie, for example, felt that she was recognised as being a VET teacher with advanced skills due to her contribution to 'building team capability and teacher capability' in the organisation (Josie, teacher, Case A).

In addition to interpersonal and communication skills, and the ability to connect meaningfully with students, a number of Case A teachers described other individual, personal characteristics and qualities which they believed contributed to their development and recognition as teachers with advanced skills. Teacher Maxine for example, explained that she become a VET teacher due to a 'genuine desire to pass on my knowledge'. Others such as Nerida, spoke of a passion for teaching, and strong sense of responsibility and commitment to student outcomes.

I'm a born teacher. I love it. That's what I'm here for. And that's where all of my passion and dedication goes to. And everything, just decisions in everyday, whatever decision needs to be made or whatever happens, it always comes back to that outcome for the student. And I think that is a teacher thing that teachers do well if they're passionate about teaching. (Nerida, teacher, Case A)

Teacher Louise also expressed a sense of commitment to students, explaining that for her, VET teaching was a conscious career choice made in order to influence outcomes for those she teaches. This commitment meant that she had to actively and consciously prioritise student-related activities while still managing the workload associated with administrative and compliance related processes and tasks. 
I'm here as a designer in design education and I see myself as a design educator. I could be doing that in the university and I chose to be in the VET sector because of the situation of the students. So, I'm here for the students, not for administration, but that doesn't mean I don't follow the proper administration processes and auditing processes etc... but that is often more of a burden. (Louise, teacher, Case A)

Without such personal commitment, Tony felt that a teacher would be unlikely to develop advanced skills.

I think they've got to have a real interest and a passion. If they haven't got that, they probably won't develop to their fullest potential. (Tony, teacher, Case A)

Tony elaborated further, explaining that he believed VET teachers with advanced skills needed 'to be very enthusiastic, a bit of an outgoing personality, and also have a bit of experience' (Tony, teacher, Case A).

Being recognised as having advanced skills is likely to result in VET teachers being attributed greater responsibility by their managers. Manager Graeme for example, noted that he required those with advanced skills 'to step up and be accountable and be leaders within the organisation within teaching teams', while Roslyn expected to be able to call on them to solve problems of relatively high risk and complexity.

Advanced teachers - they are often people who are called on to mentor other teachers, be there when industries start coming unstuck with their view of the world or we need some, we need to defend a position, for example, you know, if there's been a case or a complaint etc. (Roslyn, manager, Case A)

Not all of Case A's VET teachers with advanced skills aspired to being assigned such additional responsibility, however. Sandra for example, while recognising the value of her personal skills in leadership and communication, explained that she resisted being allocated additional responsibilities, concerned that a shift in focus towards management related tasks would detract from her commitment to teaching.

I don't want to move up in that world in that arena, at all. That's not me. (Sandra, teacher, Case A)

Some Case A participants felt that VET teachers with advanced skills stood apart from others for other reasons. Teacher Anita, for example, felt that VET teachers with advanced skills had the capability to manage multiple tasks and responsibilities.

An advanced VET practitioner, they have to be, they have to be across everything. So they have to be engaged with industry, they have to have their content knowledge, they have to have all of their 
teaching skills and teaching methods and knowledge, you know, available, to be able to teach the content. And then they have to be able to manage the class room, so [they need] behaviour management [skills], and then they also have to have excellent planning skills as well. (Anita, teacher, Case A)

Manager Catherine felt that those with advanced skills demonstrated initiative, innovation and problem solving skills, improving the quality of educational programs and contributing to the success of the organisation.

So challenging the status quo of what their courses are, how their courses are delivered, it's, you know, going beyond, we've always done it this way, to, how can we do it better, looking at the quality and looking at business opportunities. (Catherine, manager, Case A)

Maxine, on the other hand, felt that the professional way that she approached VET teaching, her commitment to the role, and her care for the outcomes of her work contributed to her recognition as a teacher with advanced skills.

And I guess that comes down to professionalism and probably having pride in what I do and not treating it just as a job. (Maxine, teacher, Case A)

In summary, Case A's VET teachers with advanced skills generally referred to them in relation to their teaching activities (such as designing educational experiences, managing classroom activities, understanding and using the curriculum and conducting assessment) and the influence of teaching on student outcomes. They also described the ability that teachers had to connect, engage and develop strong relationships with students, and expressed a genuine sense of commitment and care for their future welfare and educational outcomes. Case A managers, on the other hand, while at times voicing somewhat similar views and recognising the importance of good teaching, more often emphasised the impact that teachers with advanced skills could have on achieving the organisation's objectives rather than on student outcomes. For example, while teachers described the importance of using interpersonal skills and communication to develop the teacher-student relationship, managers explained how teachers with these advanced skills could use them to provide leadership in the organisation and to mentor other teachers.

In the second part of each interview, participants were asked about their views on how VET teachers develop advanced skills. A number of themes were identified from their responses and will be addressed in the following section. 


\section{Development of advanced skills for VET practitioners}

Case A's participants identified a variety of ways in which advanced skills may be developed. For many, time and experience was deemed important, although there was no agreement on how much time was required to become a VET teacher with advanced skills. This sense of variability was borne out in the considerably varied teaching tenure of Case A participants, which ranged from 5 years to more than 20. Some attributed the development of advanced skills to studying tertiary level qualifications in education, and most felt that mentoring played a critical role. Just as the personal attributes of the individual teacher were deemed integral to the demonstration of 'good teaching', certain individual qualities were identified which participants felt were needed in order for a VET teacher to develop advanced skills. The discussion also revealed participants' views on the effectiveness of the organisation's support for the development of advanced skills and highlighted a number of barriers which may inhibit VET teachers' professional development.

Similarly to most large organisations, and in line with other TAFE Queensland regions, Case $A$ has a policy and procedure in place to guide the planning and implementation of its teachers' continuing professional development. Even though the policy requires that each teacher's professional development plan is negotiated and agreed upon annually with his/her manager, teacher Nerida felt that the process was ineffectual, as the development activities planned during the process rarely came to fruition due to work commitments and time constraints.

We have to have them [professional development plans]; they're mandatory. We do it every year. It's a load of rubbish. It never works that way. It just doesn't. Mostly around our own work commitments, what we're doing in our own job role, and our priorities. We have to prioritise what we're doing in our job role and there's only so many hours a day. (Nerida, teacher, Case A)

At the time of data collection, the organisation was piloting the TAFE Queensland Educator Capability Framework, as a tool to determine developmental needs for individual teachers and to identify those with the skills to mentor others. The tool, according to manager Roslyn, is intended to guide the development of VET teachers from novice to advanced, and is expected to facilitate a more efficient professional planning process.

It's a tool that will eventually be online because if it's not people won't use it I'm sure, but it actually identifies a continuum of beginning teacher to the Advanced Practitioner. The idea of course, is that 
we can at least point people to something tangible because otherwise it becomes very random. So the tool is supposed to help people to self-assess, help managers to make an assessment and actually to provide some guidance about some things people can do. I think in time poor environments, in environments like this where we have a large span of control, it is difficult for managers to spend time to get to this, to plan and to provide the development opportunities and to work with people, to actually really have an in-depth conversation sufficient to actually work out whether those people really, where they need to be with their own development, yeah, it's really tricky. (Roslyn, manager, Case A)

Teacher Nerida felt that the TAFE Queensland Educator Capability Framework was somewhat useful, but fell short of describing 'good teaching' and therefore was not likely to facilitate a comprehensive developmental plan for VET teachers with advanced skills. The problem, according to Nerida, is that the framework focuses too acutely on specific teaching skills and knowledge, and not enough on student outcomes.

I still think there are key parts missing, but yeah, it's a good place to start. It does reflect the majority of values that are important; it's still not focusing enough on student outcomes, as in real student. Like it has got the word "engagement" but it's actually, you know, this capability framework: what does this look like for the student as in the actual, again, the words that you would use to describe really, really good teaching and outcomes from teaching, it's lacking. It's probably too much about us and still not reflecting enough about the student. That's what I would say. (Nerida, teacher, Case A)

Nerida, like teaching colleagues Josie, Sandra, Louise, Astrid and Fran, holds a postgraduate qualification in education. Others had varying qualification levels. Teacher Anita for example, had recently completed a Bachelor level educational qualification and Maxine, a Diploma of Training and Assessment. Tony, on the other hand, had completed only the minimum mandatory requirement for VET teaching, the Certificate IV in Training and Assessment. Despite the fact that not all VET teachers with advanced skills at Case A had attained higher level educational qualifications, most felt that such formal education contributed to the development of advanced skills.

\section{Formal education and the development of advanced skills}

Case A's managers and teachers generally valued the skills and knowledge attained through formal study in the discipline of education. This was particularly the case for the seven VET teachers who held higher level qualifications. Teacher Louise, for example, felt that she gained valuable knowledge from studying units about the psychology of learning and factors affecting learners' motivation. Teacher Sandra, on the other hand, while noting the 
particularly useful skills and knowledge gained from a unit which focused on curriculum and learning design, described the benefits of the degree in more general terms, explaining that it enabled teachers to develop pedagogical knowledge and teaching skills which are difficult to acquire through other means.

I still do think that we need to actually start having teachers with degrees. Because I think, we need to learn that side of it [pedagogical theories and strategies for teaching], not just make it up as we go along. Because that's really hard to learn. (Sandra, teacher, Case A)

Attaining an approved tertiary level educational qualification is not only linked to the development of skills and knowledge; it is also linked to salary. According to the TAFE Queensland Certified Agreement 2016, to progress past Step 4, through to Steps 5, 6, 7 and to Leading Vocational Teacher (LVT) status, TAFE teachers must hold a teaching qualification approved by TAFE Queensland.

At the time of data collection, TAFE Queensland's VET teachers (including those working at Case A) were afforded the opportunity to undertake a Bachelor of Education feefree, through an arrangement developed with a University in another state. Despite not holding an approved teaching qualification, and therefore not being able to progress any further on the teaching scale, neither Maxine nor Tony had plans to undertake the free educational opportunity. Their decision was based upon time constraints and the level of commitment required to complete a part time University program while working full time. Both also questioned the value of undertaking a degree at this point in their working lives.

It's going to take me an awful long time to achieve that Bachelor's degree, and I just don't know whether I've got it in me to make the sacrifices that would be necessary to work full-time and to study. (Maxine, teacher, Case A)

Maxine's most pressing concern was whether the benefits of the Bachelor program would outweigh the sacrifices needed to complete.

I would like to do it from the point of view that I feel as if I would give myself the confidence, [...] like I said, I'm often in situations where I'm conscious that I'm the least qualified person in the room, so I think it would be confidence boosting to have that qualification. Am I prepared to do it? Look, really I don't know. Like I said, this is my second career. (Maxine, teacher, Case A)

Tony felt that his age was a barrier, given the length of time it would take to complete the degree. 
I decided to go against doing it. I was offered to do the Bachelor [Education], but I'm probably getting a little bit long on the tooth for that. To do it while I'm working would take me about 8 years, and I'll sort of be retired by then. (Tony, teacher, Case A)

The concerns expressed by Maxine and Tony are warranted it seems, given the experience of some already enrolled in the Bachelor Education. Manager Graeme reported that despite encouragingly high enrolments into the program, VET teachers who took up the opportunity experienced significant challenges. Many found it difficult to balance their study and teaching workloads.

We had the highest take up of the regions, we had over 40 people sign up at the beginning of this year, with more to start next year, probably 10 to 15 of those have already withdrew or deferred, just because of the workload and trying to manage a full time teaching career and study. (Graeme, manager, Case A)

Others, according to Graeme, struggled because they had not undertaken formal study for many years, and as a result had not developed the necessary academic study skills.

Because a lot of them probably haven't studied for a long time, because we take people that have been working in industry for 10, 15, 20 years that haven't studied, and then just throw them into a bachelor program. (Graeme, manager, Case A)

Graeme suggested that a minimal reduction in teaching load should be provided to support those undertaking the program. He also felt that it would be more appropriate to provide the Diploma of Training and Assessment program to VET teachers and to align this qualification to the salary bar rather than the Bachelor program.

If they had a stepping stone where they could take off, you know, 12 months of their bachelor program through doing a Diploma, I think people may be more willing to do that. And it's also, for a lot of people, it would be reigniting that passion for learning. (Graeme, manager, Case A)

Graeme felt that it was also important to ensure that the education qualifications undertaken by VET teachers were relevant and appropriate for VET teaching. He felt that a disadvantage of the current fee free Bachelor program offered to TAFE Queensland's VET teachers is its requirement for a compulsory work placement component which must be completed in a secondary school environment, rather than in a VET context.

The work experience in that program is focused at schools. So to me, it's not the appropriate level for vocational teachers to be at. You know, placing someone in a school environment and it's very 
controlled, it's, you know, it's very regimented. I really believe that the work experience under that program should be in a VET sector, but in somewhere totally different to where you're working currently. (Graeme, manager, Case A)

While most Case A participants felt that there were advantages to be gained from completing an educational qualification at a higher level than the Certificate IV in Training and Assessment, not all Case A managers felt that tertiary qualifications were necessary for a VET teacher to develop advanced skills. Catherine, for example, felt that skills may be developed through other approaches.

I absolutely value degrees and I have degrees myself, but I just wanted to verify that's it not the be all and end all to identify a high level advanced practitioner where they've chosen not to do that but they can demonstrate it at a high level with other means. (Catherine, manager, Case A)

\section{The relationship between time, experience and advanced skills}

The experience and teaching tenure of Case A's VET teachers varied from less than 10 years for Anita, Maxine and Tony, to more than 15 years for Astrid and Sandra, and more than 20 for Fran, Louise, Nerida and Josie. Despite this variance, all felt that a VET teacher required time and experience 'on the job' to develop advanced skills. Teacher Nerida felt that she learned best in a 'real life setting'.

So l'd actually rather be in a real life setting. [For example]....this audit is going to occur and this is what's going to happen and here's a checklist of what you need to do and how to do it; and then a lot of those skills I felt I learned myself on the job as part of my role as coordinators, and that was the easiest and best way to learn. (Nerida, teacher, Case A)

For Maxine, learning on the job was also a valuable experience. She explained that her teaching skills and strategies were developed by reflecting upon classroom activities and problems that arose.

I think I developed [teaching] strategies myself. I realised that I needed solutions to these things that were presenting themselves and I would go home and think about it. (Maxine, teacher, Case A)

Teacher Josie actively sought out unfamiliar tasks in the workplace to learn new skills, describing her approach as '....just putting your hand up to do things that are a bit outside the box' (Josie, teacher, Case A). For Sandra, learning on the job was somewhat a process of 'trial and error', where support was only provided when mistakes were made. 
Basically I've learnt the hard way. I've learnt by, 'sorry you've failed, you haven't done it, it's not good enough.' And you're going, 'well, I've got no one to teach me, but okay, l'll try'. (Sandra, teacher, Case A)

Manager Roslyn felt that it was important to deliberately assign people to projects and tasks outside of their current job role, to enable them to develop new knowledge and skills. At the time of data collection, Case A organisation was recruiting from existing VET teachers for a number of new Team Leader positions. While the role was intended to provide educational leadership to teaching teams, it was also seen as an opportunity for those appointed to develop new skills and knowledge.

We're just putting people into Team Leader roles here now - half teacher, half Leader/Coach, and the idea is to challenge themselves on their own skills and knowledge as well as support others. So my personal belief is that if you stretch people under guidance you actually advance their skills and that's what we try to do. (Roslyn, manager, Case A)

Despite consensus that time and teaching experience were important factors in the development of advanced skills for VET teachers, Case A participants had varying opinions on the duration that was required. Maxine, for example felt that it took about 12 months to become confident and competent at teaching, while Josie thought that it took a lot longer.

Look, if you had have asked me, I reckon even if you had have asked me what a Training Package was for the first five years, I wouldn't have known. (Josie, teacher, Case A)

Astrid felt that it took her 'about eight years' to become a VET teacher with advanced skills, while Fran believed it took about ten.

Teaching is a skill and like any skill it needs to be practiced. So I guess it's just developing those skills through hard work, a deliberate effort to improve your performance. And I'd have to say for me personally, it's probably been about a decade, that that's taken. (Fran, teacher, Case A)

Nerida, Astrid, Fran and Louise had gained experience teaching in other education sectors (primary, secondary and tertiary) prior to commencing at Case A. While all felt that their skills in educational design, teaching practice and working with a curriculum were transferable to the VET context, Nerida explained that this experience is often 'undervalued' by others in the sector.

I would say the perception from colleagues is that if you were new to the VET sector [...] there's very much a perception of, 'Well, you're a nobody until you have about 20 years' experience.' And even 
though you may have done, you know, 20 years of a particular role, it was very undervalued because it wasn't within a TAFE system and, you know, those processes and systems. (Nerida, teacher, Case A)

Of the nine teachers interviewed at Case A, six (Nerida, Josie, Sandra, Louise, Fran and Astrid) had been appointed to Leading Vocational Teacher (LVT) level, the highest teaching classification afforded by the TAFE teachers' award, the TAFE Queensland Certified Agreement 2016, and one which requires approximately nine years of teaching experience and an approved educational qualification (e.g. an approved tertiary level adult or vocational education qualification) to reach. Holding significant experience and being appointed to the LVT classification however, does not necessarily mean that a VET teacher will demonstrate advanced skills, according to Case A managers. Graeme for example, described some as 'dinosaurs', who failed to take on additional leadership responsibilities.

Within the TAFE sector, we have leading vocational teachers who are meant to take on some additional responsibilities, but in most cases, in my experience, a lot of them aren't great leaders, that they take on the additional role as being planning or timetabling, but a lot of them need leadership skills to particularly develop other teachers within their teams. You know, to me, I wouldn't describe them as having advanced skills. They're probably dinosaurs, but that's some of the workforce that I have. (Graeme, manager, Case A)

Roslyn pointed out that the LVT status did not guarantee quality teaching, either.

I began to realise quite early on that seniority was not a feature of excellence. The more I had to manage teachers, the more I realised that seniority was not a feature. (Roslyn, manager, Case A)

Just as Roslyn and Graeme felt that an LVT might not necessarily be regarded as VET teachers with advanced skills, manager Catherine felt that there were also VET teachers with advanced skills who were not LVTs.

We have Leading Vocational Teachers who demonstrate those advanced VET skills. We've also got our teachers that aren't Leading Vocational Teachers but have demonstrated those advanced practitioner skills at high level. (Catherine, manager, Case A)

While experience, time and learning on the job were valued by Case A participants as a means of developing advanced skills, many felt that it was also important for VET teachers to have the opportunity to learn from others, a theme which will be explored next. 


\section{Learning from others}

Other teachers and colleagues played a significant role in the development of Case A's VET teachers. Teachers Maxine, Nerida and Josie all spoke of the benefits they gained from the informal mentoring relationships they developed in the workplace. Josie had a number of mentors who assisted with all aspects of her teaching role, from administrative tasks to teaching.

I feel relatively blessed that when I first started here I was the beginner and I was mentored really well. They had done my planning for me, done my programs for me, would sit down with me and say, 'This is what we would like you to teach. Could you prepare your resources? We will review them. Do you need any help with typing, with developing your overhead projector things? We've done your timetable for you. We'll do your pay for you.' I felt very mentored and very safe. (Josie teacher, Case A)

While there is currently no formal mentoring program in place at Case $A$, teachers take advantage of informal opportunities to learn and to develop their skills and knowledge. For example, teacher Tony explained that information is often shared and problems discussed in staffroom conversations:

There's informal stuff in the smoko rooms, in the lunchrooms; we're always talking. (Tony, teacher, case A)

Nerida found that valuable informal mentoring opportunities were always available in the workplace, provided the teacher used his/her networking skills to establish appropriate connections.

More than anything, the informal is the best; always is, always get the answers. And that's where it relies heavily on your networking. (Nerida, teacher, Case A)

Teacher Maxine agreed that mentoring could assist VET teachers to develop advanced skills, but cautioned that it was important to engage the right people as mentors.

We don't have a structured mentoring program. I know there has been talk about developing it and I really want to be involved in that, but I think you have to engage the right people to be the mentors. Because if you want people who are going to show a novice the way, you want to make sure it's the right way. (Maxine, teacher, Case A)

Interestingly, the benefits of mentoring are evidently not limited to the mentee. Manager Roslyn explained that providing advice and assistance to others 'forces you to reflect on your 
own capacity and skill' (Roslyn, manager, Case A), a view substantiated by teacher Maxine, who explained that teaching the Certificate IV in Training and Education to others helped her to further develop her own skills and knowledge.

And I actually started guiding people through [teaching and assessment practices], and when you actually have to explain something, it's one thing to be able to, you know how to do it, but it's another thing to then help someone else understand how to do it. (Maxine, teacher, Case A)

While Case A has not yet implemented a formal mentoring program, it does provide a range of training activities to its VET teachers as professional development opportunities. A significant proportion of these programs are training sessions which focus on compliance and regulatory requirements, such as Workplace Health and Safety training or VET legislation and standards. Perceptions of organisational training and support provided by Case A will be discussed in the next section.

\section{Organisational training and support}

Case $\mathrm{A}$ has developed and implemented a range of professional development activities for VET teachers, primarily provided online through webinars. Teachers Fran and Tony found the organisation's professional development offerings, including the webinars, useful.

I think the webinars, personally, are really useful, and also at the start of the year, we were given a professional development session on the new standards for this year and how it would affect us, what will we need to do that's different from what we have been doing. So that was really useful. So I think it's, to me a lot of the knowledge and skills that we have aside from teaching is from professional development. (Fran, teacher, Case A)

Some were more critical of the webinars and professional development activities provided to Case A's VET teachers. Nerida, for example, felt that the training provided was more relevant for beginning teachers, describing it as too 'simplistic and generic' for those who have been working at Case A for 'longer than a year or two' (Nerida, teacher, Case A). Nerida also indicated that the webinars were often cancelled.

I have attended some of those webinars when they actually do go ahead because they actually work, or they're not cancelled. They're not very reliable in actually occurring, but when they do occur, they're just so broadly generic, you know, just give me a textbook and show me the page where I need to read the same information, really it's too generic; it's just so generic, I never last through the whole session because I don't learn anything'. (Nerida, teacher, Case A) 
Anita was also critical of the webinars, explaining that the mode of delivering the training program was not always appropriate or suited to all learners.

But the interesting thing is that they're saying inclusive, inclusive, inclusive, and then they run these workshops that are not inclusive. I think that's quite interesting, that they do that. They're usually done by a webinar, by just one person. (Anita, teacher, Case A)

According to Louise, many of the compulsory training sessions could best be presented in a different format. Some, for example, she felt could be better communicated as an email, than as a training session.

We had to go along to one just recently and listen to someone talk for an hour on a video conference that was stuff that we'd already been told in a one minute email. We got rapped over the knuckles as to why we hadn't cancelled a scheduled class to go to a video conference to listen to this for an hour. (Louise, teacher, Case A)

Sandra and Nerida felt the organisation should ensure that professional development programs offered to VET teachers were aligned to their needs and level of experience.

I sometimes think, when they're looking at giving you professional development, they need to look at you specifically. Okay, well this person's got this degree, this degree, this degree, so they need this high end stuff. Whereas this other person is just, not just a Tutor, but a Tutor with a TAE, so they need more of that base ground stuff. How do we write Assessments? What's inclusive learning? All that sort of stuff. Whereas I tend not to need that, because I know how to do it. Me going back and doing that, is super boring. (Sandra, teacher, Case A)

The organisation also supports VET teachers to maintain their regulatory requirement for 'industry currency'. While many participate in an 'industry release', a program in which Case A provides support with paid time off to attend a workplace for a period of time (usually one week per year), they also attend industry relevant conferences and trade shows.

I'm regularly out visiting; we do some on-the-job training at a few different places. And generally about twice or three times a year I'll go out and visit the industry, or the business, to see how the apprentices are going, get feedback, and move them through their training book issues. And we also have a good relationship where we can get spare parts and things off them, like old engines and transmissions, I'm always getting those off industry. And I think it's just regular contact and being accessible. (Tony, teacher, Case A)

Tony's engagement with industry has enabled him and his team to participate in training provided by product suppliers. 
We probably attend four to five industry training sessions a year. We're sort of fortunate that we've got a good relationship with [product supplier]. They deliver courses at our campus, and industry attends those courses, so we might have up to 25 industry people in training, and we sit in with them. (Tony, teacher, Case A)

While some, such as Tony, valued the skills development opportunity afforded by participating in industry release activities, others found Case A's policy on what constitutes an acceptable industry release activity, restrictive. Sharon for example, lamented the fact that even though she regularly participated in industry relevant work activities in her own business, such activities did not meet the requirements of the organisation's policy on industry currency.

I can't work in my own business for Industry release. I thought, okay, that's fine, l'll go work for someone else. Which is a little bit hard sometimes, when you're working [as a VET teacher] full time. (Sandra, teacher, Case A)

\section{Personal attributes and development of advanced skills}

While Case A participants felt that it was important for VET teachers to have access to relevant experience, developmental opportunities and support in order to develop advanced skills, many felt that the personal attributes and characteristics of the individual teachers was also a critical factor. Astrid for example, felt that to develop advanced skills, VET teachers needed to be flexible and willing to learn.

Some people are very closed, and so I think you need to be open and accepting that there are, and willing to learn new ways of doing things, and take on working with technology or changing the way you do things because if you don't, if you do sort of have your set of skills that you've got from industry that you will share with the students then you're a little bit closed and you don't necessarily, you're not going to grow, and I think advanced skills would come with growth. (Astrid, teacher, Case A)

Fran felt that it was important for VET teachers to demonstrate a personal commitment to continually update their skills and knowledge, particularly in relation to technological changes.

Just keeping up with the technology and whether you want to or not, going with that and continually refining your training and assessment skills, because technology keeps changing we sort of have to be focused on how to improve those skills that have a technology component. (Fran, teacher, Case A)

Astrid, who describes herself as a 'lifelong learner', has completed numerous professional development activities in a continual process of self-development. Some of these activities 
were supported and funded by Case A, others by Astrid herself. As well as enjoying learning and extending her skills and knowledge, Astrid enjoyed the experience of being a learner and felt that it helped her to improve her own teaching skills and knowledge.

It's good [being a student] because you can see how things affect you and how you learn, and how you fix things that you like, things that you don't like, and different ways of doing things. (Astrid, teacher, Case A)

\section{Barriers to developing advanced skills}

While Case A participants identified ways in which the development of advanced skills for VET teachers may be supported, they also noted a number of barriers which limited their ability to participate in developmental activities - most notably related to resource and time constraints. Louise explained that although she had attended many professional development activities, including conferences and formal courses, she funded the activities herself.

Getting funding for it [professional development] is near impossible in terms of the size of the budget so you have to fit it in within what the small budget might be and obviously that's a competitive process as to who might be able to get funding to go to a conference or funding to go to a workshop and industry events and things like that. So, that's fairly limited and I guess the rest of it comes back to individual motivation. So, to do my Masters was a case of changing technology and every skill I've learned to improve as a teacher has been self-driven; it hasn't been supported by the institute. (Louise, teacher, Case A)

Louise's experience was similar to that described by Nerida, who also reported that it was difficult to gain the funds necessary to attend conferences.

Conferences, really enjoy conferences, really hard to get to because they cost money and they're expensive, so we try as best we can to go to professional development events. (Nerida, teacher, Case A)

Even if the organisation supports a VET teacher's professional development activity financially, time constraints present another, often insurmountable barrier. Teacher Anita described the difficulty of even finding time to attend compulsory training activities provided by the organisation, let alone additional external professional development activities.

There seems to be a lot of push for, and I know it's important, like we have to be compliant, and these sort of things, but there's this constant push for us to go and do this, go and learn this, go and get on 
to this webinar, go and do this. And it's about, it's time, like it's finding the time to do that and to fit it in. But then also applying that to what you're doing. (Anita, teacher, Case A)

Teacher Josie expressed a similar view to Anita's. Despite the availability of many interesting and relevant professional development activities, she found it difficult to find the time to attend them.

It is very much about time. There's a lot of professional development things that l'd like to do, like, I probably on a weekly basis get emails saying, 'This PD's here.' And I think, 'That'd be good. That'd be interesting.' But when you're teaching and when you're doing all of the extra advanced practitioner skill things, there's very little time for it...because to do PD it should be something you can do when you're not completely worried or stressed about other things, and then you can reflect on it and look at how - it's a bit like you're doing training outside work. It's just an added extra thing to do. (Josie, teacher, Case A)

Case A's VET teachers also found it difficult to attend activities if they were unable to appoint a replacement teacher to ensure teaching commitments were maintained. Without the budget to fund the wages for a casual replacement teacher, other team members were expected to accommodate the additional workload, a situation which Nerida found unacceptable.

Time. Massive. Massive barrier. Massive. No one is ever backfilled. If you're away for a week no one will come in and do your workload. Your work colleagues will do your workload. (Nerida, teacher, Case A)

\section{Conclusion}

Case A's managers and teachers have somewhat divergent views on what advanced skills for VET teachers are. While both believe that effective teaching skills are important for VET teachers, managers were more likely to regard these skills as core to the job role, rather than a unique characteristic of teachers they regard as having advanced skills. Managers at Case A felt that teachers with advanced skills fulfilled important leadership and mentoring roles in the organisation, roles which helped the organisation meet its business goals. Teachers, on the other hand, were more likely to describe advanced skills in terms of learning and teaching activities and the outcomes of these activities for students. In particular, Case A teachers identified that VET teachers with advanced skills had a unique ability to communicate, engage and connect with students and form appropriate relationships with them which facilitated 
the learning process. Many spoke of their enthusiasm and passion for teaching and their commitment to their students and the outcomes that students achieved.

Case A's teachers with advanced skills attributed their development to a variety of different activities. Time and experience were important factors in the development of advanced skills, however many felt that higher education (e.g. a Bachelor level qualification in education) was also critical, as was the opportunity to learn from others in the organisation, often through informal mentoring relationships. Although managers mostly agreed with teachers on the ways in which teachers might develop advanced skills, the developmental opportunities provided by Case A were not highly valued by a number of teachers, who felt that these activities were more likely to be focused on compliance requirements rather than on contributing to the development of their teaching skills. They also believed that as teachers with advanced skills, they required different professional development activities to beginning teachers, but the barriers of time and money diminished their ability to participate in activities that they felt would be of value to them. Most shouldered the responsibility for their own professional development, paying for their own activities themselves and undertaking them in their own time. 


\section{CHAPTER 5 CASE B}

\section{Case background}

Case B is one of six regions of the TAFE Queensland network, established following the 2013 restructure of TAFE Queensland in which thirteen TAFE Institutes were amalgamated to become six 'regions'. Prior to the 2013 restructure, Case B was a Statutory Authority Institute, operating with an alternative model of governance to the other TAFE Institutes who formed part of the publicly funded and managed educational provider. The Statutory Authority business model was intended to enable greater autonomy, business acuity and financial sustainability, with the incentive that the Institute's financial surpluses would be 'reinvested at the institute level in staff and training facilities' (Queensland Government, 2008, p. 1), rather than returned to the TAFE Queensland organisation as a whole. In addition, according to the regulatory frameworks in place at the time, only Statutory Authority Institutes were regarded as having the corporate governance structure needed to enable eligible students to access Commonwealth VET FEE-HELP, the student loans available to assist VET students undertaking diplomas and advanced diplomas (Queensland Government, 2008). Of thirteen TAFE Queensland Institutes, Case B was one of only two to be awarded statutory authority status. While there were considerable financial and competitive benefits to be gained from the provision of VET FEE-HELP assistance to students and from retaining profits at the Institute level, earning profit as a statutory authority required the Institute to operate with greater financial autonomy due to reduced access to State and Commonwealth funds. In addition, there was an expectation that a Statutory Authority governance model would enable a TAFE Institute 'to operate more efficiently and effectively' in an increasingly competitive environment (Queensland Government, 2008, p. 18).

Case $B$, similarly to other TAFE regions, delivers a diverse range of vocational courses both non-accredited and accredited from Certificate I to Advanced Diploma level, on campus and/or online. At the time of data collection, the region had also commenced delivery of a small number of Bachelor programs in partnership with an Australian university.

\section{Data collection and participants}

Data to prepare the case report was collected through semi-structured interviews with eleven participants: four managers and seven teachers with advanced skills. The managers (Linda, 
Diane, Alexandra and Susan) were direct supervisors of VET teachers in the organisation, and as such, in a position to influence and approve the professional development activities that Case B's VET teachers participated in. Each manager had accumulated more than 10 years of experience as managers in the VET sector and while they all had experience as teachers prior to being appointed as managers, the duration of this experience varied from a short term tenure of 6 months (Alexandra), to lengthy teaching careers spanning more than 10 years (Linda and Diane). Alexandra, Susan and Diane had all worked in private Registered Training Organisations (RTOs) prior to their appointment at Case B.

The seven teachers invited to participate were identified as teachers with advanced skills by their peers and/or managers. They were drawn from a range of disciplines including nursing, complementary health, hospitality, community services, employment preparation and LLN (language, literacy and numeracy) support, and had varying tenures of teaching experience. Elise, for example, had been employed in a teaching role for only four years, and Sanjita for seven, while Andrea, Loretta, Janine, Jon and Alan had each accrued between fifteen to twenty years teaching experience. Some had worked in other contexts prior to commencing their employment with Case B. Andrea, Sanjita and Jon for example, had been employed in teaching roles by private RTOs, while Jon and Alan had gained cross-sectoral and International teaching experiences.

\section{Advanced skills at Case B}

Participants were asked questions about their understanding of advanced skills for VET teachers - what they are and how they are developed. The questions asked of managers and teachers during the interviews varied, as VET teachers were asked to reflect on their own teaching practice as a VET teacher with advanced skills while managers were asked to consider the capabilities and characteristics of VET teachers in the organisation whom they regard to have advanced skills. Some found it difficult to describe advanced skills, at least initially. Manager Alexandra explained that this was because the VET sector had not yet determined what advanced skills were and that VET teachers with advanced skills were not recognised.

The advanced skills VET practitioners are not rewarded well in the VET sector because the determination of what that is, is not well established. (Alexandra, manager, Case B) 
Manager Linda meanwhile, felt that rather than being advanced in all areas of teaching, VET teachers with advanced skills were specialists in particular tasks and responsibilities and that these skills were related to the priorities of the relevant teaching team and the organisation.

Rather than thinking that there are people who are good at and advanced in everything, you have people who are specialists in areas that are important to the team and the Institute, depending on what your priorities are. (Linda, manager, Case B)

During the interviews, participants frequently referred to two major projects that Case B was involved in at the time of data collection - the Master Product project and a pilot implementation of TAFE Queensland's Educator Capability Framework. The Master Product project was an ambitious undertaking to produce high quality training and assessment resources for all TAFE Queensland qualifications. The completed products were intended to be suitable for multiple delivery and assessment modes, but particularly for online and blended training and assessment modes. The resources, once completed, would be published on TAFE Queensland's Learning Management System to be utilised homogenously by all educators in all six TAFE Queensland regions. While all regions had input into the development of Master Product, Case B had a significant level of responsibility. At the time of data collection, the Case B organisation was tasked with managing all production activities for numerous qualifications and for ensuring that quality requirements and timelines were met as the resources were developed.

In addition to its responsibilities associated with the development of Master Product, Case B was preparing to pilot the implementation of TAFE Queensland's Educator Capability Framework, another project intended to inform a broader implementation across all TAFE Queensland regions. The TAFE Queensland Educator Capability Framework is described as a '...self-profiling tool, or rubric, which clearly articulates the skills, abilities and knowledge that educators should be demonstrating on a regular basis in their roles at various stages of development', and is intended to 'provide opportunities to identify and recognise educational excellence' and to guide the professional development and career pathways of teachers in the organisation (TAFE Queensland, 2016, p. 3). The framework, which is based upon Innovation and Business Skills Australia's (2013) VET Practitioner Capability Framework, but aligned to TAFE Queensland's organisational goals (TAFE Queensland, 2016), lists eight domains: Professionalism and core values; Learning and Teaching; Assessment; Innovative 
product and practices; Technology for learning; Learner, industry and community engagement; Quality and compliance; and Educational leadership. Within each domain, there are a number of related skill areas. Together, the domains and skill areas are intended to 'define the capabilities of high-performing educators desired within all [TAFE Queensland] regions' (TAFE Queensland, 2016, p. 5). The framework assumes however, that not all educators will demonstrate the capabilities at the highest level, with each skill expanded upon to describe behaviours demonstrated by educators at four incrementally progressive levels: transitioning, proficient, highly accomplished, and leading. Linda (manager, Case B) explained that she did not expect all teachers to achieve the highest level of skills in each of the framework's eight domains. Rather, she expected that the tool would be used to develop a profile of the skills and capabilities across the organisation and its various teams and to identify those with specialist skills that might provide mentoring and leadership to others.

I think there would be limited people who would be advanced across all of those eight domains. There would be some, and they probably already have leadership roles in the organisation. But I think we would find that across the VET educators, I think that their profile would probably be a bit 'patchwork'. They could very well have advanced skills in their own VET teaching area perhaps, but maybe not so with technology. So I think, I am pretty excited about what using that tool will tell us about our whole teacher cohort and tell us about our faculties and tell us about our teams. (Linda, manager, Case B)

Given their scope and significance, it is perhaps unsurprising that many Case B participants, particularly Case B managers, referred to both the Master Product Project and the implementation of the TAFE Queensland Educator Capability Framework when discussing advanced skills during the interviews. The Master Product Project in particular, represented a significant financial investment not only for the Case B region, but for TAFE Queensland. To ensure a return on this investment, Case B managers were keen to ensure that the product was utilised as intended. This intention was often reflected in the discourse and language that they used to describe advanced skills, which referred to capabilities and characteristics such as innovation, flexibility, teaching in multiple delivery modes and skills to use technology.

If we are going to capitalise on that investment then we need to make sure that teachers are able to use the Master Product, that they can use the online material to their advantage and to their student's advantage in classroom settings. (Linda, manager)

While several of Case B's VET teachers recognised the importance of the Master Product project and the implementation of the VET Practitioner Capability Framework, some 
described an incongruence between their views on the advanced skills and those of their managers which were thought to be influenced by the organisation's business goals more often than student outcomes. Andrea (teacher), for example, described an 'us and them' scenario, in which teachers sometimes felt that their teaching practice was being driven by policy and management objectives, rather than student outcomes.

Respect is the key because there is very much, from a practitioner point of view, an Us and Them management is making us do these things and there is a lot happening. (Andrea, teacher)

Despite the initial difficulty in describing advanced skills and some divergent views between teachers and managers, a number of themes emerged from Case B interviews. Advanced skills for VET teachers, according to Case B participants include: understanding the curriculum and being able to assess its requirements efficiently; the capability to engage and teach students in different settings and modes including online, in the classroom and in the workplace; maintaining current, high level industry/vocational skills and knowledge and knowing how to teach them to others; and the ability to provide leadership in the organisation. Case B participants, particularly Case B VET teachers, also felt that those with advanced skills had certain individual attributes and characteristics which set them apart from other VET teachers, and that they demonstrated a level of commitment to teaching and a responsibility for student outcomes not adequately described in terms of teaching skills and capabilities. Each of these themes will be explored in more detail in the following sections.

\section{Curriculum, assessment and compliance}

Manager Diane felt that a discussion on advanced skills for VET teachers should begin by looking 'behind the scenes', , at the work required to comply with the sector's increasing regulatory requirements.

I guess there is a big focus on what happens in the classroom. But for us here in the VET sector, there is a whole, huge component of behind the scenes work that goes on as well. And that has become more and more important I think over the years with my experience. The behind the scenes stuff you know - the compliance, accreditation, registration. (Diane, manager, Case B)

\footnotetext{
${ }^{4}$ In-text quotes from participants have been italicised for emphasis and to differentiate them from citations of published works
} 
Manager Alexandra shared Diane's view, explaining that in her opinion, VET teachers needed an in depth understanding of the sector's 'restrictive' legislation and its compliance requirements to be considered advanced. Compliance in the VET sector is most often associated with assessment and in particular, ensuring that every required component of the curriculum is assessed adequately.

To actually be considered an expert teacher with advanced skills is one to me that understands assessment, understands how that assessment can be done to meet the compliance requirements of whatever they're delivering, how they can balance that. (Diane, manager, Case B)

Manager Alexandra explained that VET teachers with advanced skills were able to apply a holistic approach to assessment to ensure that all Training Package requirements were met efficiently and to identify when aspects of the curriculum were missed.

A good VET teacher - I talk about the [Training] Package a lot- but it is about them being able to articulate the package that is set in an environment with short time spans and big assessments. I think we over assess a bit in TAFE, in the VET sector, but it's just somebody who can stand back. I can give my lead teachers the package and the resources, and they will say, "I have had a quick look and this isn't covered in that". They just see it, they visualise the mapping and can see that. (Alexandra, manager, Case B)

For VET teachers, designing assessment processes which ensure that all components of the curriculum are adequately and appropriately assessed is arguably fraught, given the complexity of National Training Packages. The VET curriculum includes performance and evidence requirements that are explicitly stated (e.g. performance criteria, performance evidence and knowledge evidence) along with other embedded components (such as language, literacy and numeracy performance requirements) which are not always explicitly or obviously stated. Diane felt that VET teachers with advanced skills had a deep understanding of the curriculum and could develop creative methods of ensuring that the needs of students and the requirements for compliance were both met.

I think that understanding assessment, understanding the creative ways in which students can demonstrate that they are competent and how they can achieve meeting the requirements is really important. (Diane, manager, Case B)

Diane went on to express her concern that Training Packages have progressively become more comprehensive and prescriptive, and that this has made it even more difficult for VET 
teachers to ensure compliance requirements were met, while still ensuring a 'meaningful experience' for students.

Our training packages now are very descriptive and they certainly have a massive amount of requirements. I think they have tried to make it difficult for the dodgy providers that don't want to make sure that the students are complying with everything but that has also meant that it can be huge for the student to complete it all. So teachers have to come up with very good in depth understanding and a good balance between meeting compliance and making it a meaningful experience for the students. (Diane, manager, Case B)

Case B teacher, Loretta, corroborated the views of Diane and Alexandra, explaining that those with advanced skills had an understanding of Training Packages which helped them to 'draw the line' when deciding what needed to be assessed, and thereby limiting onerous or unnecessary assessment tasks.

So understanding that somebody from industry has written that and there are components that your students need to understand and comprehend. There are also extra items that you can cover in their class- but you've got to make sure that you are not over assessing them either. I see lots of over assessment happening and I think that understanding [Training Packages] is about not overloading your students with too much information; understanding that it is great to give them all that information; it's great to add in why it might be important, but when we are sitting down to assess the student, writing the assessments, constructing the assessments that you are going to use, [you are] assessing what is required and not making them jump through hoops. So understanding Training Packages also takes into consideration drawing the line about what needs to be assessed and where you are just helping them to understand the industry better. (Loretta, teacher, Case B)

Loretta also referred to assessment which took place for Recognition of Prior Learning (RPL), a VET sector process in which a person's competency against the curriculum, or parts of the curriculum is assessed. The purpose of RPL is to formally recognise and assess the knowledge and skills that a person has attained previously through work or prior formal education so that they do not have to participate in unnecessary learning activities. While it may be assumed that conducting RPL would be a standard skill for VET teachers - as it is for all intents and purposes, simply an assessment process - this may not necessarily be the case. Teachers Loretta and Jon were each assigned responsibility for coordinating the RPL activities of their respective teams. As well as completing RPL assessments, they also reviewed RPL judgements and practices completed by others, a role ostensibly entrusted to them due to their organisational standing as teachers with advanced skills. 
I think RPL is an advanced form of assessment and it needs an advanced practitioner - someone who is very competent in assessment. Even an assessment writer, maybe somebody who has come into the industry as a writer, and not teaching face to face, that would be fine. But they would need some experience with teaching, that's for sure. (Loretta, teacher, Case B)

While managers Diane, Alexandra and teacher Loretta focused on how VET teachers with advanced skills interpreted the curriculum in order to meet compliance requirements, Andrea (teacher, Case B) described her skills in relation to learning and teaching, rather than simply assessment. She explained the way in which she applied knowledge of the Training Package, the industry and the learners to develop sound educational programs.

I am an educator. It is the educational design framework that I place over the top - really understanding the training packages, understanding the industry, understanding our learners, and then finding the right tools and methodology to do that. (Andrea, teacher, Case B)

As Andrea alluded to, VET teachers are required to do more than design assessments and meet compliance requirements - they are required to teach. And according to a number of Case B's participants, particularly its managers, VET teachers with advanced skills can teach effectively in many different contexts, whether it be online, face to face or even in the workplace. They were expected to achieve this through the effective use of technology.

\section{Teaching in different contexts: technology and advanced skills}

Case B Managers Linda, Diane, Alexandra and Susan attributed advanced VET teaching skills to those who could teach effectively in different contexts and modalities. Susan for example, explained that VET teachers with advanced skills could teach effectively in any setting.

They can go from face to face workshop to a big lecture hall, to online, to go out to industry, to use an iPad to do an RPL assessment. They can switch modalities easily without having to go through extreme planning. It comes naturally every time. (Susan, manager, Case B)

Loretta (Case B teacher), shared Susan's view, explaining that teachers with advanced skills could draw upon 'different skills in different settings, practical industry settings, classroom settings, online, pretty much everything...' and that they could '...contextualise everything'. The 'everything' that Loretta referred to includes not only curriculum and content, but educational activities and assessment. According to Case B managers, teachers must apply these multi-modal teaching skills to meet student needs for flexibility, to ensure that the 
organisation can remain competitive in the market, and to capitalise on the significant investment made to implement the Master Product project. Manager Linda attributed the need for greater flexibility in teaching modalities to 'changing times'.

We are having to change to the changing times - students are changing, the demands of the students are changing. (Linda, manager, Case B)

Diane shared Linda's view, explaining that students required flexible means of studying, and that this was often achieved through technology.

Because we know from here, a lot of the demographics of the students we have, a lot don't want to sit in a classroom. They want flexible ways of getting their needs met. They want to embrace technology. (Diane, manager, Case B)

Manager Alexandra pointed out that Case B was 'IT focused' at the time of data collection, and as manager Susan explained, the organisation expected its VET teachers to embrace technology for learning and teaching.

We expect a difference in their [teachers'] approach to delivery and they should use a range of modalities for learning, including modern technologies. We are pretty heavy here in the online learning as you would know. It is pretty common now, but those with advanced skills are able to use the online platforms here at TAFE and in other organisations to use a variety of techniques to assess students or to deliver training. (Susan, manager, Case B)

Case B's increased reliance on technology and online teaching modalities is not only expected to increase flexibility for students and meet their perceived needs for technologically supported education. It is also anticipated to produce efficiencies in teaching practices. Manager Linda explained that in the business of VET, those with advanced skills could use online technologies to ensure that Case B remained 'competitive in the market'.

If we are priced well we need to be efficient in what we do. So those advanced skills teachers, I think, are the ones that can understand what it is that we are selling, understand the customer, put the student first, be responsive to the student. (Linda, manager, Case B)

Linda's view was also shared by manager, Susan, who suggested that 'if we don't work with time efficiencies, we will go out of business' (Susan, manager, Case B).

Case B's focus on utilising technology and online learning platforms may have changed the organisation's perception of advanced skills over time. Alexandra explained that even 
those with established careers and recognised experience and skills in face to face, classroom teaching practices may not be considered advanced if they do not demonstrate skills to teach in an online modality.

Personally, from our point of view, we are so IT focused at the moment and a lot of the skilled practitioners that have been around for a long time have no concept of how to facilitate and motivate a student through an online delivery modality so they don't have the skills. (Alexandra, Case B Manager)

Alexandra's view is shared by Diane, who felt that those who continued to apply a more traditional teaching approach in the organisation could not be regarded as having advanced skills.

So it's the teachers who want to keep delivering the same way they have for many years, and that is in a face to face context with students sitting in a classroom and delivering content to them. And for me, they're the ones that maybe have not become teachers that have advanced skills. (Diane, manager, Case B)

So what skills are required to teach effectively in an online context? According to manager Alexandra, teachers with advanced skills can create an online environment which ensures students feel connected and part of the class.

...[VET teachers with advanced skills can] engage with them, engage with the group, get really good robust conversations going, online rooms. All that can facilitate for the students, so that the person in Far North Queensland can feel like they are part of the class rather than just reading through the theory and doing their assessments. (Alexandra, manager, Case B)

Susan (Case B manager) described a typical online teaching context at Case B as one which somewhat replicates a classroom environment with online rooms and 'Blackboard', the Learning Management System used to support learning material and teacher-student interactions.

It is pretty common now, but those with advanced skills are able to use the online platforms here at TAFE and in other organisations to use a variety of techniques to assess students or to deliver training. We have things like online rooms and Blackboard, where the teacher is there on the screen and the students log in rather than coming in to the classroom. And how they manage that session, not just by putting up PowerPoints and talking about them, but getting the students to interact and making it a very valuable session, it might only occur once a week or once fortnight. Those are the things that I would consider an advanced VET practitioner would display in their practice. (Susan, manager, Case B) 
The electronic resources produced for the Master Product Project are an important component of the online learning context at Case B. According to Linda, however, teachers with advanced teaching skills could utilise and adapt these resources just as effectively as they would traditional printed resources in order to meet students' learning needs.

They can use the online material to their advantage and to their student's advantage in classroom settings and that's really starting to show us that the product is just like a textbook really - it doesn't really matter if it is online or if it is paper-based. Ultimately it comes down to the teacher being able to take that material and contextualise it to the needs of the students that they are dealing with. (Linda, manager, Case B)

Of course, online teaching requires teachers to have technological skills. Teacher Andrea recognised Case B's increasing reliance upon technology to achieve its organisational goals, and felt that she was identified as a teacher with advanced skills because of her expertise in this area. She applied these skills to manage administrative tasks in an online teaching context and to confidently use online learning platforms for teaching.

So administrative skills, now particularly with IT [Information Technology], the way we use IT now in these settings, I think are really important. I think I have those and I continue to develop them, which then links into general IT skills and confidence around online learning, learning management systems, online resources and things like that. So strong emphasis on IT skills, which again I sort of developed over time. (Andrea, teacher, Case B)

Case B manager, Diane, felt that technology skills were required not only for online teaching, but to 'role model' the vocational skills expected in a changing workplace.

They [students] need to embrace technology because industry tell us that is what our workforce need to have - they need to be techno savvy and they need to be able to utilise technology effectively. So it's really about teachers that can role model that, utilise that themselves and get students working in the context in the way that we know will be required in the workforce . (Diane, manager, Case B)

To role model the behaviours and practices expected in a modern workplace however, VET teachers require more than the skills to use technology. They must ensure that they maintain currency in other aspects of their vocational discipline in order to meet VET regulatory requirements.

\section{Industry and vocational skills}

To meet the sector's legislative requirements which are outlined in The Standards for Registered Training Organisations 2015, RTOs must ensure that their VET teachers hold 
vocational competencies at or above the qualification level they teach as well as relevant current industry skills (Commonwealth Government of Australia: Department of Education and Training, 2015, p. Clause 1.13). They must also continue to maintain current industry skills throughout their VET teaching career. While the standards are intended to describe the minimum benchmark requirement for VET teachers, some Case B teachers and managers felt that teachers with advanced skills had capabilities over and above these requirements. Manager Diane for example, felt that they would be regarded as 'experts in their vocational area', a view shared by teacher Loretta who explained that VET teachers with advanced skills needed 'advanced content knowledge'. According to Diane, those with advanced skills demonstrated the confidence and creativity to successfully combine their industry skills and experience with their VET teaching skills and experience.

So it's really about being confident and experienced in your industry and confident and experienced in the VET sector and being able to use some creativity and good balance to make those two come together'. (Diane, manager, Case B)

While all Case B participants agreed that VET teachers with advanced skills must continue to maintain their industry skills and knowledge, there were varying views and opinions on how this was best achieved. There were also conflicting views on how regulatory requirements relating to currency were interpreted within the organisation and how VET teachers' professional development activities might be balanced to ensure that they could maintain industry currency while also continuing to develop their VET teaching skills and knowledge (teaching currency). Some, such as manager Linda, emphasised that maintaining industry currency should be considered a critical component of the VET teacher's professional development.

They need to understand that the outcome is jobs for our students; so if the outcome is jobs, what they are teaching needs to be current, needs to be authentic; our graduates need to be employable. VET teachers need to get out into industry to ensure that they are still across all their industry, that they understand their industry and that the information they are giving their students is current and relevant. (Linda, manager, Case B)

At Case B, some VET teachers maintain their industry currency by working on a casual or part time basis in a relevant commercial business or in their own business. Most however, participate in 'Industry Release', in which they are paid by TAFE Queensland while they work for up to five days per year in a relevant external business. There was divergent views on how 
much industry release was sufficient, and which activities should be regarded as relevant. Teacher, Loretta, for example, felt that TAFE Queensland's requirement of five days industry release was not sufficient, and while some Case B managers and teachers felt that industry currency could be maintained by reading industry journals and participating in industry events such as expos and trade shows, Loretta did not agree.

Reading materials, going to a trade show, going to a network event, I just don't think it is enough - I really don't think it is enough. And so, for me, working in industry, and managing that on a regular basis is really important. (Loretta, teacher, Case B)

Case B Manager, Alexandra on the other hand, had a different view. She believed that VET teachers did not necessarily have to continue working in industry to maintain their industry currency.

It doesn't make them a better teacher, working on the floor [in industry] - you can research and read and get your currency in another format. (Alexandra, manager, Case B)

Despite this opinion however, Alexandra acknowledged that there was a requirement for teachers to work in industry to maintain their skills currency, attributing its enforcement to the Australian Skills Quality Authority (ASQA), the National VET regulator.

But that is an ASQA requirement. I think that ASQA state it. Even with our Registered Nurses maintaining their registration with AHPRA, as a registered nurse - that is not considered current for ASQA. And they do really think that being on the floor, working side by side with the staff creates better teachers. And I don't necessarily agree with that. (Alexandra, manager, Case B)

Whether driven by regulatory requirements or the organisation's priorities, some feel that there is a price to pay for the emphasis placed on maintaining industry currency. Some full time VET teachers, according to Alexandra, feel compelled to take on additional part time work, leading not only to fatigue, but also hampering their development of teaching skills.

They focus so much on your currency as a nurse and full timers have to get part time jobs on the weekend to maintain their currency, rather than focusing on making them a better teacher. They get so rundown and tired because they have to do the extra work on top of what they are doing here, and I don't think that it makes them any more current. (Alexandra, manager, Case B)

Similarly, teacher Jon felt that while industry currency activities can improve teachers' industry knowledge, it does not help them to develop skills for teaching. In fact, Jon felt that too strong an emphasis on industry currency may prove to be a barrier to the development 
of teaching skills, for those teaching in the Community Services discipline at least. Jon described the transition from Community Services worker to VET teacher as challenging, made even more so by the requirement to maintain industry currency. The problem, he explained, is that teachers approached teaching with a Community Services mindset, which placed the student in the role of client and the teacher in the role of counsellor.

Why I have such a problem with that [the focus on industry currency] is that I think that a significant percentage of Community Services teachers at TAFE did not actually polish their teaching skills. They are still operating in a Community Services framework. They were counsellors and now they are counsellors and teachers as well. And they think that they need to do things in the Community Services fashion. I did this a number of times, said that it is not Community Services, it is education, and it needs to be dealt with differently. (Jon, teacher, Case B)

Interestingly, Jon believed that the focus on industry currency was not necessarily a regulatory requirement directed by ASQA, but rather an organisationally driven initiative that was having a detrimental effect on the development of teaching skills.

As an Institute, it seems to me that they are now stuck on industry currency. And industry currency is not improving teaching performance, because if you want better teachers you have to focus on their teaching skills. Industry currency can improve their knowledge, but not their teaching skills. (Jon, Case B teacher)

Industry skills and currency on their own do not necessarily equate to advanced VET teaching practice. According to a number of Case B managers and teachers, VET teachers with advanced skills combine sound industry knowledge and experience with effective teaching strategies.

I think that a good teacher is somebody who is able to apply their years of experience to the lessons that they teach, to teach students to be able to think and to become critical thinkers. (Alexandra, Case B manager)

Manager Diane felt that VET teachers with advanced skills were confident and experienced in their industry sector as well as in the VET sector, and Susan (Case B manager) believed that teachers with advanced skills used them to incorporate their industry knowledge cleverly and effectively into their teaching.

So those teachers [with advanced skills] have developed the sorts of skills to use industry knowledge in a smart way. So not just putting up text, but using snippets of their industry information and presenting 
it to the students in a way that can be absorbed and used to develop their learning in a particular subject. (Susan, manager, Case B)

Teacher Loretta felt that even the beginning VET teacher may commence with advanced content (industry) knowledge, but needed to learn the skills to teach it to others.

I guess the novice VET practitioner comes in with this content knowledge and just needs to learn all the other skills to be able to pass that on in the right way. (Loretta, teacher, Case B)

Loretta went on to explain that it took time to transition from industry expert to teacher, and that the need to make this transition is not always recognised by beginning teachers.

When you first start you don't realise that there is a difference between being the industry expert and the teacher, so I don't really know when that [transition] happened. (Loretta, teacher, Case B)

Not all VET teachers succeed in the transition from industry expert to VET teacher, according to manager Alexandra.

We employ a lot of nurses who are very current, who are facilitators within the hospital, teaching on the floor, who cannot transition to being teachers in a VET sector. They don't get the regulations, the red tape, and the package stuff. Even if they have the TAE they don't get it. And there are not a lot who do a successful transition from being a Registered Nurse doing these educational sessions in the health care sector to being in a classroom under the VET sector. (Alexandra, manager, Case B)

Regardless of the varying views, the topic of industry experience and maintaining industry currency remains important at Case B, particularly since it may also influence the outcome of recruitment and selection processes. Loretta for example, recounted her experience as part of a recent recruitment process in which candidates with extensive VET experience were overlooked in favour of those with industry currency.

We have just gone through an interview process - we are interviewing for three new team members at the moment. I was really glad to be involved because I will be working side by side with these people and one of the biggest things was that currency. You know, we have some great people coming through with 20 years VET experience, but I can't see where the industry currency is - you are an expert in industry, when was your last contact with industry? (Loretta, teacher, Case B)

In addition to specialised industry skills and knowledge and the ability to teach them to others, Case B participants felt that VET teachers with advanced skills demonstrated business acumen, management and leadership skills. These capabilities, and the contribution that 
teachers who demonstrate them make to the organisation will be explored in the following section.

\section{Leadership and the business of VET}

VET teachers with advanced skills are leaders in the organisation, according to Case B managers Diane, Susan, Alexandra and Linda. They have organisational and management skills, and contribute to Case B's business growth. Manager Linda described them as 'the go to people in the teams', explaining that they held the 'knowledge and expertise' required to resolve problems and answer questions from colleagues. Manager Diane felt that they were confident, and structured their work to minimise problems and ensure that the organisation and classes operated well.

So I think those with advanced skills are confident in what they are doing. I think the advanced skills brings a level of confidence. I think it also brings a level where their structure and organisational skills mean that things do go on very smoothly. (Diane, manager, Case B)

Linda went on to explain that those with advanced skills continued to develop them and to learn more about their expected contribution to the organisation.

So I guess the advanced skills person is that person who is always looking to improve their skills, who is always keen to understand their role in the organisation, always learners themselves, always learning. (Linda, manager, Case B)

Manager Susan, while acknowledging that the skills and knowledge required for teaching 'pedagogical strategies and pedagogy' - were very important, also believed that other capabilities and behaviours were expected of VET teachers with advanced skills. According to Susan, it was important that those with advanced skills contributed to the commercial and business goals of the organisation.

It is also the skills to think not necessarily as a manager, but organisational skills to look at the bigger picture and plan, and look at how we can deliver a training program that can be delivered with the most efficiencies for our clients. (Susan, manager, Case B)

Manager Diane also agreed that there was expectation for VET teachers with advanced skills to develop, sell and secure new business for the organisation.

So those advanced skills teachers, I think, are the ones that can understand what it is that we are selling, understand the customer. It's, you know, going beyond 'we've always done it this way', to, 'how 
can we do it better?' Looking at the quality and looking at business opportunities. So not just VET, it's more about how they can take their qualifications to a different market. (Diane, manager, Case B)

According to Alexandra (Case B manager), the VET sector is so highly regulated that only those who can understand the sector's legislative framework can develop to become VET teachers with advanced skills.

It is quite restrictive, the VET sector, in terms of regulations, to allow teachers to develop and become really advanced. And those people who make it to the advanced levels are the ones who have the best grasp of what the VET sector is all about. (Alexandra, manager, Case B)

Case B's managers clearly place value on leadership, management skills and business acumen as advanced skills for VET teachers. Teachers Andrea and Loretta recognise that they demonstrate these skills, and that the organisation's managers value them. Andrea, for example felt that her ability to apply management and business skills while dealing with the minutiae of daily teaching tasks engendered an element of respect from management and other teachers.

I did some formal project management training, and so that underpinning skill has really been probably one of the strengths that I bring with my educational side. So being able to use strategic, higher order thinking, plus being able to do the micro, because I am a teacher and I can understand all the tasks that we have to do and then to be able to be a bridge to the executive management and write briefing papers which is another skill again, to be able to understand the business side of how we sell that concept. So there are a couple of different skills and maybe because I ran my own small business. I understand all the different aspects. (Andrea, teacher, Case B)

Andrea also pointed out that the expectations of the VET teacher's role had evolved and changed due to the increasingly competitive nature of the VET market.

The VET practitioner now is very different. I think we need to have a business acumen about us, that we are in the business of education. (Andrea, teacher, Case B)

Teacher Loretta supported Andrea's view, explaining that she was regarded by managers as a teacher with advanced skills because she demonstrated a high level of understanding of the organisation's processes and 'how and why things work'. Both managers and teachers at Case B noted that the VET teacher's role had changed in recent years, most notably due to the influence of changing funding structures, increasing competition, and the perception of changing student needs. While leadership skills and business acumen were perceived as 
important, VET teachers with advanced skills demonstrated other personal characteristics and qualities which set them apart from other teachers.

\section{Personal attributes, relationships and the individual VET teacher}

VET teachers with advanced skills, according to Case B participants, have some unique characteristics and qualities. Some of these attributes, such as flexibility and openness to change helped VET teachers to adjust to the often changing and sometimes volatile conditions of the contemporary VET sector. Other characteristics however, are unrelated to the specific demands required by organisational or contextual factors. VET teachers with advanced skills, according to Case B participants, have a unique ability to connect and engage with students to form meaningful interpersonal relationships that are conducive to learning.

VET teachers with advanced skills needed to be flexible and open to new ideas, according to Case B managers Linda, Diane, Susan and Alexandra. As Diane explained, the VET teacher's work context was constantly changing, and an openness to change helped teachers to cope and adapt.

I think that people are always in a state of flux - there are always new things that they are asked to embrace. The ones that do the best are those that embrace them and new forwards. The ones that constantly resist, it is difficult for them. (Diane, manager, Case B)

In addition to, and somewhat linked to flexibility and openness to change, is the desire to learn new skills and knowledge. As manager Linda pointed out, 'one of the key things that the VET practitioners with advanced skills have, is that they have the desire to learn, to continue to learn', a view shared by a number of Case B teachers. Teacher Janine, for example, described herself as a 'trained learner', referring to her desire to continually develop new skills and knowledge, similarly to Andrea, a self-confessed 'lifelong learner'. Jon identified and pursued his own learning pathways, stating: 'I work on myself to improve my skills - I don't wait for TAFE to give me PD [professional development]'. This is also the case for teacher Alan, who looks for new challenges in order to gain experience, insight into different areas and to learn new skills.

I have been in education for a while, been in lots of different situations, and I enjoy developing my skills. I enjoying going into new areas and developing new skills, enhancing my ability to support learners. (Alan, teacher, Case B) 
Aside from being flexible and open to learning, VET teachers with advanced skills, according to Case B participants, have other unique qualities. Both managers and teachers felt that those with advanced skills had the ability to connect and engage closely with students. Teacher Loretta, for example, stressed, 'one of the most important things is making those connections with students'. She felt that the ability to make these connections was due to a teacher's commitment to teaching and their emotional intelligence.

Most important is that you need to be passionate and engaging with all of your student cohorts and you have to be adaptable and understand different diverse groups of students. I think that advanced skill, it comes with experience, being able to manage a classroom, having the emotional intelligence to understand what is going on in a classroom and to manage everything that is going on. (Loretta, teacher, Case B)

According to teacher Sanjita, VET teachers with advanced skills connect with and engage students by inspiring them.

Aside from understanding your content and being able to deliver resources that cater to the different age groups, learning styles, that is the big skill. It is not just a case of standing up in front of a group and recounting personal events, or just putting a PowerPoint together. You have to be able to inspire while you teach, because that is how you engage. And if you engage then you have half your problem solved I think. (Sanjita, teacher, Case B)

Similarly, teacher Alan emphasised the importance of being able to connect with students to understand their learning needs, an ability which he felt was attributable to VET teachers with advanced skills.

So I think when we are looking at my specific skills, which other people might say are advanced, they would certainly be around understanding the needs of learners and also being able to identify their core skills levels. My prime focus is on the learning and being learner centred in everything. (Alan, teacher, Case B)

Manager Diane recognised that even though attending class is optional rather than compulsory for many students at Case B, participation and attendance rates are higher for teachers who are engaging and connected to the student cohort.

Teachers who are in touch with their students and their student needs are the ones that seem to do well in my opinion. Our students don't have to attend the classes. It's interesting because you will see that there are teachers that students will never miss a class for, but there are others where they think they can do it at home. (Diane, manager, Case B) 
For a number of Case B's VET teachers with advanced skills, teaching is more than a 'job'. While teacher Loretta described the 'passion' that she felt for her industry and for teaching industry skills and knowledge to others, Alan felt that his teaching work was a 'vocation' and closely linked to his personal identity.

I would say that it is a vocation for me. And that [a teacher] is basically what I am. (Alan, teacher, Case B)

Jon had a similar view, agreeing that for him, teaching was '...kind of a calling, not just a profession' (Jon, teacher, Case B). Likewise, teacher Andrea expressed a personal sense of commitment and connection to her role of teacher.

That's another attribute, of having that higher order understanding of what impact you are making. And that is the difference between a career and a job. There are a lot of vocational teachers who have a job but I think an advanced VET teacher would probably see it as a career. (Andrea, teacher, Case B)

Andrea went on to explain that she felt an inherent desire to teach, describing herself as a 'natural teacher', and similarly, Sanjita also expressed a view that VET teachers with advanced skills had some innate characteristics which set them apart from other.

This may seem corny, but I think there has to be a natural leaning. (Sanjita, teacher, Case B)

Elise, however, had a different view, describing herself as a teaching professional, and explaining that she felt uncomfortable when others referred to teaching as a 'calling', as this description discounted the thoughtful and planned approach that she applied to her role.

I know that people talk about teaching as a 'calling' and that makes me very uncomfortable because as far as I am concerned, teaching is a profession and I am a teaching professional. And so the things that I am doing in the classroom, I'm not doing it because I want to give the kids a hug and to make them feel better. I am doing it because it puts in place what I know is best practice, what I know is going to get an outcome. And all of the strategies that I use, an external person may think, 'that class is out of control', or 'that class is crazy'. Everything that I do is thought through and everything that I do has a grounding in theory. So I can back it up. Or I can write my own theories to back it up. Everything that I do has a reason for it. (Elise, teacher, Case B)

In the second part of each interview, participants were asked about their views on how VET teachers develop these advanced skills. A number of themes were identified from their responses which will be addressed in the following section. 


\section{Developing advanced skills at Case B}

Similarly to most large organisations, and in line with other TAFE Queensland regions, Case B has a strategy in place to formally manage the professional development of its teachers. At the time of data collection the region was piloting the TAFE Queensland Educator Capability Framework as a tool to determine developmental needs for individual teachers and to identify those with the skills to mentor others. The tool, according to teacher Andrea, was intended to assist the organisation in meeting strategic goals by identifying capability needs and gaps in teams and the organisation as a whole, rather than to plan the development of skills for a specific teacher. Achieving the organisation's strategic goals are a key focus of its plan for teacher capability development, a focus which flows through to the annual professional development conversation held between teachers and their managers.

We have an annual professional development plan with our manager and we have to identify professional development activities that we plan to do. Some of those are driven by the institute, so there will be a list of things that we have to do, like keeping our skills up in various areas and systems, like the Learning Management System, so keeping abreast of all those different changes when new things are introduced. (Janine, teacher, Case B)

Case B implements a number of organisation-wide skills development strategies for its VET teachers. These include mentoring programs, internal workshops, and the opportunity to undertake formal study leading to higher level qualifications. While teachers attributed a range of different activities to the development of advanced skills, both managers and teachers agreed on the value of mentoring, particularly for beginning teachers.

\section{Mentoring and learning from others}

Case $B$ has recently introduced a formal induction and mentoring program, accompanied by another initiative referred to as the Educator Capability Team. The Educator Capability Team is comprised primarily of VET teachers, each with different capabilities and skills, and their purpose is to provide support and mentoring to other teachers. This team is a key component of Case B's organisational skills development and mentoring strategy. The skills of those recruited to the Educator Capability Team, while mostly related to the requirements of the VET teacher's job role, were not necessarily aligned to advanced teaching skills. Rather, they are skills that are required in order for the organisation to meet its strategic goals and operational needs. For example, one Educator Capability Team member has advanced skills 
in using technology. Her role in the team is to assist other VET teachers to develop these skills, thus contributing to the success of the organisation's Master Product project with its emphasis on online delivery. The team also includes a teacher with considerable experience in conducting RPL assessments, and who has a responsibility to improve the validity of assessment in the organisation, and another who coordinates the induction program for beginning teachers. One of the team's members is not a teacher at all, but is tasked to consult with Case B's VET teachers to develop the policies and procedures required to meet TAFE Queensland's new governance structure.

At the time of data collection, building the capability of teams rather than individuals was a priority for Case B managers, and mentoring was a key component of this strategy. The organisation had recently introduced an induction program in which new teachers were assigned a mentor for six months. The mentors assigned to beginning teachers were trained to ensure that they had the skills and knowledge required to become successful mentors. Manager Diane spoke favourably about the initiative.

I think that one of the things that we do here now that we didn't do before, that I think is very helpful is that we try and give a mentor to new staff and I think mentors that role model the way, obviously give that impression to new teachers about seeing a teacher who is progressive, who has advanced skills, how well they do in their classroom and outside their classroom. It's a good way for new teachers to see that that is a positive way to go. (Diane, manager, Case B)

While Case B's mentoring strategy is a relatively new one, teachers Alan and Janine recognised its value, citing the role that mentoring played in their own skills development, albeit through informal mentoring relationships within their work teams. From Alan's perspective, having a mentor, somebody to seek advice from or to answer a question was 'invaluable'.

When I started here, having a mentor - and that was informal - but I had someone I could go to and that was invaluable. (Alan, teacher, Case B)

Janine described her mentoring experience as an internship, an invaluable experience which allowed her to learn from a variety of teachers in the classroom.

I had a bit of an old fashioned internship I guess, in that I was already working in the department and I had lots of mentors and people to see, being in the classroom with various different teaching styles. (Janine, teacher, Case B) 
Case B provides workshops to its VET teachers on topics relating to teaching and compliance. Manager Linda explained that professional development at Case B was based upon a 'champion' model with the purpose of increasing the sharing of knowledge and skills and enabling the development of advanced skills. Champions are appointed based upon their advanced skills and knowledge in a particular area, which they are then required to teach to other VET teachers in the organisation.

So we are trying to build this champion model to try and ensure that we are getting the best bang for our buck in that professional development team; so that they train the trainers in the team, and those trainers continue to pass on information. So we do have PD programs e.g. LLN and inclusivity. But we are trying to build those advanced skills people, making sure that they do exist, that they do have access to the professional development and that they do pass on their expertise to their team members. (Linda, manager, Case B)

A key feature of Case B's 'in-house' professional development activities, according to Linda, is that they can be customised to meet the team's specific needs and provided in their specific 'context'.

It is much easier if they get the training in their own context so that they can apply it immediately. And often times, there is also an RPL [Recognition of Prior Learning] process to the development activity isn't there - what is it that these people already know? What is it that we can capitalise on and how can we ensure that our training builds on that knowledge that they already have. So it is about recognition, I guess, of where they are. (Linda, manager, Case B)

Some Case B teachers spoke highly of the professional development offerings provided to them. Loretta, for example, felt that both Case B and TAFE Queensland in general were 'brilliant' at providing professional development. Courses and workshops offered by Case B itself were provided at no cost to participants, and according to Loretta, the organisation also funded external development options.

They offer a lot of courses free of charge, my university was free of charge. They paid for my entire degree. They paid to put me through - well the Diploma was run by our Educator Support team so of course I didn't pay for that. At the moment with the end of the financial year, probably the last 3 months they have put a hold on any professional development that has extensive cost only because we are watching our budget. But you will find that as soon as July kicks in, it will start again, there will be a new budget and you will be able to do what you want. (Loretta, teacher, Case B)

Other teachers, however, were critical of the organisation's professional development strategy, finding the training activities more appropriate for novice teachers than those with 
more experience. Jon, for example, felt that the professional development activities provided by the organisation assumed that all teachers are novices, and that existing skills and knowledge, or prior development activities are not recognised.

It seems to me that they are using the lowest common denominator for that [professional development]. For instance, at the moment, the latest buzzword is validation and everything is around validation. And we have another training for validation. I have already attended two full day workshops on validation, and yet I have to attend another one. If you do one in April, what more can you learn in June? (Jon, teacher, Case B)

Teachers Andrea, Elise and Jon spoke of the networking opportunities afforded by being part of the larger TAFE Queensland organisation, with connections to educators across the state. Jon and Andrea discussed Professional Learning Communities (PLCs), educator network groups formed by TAFE Queensland as a means of connecting teachers, with an agenda to influence the development and implementation of consistent learning and assessment resources of high quality across the regions. Case B's VET teachers and managers are extensively involved in the PLCs due to their responsibilities associated with the Master Product Project. A number of different PLCs were formed, each aligned to a particular industry training area. While teachers Andrea and Jon both felt that there was some value in the PLCS, as they facilitated communication between TAFE Queensland VET teachers from different regions, they also pointed out some disadvantages. Jon explained that the PLCS were intended to be a Community of Practice (CoP), and had operated as CoPs in the past when teachers formed them voluntarily to share ideas and knowledge. Of late however, the PLCs became more regulated, with attendance becoming compulsory and outcomes of the group mandated according to organisational goals.

The PLCs were like that [a community of practice], but if people are not volunteering for it, and if asked to do something for PLC they are not interested, it indicates that the PLCS are not really working. PLC are not a community of practice because they are task orientated, bureaucratically structured. They are not what a community of practice should be. (Jon, teacher, Case B)

Jon went on to explain that a voluntary community of practice had developed within Case B a number of years ago, but was 'shut down due to a political/personal decision' (Jon, teacher, Case B). He was critical of the impact that bureaucracy was having on innovation in the organisation and the consequences that may be felt by those who implemented new ideas. 
If you are starting to jump out and be very innovative, it may come with consequences, and it probably will. It is a typical bureaucratic organisation. And I think that is what is happening here. Some people come up with awesome ideas, and they are shut down. And that is not really good. (Jon, teacher, Case B)

Some of Case B's VET teachers with advanced skills seek inspiration and information sharing networks outside of the organisation. Teacher Andrea for example, felt that while the opportunity to network with others is an important advantage for TAFE Queensland VET teachers, those with advanced skills also needed to develop external networks to meet their professional learning needs. According to Andrea, some VET teachers with advanced skills relied upon these networks to 'validate' their own practice, particularly those who felt isolated as 'early adopters' and innovators within teaching teams.

The little circle they are in, the team, often the early adopters are seen as something different, and they are not getting the nourishment from the team. And I say 'you need to get outside and get nourishment from outside' and so their satisfaction and their professional development and their validation from peers will come from outside the network. (Andrea, teacher, Case B)

Andrea has established what she refers to as 'Personal Learning Networks' with contacts 'literally across the world'. She communicates with those in her networks face to face and through a variety of virtual networking platforms, and uses the networks not only to fulfil her own developmental needs, but also to influence the development of best practice in the organisation and VET sector.

So I have an extensive PLN - Personal Learning Network - that I draw on. And I'm in Linkedln groups, twitter spaces, yammer spaces, I'm in all sorts of different spaces. And I still do that today to get a bit of quick learning, so I get a lot of just-in-time learning and I am forever scanning that sort of thing to improve my own development and to see where I can transfer that knowledge into helping the VET sector. (Andrea, teacher, Case B)

Similarly to Andrea, teacher Elise also participates in external networks through online social media platforms. She uses the networks to communicate with others, to increase her knowledge and skills in her vocational teaching area and to validate her current practices, particularly those that others may consider innovative or unconventional.

I am really heavily involved in the [Industry sector] Facebook page which does sound like a really silly thing to do, but it is so valuable. I am part of lots of teacher groups online. Online is a big thing for me because it means that I can be communicating with people not just in Australia, I have lots of people that I talk to in the UK and the US and Sweden so I can see what is happening around the world. And I 
can go 'oh wow, look at that', or 'hey, that is best practice and I am already doing that'. (Elise, teacher, Case B).

In addition to the participating in professional networks and communities, Case B teachers attend conferences to develop their knowledge and skills. Some attend conferences which are VET specific, with a focus on the development of teaching practice and increasing knowledge of regulatory frameworks and quality requirements, such as the annual Vocational Education and Learning Group (VELG) conference. Other conferences may focus on new technology or the way in which it may be used in an educational setting, such as EduTECH, an annual Australian two day exhibition and conference. Teacher Andrea felt that participation in external conferences was essential for the continued skills development of teachers with advanced skills, describing them as energising, and as an opportunity to be inspired, and to gain new ideas for practice. Regardless of whether the networks that Case B teachers participated in were internal or external to the organisation, they facilitated sharing of knowledge with others, a strategy which all teachers recognised as critical to the development skills. Loretta explained that even those with advanced skills could learn from others.

Even experts can still observe other experts to develop skills. I get a lot out of sharing with other teachers, the opportunity to sit with other teachers and share their experience and have that discussion is a really great tool to improve. (Loretta, teacher, Case B)

It is clear that learning from others has played an important part in the development of Case B teachers' advanced skills. The networks, communities and conferences that they participate in, while often structured in their organisation, are not necessarily linked to a formal qualification or accreditation. Formal study was also a significant developmental activity for Case B's teachers, as all of those interviewed had achieved qualifications higher than the mandatory certificate IV in Training and Assessment.

\section{Formal Qualifications}

Case $B$ teachers and managers agreed on the value of higher level teaching qualifications, and this is borne out in the historical and current financial support that the organisation has provided to teachers undertaking formal education studies. Most expressed the opinion that the Certificate IV in Training and Assessment, while valuable as an entry qualification, was not sufficient for the development of advanced VET teaching skills. Manager Linda for example, 
felt that a higher level educational qualification was 'critically important' for the development of advanced skills.

I think that the Certificate IV gives you a certain amount of information about what constitutes learning and how teachers can support that, but I think that it's very much entry level. As they work their way through Diplomas and Bachelors they gain a much higher understanding of how they can scaffold learning; how they can facilitate learning; for every learner. And they gain a greater understanding of different learning styles. (Linda, Case B manager)

Manager Alexandra felt that a higher level qualification was necessary to develop the knowledge and skills required for effective classroom and behaviour management as the 'TAE doesn't really focus on this'. Some felt that the Certificate IV in TAE was not sufficient even as an entry level qualification. Case B teacher Loretta, for example, explained that the Certificate IV in TAA she completed (the predecessor course to the Certificate IV in TAE) was not adequate preparation for teaching, conceding however, that this may have more to do with the quality of the program's delivery than the content of the qualification.

I did it at a private college that doesn't exist anymore. It was a two week course, a few hours at night, it didn't even touch the sides of what I was about to walk into. I know that now and I am hoping now that the Cert IV in TAE is a better course for educators but once again I think it differs with RTOs as well. So in hindsight, I think I could have done a better one which would have prepared me better. (Loretta, Case B Teacher)

Manager Linda shared the view that the preparation afforded by the Certificate IV in TAE varied according to the quality of its delivery, stating that '...we do notice the difference perhaps, between those that do a short sharp TAE as opposed to a quality delivery of TAE' (Linda, manager, Case B).

When discussing higher level qualifications, most Case B participants - both teachers and managers - referred to tertiary qualifications such as a Bachelor of Education or higher level postgraduate qualifications. Teacher Andrea however, felt that while she had developed significant knowledge and skills from a VET focused Bachelor Education qualification, the Diploma of Vocational Education and Training was 'the real crunch qualification' for her. Even though Andrea's Bachelor qualification and the Diploma of Vocational Education and Training addressed similar topics, the Diploma was, she explained, more 'relevant and applied' in the way that it was delivered and assessed. While teachers still enrolled in and studied relevant 
Bachelor of Education qualifications, according to Andrea, 'a lot of them were just doing it to get over the pay scale', and 'not actually implementing any of that knowledge'. Teacher Loretta had a similar view to Andrea, citing the Diploma of Training and Assessment as the most valuable professional development activity that she had completed.

I think that out of all of the professional development that I have done, the Diploma of Training and Assessment was probably the most valuable - not putting a downer on University, because University was great too, but it gave me a theoretical basis for stuff. But I found that the things we did in the Diploma was so practical and hands-on, and broke down the things that we do every day. I did it over a year - it was much more intensive than the Cert IV that I did, and some of the skills that I learned in that, I still use every day. I think that was a big stepping stone for me, you know, that 'aha moment' where I started to put things together. (Loretta, Case B teacher)

That is not to say however, that Case B teachers and managers discounted the value of completing a Bachelor qualification. Most in fact, felt that it was necessary for a teacher to complete a relevant tertiary level educational qualification in order to develop advanced skills. Linda (Case B manager) deemed it 'critical' to the development of essential pedagogical skills, and Loretta felt that it helped her to develop the theoretical basis for her practice. Even Andrea felt that the Bachelor facilitated her development of the 'foundation skills' necessary to be an effective teacher. She cautioned however, that the qualification had to be 'absolutely contextualised for vocational delivery'. At the time of data collection, and like others in the TAFE Queensland network, Case B VET teachers who do not have a tertiary level education qualification were being provided the opportunity to undertake a Bachelor of Education free of charge through an arrangement with an Australian University.

\section{Experience and time}

All participants felt that experience was needed for a VET teacher to develop advanced skills. According to manager Alexandra, however, this does not necessarily mean that those with more years of experience would have more advanced skills than others.

I have to say that advanced VET teacher does not necessarily mean the years that they have worked in the sector. It is a misconception that people who have worked in the sector for years are the more advanced practitioners, but they are not. They are definitely not. (Alexandra, manager, Case B)

While Case B teachers and managers agreed that time and experience were important factors in the development of advanced skills, they were unable to agree on how much of each was actually required for this development to occur. There was a notable 
variance in the years of experience held by the Case B teacher participants. While most had between 15 and 20 years teaching experience, and teacher Janine was adamant that a 'minimum of five years' working in the VET sector was necessary to develop advanced skills, teacher Elise was a relative newcomer, with only four years of teaching experience. Alan and Jon had acquired experience teaching in other education sectors which they believed contributed to their expertise as VET teachers and standing as VET teachers with advanced skills. Alan for example, was a teacher in the K-12 sector in the United Kingdom for 10 years prior to migrating to Australia's VET sector.

So I would say that in my previous role my skills developed over about a 10 year period of being able to understand the needs of learners and to deal with those different situations, the diverse nature of learners and the different situations I would find myself in teaching. (Alan, teacher, Case B)

Similarly, Jon described himself as an 'excellent teacher' with years of experience in a variety of settings, both in Australia and the United States. Jon believes that advanced teaching skills are transferable between sectors and contexts.

I have years of experience, primary school, elementary school with special education, mainstream, special education in secondary and then university teaching. Simply, I just teach well. (Jon, teacher, Case B)

While it takes time to develop the experience needed to develop advanced skills, many felt that it was also necessary to have the opportunity to be exposed to different types of experiences and challenges. According to Case B teacher Loretta for example, to develop advanced skills and the emotional intelligence needed to manage 'everything going on in a classroom' required experience teaching 'many, many different groups [of students]', or at least the opportunity to observe others doing so. Teacher Janine supported this view, but also felt that her skills development had been enhanced further by having the opportunity to work in leadership roles for periods of time throughout her career.

I have been able to go into educational manager roles and those sorts of things have given me a taste of managerial skills, leadership skills and working with people and dealing with people and staff issues. I ultimately have ended up going back to teaching, but those things have been useful in terms of building experience and understanding how the business works from another perspective. (Janine, teacher, Case B) 
According to manager Linda and teachers Andrea and Elise, reward and recognition of teachers with advanced skills encourages and supports their development. Case B uses a range of strategies to recognise and reward staff. Some are relatively informal, such as sending a virtual 'star' or awarding a free carpark for a month. Other strategies are more formal, such as nominating outstanding teachers for TAFE Queensland Training Awards, the Queensland Training Awards and the national AUSTAFE training awards. Linda felt that people needed 'to be recognised for the effort that they put in', and in particular, that those stepping up to leadership roles and assuming a mentoring position should be rewarded. Teacher Andrea explained the value of recognising early adopters who required 'validation' and recognition from their peers as encouragement to continue their innovative practices, a view supported by teacher Elise, an early adopter herself. Just as the organisation provides many opportunities to enable and support the development of advanced skills however, Case B's teachers also identified barriers which they felt, hindered professional development progress.

\section{Barriers to developing advanced skills at Case B}

There are a number of barriers which may impact upon the development of advanced skills for Case B's VET teachers. The need to develop and maintain industry skills and currency, and the potential for this to impact negatively on the development of VET teaching skills was explored earlier in this case study report. According to Case B teachers Andrea, Loretta, Janine and Jon, the development of advanced VET teaching skills in the organisation might also be hindered by the effects of peer pressure and the need to conform to team and organisational culture. In addition, they noted that budget constraints, time pressure and the lack of suitable mentors and professional development activities impacted upon their own skills development and those of their peers. The need to work according to established team norms and to fit with the organisational and team culture was also a significant barrier facing early adopters. Teacher, Andrea described a feeling of 'swimming against the tide', at least until the innovations in technology or teaching that she had integrated into her practice had been adopted more widely throughout the team or the organisation.

So there are some teaching teams who say 'we don't do that' and they say, 'no, that is not the way we do things, don't rush that'. And so it probably highlighted what they weren't doing. So that's the other thing - fitting in - that can block advanced practitioners. You know, just that team cohesion stuff, until the critical mass changes and we can say 'this is the way we do things now'. (Andrea, teacher, Case B) 
Loretta felt that budget constraints were impacting upon the development of advanced skills, as the higher wage costs and an increasingly competitive VET market resulted in greater expectations for new teachers, with less opportunity for team teaching and the sharing and mentoring associated with such a practice.

I think in the past we were better at it, we had the budget, we had much more lead time. We are trying to stay competitive - you can't put two teachers in a classroom together. The cost of teachers at TAFE is very expensive - we pay a higher cost for that reason. I think we have less lead time. We get people and say, you're starting - now go. (Loretta, teacher, Case B)

Despite the fact that Case B managers discussed the value of the beginning teacher mentoring program, Janine shared Loretta's view, disappointed that beginning teachers at Case B in the current VET economic climate don't have access to the mentors and supervision that she herself had as an early career teacher, but recognising that this was primarily due to lack of organisational resources and the fact that supervisory teachers were already under time pressure from an increasing work load. Increasing workloads are also impacting upon Jon's ability to develop his professional skills. While he managed his own developmental needs to a large extent by accessing MOOCS, reading widely and participating in various networks and communities, Jon expressed frustration with an 'unrealistic workload' and 'unrealistic expectations' which in turn reduced the time that he could commit to professional development. He was also somewhat frustrated with the content and compliance focused approach of organisational professional development offerings, expressing a need for something more 'inspiring'.

I think it would be nice to have something else, something that can help us to further improve, not just validation or compliance, but something that is about creative teaching or inspiring. (Jon, teacher, Case B)

\section{Conclusion}

According to those at Case B, there are certainly VET teachers with advanced skills in the organisation. While managers were more likely to value skills which contributed to the organisational goals however, teachers held greater regard for skills relating to teaching and outcomes for students. Teachers also described the importance of developing relationships with students, and expressed a deep sense of responsibility for their role as a VET teacher. A number of them regarded teaching as something more than simply a job or profession. Some felt that that there was an intrinsically personal aspect to being a good VET teacher which is 
related to the individual's personal attributes or character. VET teachers with advanced skills were more likely to take responsibility for their own professional development, and many felt that organisational professional development was not necessarily suited to those with advanced skills, explaining that more experienced teachers required different developmental activities to beginning teachers. While there were some varied views between managers and teachers on the nature of advanced skills, their value to the organisation was well established.

Just that we [need to] understand how critical the educators are to what we do. They are where the rubber hits the road. And if our organisation is interested in putting the students first, then we need to ensure that the educators have all the understandings, tools and support that they need to do a good job. So, I think we have a good understanding here that we need to invest in our teachers, invest in our educators, and give them the support that they need. Because it is a demanding role, and a changing role. (Linda, manager, Case B) 


\section{CHAPTER 6 CASE C}

\section{Case background}

Case C is Queensland's only dual sector University. The organisation was founded in 1967 as an Institute of Technology and achieved status as a university in 1992. Upon merging with a TAFE Queensland Institute in 2014, Case C became a dual sector university, and the VET teachers formally employed by the TAFE Institute became employees of Case C. The organisation commenced its status as a Registered Training Organisation, providing Vocational education programs alongside its existing Tertiary Education courses. Case $\mathrm{C}$ has a large national footprint, with more than 30000 students enrolled in 24 study locations in five Australian states: Queensland; New South Wales; Victoria; South Australia; and Western Australia.

Case C offers more than 300 courses to Australian and International students. Programs include short courses and vocational certificates and diplomas, as well as undergraduate, postgraduate and research degrees. Study areas include: Trades; Business; Creative, Performing and Visual Arts; Education; Humanities; Engineering and Built Environment; Health; Information Technology and Digital Media; Psychology; Social Work and Community Services; Science and Environment; and Work and Study Preparation. Case $\mathrm{C}$ has been recognised as a pioneer of distance education, and continues to provide most of its programs in distance mode, or through a combination of distance study and regular intensive on campus workshops. Flexible study options are a particularly important component of Case C's educational model, given that almost half of its students undertake their programs via distance study mode, and many live in rural and remote areas.

\section{Data collection, participants and the case study context}

Data to prepare the case study was collected through interviews with twelve participants; three managers and nine teachers with advanced skills. The managers invited to participate (Sonya, Brian and Paul) were each responsible for direct supervision of VET teachers at Case $\mathrm{C}$ and approval of the professional development activities they participated in. All managers had more than ten years of experience working in educational management roles, but had varying experience in VET. While Paul had more than twenty years total experience in teaching and management roles in the VET sector, Brian and Sonya's experience was limited 
to management roles - Brian more than ten years, Sonya less than three. The nine teachers invited to participate were those identified by managers or peers as teachers with advanced skills. They taught in various disciplines, including nursing, fitness, Occupational Health and Safety, beauty, education, employment preparation and LLN (language, literacy and numeracy). Some had particularly lengthy careers in the VET sector. Andy, Ed and Britt had been VET teachers for more than 30 years, and Jocelyn, for more than 20 . Deborah, Candy, Tagen, Rachelle and Kassandra each had between nine and fifteen years VET teaching experience. Except for Jocelyn and Candy, all had gained experience teaching in other sectors and contexts prior to their appointment as a VET teacher. Ed, Tagen, Rachelle, Andy and Leanne were previously secondary school teachers, Deborah an early childhood educator, and Kassandra, an industry trainer. Semi-structured interviews were conducted with each participant. Managers and teachers were asked to reflect upon and discuss their views on advanced skills for VET teachers and how they are developed, however the questions asked of each group varied. Interview schedules for VET managers and VET teachers have been provided in Appendices B and C respectively.

Both managers and teachers agreed that there were VET teachers with advanced skills in the organisation, however some felt that the skills required of VET teachers were changing over time. According to manager Paul, 'the world has sped $u p^{5 \prime}$ and technology has been a major 'disruptor' for most industry sectors, including VET, as people change the way that they access information, knowledge and skills. VET teachers have been required to develop different skills and models of teaching to meet the new demands arising from these trends.

People access and want to access their information in different ways these days to when I was at school. So if you are still standing in front of a group delivering training in the same way you did 20, 30 years ago, wake up, because the world is moving on from that model and, sooner or later, you're going to find yourself standing there alone. Whether it's because people don't have time to come to study full time anymore or whether it's because people can actually go, I don't know how to do that. I'll just google it or YouTube it or whatever. But we have to change the way in which we operate according to that paradigm. (Paul, manager, Case $\mathrm{C}$ )

\footnotetext{
${ }^{5}$ In-text quotes from participants have been italicised for emphasis and to differentiate them from citations of published works
} 
Paul also discussed the influence of VET's changing economic environment, one characterised by increasing competition for students who have more choices available than ever before. To maintain Case C's market share in this environment, he believed that the organisation's VET teachers should ideally see marketing functions as part of their role.

I think the role of the VET practitioner is also changing over time, particularly the leading practitioner. It used to be very much [the case that] we had a monopoly in TAFE and really didn't have to do a hell of a lot. The requirement for us to compete for students is obviously dramatically more pointed. We see the effects of competition on us now. The requirement is for a teacher to be selling the organisation. (Paul, manager, Case C)

Case $\mathrm{C}$ teacher Andy shared Paul's views, outlining his experience and the changes that have occurred in his VET teaching job role, which has evolved over a 40 year career. He explained though, that VET teachers were experiencing increasing levels of responsibility to complete a range of tasks not necessarily related to teaching. In particular, Andy felt that an increase in the sector's compliance and regulatory requirements has led to an increase in administrative tasks for VET teachers. These tasks were primarily related to meeting VET regulatory requirements and included such tasks as keeping records of student attendance and providing evidence of assessment validity and judgement. According to Andy, the emphasis on compliance and the resultant increase in VET teachers' administrative load has in turn, decreased the proportion of time that teachers could allocate to improving their teaching resources and practices. It has also (according to Andy) had an influence on the types of skills that teachers are recognised and rewarded for by managers.

When I first came to TAFE I did probably $10 \%$ [administrative tasks] way back in the ' 80 s, $10 \%$ admin and $90 \%$ teaching, and by the time it was early 2000 s it was $40 \%$ admin and $60 \%$ teaching. I think now it's 65 to $70 \%$ admin. I think that that the biggest decline we've seen in the standards of the education we provide in this area, is the fact that we no longer look at how good a teacher is, or what a teacher does, or the learning experiences; it's all about did you have your participation on the system? Have you got this ticked? (Andy, teacher, Case C)

Manager Sonya expressed a great sense of empathy for VET teachers and the effect that increasing administrative tasks, compliance requirements and additional responsibilities had on workloads. She felt that there were too many expectations placed on VET teachers.

I think it's too hard for teachers. I agree with them when they say that their work is [too hard], they're in front of a class three days a week and then they've got all the marking, they're delivering 25 units, 
and then they've got to deal with issues and then they've got to go to meetings. I don't think it's possible in a 36 hour week. (Sonya, manager, Case C)

Teacher Britt corroborated Sonya's statement, explaining that for some VET teachers, the administrative load became too large to manage.

And I think that unfortunately the biggest drawcard to teaching in VET is actually not the teaching, it's the paperwork that goes with the teaching. Everything you're required to do on top of, or because of, or for, you know, your purpose and being in the class room, it's just overpowering for some people. You know, it's just too all-consuming. (Britt, teacher, Case C)

At the time of data collection, Case $\mathrm{C}$ was undergoing a registration renewal audit by the national VET regulator ASQA (Australian Skills Quality Authority). Registered Training Organisations are registered for a period of up to seven years, and must apply for renewal of registration prior to the registration's expiration date. The renewal of registration process includes a comprehensive audit to ensure the RTO's continuing compliance against the Standards for Registered Training Organisations (RTOs) 2015. The audit was clearly a key focus for those involved in VET at Case $C$, and one which was mentioned by all participants throughout the interviews. Standard 1 of the Standards for Registered Training Organisations (RTOs) 2015 describes the RTO's responsibilities in relation to training and assessment practices. The intent of this standard is to ensure the 'integrity, currency and value' of qualifications awarded by RTOs, including the assurance that all curriculum (i.e. Training Package) requirements are met. Many of the increasingly onerous processes and administrative tasks described by Case C's teachers and managers relate to substantiating compliance with this standard and its relevant clauses. These processes include (for example): validating and mapping assessment processes and documents to ensure that all training package components are addressed; planning and recording training and assessment strategies to outline how the qualification and unit requirements will be met by the program of study; recording learner participation and assessment outcomes; and moderating assessment judgements to ensure consistency. Teacher Andy felt that a focus on positive audit outcomes led to an increased focus on excellence in assessment mapping and processes rather than on the quality of teaching and learning.

So if we get audited the auditing is aligned to what assessment have you done and where's your assessments, and it's all part of the process, there's no doubt, but I think we've gone away from the 
appreciation of what good teaching does, and we've become so narrow in the fact that we've got to address all these performance criteria, knowledge, evidence and so on. (Andy, teacher, Case C)

Despite these concerns, Andy was surprised and heartened by his most recent experience during the re-registration audit which seemed to place a greater emphasis on the teacher driven results relating to student outcomes and experiences.

The auditor did a great job because it actually was a little bit refreshing that she mainly audited me on our learning resources, how we put the course together, who teaches what, why they teach this. It was all about the student experience and all about the teaching side. (Andy, teacher, Case C)

The audit was also a relatively positive process for teacher Candy and her team. In contrast to Andy's observations however, the experience wasn't positive due to a focus on teaching and learning or student experience and outcomes; rather it was due to the team being 'up to date' and adept with compliance related processes.

The team went absolutely excellent with all the processes. Because we're up to date with all our processes and everything like that it wasn't as arduous as what could have been. (Candy, teacher, Case C)

For some of Case C's VET teachers, an increasing workload associated with compliance and in particular recording evidence of compliance against the standards, may in fact be preventing them from improving teaching practices and resources. Manager Sonya related the story of a VET teacher who, experiencing frustration at not having the time to make changes to learning resources, likened his situation to a 'woodcutter who never has time to sharpen his $a x e^{\prime}$. Meeting the requirements of the Standards is a requirement for RTO registration however, and while manager Sonya empathised with VET teachers' concerns, Andy believed that managers were more likely to value and reward skills associated with compliance than good teaching practice.

When it comes down to the nitty gritty of what you do in the VET sector you've got to get all the admin done, and if you're a good teacher as well that's a bonus. So really, you can survive in the system by being a really poor teacher but good at doing paperwork, and you will get ticks from your manager all the time. (Andy, Case $\mathrm{C}$ teacher)

\section{The constancy of change}

According to teacher Deborah, the work of VET teachers is changing, not only due to the escalating regulatory requirements and increasing competition, but also because of student 
demands for flexibility in the way that they access education. At Case $\mathrm{C}$, an organisation with a long standing reputation as a distance education provider, these changing student demands and the merger between the TAFE Institute and Case $C$ has meant a shift for many of its VET teachers, from a primarily face to face style of teaching practice to one which incorporates online and distance delivery modes combined with individual and group tutorials. Many of Case C's VET teachers have had to learn new skills in order to use the technological platforms and tools that support its online and distance delivery modes.

Our students are changing, as well. Not just the ASQA standards and all that other audit side of things. We're now teaching online, so I've even had to retrain myself and source different PDs and read articles about doing online Moodle and how to engage your learners in e-learning. It's easy in a classroom setting, but when you change that context of teaching you've got to upskill, so it's constant. (Deborah, teacher, Case C)

Case C's VET teachers are not alone in their experience. The changes and pressures they described are largely due to the influence of changes within the macro economic and regulatory environment for VET, changes which will affect all VET teachers to varying degrees, regardless of the organisation in which they practice. In addition to these changes and challenges however, Case C's VET teachers have also had to navigate their way through the merger between the TAFE and the university, a situation which has created additional changes and uncertainty to the context in which they practice as VET teachers. The merger required VET teachers to adapt to a significantly different and unfamiliar work context. Previously employed by Queensland's public VET provider with a responsibility to provide vocational education within a relatively constrained geographical boundary, they found themselves, post-merger, working within a regional university with multiple, geographically dispersed campuses and with business processes and systems developed to support higher education, many of which did not align well to VET. Since Case $C$ acquired existing TAFE buildings as part of the merger, many teachers continued to work in the same location, but for a different organisation. As the university combined its VET operations within its existing higher education structure, teachers found themselves working with new HE colleagues and being supervised by HE managers, most of whom had limited understanding and little or no experience of vocational education and training. Tagen (Case $\mathrm{C}$ teacher) explained that Case C'...had different programs, different processes, and understanding from a higher educational 
sector; that's a learning for everybody, both sides'. She went on to describe the considerable efforts that were required to merge the two systems.

We're a square peg that they're trying to put in a round hole and they're trying to cut the corners off. So we're trying to work out what works best for everyone, what works for them, what works for us, what works for the student, and what works for industry. (Tagen, teacher, Case C)

Manager Sonya empathised with the challenges Tagen described, acknowledging that the transition was extremely hard for VET teachers as they became accustomed to the existing organisational structure, culture and processes.

It's hard for the VET teachers at the moment. They're in someone else's playground. I think at the moment they've lost their home and they're in someone else's playground and it's not really their equipment...it's a tough time for them. I do feel for them. (Sonya, manager, Case C)

\section{Advanced skills at Case $C$}

Despite the emergent issues around administrative workloads and the changing nature of the VET teacher's role in Case C, all participants (managers and teachers) readily agreed that there were VET teachers with advanced skills in the organisation. According to manager Brian, however, they represented no more than 50 percent of Case C's VET teaching workforce, and while there was consensus on the existence of teachers with advanced skills in Case $C$, there were some varying views on the nature of these skills. There were also varying opinions on whether a VET teacher needed to demonstrate excellence in all aspects of the role to be considered advanced, or alternatively, whether he/she need only be advanced in some. Manager Sonya described VET teachers with advanced skills as 'all-encompassing' employees who also possessed the values, personality and attitudes which made them a 'good fit' for the organisation and the job.

Compliance and regulations are very important to me. They [VET teachers with advanced skills] are confident and they have like a deep knowledge of their particular industry that they're working in. So if they're a nurse, they have that broad knowledge across there, across that skill. And then for me, what I think makes a great VET teacher is really, aside from those things which are fundamental, it is really - I'm very much about a person job fit and organisational job fit, so it is about attitudes, and personality, that I think fits someone to make a great employee. They can have all that knowledge and all that experience, but they're not a great employee unless, and I don't want to sound crazy, but I am very much about the values of the organisation as well. So they do have to be a can-do and they have to be a flexible person and they have to be an open communicator. That's what I see as a great teaching 
staff member, practitioner, is someone who has strong communication skills, has that foundation knowledge and is flexible and open for VET. (Sonya, manager, Case C).

Manager Paul shared Sonya's view, explaining that in his opinion, advanced skills were not necessarily associated with teaching. According to Paul, VET teachers were expected to hold effective teaching skills as a requirement of the role, and those with advanced skills possessed a depth of knowledge about the VET sector, including relevant State and Federal policy, which they had developed over a period of time. This knowledge, he felt, ensured that the RTO could operate effectively in the contemporary political and economic environment. Paul conceded that his view is likely to have been influenced by his role as a manager, but also believed these views to be shared by others in the organisation.

I'm thinking about my current role and engaging with them directly around, 'okay, we need this report done' or 'we need this information' or 'how's it going with finance', etcetera. It's not necessarily about what's going on in the classroom. I think it's an important distinction to make, because that's just because of my terms of reference in the sense of my job. But I think in TAFE, generally, we underestimate and we undervalue and we under support the kind of teaching side. There's almost an expectation that: 'Oh, you've got your TAE, you've been working as a mechanic or a business person for 20 years. You know your stuff. Off you go. There's the classroom'. (Paul, manager, Case C)

Some felt that teachers with advanced skills were expert in some areas, but not all. Teachers Jocelyn and Tagen for example, believed this to be the case, and in fact felt that it was important to have, as Tagen described it, a 'mix of people' with differing advanced skills in a team. Jocelyn pointed out that she is regarded as a teacher with advanced skills even though she is 'not advanced in technology' and preferred instead to delegate technologicallyoriented tasks to others in the team who hold the required skills.

I think you have to find your niche. You can't be an expert in everything. So, while there's stuff I know

- I know a lot about some things - I also acknowledge that I'm not a guru of everything. And I am really comfortable deferring to those who are, or who have skills that I don't have. (Jocelyn, Case C teacher)

Regardless of whether Case C participants believed that teachers with advanced skills were experts in all areas or only in some, they were able to identify a number of skills, behaviours and personal attributes associated with this level of VET teaching. VET teachers with advanced skills at Case C, according to participants, have excellent interpersonal and communication skills which enable them to engage with and provide leadership to students, colleagues and industry. They are expected to be experts in their industry field, although this 
is also considered to be a foundational requirement of the job. Further, VET teachers with advanced skills understand the context and broader environment in which their work was situated, and they effectively managed their time and the requirements of their job role including the associated administrative responsibilities. Case C's VET teachers reported that their administrative responsibilities were mostly associated with complying with regulatory requirements, however compliance was also related to the need to understand the curriculum - the Training Package - and to design assessment that ensured all of curriculum requirements were met. Case C participants felt that VET teachers with advanced skills demonstrated some personal, individual characteristics, which included the flexibility to embrace change, a passion for teaching, and a connection to the role of VET teacher which leads to a sense of fulfilment and satisfaction. These themes will be explored in further detail in the following section.

\section{Interpersonal and communication skills}

Communication is an inherent part of teaching, according to Case $\mathrm{C}$ managers Paul, Sonya and Brian and teachers Jocelyn, Kassandra, Britt, Deborah and Tagen. Case C's VET teachers are required to communicate with students using a variety of different channels depending upon the teaching mode, which may be via distance/online, face to face, or as a combination of both. Teachers may interact with students face to face in a classroom or in an individual meeting, by telephone, videoconference, or using web based platforms including email, live web messaging and online discussion forums. For teacher Jocelyn, regular communication is an important component of the programs she delivers to Certificate IV and Diploma students in distance and blended modes. Students in Jocelyn's programs access course materials electronically or in a printed format and may only need to attend the campus to participate in compulsory tutorials and/or assessment activities, if they are required to attend at all. Despite the minimal compulsory attendance requirements however, Jocelyn welcomes interactions with students, and encourages this by establishing rapport soon after enrolment.

Right from the start, within 24 or 48 hours of them enrolling, I'm on the phone having a yarn. So I do establish that communication really quickly with them. I think that's a really good thing. (Jocelyn, Case C Teacher) 
Teacher Britt also focuses on building rapport with students, however in her case, this extended more widely to also include students' families and the communities in which they live.

I think I have a very good rapport with students, I've always had that. My first couple of years were in small indigenous communities...they were only small in number and you live within the community and I always thoroughly enjoyed meeting people in the community, being part of those small communities, getting to know their families, getting to know the students. (Britt, teacher, Case C)

According to teachers Kassandra and Deborah, VET teachers with advanced skills communicate in a way that enables students to relate to the content and to understand it. For Kassandra, storytelling is the key to making learning activities relevant and interesting. She uses storytelling to interweave narratives of her experiences in industry with discussions on required theory and practice.

You put real life on it, you put it in to reality and tell them stories. Storytelling, VET students especially, I think all students love story telling. And if you've got a story to tell, tell it. (Kassandra, teacher, Case C)

Deborah applies her communication skills to relate information to students in language that is familiar to them and appropriate to the level at which they are studying.

I always get comments about how I can break things down into very easily understood terminology and I think that might be it. I teach Certificate III and Diploma, so we're not degree level. I also used to teach Certificate II to high schools. So I think when you're talking about theories and all of that really important, 'big words', as they call it, you need to bring it back to real life and easily understood terminology. (Deborah, teacher, Case C)

Teacher Tagen believes that having advanced communication and interpersonal skills enabled her to identify when students require additional assistance, and to address their needs appropriately.

Probably I can identify students that have got needs or they've got insecurities. I'll often, say, pull them along, pull them out on a quiet spot when no one's around and say, 'Hey look, l've noticed, are you having trouble with this?', but not bring it to the attention of other students. (Tagen, teacher, Case C)

While Case C managers agreed that VET teachers with advanced skills had excellent communication and interpersonal skills, their views on how these skills were best utilised differed from the views expressed by teachers. While teachers felt that those with advanced 
skills used them to connect, engage and communicate with students, managers focused on how these skills enabled VET teachers to communicate effectively within the organisation and with industry. Manager Paul, for example, explained that in his view, VET teachers with advanced skills could relate well to others in the organisation, and became the trusted 'go to' people that colleagues approached for assistance.

You know, [the VET teacher with advanced skills is one] who actually understand how to work in a complex organisation with people who have different ideas, different needs, etcetera. That doesn't just come because you're good at teaching or good at finance. That comes with, I think, a bit of selfawareness and a bit of understanding of human nature. I know there's other aspects to that. Because if you are truly, I think, a flexible person who does things well and who is responsive and kind of gets people and wants to work with people and doesn't fly off the handle, almost by degree, you'll find yourself taking on more and more because people will go to you, or that person, before going to other people. Because they kind of see that person as a good egg, a good practitioner, etc. (Paul, manager, Case C)

For manager Sonya, interpersonal skills are so important, that when recruiting for new VET teachers she actively seeks those who demonstrate such attributes, which she believes to be innate, rather than learned.

I probably think it's [the ability to communicate well with others] an innate characteristic. I don't think that can be learned. I think they're the right person or they're not the right person. I think they can learn the RTO standards and I think they can learn about the qualification they're teaching. But I don't think they can learn to be flexible and agile and a good communicator. Like I'm, if I'm talking about leadership theory I think that leaders are born, not created. So, hopefully, when I recruit people I am looking for a particular communication style and an openness in the way they interact with people. (Sonya, manager, Case C)

According to manager Brian, teachers with advanced communication and interpersonal skills use them to 'engage at three levels': with the student; with industry; and with their colleagues and managers within the organisation. Engagement with students, according to Brian, is 'critical', explaining that engagement is 'capturing the student's interest in a particular topic, aligning that to the curriculum and making sure that they understand it'. A teacher with advanced skills also understands that not all students learn the required knowledge and skills at the same pace.

Not everyone learns at the same continuum. A good teacher can take a cohort of students across that particular continuum in varying ways. (Brian, Case $\mathrm{C}$ manager) 
Brian added that VET teachers with advanced skills used them to engage effectively with industry, explaining that this level of engagement was necessary in order to evaluate whether the skills and knowledge learned by students at Case $C$ reflected the current practices and needs of the relevant industry sector. According to Brian, the requirements outlined in the curriculum and the training provided in the simulated workplace training environment at Case C, may at times be 'diametrically opposed' to current industry practices. The VET teacher with advanced skills however, uses communication and interpersonal skills to consult with industry representatives so that they can ensure that training meets the requirements of the curriculum, as well as the practices and needs of industry. The third level of engagement for VET teachers with advanced skills, according to Brian, is that which occurs with colleagues and managers within the organisation. They use communication and interpersonal skills in this context to critically review teaching and assessment practices and resources and to provide the necessary feedback to say 'I don't actually think we're hitting the mark because of this, this and this' (Brian, manager, Case C).

\section{Industry skills}

VET teachers must hold vocational skills, qualifications and experience as specified by the Standards for Registered Training Organisations 2015 and the relevant curriculum document for the qualifications that they are teaching and/or assessing. These are, as manager Sonya explained, 'foundation requirements for the job'. Interestingly, though, while Case C managers Sonya and Brian and teachers Britt, Candy and Kassandra all felt that it was important for VET teachers to be have the requisite industry skills and knowledge, they did not necessarily feel that those with the best industry knowledge and skills became the best teachers, or that they would necessarily be regarded as teachers with advanced skills. Teacher Britt for example, explained that over her lengthy career in the VET sector (spanning more than 30 years), she had seen many people with excellent industry skills commence as VET teachers, but not develop advanced skills. Those who became the best teachers, she felt, were those who were 'passionate' about their industry and their job as a VET teacher, and with the ability to pass their industry skills and knowledge onto others.

The people that make the best teachers in this area are the people who really are passionate about their industry and about their job. They know their trade, they know what industry wants, they know 
the correct way to do things, they have a great rapport with people and they're able to impart that knowledge. (Britt, teacher, Case C)

Britt's views are supported by the account teacher Kassandra gave of her own experience. Kassandra's entry into her chosen field of nursing wasn't an easy one. In fact, she was told by the Director of Nursing (DoN) at the hospital-based school of nursing, that she was unlikely to succeed. The DoN's prediction proved incorrect however, and Kassandra completed her studies and enjoyed a very successful career as a nurse and a nurse manager before becoming a VET teacher. At her own admission, she had to work very hard and 'be pushed' to maintain the level of study required to complete the nursing qualification. Upon graduating however, she very quickly discovered an affinity for teaching others, first in the workplace, and later in the VET sector.

I wasn't a top student at nursing in my nursing school, I was actually the very opposite. I had to be pushed through. But for some reason when I left I discovered that I had this ability to teach in the wards, to show and to tell and then to nurture people. And then I just got really confident. And I actually became more confident in the class room than I was on the wards. (Kassandra, teacher, Case C)

Kassandra described an easy transition from industry professional to VET teaching. For other VET teachers however, the transition is more difficult, and for some, according to teacher Ed, it does not occur at all.

I get the impression, some [VET teachers] see themselves more as a tradesperson employed by the university, rather than a VET practitioner or a teacher. (Ed, teacher, Case C)

For teacher Kassandra however, maintaining a role as both VET teacher and industry professional means that even when she is working in industry in a casual supervisory role, she is still teaching.

I'm a teacher at work as well. I'm at my other job but l'll still teach. I'll teach 'til the cows come home and it makes my shift go smoother. I don't just go and work a problem out with them [other staff], I'll actually work it out and tell them why we worked it that way so that they can go on and learn from that. (Kassandra, teacher, Case C)

Jocelyn (Case $\mathrm{C}$ teacher) felt that developing an identity as a VET teacher involved more than just teaching well and engaging with students. In her opinion, some industry experts did not complete the professional transition to VET teacher because they were not committed to 
undertaking all aspects of the VET teachers' role, including the tasks relating to compliance and recordkeeping.

The professional identity - I see it so often that they are terrific with their content; they are really committed to their students. But those people who have not moved beyond their industry identity. They are not committed to all the other stuff that sits behind teaching. Their focus is their students and the classroom. And that is only part of your job. They're dragged kicking and screaming to validation. Or they can always think of a thousand reasons why they haven't got their documentation up to date. (Jocelyn, teacher, Case C)

So while it is important for VET teachers to be both industry experts and teachers, it seems that they must also acquire other skills and knowledge to be regarded as VET teachers with advanced skills, such as those that are needed to meet the contextual requirements of the organisation and the job, and to understand their role within the broader VET context. This theme will be discussed in the following section.

\section{Managing the requirements of the job, the organisation and the VET sector}

VET teaching is only one part of the VET teacher's work, and although one may logically assume it to be the most critical component of the role, this may not always be the perception. At Case C, VET teachers are required to develop their skills and job role 'in situ', complying with the organisation's policies and procedures, legislation and regulatory requirements, and working according to the organisation's vision and values. To meet the compliance component of their role, VET teachers must ensure that their training and assessment practices comply with the relevant legislated standards specified by the Standards for Registered Training Organisations (RTOs) 2015. In addition to complying with these standards, they must maintain evidence of compliance and keep records so that the evidence may be produced in the event of an enquiry or audit by the VET regulator. Manager Sonya and teachers Tagen and Deborah felt that it was necessary for a VET teacher to have the skills and knowledge to meet these compliance requirements in order to be considered VET teachers with advanced skills. According to Sonya, a VET teacher with advanced skills must be able to interpret the standards and provide information about them to others.

I think for me an advanced teacher, someone that I would rely on for information is someone with a solid understanding of the RTO standards. So that's important to me, that they know the standards. (Sonya, manager, Case C). 
According to teacher Tagen, an understanding of the regulatory and qualification requirements underpin good teaching practice, as it ensured the quality and consistency of graduate skills and knowledge.

You can have a really good teacher in a classroom but if they don't have the skills to assess and follow the process of what happens, I mean it doesn't benefit anybody, because, what are we sending out? (Tagen, teacher, Case C)

Teacher Deborah also referred to the complexity of the curriculum and regulatory requirements, explaining that 'critical thinking and high order thinking skills' were required for VET teachers to interpret and apply the standards. Teacher Kassandra on the other hand, felt that interpreting the curriculum and complying with standards was relatively simple.

That just comes down to being good at looking at the training package, looking at the individual aspects of each part of that training package and saying how are we going to meet this point? And never fail audit. Like how are we going to meet this point right now until review? And I think if you can do that and you can confidently go and teach a package and know that you've covered every detail then the rest is easy. (Kassandra, teacher, Case $\mathrm{C}$ )

As well as working within the frameworks and systems which regulate the VET sector, VET teachers must learn to work and teach within the context and framework of their employer organisation. The organisation's compliance framework and the internal policies and procedures that comprise it, are in turn influenced by the legislative and regulatory requirements of the Standards for Registered Training Organisations (RTOs) 2015. According to teacher Candy, understanding the organisation's quality system, and more importantly, staying abreast of changes to it, is a critical requirement for a VET teacher with advanced skills, and one that is becoming even more important in contemporary VET.

It's really important for all teachers to keep up to date with the processes of an organisation as well. Previously in the TAFE system, that wasn't a priority. A lot of people weren't really current with all the quality forms. So I think quality has really come to the fore in the last few years and it's really a measurement of an organisation, what their processes are, how they work, how up to date, how current they are. (Candy, teacher, Case C)

Manager Paul explained that each organisation's quality framework is likely to be a little different, so even those who come to work at Case C from other RTOs may require time and some effort to become familiar with 'its peculiarities and its policies and procedures' in order to become regarded as VET teachers with advanced skills. Given this apparent complexity and 
inconsistency across RTOs, it is perhaps unsurprising that there are, as teacher Britt reports, those who find themselves unable to navigate the quality and regulatory systems and leave the organisation before reaching their potential as a VET teacher.

They realise that there is a world of regulations and restrictions and things that you have to adhere to as well. And that's what frightens a lot of people off. I've had someone come in and only be here for a week and they've said, "no, I can't do this". They'd be great teachers, but they cannot do the mass of other things that have to go with it. (Britt, teacher, Case C)

The processes and systems that influence the VET teachers' work in a specific RTO are in turn influenced by changes and trends that impact the broader VET sector. According to manager Paul, VET teachers with advanced skills understand this context.

It's about taking responsibility for your own destiny and understanding; understanding the links to what's happening in our workplace and at TAFE to what's going on in the broader society. (Paul, manager, Case C)

Teacher Rachelle agreed, adding that VET teachers with advanced skills understand global changes and have the flexibility to adapt to them, inferring that personal attributes also play a role in developing or being recognised as a VET teacher with advanced skills, a theme that will be explored in the following section.

\section{Personal attributes and other qualities}

While Case C's managers and teachers described specific skills and knowledge as advanced skills for VET teachers, they also identified certain personal attributes and characteristics inherent to those who succeed in the sector. Managers Paul and Sonya felt that those with advanced skills demonstrated a positive attitude which enabled them to be adaptable, to take responsibility for their own responses and actions and to approach challenges and change proactively and flexibly.

[As a VET teacher] your best option is to go out of the bunker and go, 'I'm ready, I'm here. I'm ready for new opportunities. I'm going to take some responsibility myself. I will be proactive and responsive and I'll do my damnedest to support the organisation. And by doing so, I will support myself'. (Paul, manager, Case C)

Teachers Jocelyn, Candy and Kassandra reflected on their own personal attributes and characteristics which, in their opinion, contributed to their expertise and success in teaching. Jocelyn for example, explained that she had a passion and enthusiasm for teaching which 
developed from a 'real belief in education as a pathway for people' (Jocelyn, teacher). She went on to describe the enjoyment and satisfaction that she gains from teaching:

I genuinely enjoy teaching. I genuinely want to engage people. I genuinely want them to learn and then go and get a good job. And whilst I'm not saying that I get it right every time, I think people respond very well to that enthusiasm. (Jocelyn, teacher, Case C)

Candy also described a passion for teaching, adding that it was necessary to demonstrate a commitment to teaching, and a desire to do it well.

I'm very passionate about what I do for a start, and I believe you have to have that passion. (Candy, teacher, Case C)

Similarly, Kassandra expressed a strong sense of fulfilment derived from her role as a VET teacher, explaining that she loved 'turning up for work and making a difference to a student's life' (Kassandra, teacher, Case C).

In addition to these personal attributes and characteristics, and perhaps in part due to them, VET teachers with advanced skills were often seen as leaders in the organisation who were able to mentor and influence others. Some of Case C's VET teachers had achieved the highest incremental teaching level available under their industrial award and were subsequently appointed as Leading Vocational Teachers (LVTs). To achieve and maintain this increment, LVTs are tasked with additional responsibilities, often related to managing or mentoring other teachers within their teaching discipline. Jocelyn is very proud of her status as an LVT, and conscious of the contribution that she can make to others in the organisation due to her considerable experience and knowledge.

I didn't set out to be somebody special. But I very much value being an LVT person now. As a leading vocational teacher, an LVT, I take great pride in the fact that people do genuinely seek me out, that is my role. It's not just doing some little extra bits just for myself. You need to be a leader. And I've been around 34 years. And so I do know stuff. And I've got stuff in my head that I remember that I know. And then someone will ask me a question, and I'll be able to just pluck it [the answer] out of the air. (Jocelyn, teacher, Case C)

While not all teachers interviewed at Case C were LVTs, all had played a role in mentoring other VET teachers and recognised the benefits of this for the individual mentees as well as for teaching teams and the organisation, highlighting the role that VET teachers with advanced skills play in the organisation, not only in supporting successful student outcomes, 
but in supporting the skills development of other VET teachers. In the second part of each interview, Case C participants were asked to discuss how VET teachers develop advanced skills. The data from each interview transcript was analysed and important themes arising from this analysis will be dealt with in the next section.

\section{Developing advanced skills at Case C}

Each of the Case $\mathrm{C}$ teachers invited to participate in the research project were nominated by their managers and/or peers as VET teachers with advanced skills. The interviews revealed that the development of their skills had been influenced by a variety of different factors. While time and experience are likely to have played a significant role, particularly given the participants' lengthy teaching tenures, ranging from nine to more than 30 years, Case $\mathrm{C}$ teachers identified a range of other contributing factors, including participation in formal study activities, opportunities to learn from others and undertaking self-directed developmental activities. VET teachers require not only the skills and knowledge to teach well; they must also learn how to navigate the complexities and regulatory requirements of the VET sector as well as the systems developed by the organisation in which they work. In addition to this, they are required to uphold their status as a dual professional by maintaining current industry skills and knowledge as part of their professional repertory. Case $\mathrm{C}$ is a higher education provider of teacher education programs for all education sectors, including the VET and higher education sectors. While this circumstance, presumably, might infer some synergistic benefits for the organisation's own VET teachers, Case C participants (both managers and teachers) expressed varying views on how well this opportunity transpired into practice.

Like many large organisations, Case $\mathrm{C}$ has policies and procedures in place to formally manage the performance and professional development of all employees, including VET teachers. Case $\mathrm{C}$ monitors and records industry currency activities through a web based platform which attributes a points for each relevant activity undertaken. Using this system, VET teachers must accrue and record 100 points each year, with points attributed to various activities according to the time commitment required and the activity's relevancy to the teacher's educational and/or industry developmental requirements. Teacher Tagen described the system as quite structured and also somewhat prescriptive in terms of the types of professional development activities that are acknowledged and supported, explaining that 
reporting options are limited to industry visits, industry meetings, professional development and industry release activities.

There's a breakdown, and it's very descriptive. You can't guess it, so you go in and you have to actually lodge your evidence under the tabs; it actually gets checked, and then you get those points allocated. So you can anywhere from 5 to 15 points, depending on the activity. For a 3 day conference you might get 20 points. (Tagen, teacher, Case C)

As well as industry currency activities, teachers can record 'teaching currency' activities using this system. While these activities also contribute to the required 100 points, teacher Rachelle argued that it was difficult for many VET teachers to achieve points for teaching currency as the prescribed activities do not necessarily relate to their day to day teaching role.

Well it's a variety of activities that we can do, and it's split between industry currency and training currency. You have to reach 100 points by the end of the year, and there's two tabs. So there's a tab for industry currency and it's broken down into industry visits, industry meetings, professional development, industry release. The other tab is teaching currency, which is more difficult to attain, because some of it is only geared to higher level activities. The most that the majority of us can get is [participating in a] validation panel, so we nearly can only do validation panels to get, training currency. (Rachelle, teacher, Case C)

Despite this relatively structured approach to managing and recording VET teachers' currency activities, according to manager Sonya, there is no 'overarching' policy to guide their professional development. Rather, it is up to individual managers to negotiate professional development plans and opportunities with VET teachers. As teacher Tagen explains, each teacher has an allocation of funds that can be used for professional development activities, however the activities must be approved by his/her manager.

We have allocated PD [professional development] money. The manager I've got, as long as you're not actually physically teaching [when the PD event is scheduled] is happy to support, and you haven't gone outside your allocated money. (Tagen, teacher, Case C)

While ensuring the availability of funds for professional development activities is important, it is has been of little value to Tagen, as she has been unable to use the allocated funds due to conflicting teaching, assessment and administrative commitments.

In the last 12 months I haven't done too much, but that's because every time there's something on I've got other commitments for the organisation. (Tagen, teacher, Case C) 
Tagen's experience is certainly not unique. Manager Brian, while lamenting the fact that not enough time is allocated to training for VET teachers, acknowledged that it is sometimes too difficult to replace teachers on high teaching workloads, particularly when in some areas, teachers are already working overtime. Similarly, teacher Andy explained that while Case C provided an 'enormous number of opportunities' for professional development and is genuinely supportive of VET teachers' needs, it is often very difficult to take advantage of the opportunities available.

When it comes down to the coal face sometimes it's a case of, well, I could go for that course next week but results have to be in. There always seems to be that extra teaching duty that overrides. (Andy, teacher, Case C)

Accessibility and the tyranny of distance may also present a barrier to those Case $C$ VET teachers not based at the primary campus location. Due to the organisation's multiple locations, VET teachers (and others in the organisation) are accustomed to conducting and participating in meetings using zoom or jabber, web conferencing applications. This affordance, which enables increased accessibility for those in geographically dispersed locations, is not always provided to VET teachers who wish to undertake training.

They [internal training activities] are relevant, it's just the availability, time and availability. For example, they had a really good one the other day that they offered face-to-face up north. I said, 'Can we jabber in on that? I'd really love to do it.' 'Oh no, it's only face-to-face.' So there's probably a little bit of isolation being at a more remote campus to the main ones. (Tagen, teacher, Case $\mathrm{C}$ )

Most participants agreed that Case C provided many opportunities for VET teachers' professional development. Some felt however, that the opportunities available were often more relevant to Higher Education teaching than to VET. Manager Sonya, for example did not think Case $\mathrm{C}$ had a good model of training for VET teachers.

Any of the learning and teaching that comes out is designed under a HE model, and so it's up to the teachers to transpose that knowledge into their [VET] style. (Sonya, manager, Case C)

Manager Paul agreed that there was a need to 'contextualise' the opportunities to better suit the needs of VET teachers. Teacher Jocelyn on the other hand, felt that the organisation placed too much emphasis on ensuring VET teachers' industry currency, and not enough on developing their teaching skills.

I think as an organization, there has been a lot of focus on professional development and currency around your technical expertise and very limited PD around teaching practice. So, we're asking people 
to think of themselves as teachers. But we're not helping them develop those skills. (Jocelyn, teacher, Case C)

Despite the reported challenges and barriers, most participants felt that the organisation has a genuine interest and desire to improve the professional development opportunities available to its VET teachers. According to teacher Tagen, more appropriate opportunities for development were becoming available as Case Clearned more about its VET teachers' needs. Andy also felt that the opportunities for development were improving, crediting the organisation with becoming more 'outwardly supportive' of VET teaching.

\section{Higher Education for VET teachers}

Formal education has played a significant role in the development of advanced skills for many of Case C'S VET teachers. Most have obtained vocational or higher education qualifications, in addition to the minimum Certificate IV in Training and Assessment required by the Standards for Registered Training Organisations (RTOs) 2015. All but one of the teachers interviewed had attained an education qualification at Bachelor level or higher. Deborah, Ed, Rachelle, Andy and Britt had qualified as teachers in the compulsory education sector prior to becoming VET teachers, while Jocelyn, Candy and Tagen completed postgraduate education qualifications specific to VET. Kassandra's highest educational qualification was the requisite Certificate IV in Training and Assessment (TAE40116), however she expressed an intention to commence a Graduate Certificate in Education in the near future, believing that she would gain ' $a$ lot of benefit' from the course. This would most certainly be the case if the experiences of Ed, Deborah, Rachelle, Candy and Britt are any indication. Candy felt that completing tertiary studies helped her to develop confidence and to 'find a voice' as a teacher. Ed explained that he still draws upon the knowledge of learning theories and classroom management skills gained throughout his university level education studies. This is also the case for Deborah, although she acknowledges that having completed a qualification which was specific to the K-12 sector and not VET, her knowledge of curriculum did not easily transfer to the Training Packages which comprise the VET curriculum. While acknowledging that the Certificate IV in Training and Assessment was useful in learning about VET specific knowledge and skills, Deborah felt that tertiary level educational qualifications were needed for a VET teacher to develop advanced skills. 
I don't think that the TAE goes into the student, the teaching skills, and the theories behind it, and why we do what we do. I think the TAE is very good for unpacking training packages, and everything like that. It's at a Cert IV level though, so when you're doing a degree you're doing it at a much, a higher level, and on a deeper level. (Deborah, teacher, Case C)

Perhaps influenced by the research environment of the higher education environment in which they work, a number of Case C's VET teachers have commenced higher degrees by research within the organisation, and some have published journal articles. Two were undertaking research relating to VET, one for a PhD, another for a Masters. Yet another is undertaking a Masters degree by research in his industry discipline area. Candy has noticed that since she began participating in further study and research, her approach to teaching has become more 'academically focused', with a greater emphasis on developing and implementing strategies to improve teaching and learning. This is in contrast to her colleagues who have not undertaken such further study, whom she described as being more 'industry-focused' in their approach to education, emphasising industry outcomes and requirements for specific skills and knowledge. Ed expressed some surprise that more VET teachers weren't taking the opportunity to undertake higher degrees by research given that the merger between TAFE and the University took place more than three years previously.

Regardless of their varying industry backgrounds, professional development history and work experience, Case C's VET teachers with advanced skills shared a common conviction. They all expressed a commitment to self-improvement, and in particular, to improving their skills and knowledge as teachers. For Jocelyn, this commitment, which she describes as an 'intrinsic change' in her identity, arose from a desire to be a better VET teacher and to develop the knowledge and skills required for compliance with the VET regulatory framework. Rather than waiting for others to 'spoon feed' her, Jocelyn consciously set out to learn as much as possible about VET and VET teaching, explaining that she 'just wanted to be really good at it' (Jocelyn, teacher, Case C). Case C'S VET teachers primarily undertake professional development activities to learn new skills and knowledge, not necessarily to achieve a certain qualification. While most have gained further skills and knowledge in their industry discipline, some have developed new skills relating to their role or aspirational roles in the organisation, such as management and leadership. Candy has attained a number of vocational and tertiary qualifications in various disciplines, explaining that learning is something that she intends to continue throughout her life. 
I've paid for all of my education as I like to invest in myself. Also, when I pick a pathway and I can see how that interlinks and how that's going to assist me to go further l'll do that. So you see it's like a building, it's like scaffolding, learning as you're going through life. (Candy, teacher, Case C)

Similarly, Andy is still conscious of his own developmental needs, even after more than 40 years as a teacher.

I'm always aware of doing a better job as a teacher. I haven't hung up the boots there and said, 'Well, this is as good as l'll be.' (Andy, teacher)

Engaging as a learner may produce some unexpected and unintentional benefits that contribute to the development of advanced skills for Case C's VET teachers. Aside from gaining new skills, knowledge and qualifications, VET teachers may also gain new insights into their own teaching practices by engaging as a learner, with an opportunity to observe and be the subject of the teaching practices of others. According to Rachelle, Iearning from being a learner' meant that she could not only learn new techniques and practices to improve her teaching skills, but also what not to do as a teacher.

It's only when you're sitting in a class yourself and you realise that the teacher probably hasn't been well prepared and that it isn't sort of running how it should be run. (Rachelle, teacher, Case C)

While Case C'S VET teachers have indicated the need to be self-motivated in order to develop advanced skills, Rachelle's example also hints at the importance of learning from observing and interacting with others. Learning from others, along with the considerable value attributed to experience and time, was another significant theme that emerged from interviews with Case C's VET teachers with advanced skills.

\section{The value of learning from others}

Each of Case C's interview participants felt that mentoring and the opportunity to learn from others played a significant role in VET teachers' development. While Case C does not have a formally organised mentoring program in place, some Leading Vocational Teachers have a responsibility for mentoring others according to their negotiated leadership agreement. It may also be the case that mentoring others is a part of Case C's organisational culture, given that each participant could identify a time in which they had been either experienced the benefits of mentoring as a mentee, and/or acted as a mentor for others, even in the absence of a formally mandated requirement. This is indeed the case within Andy's team which, he explained, has developed a culture to support improved teaching practices for all teachers. 
We have a culture we believe works, and I think it's very good but I'm obviously biased. We ease a person into that culture and we've got a very open policy within the staff. We discuss teaching situations on a regular basis, how to do this and 'I want to teach this; have you got any good ideas?' or, 'I taught this the other day and this is not working, and this is what we're teaching here. How are we doing? We've got to change. How do we change it?' (Andy, teacher, Case C)

Mentoring, according to Case C participants, can accelerate the development of VET teachers by assisting them to navigate their new role within a large organisation and to learn the requirements of the complex VET system faster than they would without such support. Mentoring can also ensure teacher retention and reduce student attrition by ensuring that 'teachers don't get lost in the system', which in turn ensures that students 'get what they need' (Tagen, teacher, Case C). Further, according to Tagen, mentoring is critical to the development of advanced skills for VET teachers, and that different mentors may be required according to the skills and knowledge that the mentee needs support to learn.

I think to develop really good teachers you need to have really good mentors. All teachers need a mentor, and they need to be appropriate mentors. Some people might need two mentors with different skills; they might need a mentor to give them tips for managing classroom behaviour, you might need another mentor to assist with the paperwork side of the job because we all have different skills. If you've got a good mentor that helps a teacher with classroom management, that helps your attrition rate. (Tagen, teacher, Case C)

A mentor does not necessarily have to teach the same discipline or have a similar industry background to that of the mentee to be effective. While Deborah felt that it was an advantage to commence her new teaching role within a large team of experienced teachers who could act as mentors, in Britt's experience, a mentor did not have to be a 'content expert' to be effective.

Well I think the mentoring does work well if you've got good mentors in place. That doesn't have to be someone working in the same area; it's not so much that you're the content expert, but you're the support person. (Britt, Case $\mathrm{C}$ teacher)

While mentoring appears to have played an important role in the development of Case C's teachers, it should not replace other developmental activities according to manager Paul, who believes mentoring to be most effective when combined with other more formal professional development strategies. 
What I think we have seen work best is where you combine some formal PD, workshops or conferences or whatever with real support and mentoring on the job in a real situation. (Paul, Case C manager)

In addition to, and alongside mentoring, all agreed that there is no substitute for time and experience in the development of VET teachers with advanced skills. Views on the amount of time a VET teacher required to develop advanced skills varied, however teacher Tagen felt that for her, it took three years 'with a good mentor'. Similarly, teacher Deborah believed that she developed advanced skills very quickly, because she learned 'on the job' a process which was facilitated by the support and supervision of other experienced teachers. Manager Paul also emphasised the need for a situated skills development approach for VET teachers, due to the complexity of the VET system and the VET teachers' role.

I think for someone to be advanced in this space, first of all, I think you can't underestimate the importance of time. Time with the organisation in the role. People come in from outside [the sector] with very good CVs or resumes and very experienced in the business world. But they actually falter when they try and engage with the VET system. (Paul, manager, Case C).

In addition to mentoring, Case C's VET teachers can learn through their interactions with other teachers within their own team and from other disciplines. Teacher Jocelyn explained the enormous value of what she described as 'cross-pollination' - the sharing of ideas, skills and knowledge which occurs when VET teachers have the opportunity to observe others teach, ask questions of other teachers, or to discuss problems and issues with other teachers.

\section{Conclusion}

Case C's managers and teachers revealed some divergent views on what advanced skills for VET teachers are. While teachers focused on advanced skills which contributed to improved teaching and student outcomes, managers generally regarded these skills as core to the job role and advanced skills as additional skills and capabilities which contributed to the broader goals of the organisation. Case C's VET teachers also described unique individual qualities and characteristics of VET teacher with advanced skills, such as the ability to connect and engage with students and a passion for teaching. A number of teachers spoke of the sense of satisfaction and enjoyment they derived from the teaching role and the strong sense of commitment they had to students and their achievements.

Case C's VET teachers had recently experienced a merger between the TAFE Institute in which they had been previously employed and the university. This, along with a very recent 
ASQA re-registration audit, was a focus for many of the interview responses. Teachers for example, felt that managers placed a higher value on skills required to manage compliance requirements than on 'good' teaching practices. They also reported challenges and expressed some disquiet associated with the merger, as some felt that the organisation did not yet have a good understanding of what advanced skills for VET teachers were or the types of learning activities needed to develop them. According to Case C's VET teachers, mentoring and higher level educational qualifications were valuable in the development of advanced skills. They expressed frustration however, that the organisation's emphasis on meeting compliance and industry currency requirements was detrimental to the development of teaching skills for its VET teachers. Most reported taking responsibility for their own learning and development identifying, paying for and undertaking professional development activities in their own time. 


\section{CROSS CASE ANALYSIS}

In Chapters 4,5 and 6 I presented detailed Case Reports for each of the three cases investigated in this research study (Cases A, B and C respectively). In this chapter I will discuss the results of cross case analysis, completed according to the process outlined in Chapter 3.0, Methodology. The purpose of cross case analysis is to identify findings which are common across cases and those that are unique to specific cases in relation to the themes and the topic of the research study (Stake, 2006). The focus of a multiple case study project is on what cases can tell us about the quintain - a common phenomenon, object or condition shared by the cases (Stake, 2006). For this study, the quintain is 'advanced skills for VET teachers and how they are developed'. In Chapter 3, I described each of the four phases of analysis undertaken in the research project, according to a process based upon Stake's (2006) cross case analysis:

Phase 1: Determining research Themes

Phase 2: Identifying findings for each case

Phase 3: Merging the findings

Phase 4: Developing assertions

In this chapter I will discuss the implementation of the cross case analysis process and the results of each Phase in turn.

\section{Phase 1: Research Themes}

In this first phase of cross case analysis I determined the Themes upon which the analysis would be based. Although the word 'theme' usually refers to an important or patterned response in the data when undertaking thematic analysis, Stake (2006) instead uses it to refer to the questions or 'primary information about the quintain that the researchers seek' (p. 43). I determined five Themes (questions) relevant to this study:

Theme 1: Can advanced skills be described as a list of skills, knowledge and capabilities?

Theme 2: Is there an aspect of advanced skills which is related to the individual character of the teacher? 
Theme 3: Are there differences between the way that managers and teachers understand advanced skills?

Theme 4: What factors contribute to the development of advanced skills?

Theme 5: What are the barriers to the development of advanced skills?

I returned to the case study reports again after determining the Themes, in order to rank each Case's expected utility (or usefulness) in relation to each Theme. Due to the situated 'uniqueness' of each Case, the contribution that each made to address the themes varied. I determined the usefulness or utility of the Cases according to the quantity and quality of relevant evidence that each contained against each of the Themes. This phase of cross case analysis helped to guide the latter phases by ensuring that my enquiry remained focused on the relevant Themes and by identifying the cases more likely to provide relevant data for each Theme. Cases were ranked as ' $L$ ' if expected to provide limited evidence in relation to a particular Theme, ' $M$ ' if expected to be moderately useful in addressing the Theme, and ' $\mathrm{H}$ ' if expected to be highly useful and relevant to the Theme. The results of this phase of cross case analysis have been outlined in Table 1: Expected Utility of Cases for Each Theme (Appendix D).

\section{Phase 2: Individual Case Analysis and Findings}

The second phase of Cross Case Analysis was undertaken to identify Case Findings - what the individual Cases could tell me about the quintain - in a process which focused on the uniqueness of each Case, preserving its 'situationality' (Stake, 2006, pp. $40-41$ ). As I identified Case Findings, I ranked them according to their importance to each of the five Themes. Findings which I considered to be particularly relevant and important to a particular Theme I ranked as ' $\mathrm{H}$ ', those of moderate importance or relevance ranked as ' $\mathrm{M}$ ' and Case Findings which provided some insight, but which I considered to be less important or relevant than other findings, I ranked as ' $L$ '. I have outlined the Case Findings for each of the three Cases and ranked their importance against each Theme in Table 2: Case Findings and Importance to Themes (Appendix D). In this section I will provide more detail about the Case Findings and the Cases.

The three Cases, Case A, B and C, share a number of similarities, but are also unique, providing the advantage of consistency, as well as the 'situationality' required for insight into 
the quintain. All are public VET providers in Queensland, however while Case A and B are regions of TAFE Queensland, Case C is a dual sector university. Each provides a wide range of VET courses in multiple locations throughout Queensland, although while VET is the core business for Cases A and B, Case C previously provided only Higher Education programs, with VET programs a relatively new addition to its scope. VET teachers from Cases A and B are employed according to the TAFE Queensland Certified Agreement 2016, while Case C's VET teachers are subject to a different enterprise agreement, negotiated with their employer, the university. While each case was an RTO of similar size, each had different strategic business goals and contextual differences which in turn influenced the managers' performance goals and focus.

\section{Case A Analysis and Findings}

Case $A$ is one of six regions within the TAFE Queensland network. At the time of data collection, Case A's managers were focused on an internal recruitment and selection process undertaken to appoint teaching team leaders, an initiative intended to devolve some of the responsibility for compliance and mentoring of VET teaching teams from their managers and other relevant organisational departments, to the teachers appointed to the newly created Team Leader position. While Case A's managers and teachers expressed some divergent views on advanced skills for VET teachers, there were some specific skills, knowledge and capabilities which both groups agreed were necessary, although not necessarily advanced. According to a number of participants (both managers and teachers) VET teachers with advanced skills were adept at understanding the curriculum (Training Packages) and managing compliance requirements (including developing compliant assessment tasks). Although industry skills were regarded as important, a teacher with advanced industry skills was not necessarily regarded as a VET teacher with advanced skills, unless he/she demonstrated other capabilities and qualities. Case A participants also felt that, no matter what other skills or capabilities a VET teacher demonstrated, he/she must also be able to fulfil the requirements of the job role (including the administrative, recordkeeping and reporting requirements) in order to be considered a VET teacher with advanced skills. These findings are described as Case Findings 1,2 and 3.

Case A Finding 1: VET teachers with advanced skills understand the curriculum and compliance requirements. 
Case A Finding 2: A person with advanced industry skills is not necessarily a VET teacher with advanced skills.

Case A Finding 3: To be a VET teacher with advanced skills, a teacher must also have the skills and knowledge to meet the requirements of the job role.

Case A's teachers, while acknowledging the importance of specific skills and capabilities required for effective teaching in the VET sector, also described their skills more holistically, identifying characteristics and traits unique to VET teachers with advanced skills, such as an enthusiasm and passion for teaching, the ability to connect and engage effectively with students, and genuine care for students and the outcomes they achieve. Further, because they care about students and the effect that their teaching has on students' learning, teachers with advanced skills reflect upon their teaching practice in order to improve. These views are articulated in Case Findings 4,5,6 and 7:

Case A Finding 4: Teachers with advanced skills have interpersonal skills to connect and engage with students, to identify and meet their needs in relation to learning.

Case A Finding 5: Teachers with advanced skills have an enthusiasm and passion for teaching.

Case A Finding 6: Teachers with advanced skills can engage with students when teaching in any mode/format.

Case A Finding 7: Teachers with advanced skills use reflection to improve their teaching.

Case A's managers and teachers demonstrated some divergent views on the nature of advanced skills for VET teachers. While both agreed that the ability to develop relationships and communicate well were important, managers were more likely to value those skills when teachers utilised them to achieve the organisation's business goals e.g. by developing new business opportunities or leading and mentoring others in the organisation. Teachers, on the other hand, placed a higher value on skills related to learning and teaching. Further, they were aware that their managers often had different conceptualisations of advanced skills to their own, which at times created tension. Findings relating to the divergent views of Case A's managers and teachers are outlined in Case Findings 8,9 and 10. 
Case A Finding 8: Managers are more likely than teachers to believe that teachers with advanced skills are those who have the business skills to maintain the organisation's market competitiveness.

Case A Finding 9: Managers regard leadership and communication skills as advanced skills, but teachers place a higher value on teaching.

Case A Finding 10: Tensions develop due to the divergent views of managers and teachers about advanced skills and how they are developed.

Case A's VET teachers felt that they developed advanced skills through a variety of means. While time and experience were regarded as important factors, many felt that studying higher level qualifications in education and having the opportunity to be mentored by more experienced teachers also contributed to their development. The organisation provided professional development activities for VET teachers, however many with advanced skills felt these activities were more relevant to beginning teachers, and often committed their own time and finances to pursue alternative learning and development activities they believed to be most beneficial to them. Findings relating to the way in which Case A's VET teachers developed advanced skills are expressed in Case Findings $11-15$.

Case A Finding 11: Teachers with advanced skills demonstrate a commitment to their own learning and development.

Case A Finding 12: Higher Education contributes to the development of advanced skills.

Case A Finding 13: The opportunity to learn from others contributes to the development of advanced skills (e.g. mentoring, coaching, networks).

Case A Finding 14: Advanced skills are learned through experience.

Case A Finding 15: The learning and development needs of teachers with advanced skills are different to those of novice teachers.

Case A's VET teachers identified barriers which they felt had a negative impact on the development of advanced skills. Many reported that it was difficult to find time to participate in professional development activities while juggling full-time teaching loads and the administrative demands of the job, and some felt that additional support would be required 
for teachers to successfully complete higher level study. Further, additional academic learning support may be required for those VET teachers who had not undertaken formal study for a long period of time. Lack of access to funds to support participation in professional development activities was also a barrier for many. As well as finding it difficult to access funds to pay for and travel to developmental activities (such as external courses, workshops and conferences), teachers reported that funding constraints limited their participation in other ways. For example, many were reticent to disadvantage students by cancelling a class or to burden their colleagues by asking them to stand in as a replacement teacher, so professional development activities were limited to those that could be scheduled around existing teaching commitments. Case Findings 16 and 17 articulate these barriers.

Case A Finding 16: Insufficient time and money to participate in learning opportunities are constraints which may impact upon the development of advanced skills.

Case A Finding 17: Additional support and academic skills may be required by VET teachers to undertake higher level study.

\section{Case B Analysis and Findings}

Like Case A, Case B is a region within the TAFE Queensland network. At the time of data collection, the organisation was involved in an extensive project to develop online learning and assessment resources to be used in all regions of TAFE Queensland. This project required a significant investment of time and resources by TAFE Queensland, and as such, conveyed a significant burden of responsibility to Case B's managers, who were tasked with ensuring the successful completion and implementation of the resources. Case B was also piloting the implementation of TAFE Queensland's newly developed VET Educator Capability Framework, a tool intended to help guide the professional development planning of VET teachers in the organisation.

A number of Case B's managers and teachers felt that VET teachers with advanced skills would be highly skilled in some areas, but not all. This view may have been somewhat influenced by the approach taken by Case B's managers as they implemented the VET Educator Capability Framework. Rather than expecting all teachers to be highly skilled in all areas of the Capability Framework, the focus for Case B managers was on evaluating the collective capability of teaching teams and ensuring that within a team there would be VET teachers with different specialist advanced skills who could take responsibility for each area 
of the teaching team's responsibility. This model is also reflected in the principles which guide Case B's teacher development initiative - the Educator Capability Team. The Educator Capability Team is comprised of VET teachers with specialist advanced skills, who have a responsibility to assist other teachers in the organisation develop similar skills. It is perhaps unsurprising then, that Case B Finding 1 reflects this:

Case B Finding 1: VET teachers with advanced skills are more likely to be specialists in some areas, not advanced in everything.

While agreeing that VET teachers with advanced skills were more likely to be advanced in some capabilities but not in others, Case B's participants also identified certain personal characteristics and attributes of the 'good' VET teacher, as outlined in Case B Findings 2 - 5. They described the almost innate ability of VET teachers with advanced skills to connect, engage with and teach students using interpersonal skills and other personal attributes. Teachers with advanced skills also share a commitment to teaching and a strong identification with the role, with some describing it as a vocation or a calling.

Case B Finding 2: Teachers with advanced skills have an intrinsic ability to be good teachers - it comes naturally to them.

Case B Finding 3: Teachers with advanced skills use personal skills of creativity, critical thinking and flexibility.

Case B Finding 4: Teachers with advanced skills have personal attributes and interpersonal skills which help them to engage closely with students.

Case B Finding 5: Teachers with advanced skills have a passion for teaching - it is more than a job.

Similarly to Case A, Case B's managers and teachers held divergent views on advanced skills, which at times, caused some tension between them. Managers were more likely than teachers to regard skills as advanced if they were aligned to the organisation's business goals. For example, as Case B was focused on the development and implementation of online courses at the time of data collection, technological skills were highly valued. Managers also valued business skills, along with the knowledge and skills teachers needed to comply with regulatory requirements and to develop compliant assessment tools. These findings are outlined in Case Findings 6 - 9 . 
Case B Finding 6: Managers are more likely to value skills relating to the use of technology to attain efficiencies and to meet perceived student demands for flexible learning options.

Case B Finding 7: Managers are more likely to regard teachers with advanced skills as those who help the organisation meet its business goals (e.g business skills and knowledge of the organisation's goals).

Case B Finding 8: Managers are more likely to regard teachers with advanced skills as those who are good at compliance and assessment.

Case B Finding 9: Tensions develop due to the divergent views of managers and teachers about advanced skills.

Case B Findings regarding the way that advanced skills are developed are very similar to those of Case A. Like Case A, VET teachers with advanced skills at Case B are likely to take responsibility for meeting their own learning and development needs. They valued the skills and knowledge gained through formal study of high qualifications in education, along with the opportunity to learn from others, and like Case A teachers, they expressed a view that VET teachers with advanced skills required different professional development opportunities to those provided to beginning teachers.

Case B Finding 10: Teachers with advanced skills take responsibility for their own learning and development.

Case B Finding 11: The opportunity to learn from others contributes to the development of advanced skills.

Case B Finding 12: The professional development needs of teachers with advanced skills are different to those of beginning teachers.

Case B Finding 13: Studying higher level educational qualifications contributes to the development of advanced skills.

Case B Finding 14: Experience contributes to the development of advanced skills.

Case B teachers identified a number of barriers to the development of advanced skills. Similarly to Case A, financial constraints were an issue for Case B teachers who sought funds 
to attend professional development activities or to facilitate employment of a casual teacher when developmental activities clash with teaching timetables. Case B participants also felt that the development of advanced skills may be impeded when too great an emphasis is placed on developing the skills and knowledge needed to comply with regulatory and industry currency requirements. Findings relating to barriers are outlined in Findings $15-17$.

Case B Finding 15: Learning and development offered by the organisation is often too narrowly focused on the skills and knowledge needed for compliance, rather than providing the opportunity to develop advanced skills for teaching.

Case B Finding 16: Financial constraints, including the cost of replacement teachers, are a barrier to participation in professional development activities and the development of advanced skills.

Case B Finding 17: An emphasis on industry currency requirements may create an unbalanced approach to professional development and impact negatively on the development of teaching skills.

\section{Case C Analysis and Findings}

Unlike Case A and B which are regions of TAFE Queensland, Case C is Queensland's only dual sector university, the result of a merger between a Queensland university and a TAFE Queensland Institute. The merger occurred only a few years prior to data collection. Case C had experienced a re-registration audit in the weeks prior to data collection, and perhaps unsurprisingly, the audit, along with the challenges associated with the merger, were often mentioned in interview responses from both managers and teachers. Similarly to Cases $A$ and $B$, Case $C$ teachers and managers placed high value on advanced industry knowledge and skills for VET teachers, but like Case A, they recognised that this did not necessarily equate to advanced teaching skills. And similarly to Case B, Case C's managers and teachers felt that VET teachers could be regarded as having advanced skills even though they may not be advanced in everything. This analysis led to Case C Findings 1 and 2:

Case C Finding 1: VET teachers require current industry skills, but high levels of industry skills do not guarantee 'good teaching'.

Case C Finding 2: VET teachers may have advanced skills even though they are not advanced in all aspects of the job role. 
Case C's teachers, like those from Case A and B, were more likely to describe advanced skills holistically and in relation to individual qualities of the VET teacher. For example, VET teachers with advanced skills were able to connect and engage, forming productive relationships with students easily. A number of teachers expressed a 'passion' for teaching, while others described the sense of satisfaction and enjoyment that they derived from helping students achieve their goals. These were similar to the views shared by teachers from Case $A$ and $B$, and have been outlined as Case C Findings 3 and 4:

Case C Finding 3: Teachers with advanced skills have a passion for teaching, and gain enjoyment and satisfaction from teaching.

Case C Finding 4: Teachers with advanced skills engage and connect easily with students to develop productive relationships for learning.

Like VET teachers from Cases $A$ and $B$, those at Case $C$ reported that tensions sometimes arose due to divergent conceptualisations of advanced skills between managers and teachers. While teachers were more likely to refer to advanced skills as those which contributed to improved teaching and student outcomes, managers generally regarded these skills as core to the job role, and advanced skills as additional skills and capabilities which contributed to the organisation's goals. At the time of data collection, Case C had just experienced a re-registration audit and this had undoubtedly influenced the managers' focus on compliance and meeting regulatory requirements. Findings $5-7$ focus on the divergent views of Case $\mathrm{C}$ managers and teachers in relation to advanced skills:

Case C Finding 5: Managers are more likely to value and reward skills relating to compliance than outcomes of good teaching.

Case C Finding 6: Managers are more likely to see teaching skills as core to the VET teachers' job role, and advanced skills as additional skills (such as business skills) which contribute to the organisation's goals.

Case C Finding 7: Tensions develop due to the divergent views of managers and teachers about advanced skills and how they are developed.

Like those from Case A and Case B, Case C's VET teachers with advanced skills take personal responsibility for meeting their ongoing personal and professional development 
needs and valued the opportunity to learn from others. They also felt that to develop advanced skills, VET teachers needed access to a wide range of development activities.

Case C Finding 8: VET teachers with advanced skills take responsibility for their own learning and development.

Case C Finding 9: VET teachers need access to a wide range of developmental activities, and also the time to participate in them.

Case C Finding 10: Learning from others (e.g. mentoring) is an effective means of developing advanced skills.

For Case C's teachers, and similarly to those from Case A and B, time was a significant barrier preventing their participation in developmental activities. They reported increasing workloads associated with compliance requirements which exacerbated the problem, and like Case $B$, many felt that the organisation placed too great an emphasis on ensuring that teachers maintained industry currency, which further limited the time and activities available for VET teachers to develop advanced skills for teaching.

Case C Finding 11: An emphasis on maintaining industry currency may compromise the development of teaching skills.

Case C Finding 12: The administrative burden associated with compliance creates time constraints which is a barrier to developing advanced skills.

\section{Phase 3: Merged Findings}

From the individual Case Findings, I identified clusters of similar topics and Case Findings which I refined to develop 14 'Merged Findings'. Some Findings were more contextual and unique to specific cases, and I described these as 'Special Findings', using Stake's (2006) terminology and recommendations. In this section I will deal with the Merged Findings and Special Findings, organised according to the insights I sought about the quintain - the Themes. I have listed each of the Merged Findings and Special Findings in Table 3: Merged Findings and Importance Rankings (Appendix D). In Table 3 I have also ranked the importance of each Merged and Special Finding in relation to the Themes and indicated which Case/s each Finding was derived from. 
Theme 1: Can advanced skills be described as a list of skills, knowledge and capabilities? While managers and teachers from all three Cases described a number of different skills, knowledge and capabilities which they considered to be necessary for VET teachers, it was not possible to develop a comprehensive list of skills which all would agree on as being 'advanced'. Some, for example, referred to the skills required to 'unpack' Training Packages and to design interesting educational experiences and compliant assessment as advanced, while others felt that these skills were core capabilities for VET teachers and not necessarily advanced. Many felt that it was not possible to identify a comprehensive list of advanced skills for VET teachers because it was more likely that a teacher would be a specialist in a particular area, rather than advanced in all aspects of VET teaching. In each Case, participants expressed the requirements for VET teachers to have advanced industry skills and knowledge, however those from Case $A$ and $B$ felt that these capabilities alone were not sufficient for a VET teacher to have advanced skills in teaching. In response to Theme 1, I have developed Merged Findings 1 and 2:

Merged Finding 1: A VET teacher requires advanced industry/vocational skills and knowledge, but this does not necessarily lead to advanced teaching skills.

Merged Finding 2: Teachers with advanced skills must have certain skills and knowledge to do the job, but are more likely to be specialists in some areas, not advanced in all.

Theme 2: Is there an aspect of advanced skills which is related to the individual character of the teacher?

While it was not possible from this study to develop a comprehensive and agreed list which articulates advanced skills for VET teachers, teachers from all three cases were more likely than managers to describe their skills holistically, reporting a passion, enthusiasm and genuine commitment to teaching which they felt was necessary for VET teachers with advanced skills. They considered their ability to develop meaningful connections and relationships with students as critical to their success as a teacher, leading to Merged Findings 3 and 4 in response to Theme 2 : 
Merged Finding 3: Teachers with advanced skills have personal attributes and interpersonal skills to connect and engage authentically and meaningfully with students.

Merged Finding 4: Teachers with advanced skills have a passion and enthusiasm for teaching, express a genuine commitment to successful outcomes for students, gain satisfaction and enjoyment from teaching and a somewhat 'natural ability to teach'.

\section{Theme 3: Are there differences between the way that managers and teachers understand advanced skills?}

In each of the three Cases, some divergent views emerged between managers and teachers about advanced skills. While teachers were likely to conceptualise advanced skills in terms of teaching practice and successful student outcomes, managers were more likely to value the skills and knowledge aligned to the organisation's goals, or in achieving compliance with regulatory requirements. Tensions emerged as teachers were aware of the divergent views of managers. Outlined below, Merged Findings 5, 6 and 7 were consistent in each of the three cases:

Merged Finding 5: Managers' conceptualisations of advanced skills are more likely to be contextual and related to the skills needed to contribute to the organisation's business goals.

Merged Finding 6: Managers are more likely to regard teachers with advanced skills as those who understand the curriculum and are good at compliance and assessment.

Merged Finding 7: Tensions may develop due to the divergent views of managers and teachers about advanced skills and how they are developed.

Not only were managers' conceptualisations of advanced skills in Cases A, B and C likely to be different to those of teachers, they were also contextual and subject to change, depending upon the organisation's specific focus and business goals at a particular time. During the period of data collection, Case A was undertaking a recruitment process for Team Leader positions and actively reviewing VET teachers' skills according to the communication and leadership capabilities required for this position. Managers from Case A described advanced skills as those that enabled VET teachers to demonstrate leadership in the organisation, and to mentor other teachers in order to meet the organisation's goals. Case B 
on the other hand, was focused on developing resources for online programs and ensuring that teachers could manage their teaching role in an online environment. Case B's managers were more likely to regard those with high levels of technological skills as advanced than those without such skills. These contextual, case specific findings are articulated in Special Finding 1 and Special Finding 2 respectively:

Special Finding 1 (Case A): Managers regard leadership and communication skills as advanced skills.

Special Finding 2 (Case B): Managers are more likely to regard those with high technological skills as advanced.

There were no Special Findings unique to Case $C$.

\section{Theme 4: What factors contribute to the development of advanced skills?}

VET teachers from all cases identified a number of activities which they believed contributed to the development of advanced skills. All who had achieved higher level qualifications in education felt that this additional study was beneficial to the development of their teaching skills. Not only did they learn new knowledge and skills, but the experience of being a learner was also beneficial as it provided insight into the student's perspective. Managers and teachers from all cases agreed that advanced skills develop over time and through experience, but there was no agreement on how many years of experience was required. VET teachers valued the opportunity to learn from others, and felt that this contributed to the development of advanced skills.

Case $A$ and $B$ organisations provide a range of professional development opportunities for VET teachers, however those with advanced skills felt that these were often more appropriate for beginning teachers, and that VET teachers with advanced skills required different types of activities. Teachers from Cases B and C agreed that a wide range of developmental activities were required to develop advanced skills. They were critical of many offerings provided or supported by their organisation, which mostly focused on meeting compliance requirements rather than the development of advanced teaching skills. In all three Cases, VET teachers with advanced skills took responsibility for their own learning and development needs. A number described themselves as 'lifelong learners', and as well as seeking out appropriate activities, they mostly funded their development themselves and 
undertook activities in their own time. They were also critically reflective of their own teaching, reviewing teaching activities and instances in order to make improvements. Merged Findings $8-13$, outlined below, relate to the development of advanced skills for Cases $A, B$ and $C$ :

Merged Finding 8: Studying education at a higher level than the Certificate IV TAE (e.g. Diploma, Bachelor, and Postgraduate) contributes to the development of advanced skills by improving pedagogical skills and knowledge and by allowing teachers to experience the role of learner.

Merged Finding 9: The opportunity to learn from others (e.g. mentoring, coaching, and networking) contributes to the development of advanced skills.

Merged Finding 10: Advanced skills are developed through time and experience.

Merged Finding 11: Teachers with advanced skills are likely to be lifelong learners who demonstrate a commitment to their own learning and development and who reflect on their own teaching to make improvements.

Merged Finding 12: Teachers with advanced skills have different learning and development needs to beginning/novice teachers.

Merged Finding 13: Teachers require a wide range of developmental activities to develop advanced skills.

\section{Theme 5: What are the barriers to the development of advanced skills?}

According to VET teachers from all three Cases, insufficient time and financial constraints are the major barriers which impact upon the development of advanced skills. Many felt that an increasing administrative burden relating to compliance and reporting (to meet the sector's regulatory requirements) significantly reduced the time available for professional development. Managers and teachers from Cases $B$ and $C$ also reported that an increasing emphasis on industry currency requirements (also related to regulatory requirements) created an unbalanced approach to teachers' professional development, which impacted negatively on the development of skills for teaching. Merged Findings 14 and 15 encapsulate these barriers. 
Merged Finding 14: Insufficient time and money to participate in learning opportunities are constraints which may impact upon the development of advanced skills.

- Financial constraints include the cost of replacement teachers to enable participation.

- The administrative burden associated with compliance takes time which could be used for learning and development.

Merged Finding 15: An emphasis on industry currency requirements may have a negative impact upon the development of teaching skills

\section{Phase 4: Assertions}

The final step in cross case analysis, in Stake's (2006) view, is to develop Assertions from the Merged Findings. Assertions are the final findings of the analysis which, according to Stake (2006, p. 71), 'should have a single focus, an orientation for understanding the quintain and evidence to support it'. The three Assertions I have developed from the cross case analysis are:

Assertion 1: Teachers with advanced skills are more likely to conceptualise these holistically and recognise the importance of the teacher's individual qualities, while managers are more likely to express an atomised and contextual interpretation of advanced skills.

Assertion 2: Teachers develop advanced skills through a variety of activities and those with advanced skills take personal responsibility for their own continued learning and development.

Assertion 3: The development of advanced skills may be negatively affected by insufficient resources and an unbalanced approach to professional development.

A Table of Assertions which maps each Assertion to the relevant Merged Findings and Themes is provided in Table 4 (Appendix D). The three Assertions will be discussed and supported by the empirical data and relevant literature in Chapter 8. 


\section{CHAPTER 8 DISCUSSION}

The teacher is frequently addressed as if he had no life of his own, no body, and no inwardness. Lecturers seem to presuppose a 'man within man' when they describe a good teacher as infinitely controlled and accommodating, technically efficient, impervious to moods. They are likely to define him by the role his expected to play in a classroom, with all his loose ends gathered up and all his doubts resolved. The numerous realities in which he exists as a living person are overlooked. His personal biography is overlooked; so are the many ways in which he expresses his private self in language, the horizons he perceives, the perspectives through which he looks on the world.

(Greene, 1973, pp. $269-270)$

Chapter 7 presented the cross case analysis process used to develop the research project's final Assertions (Findings). This chapter will respond to the research question: 'How are advanced skills for VET teachers understood and how are they developed?' by discussing the Assertions and presenting the empirical evidence and literature to support them. Possible implications of the research project's findings for the VET sector will be proposed in Chapter 9, along with recommendations on how they might be used to inform conceptualisations of advanced skills and professional development for VET teachers in the future.

Three Assertions have been developed from the research study:

Assertion 1: Teachers with advanced skills are more likely to conceptualise these holistically and recognise the importance of the teacher's individual qualities, while managers are more likely to express an atomised and contextual interpretation of advanced skills.

Assertion 2: Teachers develop advanced skills through a variety of activities and those with advanced skills take personal responsibility for their own continued learning and development.

Assertion 3: The development of advanced skills may be negatively affected by insufficient resources and an unbalanced approach to professional development.

The Assertions and their relevance to the Merged Findings and Themes are outlined in Appendix D (Table 4: Assertions), and each will be dealt with in turn in the following sections. 


\section{Assertion 1}

Assertion 1 deals with conceptualisations of advanced skills for VET teachers and responds to the question: 'How are advanced skills for VET teachers understood?' revealing divergent understandings of advanced skills between VET managers and VET teachers.

Assertion 1: Teachers with advanced skills are more likely to conceptualise these holistically and recognise the importance of the teacher's individual qualities, while managers are more likely to express an atomised and contextual interpretation of advanced skills.

The research suggests that there are differences between the way that VET managers and VET teachers conceptualised advanced skills, a finding that was consistent across all Cases. While both managers and teachers identified certain skills, knowledge and capabilities necessary for 'good teaching' when discussing advanced skills, managers placed greater emphasis on an atomised set of skills that contributed to organisational and management goals. Further, some of the skills identified by VET managers appeared to be contextual, varying between cases and dependent upon the goals and focus of the organisation at the time. Conceptualisations of VET teachers about advanced skills on the other hand, were less dependent upon context and more likely to focus on teaching and the outcomes of teaching for students. Teachers also recognised the importance of their own personal character and the individual qualities they brought to their role as teachers, conceptualising the notion of advanced skills more holistically, rather than as a set of specific skills and knowledge. The discussion to follow will examine managers' and teachers' conceptualisations in more detail, supported by evidence drawn from the case reports and underpinned by the theoretical framework provided by social constructionism and existentialism. It will also examine the tensions that may develop as a result of the divergent views held by VET managers and VET teachers about advanced skills, and provide a rationale for the way that VET teachers may manage these tensions through the lens of Connelly and Clandinin's (1995) theory of secret, sacred and cover stories. 


\section{VET managers' conceptualisations of advanced skills}

Each of the three Cases are a separate, bounded system, providing unique opportunity for insights into the research question by virtue of their contextual differences - the phenomenon which Stake (2006, pp. $40-41$ ) describes as their 'situationality'. While each case shared similarities, the situationality created through differing organisational projects and goals shaped the context in which VET teachers carried out their work and in which conceptualisations of VET teaching skills were developed. The specific Case context however, is not the only situationality factor to influence conceptualisations of advanced skills for VET teachers at Case A, B and C. The research study is also situated within the Australian VET sector, and as such each Case, while representing a unique, context bound system, must operate within the landscape and boundaries of the sector, its unique context also moulded by the regulatory, market and funding influences which impact upon the broader context of Australian VET.

The study's conceptual framework is underpinned by an overarching theory of social constructionism, recognising the importance of context and pre-existing ideas in the development of meaning making (Crotty, 1998). Rather than assuming that each VET manager and VET teacher will have a unique and individual conceptualisation of advanced skills for VET teachers, it presumes that understandings of VET teaching and advanced skills would be constructed through the influence of pre-existing understandings and culture within multiple social contexts, including: the organisation in which the VET teacher carries out his/her work; the vocational sector in which the RTOs operations are situated and regulated; and the broader community and the shared views on good teaching which exist within it. Preexisting conceptualisations of VET teacher skills, knowledge and capabilities have been established through a variety of meaning making influences, including the conceptualisations of teachers and teaching that exist in other education sectors. In the contemporary Australian VET sector, however, perhaps the most compelling influence on the VET teachers' skills exist in the capability frameworks which dominate the current discourse on VET teaching quality. In what Mulcahy (2011) may describe as a 'standards movement', there have been multiple attempts to atomise VET teachers' work into a comprehensive framework of essential capabilities and behaviours (see for example, Innovation and Business Skills Australia, 2013; LH Martin Institute, 2016; Mitchell \& Ward, 2010). The influence of these frameworks and 
the work undertaken to develop them is evident in the way that participants from Cases $A, B$ and C conceptualised VET teachers' skills and the language used to describe them. TAFE Queensland for example, was involved in the research study that informed Mitchell and Ward's (2010) Model of VET Practice. As all three Cases had originated from TAFE Queensland and many of the research participants had been employed there during the time of Mitchell and Ward's study, they frequently used language which originated from that period to describe VET teachers such as 'VET Practitioners' and 'Advanced VET Practitioners'. Despite TAFE Queensland's involvement in Mitchell and Ward's study and in the consultation process undertaken to develop IBSA's VET Practitioner Capability Framework (Innovation and Business Skills Australia, 2013) and QCT's Professional Standards for Further Education and Training (Queensland College of Teachers, 2015, the organisation identified a need to develop its own framework, the TAFE Queensland Educator Capability Framework (TAFE Queensland, 2016). At the time of data collection, Cases $A$ and $B$ were piloting the implementation of the framework, described as a '...self-profiling tool, or rubric, which clearly articulates the skills, abilities and knowledge that educators should be demonstrating on a regular basis in their roles at various stages of development', and intended to 'provide opportunities to identify and recognise educational excellence' and guide the professional development and career pathways of teachers in the organisation (TAFE Queensland, 2016, p. 3).

TAFE Queensland's Educator Capability Framework is based upon Innovation and Business Skills Australia's (2013) VET Practitioner Capability Framework, but aligned to TAFE Queensland's organisational goals (TAFE Queensland, 2016). The Framework distils VET teachers' capabilities into eight domains which, while referring to the skills associated with Learning, Teaching and Assessment, also list other capabilities more likely to be associated with professional, business and management tasks, reflective of the expanding VET teachers' role and the educational commercialisation phenomenon which Chappell and Johnston (2003, p. 10) described as the 'businessing' of VET. The domains are: Professionalism and core values; Innovative product and practices; Technology for learning; Learner, industry and community engagement; Quality and compliance; and Educational leadership. Each domain is atomised further into a number of related skill areas and together, the domains and skill areas are intended to 'define the capabilities of high-performing educators desired within all [TAFE Queensland] regions' (TAFE Queensland, 2016, p. 5). The framework assumes however, that not all educators will display the capabilities at the highest level. Instead, each skill has 
been expanded upon to describe behaviours demonstrated by educators at four incrementally progressive levels: transitioning, proficient, highly accomplished, and leading. Case B manager Linda proposed that it would be unlikely for educators to reach the highest level of proficiency in each domain and skill area, but acknowledged that the specialist or advanced skills likely to be recognised or valued by managers and the organisation will vary according to contextual factors, such as the organisation's priorities at the time.

Rather than thinking that there are people who are good at and advanced in everything, you have people who are specialists in areas that are important to the team and the Institute, depending on what your priorities are. (Linda, manager, Case B)

Case A manager, Roslyn, also expressed the importance of context in the way that advanced skills are recognised and understood, explaining that perceptions and performance may be dependent upon the context and role in which the VET teacher was working.

It is really about the environment they're in and their level of comfort in dealing with the scenario that they're currently in. I think that is quite a significant thing. (Roslyn, manager, Case A)

The capability frameworks are not the only factor to influence contemporary perceptions of advanced skills for VET teachers. Most recently, the increasing commercialisation of VET and shift towards a demand driven, competitively funded VET sector has meant that VET providers have had to develop leaner models of education provision, implementing new business strategies to increase the organisation's commercial competitiveness, reduce costs and increase efficiencies and productivity in the way that education and training is delivered (Braithwaite, 2018; Griffin, 2017; Guthrie et al., 2014; Toner, 2014). More than ever, VET providers are searching for new markets and ways to increase revenue while managing expenses, as Case B manager Diane points out:

So those advanced skills teachers, I think, are the ones that can understand what it is that we are selling, understand the customer. It's, you know, going beyond 'we've always done it this way', to, 'how can we do it better?'...looking at the quality and looking at business opportunities. So not just VET, it's more about how they can take their qualifications to a different market. (Diane, manager, Case B)

Similarly, Case B manager Susan, while acknowledging that the skills and knowledge required for teaching - 'pedagogical strategies and pedagogy' ${ }^{6}$ - were important, explained that VET

\footnotetext{
${ }^{6}$ In-text quotes from participants have been italicised for emphasis and to differentiate them from citations of published works
} 
teachers with advanced skills had other capabilities which helped them to contribute to the commercial and business goals of the organisation.

It is also the skills to think not necessarily as a manager, but organisational skills to look at the bigger picture and plan, and look at how we can deliver a training program that can be delivered with the most efficiencies for our clients. (Susan, manager, Case B)

The commercial and business skills described by Susan are also reflected in Linda's comments:

If we are priced well we need to be efficient in what we do. So those advanced skills teachers, I think, are the ones that can understand what it is that we are selling, understand the customer, put the student first, be responsive to the student. (Linda, manager, Case B)

The increasingly competitive and commercial market described by managers from Case $A, B$ and $C$ has led to reputational damage for the sector, largely due to the actions of unscrupulous providers with a focus on profit over quality (Braithwaite, 2018; Buchanan, 2012; Griffin, 2017; Harris, 2015; Nakar, Bagnall, \& Hodge, 2018; Toner, 2014). As a result of this and the ensuing discourse on quality - one which has now reached 'fever pitch', according to Griffin $(2017$, p. 7) - the sector sought a solution through changes to its legislated standards and increased activities of ASQA, the national VET regulator. The heightened focus on quality and compliance has not only increased the proportion of VET teachers' work spent on administrative tasks relating to regulatory requirements, but has also influenced managers' conceptualisations of advanced skills, as Case B manager, Diane explains:

I guess there is a big focus on what happens in the classroom. But for us here in the VET sector, there is a whole, huge component of behind the scenes work that goes on as well. And that has become more and more important I think over the years with my experience. The behind the scenes stuff you know - the compliance, accreditation, registration. (Diane, manager, Case B)

Manager Alexandra, also from Case B, shared Diane's view, explaining that in her opinion, VET teachers needed an in depth understanding of the sector's 'restrictive' legislation and its compliance requirements to be considered advanced.

It is quite restrictive, the VET sector, in terms of regulations, to allow teachers to develop and become really advanced. It is quite restrictive. They have to understand the VET sector to become advanced. And those people that make it to the advanced levels are the ones that have the best grasp of what the VET sector is all about. (Alexandra, manager, Case B)

Similarly, Case C Manager Sonya stated that the VET teachers she considered to have advanced skills possessed sound knowledge of the sector's regulatory requirements as 
outlined in the current legislative instrument, the Standards for Registered Training Organisations (RTOs) 2015 (Commonwealth Government of Australia: Department of Education and Training, 2015).

I think for me an advanced teacher, someone that I would rely on for information is someone with a solid understanding of the RTO standards. So that's important to me, that they know the standards. (Sonya, manager, Case C)

The focus on compliance is so great, according to Case C teacher Andy, that as a result, managers were now more likely to value and reward skills associated with compliance, rather than recognising good teaching practice.

When it comes down to the nitty gritty of what you do in the VET sector you've got to get all the admin done, and if you're a good teacher as well that's a bonus. So really, you can survive in the system by being a really poor teacher but good at doing paperwork, and you will get ticks from your manager all the time (Andy, teacher, Case C).

Andy's observations are an accurate reflection of the views expressed by managers from all three Cases, who regarded teaching skills as core capabilities for the VET teacher's role, and not related to advanced skills. Roslyn (manager, Case A) for example, described teaching skills as the 'technical skills' which VET teachers were expected to bring to the role.

There are definitely people with the technical skills [for teaching] and that's sort of to me, it's a core, I mean, fundamentally we've got to have that. (Roslyn, manager, Case A)

Manager Paul (Case C) supported Roslyn and Linda's views, explaining that advanced skills were 'not necessarily about what's going on in the classroom', going on to explain that teaching skills were not always highly valued in the sector.

...[in the sector] generally, we underestimate and we undervalue and we under support the kind of teaching side. (Paul, manager, Case C)

Paul also recognised that his conceptualisation of advanced skills which overlooks the importance of teaching, was dependent upon his 'terms of reference' as a manager and his work priorities at the time.

I'm thinking about my current role and engaging with them directly around, 'okay, we need this report done' or 'we need this information' or 'how's it going with finance', etcetera. It's not necessarily about what's going on in the classroom. I think it's an important distinction to make, because that's just because of my terms of reference in the sense of my job. (Paul, manager, Case C) 
The phenomenon which Stake (2006) refers to as the 'situationality' of each unique case study has enabled further insight into the contextual nature of VET managers' conceptualisations of advanced skills for VET teachers. During data collection, managers from Case A were in the midst of a recruitment process to appoint existing VET teachers to newly created Team Leader positions. Their focus during this time was very much on the capabilities needed to demonstrate leadership in the organisation and to mentor other teachers.

To me, and my experience in the VET sector, the advanced skills are around the leadership of teams, mentoring of other teachers, being able to work across vocational areas, certainly having an accountability. (Graeme, manager, Case A)

Case B on the other hand, was leading a project to develop online resources for many different disciplines which would be used across all TAFE Queensland regions. This project represented a significant investment of resources, and it was important that the resources were utilised effectively to ensure a return on this investment. It was perhaps unsurprising then, that Case B's managers' conceptualisations of advanced skills were very much focused on the skills required to use technology and to teach in an online environment.

We expect a difference in their [teachers'] approach to delivery and they should use a range of modalities for learning, including modern technologies. We are pretty heavy here in the online learning as you would know. It is pretty common now, but those with advanced skills are able to use the online platforms here at TAFE and in other organisations to use a variety of techniques to assess students or to deliver training. (Susan, manager, Case B)

In summary, the research suggests that VET managers are more likely to conceptualise advanced skills for VET teachers using a reductionist approach, or what Hansen (2001, pp. 23) might describe as an instrumental, activity based conceptualisation - one which focuses on what the teachers should be able to do and what the outcome should be. While regarding teaching skills as core to the VET teacher's role, the skills managers considered to be advanced have been distilled to those that they value most, due to the considerable contribution that those with such capabilities can make to the organisation's business goals. These are the skills associated with: leadership; commercial business; technological proficiency and compliance. Further, there is a contextual aspect to the VET managers' conceptualisations of advanced skills and the value that they place on them. Contextual factors which influence their conceptualisations may be situated at the local, organisational setting, or within the broader 
whole of sector landscape. VET teachers' conceptualisations of advanced skills may be different to those of their managers, as the research suggests their views were less likely to be dependent upon contextual factors and more focused on holistic conceptualisations of teaching and the outcomes for students.

\section{VET teachers' conceptualisations of advanced skills}

VET teachers carry out their work in a landscape characterised by the socially constructed, pre-existing understandings of VET teachers' work and advanced skills for VET teachers. These understandings have been influenced by contextual, situational factors relating to the RTO in which they work and the macro influences which impact upon the whole of VET sector. The research found that while VET teachers with advanced skills were aware of these preformed conceptualisations and the resultant expectations they created regarding the work that they do, their own understandings of advanced skills were more holistic, personal and focused on teaching, learners and learning, rather than being subject to the organisational and sector-wide goals and influences which impacted so strongly on the perceptions of their managers. For VET teachers, advanced skills are more than the skills, knowledge and capabilities that can be articulated in the sector's latest capability frameworks. For them, advanced skills are about the relationships that they develop with students which motivate, inspire and nurture them to learn, the passion and commitment they bring to their role as VET teacher, and the satisfaction that they derive from being both witness and accessory to their students' learning and achievements.

\section{The relational aspect of good VET teaching}

Teachers from all three Cases expressed consistent views on the importance of engagement with students, and the need to develop relationships which motivated, inspired and facilitated student learning. The process of connecting, engaging and relationship-building described by VET teachers was a serious one, approached with a sense of deep commitment and genuine care for the student. Case B teacher Loretta, for example, felt that for VET teachers, 'one of the most important things is making those connections with students'. Astrid (Case A teacher) shared a similar view, emphasising the importance of developing relationships in which students felt 'valued': 
Yeah, I mean I think I'm pretty comfortable with planning and creating the learning experiences, also building relationships with the students is a big part of it...the ability to connect with students and make them feel like valued. (Astrid, teacher, Case A)

Likewise, teacher Nerida (Case A) felt that her ability to engage and build relationships with students was critical in her role as VET teacher, and an attribute which others recognised and valued.

It's all about engagement with students. I know my colleagues would say that is a strength of mine, that ability to engage and have those relationships with students. (Nerida, teacher, Case A)

Case $\mathrm{C}$ teacher, Britt, also recognised her ability to build relationships with students, however in her case, this extended more widely to include students' families and the communities in which they live.

I think I have a very good rapport with students, I've always had that. My first couple of years were in small indigenous communities. They were only small in number and you live within the community and I always thoroughly enjoyed meeting people in the community, being part of those small communities, getting to know their families, getting to know the students. (Britt, Case C Teacher)

The views expressed by teachers Loretta, Astrid, Nerida and Britt would likely meet the approval of Macmurray (1964), who described the essential teacher-pupil relationship as one of genuine care, and of Noddings (2003), whose work aimed to conceptualise teaching as a relational practice based upon the development of a 'culture of care and trust' (Noddings, 2012, p. 777). Like Noddings and Macmurray, Van Manen (1991a, 1991b, 1994) also espoused the importance of the teacher-student relationship in 'good teaching'. While the focus of Noddings' and Macmurray's teacher-student relationship however, is on trust and care, Van Manen (1991a) described a relationship based upon the teacher's 'pedagogical thoughtfulness and tact' (p. 524). Tact, in Van Manen's (1991a) sense, refers to 'mensenkennis' in a Dutch term describing 'people-knowledge' (Van Manen, 1994, p. 137). Those with tact have a certain kind of interpersonal sensitivity and perceptiveness towards others, 'a kind of wisdom about how people are and how they tend to act or react in specific situations' (Van Manen, 1994, p. 138). Van Manen's (1991a) view also resonated with the narratives of good teaching conveyed by VET teachers with advanced skills from Cases A, B and C. Some, such as Case A VET teacher Josie, for example, echoed Van Manen's (1991a) sentiments that in some respects, good teachers are born, not made - that 'there is a hint that the quality of 
tact is somewhat like talent' (p. 526) and that some people possess more of this talent than others (Van Manen, 1994).

I've a bit of a theory that [as a teacher with advanced skills] you are naturally good with students and people anyway. So I feel like I came with, sort of, well developed interpersonal skills, communication skills, people skills, empathy. (Josie, teacher, Case A)

Sandra (teacher, Case A) also recognised that an essentially innate ability to connect and build relationships with students enabled her to provide an optimal environment for learning for each individual.

I think the major thing is, I can actually sit with a student for just five or 10 minutes, and actually really identify how that student actually learns. And pin point it. And gear my whole lesson, every single time that student comes in, to specifically get the best out of that student in the shortest space of time. I think that's the difference. (Sandra, teacher, Case A)

According to Case A teacher Louise, teachers with advanced skills understand not only how to communicate, engage and connect with students, but to inspire and motivate them to 'want to discover more or to be critical thinkers' (Louise, teacher, Case A). Case C teacher Tagen, however, felt that having advanced communication and interpersonal skills enabled her to identify when students require additional assistance, and to address their needs appropriately.

Probably I can identify students that have got needs or they've got insecurities; I'll often, say, pull them along, pull them out on a quiet spot when no one's around and say, 'Hey look, I've noticed, are you having trouble with this?', but not bring it to the attention of other students. (Tagen, teacher, Case C)

Jocelyn (teacher, Case C) also recognised that her ability to engage and build relationships with students contributed to their success, even though she may never meet her students face to face. Despite the fact that Jocelyn teaches a course entirely online, she welcomes interactions with students and encourages this by establishing rapport soon after enrolment.

Right from the start, within 24 or 48 hours of them enrolling, I'm on the phone having a yarn. So I do establish that communication really quickly with them. I think that's a really good thing. (Jocelyn, teacher, Case C)

The importance of the individual and advanced skills for VET teachers

Holistic conceptualisations of teaching, such as Nodding's (2003) and Van Manen's (1991a), recognise the importance of the individual teacher and the personal characteristics, attributes and moral values of the 'good teacher'. Hansen (2001) has a similar view, describing teaching 
as a 'moral and intellectual practice', emphasising the importance of the 'distinctive, irreproducible' person who inhabits the role of VET teacher (Hansen, 2001, p. 1). The VET teachers who participated in the research project recognised the importance of their unique selves and individual characters in the role of VET teaching, which meant that they each had different ways of teaching, different ways of engaging and communicating - different ways of being in the role of teacher. Case $\mathrm{C}$ teacher, Kassandra, for example describes herself as a storyteller. Her classroom is a place where students learn through the stories she tells of her experience and of others' experience. She uses storytelling to interweave narratives of her experiences in industry with the theory and practice components of the curriculum that the students have come to learn.

You put real life on it, you put it in to reality and tell them stories. Storytelling...VET students especially, I think all students love story telling. And if you've got a story to tell, tell it. (Kassandra, teacher, Case C)

Some of Kassandra's stories are so engaging that students return the following week wanting to find out more, to hear the ending.

The students will come back a week later and they'll say what happened about that story, about that lady you told us about? I go oh, which lady was that? And they say you know the one that had the shortness of breath. And oh, okay, alright, you want to hear the rest of that. And so I tell them. (Kassandra, teacher, Case C)

Tony, on the other hand, sets up his classroom as a workshop with many different workstations so that students can remain actively engaged and learning regardless of their knowledge and skill level.

I've got the workshop set up with specialist areas, so electronical area, or under-body area, or brake area. And l've got all projects already developed that the students have to do, so all the parts and tools and everything are there, instructions. Once they do their theory I can move them off into different areas and also be hovering around the classroom; I've got a classroom with all glass out into the workshop, so I can keep an eye on them while I'm working with other students. (Tony, teacher, Case A)

Elise (Case B), who teaches primarily disengaged youth, is another who recognises the importance and value of her own individual 'uniqueness' in her role as VET teacher. Elise's students are those who have not yet completed Senior Secondary studies, and who have disengaged from traditional education. Many also have multiple personal and socioeconomic 
challenges to deal with. Elise has developed many new and different ways to engage the students in learning activities, using technology where appropriate and incorporating aspects of the students' own youth culture, to ensure that classroom activities are relatable and interesting as well as educational. Her individual personality and her open, accepting, but nononsense approach has proved successful for many students, and she speaks proudly of their achievements. Elise's methods are non-traditional, and she recognises that others might not necessarily be able to replicate them. She also recognises that some would be challenged by her methods, but despite this, remains confident that they are sound.

The things that I am doing in the classroom, I'm not doing it because I want to give the kids a hug and to make them feel better. I am doing it because it puts in place what I know is best practice, what I know is going to get an outcome. And all of the strategies that I use, an external person may think, 'that class is out of control', or 'that class is crazy'. Everything that I do is thought through and everything that I do has a grounding in theory. So I can back it up. Or I can write my own theories to back it up. Everything that I do has a reason for it. (Elise, teacher, Case B)

\section{VET teaching as something 'more than a job'}

The importance of the individual teacher's character is evident in the passion, enthusiasm and commitment expressed by VET teachers when talking about their role. Candy (teacher, Case C) for example, explained that she was 'very passionate' about teaching, while Jocelyn described an enthusiasm for teaching which had developed from a 'real belief in education as a pathway for people' (Jocelyn, teacher, Case C). Jocelyn also described the enjoyment and satisfaction that she gains from VET teaching:

I genuinely enjoy teaching. I genuinely want to engage people. I genuinely want them to learn and then go and get a good job. And whilst I'm not saying that I get it right every time, I think people respond very well to that enthusiasm. (Jocelyn, teacher, Case C)

Nerida (teacher, Case A) described herself as a 'born teacher', with a strong commitment to student outcomes as the basis for her teaching practice.

I'm a born teacher. I love it. That's what I'm here for. And that's where all of my passion and dedication goes to. And everything, just decisions in everyday, whatever decision needs to be made or whatever happens, it always comes back to that outcome for the student. And I think that is a teacher thing that teachers do well if they're passionate about teaching. (Nerida, teacher, Case A)

Case $\mathrm{C}$ teacher, Kassandra gained a strong sense of fulfilment from her role as a VET teacher, explaining that she loved 'turning up for work and making a difference to a student's life' 
(Kassandra, teacher, Case C), and similarly, Case A teacher Louise explained that her priority is for the students she teaches, having specifically chosen to work in the VET sector because it was there that she felt she could have the biggest impact:

I'm here as a designer in design education and I see myself as a design educator. I could be doing that in the university and I chose to be in the VET sector because of the situation of the students. So, I'm here for the students, not for administration, but that doesn't mean I don't follow the proper administration processes and auditing processes etc., but that is often more of a burden. (Louise, teacher, Case A)

The sense of genuine passion, enthusiasm and commitment expressed by VET teachers such as Candy, Jocelyn, Nerida, Kassandra and Louise, hint at a connection to their role which is stronger, more pervasive and all-encompassing than that of a job. Their narratives align to Hansen's $(1995$, p. 8) conceptualisation of teaching as a vocation, inferring that the teacher derives a sense of 'identity', 'personal fulfilment' and 'enduring personal meaning' from the work (Hansen, 1995, p. 8). Case B Teacher Alan, for example, felt that his teaching work was a 'vocation' and closely linked to his personal identity:

I would say that it is a vocation for me. And that [a teacher] is basically what I am. (Alan, teacher, Case B)

Jon had a similar view, explaining that teaching was '...kind of a calling, not just a profession' (Jon, teacher, Case B), and Andrea (teacher, Case B), describing herself as a 'natural teacher', explained that the good VET teachers, those with advanced skills, saw the role as more than just a job because they understood the impact they had on students. For Hansen, the vocation of teaching involves a sense of duty and public service as well as moral and personal commitment (Hansen, 1994; 1995; 1998), a statement which resonates with the strong sense of commitment described by the study's VET teachers. Hansen's (1995; 1998) conceptualisation of teaching as a vocation does not overlook the importance of VET teachers having the necessary industry knowledge and skills, nor does it preclude them from developing additional intellectual knowledge and skills for teaching. It does presume however, that those who feel the 'call to teach' will quickly discover the moral qualities that are embedded in the role, such as patience, attentiveness and fairness (Hansen, 1998, p. 649).

Hansen's (1995) conceptualisation of teaching as a vocation recognises that a VET teacher's work is somewhat larger than fulfilling a set of discrete requirements (Hansen, 1995, 
p. 15). The perception that good teaching is something more than simply the sum of its parts has implications for the sector's contemporary preoccupation with reductionist approaches which seek to atomise teaching to produce a comprehensive list of capabilities and behaviours. Even TAFE Queensland's own Educator Capability Framework (TAFE Queensland, 2016), doesn't adequately articulate the moral and personal commitment described by the study's VET teachers. Nerida (teacher, Case A) for example, felt that while the Capability Framework was 'a good place to start', there were 'key parts missing'.

...it's still not focusing enough on student outcomes, as in real student. Like it has got the word 'engagement' but it's actually, you know, this capability framework: what does this look like for the student as in the actual, again, the words that you would use to describe really, really good teaching and outcomes from teaching, it's lacking. (Nerida, teacher, Case A)

Similarly, Louise felt that the framework was more likely to ensure compliance with regulatory standards than provide guidance to develop the skills required for effective teaching:

I'm not saying isn't important but it really does nothing for you in the classroom.

(Louise, teacher, Case A).

Tension and the quiet resistance: the challenge for VET teachers with advanced skills

For VET teachers, advanced skills are about teaching, and the outcomes achieved through the connections and relationships they develop with their students. Their focus is on achieving these aims, even when others may challenge their methods and when they understand that their managers prioritise and value other skills and activities, such as those that might help to grow the organisation's business, produce efficiencies which result in more profitable programs, or to complete the increasing administrative and recording keeping tasks required to manage the organisation's compliance commitments. VET teachers know that their managers have a different understanding of advanced skills:

What I think as being advanced and what management sees as advanced or values, are two different things. (Josie, teacher, Case A)

Despite this awareness, they continue to carry out their teaching work in the way that most benefits the student.

Educational theorists Greene and Noddings would likely commend VET teachers from Case $A, B$ and $C$ for upholding their existentialist right and responsibility to make authentic, 
intelligent and individual choices, to do the thing that they believe to be morally 'right', rather than to conform compliantly and unthinkingly to what is expected by their managers, complicit colleagues, the regulators, the sector or the policy-makers. Greene (1973) applied a phenomenological existentialist approach to understand teacher's work, challenging them to critically question their thoughts, actions and beliefs. She urged teachers to resist conformance with predefined roles, calling upon them to 'struggle against unthinking submergence in the social reality that prevails' and not to accept 'ready-made standardised schemes at face value' (Greene, 1973, p. 269). Importantly, while existentialism emphasises the right of the individual teacher to choose, according to Sartre (1977), it is also concerned with the responsibility of the individual towards others, a view which is reflected in the sense of duty and commitment expressed by VET teachers towards their students.

For VET teachers with advanced skills, such resistance, albeit quietly carried out, is accompanied by some tension and disquiet. For most, the classroom (whether that is in the physical space of a classroom or an online classroom) is a safe place. In here, they can practice authentically and exercise their freedom of choice. It is the place where the all-important connections and relationships with students are developed, and where learning takes place. Louise (teacher, Case A) explained that her managers 'don't know what I do in the classroom', but admitted that she was happy to enjoy a level of trust which allowed the classroom to be her domain to manage. Similarly, Nerida (teacher, Case A) also knows that within the classroom she has relative freedom in teaching, as long as she meets the minimum curriculum requirements.

I think over the years when I have realised that more and more and more, well, I have a lot of free reign within my classroom and with my students and how I do this, and as long as I stick to what I need to with the training package. (Nerida, teacher, Case A)

Once outside of the classroom however, VET teachers must manage the expectations of others, such as their managers, the regulators and the policy and rule-makers. As Elise (teacher, Case B) pointed out, an outsider may think her class is out of control because her teaching strategies, though effective, might be regarded as unconventional. Elise manages this by sharing her teaching strategies within her team carefully and diplomatically, without forcing change onto others. Although she is the leader of her teaching team, she recognises that others are not always readily prepared to change and to challenge this will likely create further tension and disquiet. 
I want my students to take initiative and I want the rest of the team to take initiative and to build that kind of culture. I don't want to be part of something that is obsolete. And I figure that if I know something, then I should share it with other people - I feel that is an obligation. That upsets people sometimes because a lot of people get defensive and say 'but we have always done it this way'. Diplomacy - generally if you can show that it is a better way of doing things and that it is going to make the teacher's life easier. Sometimes it is a slow process, and sometimes it upsets people a little bit. (Elise, teacher, Case B)

Andy (teacher, Case C) and his team face a different challenge, resisting their managers' expectations that administrative, recordkeeping and compliance requirements should be prioritised over activities directly relating to students and teaching:

The resources could be minimal, the teaching could be really poor level, but it's all the administration side [that is valued]. We try to fight it in our own team. (Andy, teacher, Case C)

\section{Managing Epistemological Dilemmas: Secret, Sacred and Cover Stories}

The tension and conflict described by teachers Andy and Elise is created by what narrative educational researchers Connelly and Clandinin $(1995$, p. 4) might refer to as 'epistemological dilemmas'. These are dilemmas that occur as teachers learn that their views of appropriate and best teaching practice are in conflict with views outside of the safe and autonomous space in their classroom. Such dilemmas can also occur as teachers move forwards and backwards between two epistemological different spaces, between what happens in the classroom, and what is visible and happens in a professional sense outside of it (Connelly \& Clandinin, 1995). By examining teachers' work as they navigated the educational landscape both inside and outside of the classroom, Connelly and Clandinin (1995) identified the impact of contextual factors on teachers' behaviour and the expectations of others, such as researchers and policy makers, who seek to change the way that teachers work. They also learned of the ways in which teachers managed such epistemological dilemmas through the stories that they constructed and told about their practice: sacred, secret and cover stories (Clandinin \& Connelly, 1996).

The professional knowledge landscape which teachers must navigate in order to carry out their work, according to Connelly and Clandinin (1995, p. 25), is both 'intellectual and moral', and influenced by social context due to its composition of 'relationships among people, places, and things' (p. 5). It is also a landscape which is often changing, shaped by 'sacred stories' or 'what is coming down the pipe', through a 'funnelling process' (Clandinin 
\& Connelly, 1996, p. 24). Through the funnelling process, information and messages flow into the educational setting which are intended to change teaching practices. These are the sacred stories (Clandinin \& Connelly, 1996) which shape perceptions of good teaching practice. The VET sector is highly sensitive to political and economic influences (Harris, 2015) and therefore likely to be particularly susceptible to the influence of the funnelling process and the sacred stories that result (Schmidt, 2017). Certainly, the earlier discussion on VET managers' conceptualisations of advanced skills which were highly contextual and related to organisational and sector-wide influences would suggest this to be the case. The VET sector's sacred stories are likely to develop from communication of changes to VET policy, funding, curriculum, and legislation, as well as research about VET and VET teaching, including the projects which aim to understand VET teachers' skills and the capability frameworks which have been developed as a result. Sacred stories are also likely to be shaped by the organisation's communication of its goals, values and focus, the factors that inform and influence local policy and practice.

Teachers experience tensions, or epistemological dilemmas when their individual, authentic choices about teaching are at odds with the expectations created by the sacred stories. To manage these dilemmas, according to Clandinin and Connelly (1996), they develop 'secret stories' - stories lived out through authentic, moral practice and which happens in the safe space of the classroom. Josie, (teacher, Case A) for example, explained that the needs of students will always prevail in the sanctity of the classroom, regardless of sacred stories funnelled in as directives from outside. Classroom practice remains a secret story, and just as Nerida and Louise were appreciative its sanctity, Josie agreed that it was important to preserve this secret, safe space:

We don't talk about what happens in classrooms. (Josie, teacher, Case A)

Teachers may also need to construct 'cover stories' to preserve their individual, moral and authentic teaching practices. These are the alternative narratives teachers tell in environments outside of the classroom, to preserve its sanctity when they know their classroom practice or teaching priorities may not meet the expectations communicated through the organisation's sacred stories. Quite often these are the stories told by the innovators and early adopters (like Case B teacher Elise, for example) who face resistance when implementing alternative, innovative teaching practices or using new technology, for 
example. Andrea (teacher, Case B) described the challenges experienced by many VET teachers with advanced skills when they develop innovative practices which are not well accepted by their team or the organisation.

So there are some teaching teams who say 'we don't do that' and they say, 'no, that is not the way we do things, don't rush that'. And so it probably highlighted what they weren't doing. So that's the other thing - fitting in - that can block advanced practitioners. You know, just that team cohesion stuff, until the critical mass changes and we can say 'this is the way we do things now'. (Andrea, teacher, Case B).

It is important to note that Clandinin and Connelly (1996) regard secret and cover stories as neither good nor bad, however they do serve a purpose. The VET teachers with advanced skills involved in this research project, construct these alternative narratives to ensure that they can teach in the way they believe to be the best for the student, regardless of the constraints and conflicting priorities communicated through the sacred stories of the organisation and the sector. It also provides a way for them to manage the tensions that arise when others' conceptualisations on what constitutes a 'good VET teacher' differ from theirs, and to maintain their individual and authentic practice, even as expectations and conceptualisations change due to external economic, regulatory or political factors.

\section{Assertion 2}

While Assertion 1 dealt with VET teachers' and VET managers' conceptualisations of advanced skills for VET teachers, Assertion 2 sheds light on how advanced skills may be developed:

Assertion 2: Teachers develop advanced skills through a variety of activities and those with advanced skills take personal responsibility for their own continued learning and development

Professional development strategies and activities for VET teachers were historically coordinated at national, state, RTO and individual teacher level, or as a combination of these (Smith, 2009; Smith \& Keating, 2003). Since the 1990s however, the delegation of responsibility for VET has been devolved from the Commonwealth to the State Government, and the responsibility for professional development activities now rests primarily with the employing RTO and the individual VET teacher. While some of those who participated in the research study were longer-serving VET teachers with past experience of Commonwealth or State government funded and coordinated activities, their most recent experience and the 
experience of newer entrants to VET teaching has been limited to participation in opportunities provided or supported by their employer or in those which they funded themselves.

The research found that VET teachers with advanced skills attributed their development to a variety of learning activities. They valued the skills and knowledge gained from studying higher level educational qualifications, but many found the professional development options provided by their organisation to be of limited value, as they were most often related to compliance or other topics more appropriate to beginning teachers than to those with advanced skills. Most regarded the opportunity to learn from others, through formal or informal mentoring relationships, to be an important factor which contributed to their development as VET teachers with advanced skills. The research also found that those with advanced skills were generally committed to their own personal and professional skills development, and as such, took responsibility for their own learning and development needs, even if this meant that they self-funded their development activities and completed them in their own time.

In this section, I will explore the research findings on how VET teachers develop advanced skills, supported by evidence drawn from the case reports, the study's conceptual framework and the relevant literature. I will also examine the current approaches to professional development in Cases A, B and C in relation to the conceptualisation of advanced skills which has influenced them. This is important, as the types of professional development activities offered, supported and funded for VET teachers are likely to be those which support the development of the skills and knowledge most valued by their managers and the organisation. Conceptualisations of VET teaching skills which have been derived through a reductionist approach are more likely to align to a professional development strategy which is equally atomised and distilled, and which focuses on certain activities to develop a specific area of perceived need i.e. the skills and knowledge which the VET teacher is expected to have in order to demonstrate the capabilities expected by the organisation or articulated in the capability framework which the organisation depends upon to evaluate VET teaching skills. On the other hand, more holistic conceptualisations of advanced skills which emphasise the importance of the individual teacher and which charge him/her with a broader scope of influence and responsibility than that which can be articulated in a capability framework, may 
favour an educational approach which enables the development of the 'whole person', not just the specific technical skills, knowledge and capabilities required to perform competently in the job role.

\section{Higher level study and the development of advanced skills}

Even though requisite requirement for VET teaching is the Certificate IV in Training and Assessment, most of the VET teachers who participated in the research project had achieved higher level educational qualifications (from Diploma to Masters). Completing an educational qualification at Bachelor level or higher provided financial incentives - without it, teachers at Cases A, B and C were unable to progress to the higher levels of the salary scale, due to the stipulations of their relevant enterprise agreements. Regardless of the financial incentive though, all who had completed higher level qualifications valued the additional knowledge gained from their studies. Deborah (Case $\mathrm{C}$ teacher), for example, acknowledged that the Certificate IV in Training and Assessment was useful for new VET teachers as it provided them with VET specific knowledge and skills, however she felt that tertiary level educational qualifications were needed for a VET teacher to develop advanced skills.

I don't think that the TAE goes into the student, the teaching skills, and the theories behind it, and why we do what we do. I think the TAE is very good for unpacking training packages, and everything like that. It's at a Cert IV level though, so when you're doing a degree you're doing it at a much, a higher level, and on a deeper level. (Deborah, teacher, Case C)

Likewise, Case A teacher Sandra believed that tertiary studies in education improved the VET teachers' skills and knowledge for teaching.

I still do think that we need to actually start having teachers with degrees. Because I think, we need to learn that side of it [pedagogical theories and strategies for teaching], not just make it up as we go along. Because that's really hard to learn. (Sandra, teacher, Case A)

While most VET teachers in the study had tertiary level qualifications in education (Bachelor level or higher), some from Case B had also been supported to complete the Diploma of Vocational Education and Training. Case B teachers Andrea and Loretta in particular, spoke highly of the benefits gained by studying the Diploma, which was delivered by VET teachers from Case B's educator capability team, a team of teachers with specialist skills tasked with supporting the development of VET teachers' skills and knowledge at Case B. Andrea for example, stated that the Diploma was 'the real crunch qualification' for her, 
even though it addressed similar topics to the Bachelor of Vocational Education and Training she had completed earlier. The Diploma was, she explained, more 'relevant and applied' in the way that it was delivered and assessed. Case B teacher Loretta held a similar view, describing the Diploma of Training and Assessment as the most valuable professional development activity that she had completed due its practical, applied design.

I think that out of all of the professional development that I have done, the Diploma of Training and Assessment was probably the most valuable - not putting a downer on University, because University was great too, but it gave me a theoretical basis for stuff. But I found that the things we did in the Diploma were so practical and hands-on, and broke down the things that we do every day. I did it over a year - it was much more intensive than the Cert IV that I did, and some of the skills that I learned in that, I still use every day. I think that was a big stepping stone for me, you know, that 'aha moment' where I started to put things together. (Loretta, Case B teacher)

That is not to say however, that Case B's teachers and managers discounted the value of completing a Bachelor or higher level qualification. Most in fact, felt that it was necessary for a teacher to complete a relevant tertiary educational qualification to develop advanced skills. Case B manager Linda deemed it 'critical' to the development of essential pedagogical skills, and teacher Loretta felt that it helped her to develop the theoretical basis for her practice. Similarly, Case B teacher Andrea felt that the Bachelor facilitated her development of the 'foundation skills' necessary to be an effective teacher. She cautioned however, that the qualification had to be 'absolutely contextualised for vocational delivery'. At the time of data collection, and like others in the TAFE Queensland network, Case B VET teachers without a tertiary level education qualification were offered the opportunity to undertake a Bachelor of Education free of charge through an arrangement with an Australian University. Many teachers enrolled in the Bachelor of Education qualification, however according to Case B teacher Andrea, 'a lot of them were just doing it to get over the pay scale', and 'not actually implementing any of that knowledge'.

At the time of data collection, Cases A and B were implementing the newly developed TAFE Queensland Educator Capability Framework (TAFE Queensland, 2016). With a structure consistent with prevailing opinion in the Australian VET sector which calls for a professional development strategy leading to higher qualifications and greater teaching expertise (Corbel, Wheelahan, Forward \& Darwin, 2014; Guthrie et al., 2011; Hodge, 2014; Jones, Pitard \& McClusky, 2011; Rasmussen, 2016; Skills Australia, 2011; Smith \& Grace, 2011; Wheelahan \& 
Moodie, 2011), TAFE Queensland's Educator Capability Framework describes four hierarchical levels of capability aligned to 'qualification pathways' (TAFE Queensland, 2016, p.5). The lowest level, 'transitioning', aligns to achievement of the Certificate IV in Training and Assessment, and the 'highly accomplished' level to skills and knowledge gained through completion of Diploma Training and Assessment. To reach the 'leading' level, TAFE Queensland VET teachers are expected to complete a relevant Advanced Diploma, Bachelor or Masters qualification (TAFE Queensland, 2016, p. 7). Only the 'proficient' level is not aligned directly to a qualification level; instead it describes 'behaviours which demonstrate evidence of applied knowledge within educational practice' (TAFE Queensland, 2016, p. 7).

Despite the opportunity offered to Case A and B VET teachers to undertake fee-free tertiary education qualifications, not all are prepared to undertake the study required to transition to the higher levels of the framework's proficiency rankings. Case A teachers Maxine and Tony, for example, while nominated by their managers and peers as VET teachers with advanced skills, had not yet completed a higher level teaching qualification, and neither had plans to do so. Their decision was based upon time constraints and the level of commitment required to complete a part time University program while employed as a VET teacher full time. Both also questioned the value of undertaking a degree at this point in their working lives.

It's going to take me an awful long time to achieve that Bachelor's degree, and I just don't know whether I've got it in me to make the sacrifices that would be necessary to work full-time and to study. (Maxine, teacher, Case A)

Maxine's most pressing concern was whether the benefits of the Bachelor program would outweigh the sacrifices needed to complete it.

I would like to do it from the point of view that I feel as if I would give myself the confidence, [...] like I said, I'm often in situations where I'm conscious that I'm the least qualified person in the room, so I think it would be confidence boosting to have that qualification. Am I prepared to do it? Look, really I don't know. Like I said, this is my second career. (Maxine, teacher, Case A)

Tony felt that his age was a barrier, given the length of time it would take to complete the degree.

I decided to go against doing...I was offered to do the Bachelor [Education], but I'm probably getting a little bit long on the tooth for that. To do it while I'm working would take me about 8 years, and I'll sort of be retired by then. (Tony, teacher, Case A) 
While most of the VET teachers who participated in the project had completed higher level educational qualifications, those who had not, like Maxine and Tony, were still recognised and nominated by their managers and peers as VET teachers with advanced skills, indicating that while such formal study is valuable, it may not necessarily be essential for the development of advanced skills associated with 'good VET teaching'.

\section{Learning from others and the development of advanced skills}

Mentoring, according to teachers from Cases A, B and C, can assist beginning teachers to navigate their new role within the organisation and to learn the requirements of the complex VET system faster than they would without such support. According to Case $C$ teacher, Tagen, mentoring can also improve teacher retention by ensuring that 'teachers don't get lost in the system' (Tagen, teacher, Case C). Mentoring was certainly an effective support for Case A teacher Josie when she commenced a VET teaching role:

I feel relatively blessed that when I first started here...I was the beginner and I was mentored really well. They had done my planning for me, done my programs for me, would sit down with me and say, 'This is what we would like you to teach. Could you prepare your resources? We will review them. Do you need any help with typing, with developing your overhead projector things? We've done your timetable for you. We'll do your pay for you.' I felt very mentored and very safe. (Josie teacher, Case A)

Janine (teacher, Case B) described her mentoring experience as an internship, an invaluable experience which allowed her to learn from a number of different VET teachers.

I had a bit of an old fashioned internship I guess, in that I was already working in the department and I had lots of mentors and people to see...being in the classroom with various different teaching styles. (Janine, teacher, Case B)

Case $\mathrm{C}$ teacher Tagen agreed that it was advantageous for a VET teacher to have access to more than one mentor. She also felt that students benefited if their teachers were provided with a mentor, as the support beginning teachers received and the additional knowledge and skills they gained were likely to result in better experiences for the students they taught, thereby reducing attrition.

I think to develop really good teachers you need to have really good mentors. All teachers need a mentor, and they need to be appropriate mentors. Some people might need two mentors with different skills; they might need a mentor to give them tips for managing classroom behaviour, you might need another mentor to assist with the paperwork side of the job because we all have different 
skills. If you've got a good mentor that helps a teacher with classroom management, that helps your [student] attrition rate. (Tagen, teacher, Case C)

A mentor does not necessarily have to teach the same discipline or have a similar industry background to that of the mentee, according to Case $\mathrm{C}$ teacher, Britt.

Well I think the mentoring does work well if you've got good mentors in place. That doesn't have to be someone working in the same area; it's not so much that you're the content expert, but you're the support person. (Britt, Case $\mathrm{C}$ teacher)

Case A no longer supported formal mentoring programs for its VET teachers. At the time of data collection however, Case $C$ was considering the introduction of such a program as part of a VET teacher professional development pathway, and Case B had recently introduced an induction program in which new teachers were assigned a mentor for six months. The mentors assigned to beginning teachers were trained to ensure they had the skills and knowledge required to be effective mentors. Case B manager Diane spoke favourably about the initiative.

I think that one of the things that we do here now that we didn't do before, that I think is very helpful, is that we try and give a mentor to new staff and I think mentors that role model the way obviously give that impression to new teachers about seeing a teacher who is progressive, who has advanced skills, how well they do in their classroom and outside their classroom. It's a good way for new teachers to see that is a positive way to go. (Diane, manager, Case B)

While Cases $A$ and $C$ do not currently have a formal mentoring program in place, VET teachers from both organisations still find opportunities to learn from others through informal mentoring and networking opportunities. As Case A teacher Tony explained, 'There's informal stuff in the smoko rooms, in the lunchrooms - we're always talking' (Tony, teacher, Case A). Similarly, Case A teacher Nerida also found that there were opportunities to learn from others if a teacher developed the appropriate networks.

...more than anything, the informal is the best; always is, always get the answers. And that's where it relies heavily on your networking. (Nerida, teacher, Case A)

At Case $C$, teacher Andy is proud of the supportive networking culture developed within his team, which he explained, provides an opportunity for all teachers to learn from others and gain support to improve teaching practice. 
We have a culture we believe works, and I think it's very good but I'm obviously biased. We ease a person into that culture and we've got a very open policy within the staff. We discuss teaching situations on a regular basis, how to do this and 'I want to teach this; have you got any good ideas?' or, 'I taught this the other day and this is not working, and this is what we're teaching here. How are we doing? We've got to change. How do we change it?' (Andy, teacher, Case C)

It is not only beginning teachers who can learn from others - even those with advanced skills valued the opportunity to communicate with other VET teachers in order to develop their knowledge and skills. If networks are not readily available to them, VET teachers with advanced skills will find or create them. Some of Case B's VET teachers for example, participated in information sharing networks outside of the organisation. Teacher Andrea felt that TAFE Queensland VET teachers had ample opportunity to network with others as each region was part of the larger TAFE Queensland network. She also felt however, that it was important for VET teachers with advanced skills to develop networks outside of TAFE Queensland in order to meet their professional learning needs, which, she believed, were different to those of less experienced VET teachers. According to Andrea, VET teachers with advanced skills relied upon these networks to 'validate' their own practice as they often felt isolated within their teaching teams due to being 'early adopters' and innovators.

The little circle they are in, the team, often the early adopters are seen as something different, and they are not getting the nourishment from the team. And I say 'you need to get outside and get nourishment from outside' and so their satisfaction and their professional development and their validation from peers will come from outside the network. (Andrea, teacher, Case B)

Andrea has established what she refers to as 'Personal Learning Networks' with contacts 'literally across the world'. She communicates with those in her networks face to face and through a variety of virtual networking platforms, and uses the networks not only to fulfil her own developmental needs, but also to influence the development of best practice in the organisation and VET sector.

So I have an extensive PLN - Personal Learning Network - that I draw on. And I'm in LinkedIn groups, twitter spaces, yammer spaces, I'm in all sorts of different spaces. And I still do that today to get a bit of quick learning, so I get a lot of just-in-time learning and I am forever scanning that sort of thing to improve my own development and to see where I can transfer that knowledge into helping the VET sector. (Andrea, teacher, Case B) 
Similarly to Andrea, Case B teacher Elise also participates in external networks through online social media platforms. She uses the networks to increase her knowledge and skills in her vocational teaching area and to validate her current practices, particularly those that others may consider innovative or unconventional.

I am really heavily involved in the [Industry sector] Facebook page which does sound like a really silly thing to do, but it is so valuable. I am part of lots of teacher groups online. Online is a big thing for me because it means that I can be communicating with people not just in Australia. I have lots of people that I talk to in the UK and the US and Sweden so I can see what is happening around the world. And I can go 'oh wow, look at that', or 'hey, that is best practice and I am already doing that'. (Elise, teacher, Case B)

Not all attempts to create networks are successful though, as teachers' efforts to create and participate in them are not always supported by their managers or the organisation. Jon (teacher, Case B) for example, related the story of a teacher who tried to establish a Community of Practice within Case B to provide an opportunity for teachers to learn from each other. Unfortunately the project did not gain support from the organisation and was unsuccessful:

There was a person who tried to establish a proper Community of Practice here, but her project was shut down. I think that was due to a political/personal decision. I think that there is...I am not sure how the bureaucracy actually operates, but if you are starting to jump out and be very innovative, it may come with consequences, and it probably will. (Jon, teacher, Case B)

For Australian VET teachers, the opportunity to participate in networks with other teachers has likely diminished since the Reframing the Future program ended in 2008. An initiative of Commonwealth, State and Territory Governments, the program was funded from 1997 - 2008 to build 'capacity of the Australian vocational education and training (VET) system to support the implementation of the national training system and the aims of the Council of Australian Governments (COAG) and its national reform agenda' (Reframing the Future, 2008). The program's goals were to provide VET teachers with professional development opportunities aligned to improving the quality of $C B T$, responding to the needs of students and industry, and increasing productivity of the VET workforce (Reframing the Future, 2008). For more than 66,000 VET teachers, Reframing the Future provided access to numerous networking opportunities, including 'Practitioner Forums' and 'Communities of Practice' before it ended in 2008 (Reframing the Future, 2008). The research findings indicate 
that VET teachers highly value such opportunities to learn from and network with other teachers, so much so, that even if opportunities are not readily available, they will locate or create the opportunity themselves. For beginning teachers, access to mentors and networks of other teachers provides an opportunity to gain the all-important understanding of the organisation and the VET sector. Viewed through the lens of social constructionism, this is a necessary component of meaning making, of learning the pre-existing, inherited and socially communicated meanings, culture, environment, society and institutions - the things described by Heidegger (1962, p. 65) as the 'world always already there'. The ongoing opportunity to learn from and with others is also necessary for VET teachers with advanced skills, for as Preskill (1998, p. 344) points out, 'the work of making the self is the labour of a lifetime occurring in concert with others, not in isolation from them'.

\section{The importance of the individual and personal agency in developing advanced skills}

The previous section presented findings which indicated that VET teachers with advanced skills value the opportunity to network with and learn from others, so much so, that they will seek these out or develop them on their own initiative if suitable opportunities are not available in their work environment. This is an example of the personal agency demonstrated by VET teachers with advanced skills, who take responsibility for their own professional development even if they are not supported to do so by their employer through financial assistance or the provision of time off to undertake learning activities. Case $\mathrm{C}$ teacher Candy, for example, has attained a number of vocational and tertiary qualifications in various disciplines, explaining that learning is something that she intends to continue throughout her life.

I've paid for all of my education as I like to invest in myself. Also, when I pick a pathway and I can see how that interlinks and how that's going to assist me to go further l'll do that. So you see it's like a building, it's like scaffolding, learning as you're going through life. (Candy, teacher, Case C)

Similarly, Andy (teacher, Case C) is still conscious of his own developmental needs, even after more than 40 years as a teacher.

I'm always aware of doing a better job as a teacher. I haven't hung up the boots there and said, 'Well, this is as good as I'll be'. (Andy, teacher, Case C) 
Fran (teacher, Case A) believed that it was important for VET teachers to demonstrate a personal commitment to continually update their skills and knowledge, particularly in relation to technological changes.

....just keeping up with the technology and whether you want to or not, going with that and continually refining your training and assessment skills, because technology keeps changing we sort of have to be focused on how to improve those skills that have a technology component. (Fran, teacher, Case A)

Case A teacher Louise is also committed to her own personal and professional development, and is particularly focused on increasing the skills and knowledge relevant to her industry discipline. Even though such activities help Louise meet the VET teachers' legislated requirements to maintain industry current skills and knowledge, she is still required to commit her own time and finances to her ongoing development, a situation which she reported to be common amongst VET teachers:

Yeah, [professional development is done] in your own time...and there's been many years where I've done seven days of nothing else. (Louise, teacher, Case A)

Like Louise, Sandra (teacher, Case A) also managed her own professional development including the financial costs.

Well, to be honest, I've always done my own professional development. I've paid for all of my professional development. I don't think they've ever paid for any of it. (Sandra, teacher, Case A)

Astrid (teacher, Case A) described herself as a 'lifelong learner', explaining that she is perpetually focused on self-development. Some activities have been supported and funded by her employer (Case A), however, even without that support, Astrid admits that she would continue to participate in learning and development activities. As well as enjoying learning and the opportunity to extend her skills and knowledge, Astrid valued the experience of being a learner and felt that it helped her to improve her own teaching skills and knowledge.

I just recently did an online course myself in a subject that I'm pretty familiar, I didn't need to do it but I just wanted to be forced to be a bit creative, and it was really good, it was a really good model. It's good [being a student] because you can see how things affect you and how you learn, and how you fix things that you like, things that you don't like, and different ways of doing things. I am always trying to understand how to do things better and appreciate different people's circumstances and how they're going to get the most out of what they're doing with us. (Astrid, teacher, Case A) 
Case $\mathrm{C}$ teacher, Rachelle, also valued the insight gained by switching from the familiar role of teacher to that of learner. She explained that 'learning from being a learner' meant she could not only learn new techniques and practices to improve her teaching skills, but also what not to do as a teacher.

It's only when you're sitting in a class yourself and you realise that the teacher probably hasn't been well prepared and that it isn't sort of running how it should be run. (Rachelle, teacher, Case C)

Many of the VET teachers with advanced skills who participated in the research project expressed a passion for both their industry discipline and for education. Given their interest in both, and the legislation which requires VET teachers to maintain teaching currency and to continue developing knowledge and skills for VET teaching and assessment (Clause 1.16, Commonwealth Government of Australia: Department of Education and Training, 2015, p. 19), it is unsurprising that most professional development activities they undertake are directly relevant to either their industry discipline or to education. VET teachers with advanced skills do not necessarily limit their development to these specific areas however. Many reported a wide range of developmental interests, and had undertaken both formal and non-formal activities to learn new knowledge and skills in unrelated disciplines. Case B teacher Jon, for example, explained that by pursuing personal development in a diverse range of interests, he also develops as a teacher.

I don't focus only on education. For example, I have a keen interest in politics and how politics unfolds in the bigger picture, especially in the Europe and the US - so I follow that and the easiest way to do it is through open courses and online and webinars that are open for different interests that I have. So one hand, I get the information that I want for personal growth. But on the other hand I see the possibilities of online environments for delivery. (Jon, teacher, Case B)

VET teachers with advanced skills recognise the value of learning - not just the learning prescribed by legislative requirements for industry and educational currency, but learning which provides both personal and professional development. Such a holistic approach to development is important if one is to recognise the importance of the teacher's unique, individual character in teaching, 'the distinctive, irreproducible human being who inhabits the role of the teacher' (Hansen, 2001, p. 1). Such a personalised and individual approach to teacher development would likely be supported by Greene (1988, p. 238) who stated that, 'We are not, after all, disembodied, decontextualized, nor even degenderized human beings', and who encouraged teachers to become learners themselves, to become 
'personally involved in the processes of coming to know and understand' (Greene, 1988, p. 239). Likewise, Noddings (2012, p. 777), believing the best teachers to be those with an 'unusually broad intellectual competence', recommends a rich, broad education and development strategy that enables them to draw upon 'literature, history, politics, religion, philosophy, and the arts' (Noddings, 1999, p. 215).

The research found that VET teachers with advanced skills were committed to their ongoing personal and professional development, and frequently expended their own time and money to facilitate this. They also identified a number of barriers however, which impeded the development of advanced skills for VET teachers. These will be dealt with in the following section.

\section{Assertion 3}

The previous section dealt with Assertion 2 and the research findings in relation to the question: 'How do VET teachers develop advanced skills?' This section will discuss Assertion 3 and the factors which may impede the development of advanced skills for VET teachers:

Assertion 3: The development of advanced skills may be negatively affected by insufficient resources and an unbalanced approach to professional development.

The research study found that even though VET teachers committed their own time and financial resources to their professional development, resource limitations impacted upon their ability to participate in learning activities. It also found that an unbalanced organisational approach to professional development which emphasised activities relating to compliance and industry currency requirements may have a negative impact on the development of other skills and knowledge required for good teaching.

\section{The barrier of limited resources}

VET teachers from all three Cases identified resource constraints as a significant barrier their ongoing professional development. Financial support to attend professional development activities was limited, and in some cases, competitively allocated. Case A teacher Louise, for example, explained that although she had completed many professional development activities, attended conferences and undertaken formal study, she had only been able to do so by paying for the activities herself. 
Getting funding for it [professional development] is near impossible in terms of the size of the [organisation's] budget so you have to fit it in within what the small budget might be. Obviously that's a competitive process as to who might be able to get funding to go to a conference or funding to go to a workshop and industry events and things like that. So, that's fairly limited and I guess the rest of it comes back to individual motivation. So, to do my Masters and every skill I've learned to improve as a teacher has been self-driven; it hasn't been supported by the institute. (Louise, teacher, Case A)

Teacher Nerida, also from Case A, related a similar experience:

...conferences, really enjoy conferences, really hard to get to because they cost money and they're expensive, so we try as best we can to go to professional development events. (Nerida, teacher, Case A).

Case B teacher Loretta felt that budget constraints were not just preventing VET teachers from attending external professional development events, but also impacting upon the way that beginning teachers were supported to develop VET teaching capabilities. Higher wage costs and an increasingly competitive VET market, she felt, had resulted in greater expectations for new teachers, with less opportunity for team teaching and the sharing and mentoring associated with such a practice.

I think in the past we were better at it, we had the budget, we had much more lead time. We are trying to stay competitive - you can't put two teachers in a classroom together. The cost of teachers at TAFE is very expensive - we pay a higher cost for that reason. I think we have less lead time. We get people and say, you're starting - now go. (Loretta, Case B teacher)

Budgetary constraints weren't the greatest barrier to developing advanced skills for Case $C$ teacher, Tagen. She explained that at Case C, each teacher has funds allocated to him/her for professional development, and in her experience, approval to attend activities was not difficult to attain as long as the activity did not clash with the teaching timetable.

We have allocated PD [professional development] money. The manager I've got, as long as you're not actually physically teaching [when the PD event is scheduled] is happy to support, and you haven't gone outside your allocated money. (Tagen, teacher, Case C)

Herein lies the problem, according to Tagen, as increasing workloads, which include not only teaching, but assessment and administrative tasks, reduce the time that the teacher has available to attend professional development activities.

In the last 12 months I haven't done too much [professional development], but that's because every time there's something on I've got other commitments for the organisation. (Tagen, teacher, Case C) 
Tagen's experience is certainly not unique. Case C manager Brian, for example, while lamenting the fact that not enough time is allocated to training for VET teachers, acknowledged that it is sometimes too difficult to replace teachers on high teaching workloads, particularly when in some areas, teachers are already working overtime. Similarly, teacher Andy explained that while Case C provided an 'enormous number of opportunities' for professional development and is genuinely supportive of VET teachers' needs, it is often very difficult for them to take advantage of the opportunities available.

When it comes down to the coal face sometimes it's a case of, well, I could go for that course next week but results have to be in. There always seems to be that extra teaching duty that overrides. (Andy, teacher, Case C)

Similarly, VET teachers from Cases A and B also reported that their professional development had been impacted significantly by constraints associated with time. Case A teacher Anita, for example, found it difficult to find enough time to attend even the compulsory training activities provided internally:

There seems to be a lot of push for, and I know it's important, like we have to be compliant, and these sort of things, but there's this constant push for us...go and do this, go and learn this, go and get on to this webinar, go and do this. And it's about, it's time, like it's finding the time to do that and to fit it in. But then also applying that to what you're doing. (Anita, teacher, Case A)

Josie (teacher, Case A) conveyed a similar view. Even though interesting and relevant professional development activities might be available, she found it difficult to find the time to attend them.

It is very much about time. There's a lot of professional development things that l'd like to do, like, I probably on a weekly basis get emails saying, 'This PD's here.' And I think, 'That'd be good. That'd be interesting.' But when you're teaching and when you're doing all of the extra advanced practitioner skill things, there's very little time for it...because to do PD it should be something you can do when you're not completely worried or stressed about other things, and then you can reflect on it and look at how - it's a bit like you're doing training outside work. It's just an added extra thing to do. (Josie, teacher, Case A)

Case C teacher Jon expressed a sense of frustration, as the demands of an 'unrealistic workload' and 'unrealistic expectations' (Jon, teacher, Case C), meant that he found it difficult to participate in professional development activities. Even if VET teachers received the financial support to attend a professional development activity, prior teaching commitments 
may still preclude their participation without the appointment of a replacement teacher. Without an allocated budget to fund a casual replacement teacher, other team members were expected to accommodate the additional workload, a situation which Case $A$ teacher, Nerida found unacceptable.

Time. Massive. Massive barrier. Massive. No one is ever backfilled. If you're away for a week no one will come in and do your workload. Your work colleagues will do your workload. (Nerida, teacher, Case A)

Josie, also from Case A, related a similar experience and pointed out that the situation is a more recent development due to increasing workloads.

You know, we have really full teacher loads now, and there's - it used to be - back in the day, if you needed to go for a three day conference that was an easy thing. Now, if you go for three days somebody has to replace you and they generally don't get any time or pay for that. So that is harder. (Josie, teacher, Case A)

\section{Unbalanced approaches to professional development and the impact on advanced skills}

As well as resource constraints, the research suggests that an unbalanced approach to professional development which emphasises industry currency or compliance related content, may limit the range of learning opportunities available to VET teachers and have a negative impact on the development of advanced teaching skills. Evidence from all three Cases indicated that RTOs may implement professional development policies and strategies which directly or indirectly create such an imbalance in an effort to ensure compliance with the sector's regulatory standards. This may be an overzealous approach however, based upon the variable and sometimes conflicting interpretations of the legislated Standards for Registered Training Organisations 2015 (Schmidt, 2019 in print), and one which has implications on teachers' workloads as well as their ongoing professional development as VET teachers with advanced skills.

\section{Unbalanced approaches which emphasise industry currency}

According to the regulatory requirements for Australian RTOs, VET teachers must hold vocational competencies at or above the qualification level they teach, as well as relevant current industry skills (Commonwealth Government of Australia: Department of Education and Training, 2015, p. Clause 1.13). To meet these requirements, they must have been employed in a related occupation prior to becoming a VET teacher, thereby becoming 'dual 
professionals' with a requirement to develop and maintain both industry and educational skills (Productivity Commission, 2011, p. XXI; Commonwealth Government of Australia: Department of Education and Training, 2015). Australian Skills Quality Authority (ASQA), Australia's VET regulator, maintains that quality training and assessment depends upon VET trainers and assessors holding current skills and knowledge in both their industry area and in vocational education and training (Australian Skills Quality Authority, 2017, p. 61). Further, VET teachers, managers and students regard current industry knowledge as essential to good VET teaching practice (Clayton et al., 2013; Schmidt, 2017; Smith \& Yasukawa, 2017). There is some confusion however, on what is required to fulfil VET teachers' industry currency requirements (Clayton, Jonas, Harding, Harris, \& Toze, 2013; Dickie et al., 2004; Wheelahan \& Moodie, 2011). Schmidt (2019 in print), for example, reported varying and sometimes conflicting views in the way in which policy is translated to practice by RTOs, RTO managers and the regulator, and suggested that too great an emphasis may be placed on industry currency activities, leading to an unbalanced approach to VET teachers' professional development. There is a 'lack of clarity on the volume, duration and frequency of activities' (Schmidt, 2019 in print) considered sufficient to meet a teachers' industry currency requirements and because of views which focus on a 'narrow range of sometimes trivial industry currency activities which yield little improvement of industry skills and knowledge for VET teachers', other 'richer developmental opportunities' may be overlooked (Schmidt, 2019 in print).

According to the legislated standards, VET teachers may maintain industry currency skills and knowledge through a variety of activities. Regulators and managers however, are likely to place greater value on those activities which require VET teachers to interact directly with industry, such as 'industry release' in which teachers are paid by the RTO while they volunteer in a relevant role with an industry employer (Clayton et al. 2013; Schmidt, 2019 in print). VET teachers from Cases A and B are employed according to Queensland TAFE Educators Agreement, which requires them to undertake 'a minimum of 10 days professional development and release to industry' (Queensland Industrial Relations Commission, 2016, p. 24) each year. There is no guidance, however on how many of the 10 days should be apportioned to maintaining industry currency and how many to other professional development activities. Although Case C's VET teachers are employed according to a different 
Enterprise Agreement to VET teachers from Case A and B, it has similar provisions and equally limited guidelines on the proportion of the agreed professional development time which should be attributed to industry currency activities.

VET teachers from Case A, B and C reported significant barriers to participation in industry currency activities. Many reported timing and workload issues, while others found it difficult to access appropriate, meaningful and productive activities, a finding consistent with that reported by Toze and Tierney (2010, p. 8). Case A teacher, Sandra for example, found it difficult to schedule industry release around her full time teaching role. Sandra works part time in her own business, but this is not regarded as an approved activity by her employer, even though the tasks she performs in her business are the same as those she is required to undertake during industry release.

I can't work in my own business for industry release. I thought, okay, that's fine, l'll go work for someone else. Which is a little bit hard sometimes, when you're working [as a VET teacher] full time. (Sandra, teacher, Case A)

Sandra was frustrated by her employer's lack of flexibility about industry release and regarded it detrimental to her ongoing development, given that approved industry release activities provided exposure to only 'basic industry' and prevented her from attending 'advanced high end industry activities' more appropriate to her level of skill (Sandra, teacher, Case A). Similarly, Case C teacher Jocelyn reported that the organisation's approach to industry release meant that many teachers were attending activities of little developmental value. Explaining that 'some of the industry release is not worth a toss', Jocelyn described the experience of a cookery teacher, who was required to complete industry release at a local restaurant in order to meet the requirements of the Case C's industry currency policy, even though he was 'a very talented chef' and gained very little from the experience.

It is no benefit for him to go to a local restaurant, where he probably taught those apprentices and now they're chefs. He's got nothing to learn from them other than what he could probably pick up in an industry visit for a couple of hours. What he would really benefit from is going to a wine and food event or a conference. (Jocelyn, teacher, Case C)

Some teachers, such as Kassandra (teacher, Case C), reported that they managed their industry currency requirements by working part time in industry. Case B manager Alexandra, reported that this was also the case in her organisation, and expressed concern that the 
practice was detrimental not only to the VET teachers' health, but also to their development as a teacher.

They [the regulators and the RTO] focus so much on currency and full timers have to get part time jobs on the weekend to maintain their currency, rather than focusing on making them a better teacher. They get so rundown and tired because they have to do the extra work on top of what they are doing here, and I don't think that it makes them any more current. (Alexandra, manager, Case B)

Like Alexandra, Case C manager Sonya was concerned that too great a focus on industry currency, particularly when combined with the demands of a full time teaching load, was detrimental to VET teachers' development. She explained that one VET teacher described himself as a woodcutter who never has time to sharpen his axe' (Sonya, manager, Case C). Similarly, Case B teacher Jon expressed concern that the organisation's focus on industry currency was detrimental to teachers' professional development.

As an Institute, it seems to me that they are now stuck on industry currency and industry currency is not improving teaching performance, because if you want better teachers you have to focus on their teaching skills. Industry currency can improve their knowledge, but not their teaching skills. (Jon, teacher, Case B)

Jocelyn (teacher, Case C) described the negative impact that such a focus on industry currency may have on VET teachers' development:

I think as an organization, there has been a lot of focus on professional development and currency around your technical expertise and very limited PD around teaching practice. So, we're asking people to think of themselves as teachers, but we're not helping them develop those skills. (Jocelyn, teacher, Case C)

Likewise, Ed (teacher, Case C) agreed, explaining that an unbalanced approach to professional development which prioritised a teachers' industry currency over the development of pedagogical skills and knowledge is likely to result in the teacher thinking of himself as a 'tradesperson employed by the university, rather than a VET practitioner or teacher' (Ed, teacher, Case C).

The research suggests that for VET teachers at Cases A,B and C, current policies and practices have resulted in an unbalanced professional development approach, which emphasises opportunities relating to industry currency requirements and which supports participation in a relatively narrow range of activities. This essentially reductivist approach 
tends to overlook the value of other activities which may yield richer, more meaningful developmental opportunities and as such, may impact negatively on the development of advanced skills for VET teachers. This is also likely to be the case for other RTOs, as Tyler and Dymock (2017), who undertook a review of continuing professional development for teachers in the sector, found that VET teachers were more likely to undertake professional development activities which focused on compliance with regulatory requirements than on VET teaching quality (p. 46). Such imbalance has become increasingly evident since the responsibility to meet VET teachers' professional development needs (relating to both regulatory requirements and the improvement of VET quality) has shifted, from once being shared by the Commonwealth, the State, RTOs and the individual VET teacher (Smith \& Keating, 2003), to now lie primarily with RTOs and teachers (Braithwaite, 2018; Productivity Commission, 2011; Wheelahan \& Moodie, 2011).

\section{Unbalanced approaches which emphasise compliance}

Industry currency is not the only compliance-related factor to impact upon professional development strategies for VET teachers. The research found that all three Cases provided organisation-wide professional development opportunities for VET teachers, some compulsory, others voluntary. Case A, for example has developed and implemented a range of professional development activities for VET teachers, primarily provided online through webinars. Teacher Fran found the organisation's professional development offerings, including the webinars, useful.

I think the webinars, personally, are really useful, and also at the start of the year, we were given a professional development session on the new standards for this year and how it would affect us, what will we need to do that's different from what we have been doing. So that was really useful. So I think it's, to me a lot of the knowledge and skills that we have aside from teaching is from professional development. (Fran, teacher, Case A)

Many Case A teachers however, were more critical of the webinars and professional development activities they were required to attend. Case A teacher Nerida, for example, found the training more relevant for beginning teachers, describing it as too 'simplistic and generic' for those who had been teaching 'longer than a year or two' (Nerida, teacher, Case A). 
They're just so broadly generic, you know, just give me a textbook and show me the page where I need to read the same information, really it's too generic; it's just so generic, I never last through the whole session because I don't learn anything. (Nerida, teacher, Case A)

Anita (teacher, Case A) was also critical of the webinars, explaining that the mode of delivering the training program was not always appropriate or suited to all learners.

But the interesting thing is that they're saying inclusive, inclusive, inclusive, and then they run these workshops that are not inclusive. I think that's quite interesting, that they do that. They're usually done by a webinar, by just one person. (Anita, teacher, Case A)

Likewise, according to Case A teacher Louise, many of the compulsory training sessions could be better presented in a different format. For example, some, she believed, would be better communicated as an email, than as a training session.

We had to go along to one just recently and listen to someone talk for an hour on a video conference that was stuff that we'd already been told in a one minute email. We got rapped over the knuckles as to why we hadn't cancelled a scheduled class to go to a video conference to listen to this for an hour. (Louise, teacher, Case A)

According to teachers Sandra and Nerida, Case A should ensure that professional development programs offered to VET teachers were aligned to their needs and level of experience.

I sometimes think, when they're looking at giving you professional development, they need to look at you specifically. Okay, well this person's got this degree, this degree, this degree, so they need this high end stuff. Whereas this other person is just, not just a Tutor, but a Tutor with a TAE, so they need more of that base ground stuff. How do we write Assessments? What's inclusive learning? All that sort of stuff. Whereas I tend not to need that, because I know how to do it. Me going back and doing that, is super boring. (Sandra, teacher, Case A)

Like Case A, Case B also provides workshops to its VET teachers on topics relating to compliance and teaching. According to manager Linda, though, Case B also implemented a professional development strategy based on a 'champion' model with the aim of increasing the sharing of knowledge and skills across the organisation and enabling the development of advanced skills. Champions are appointed based upon their advanced skills and knowledge in a particular area, which they are then required to teach to other VET teachers in the organisation. 
So we are trying to build this champion model to try and ensure that we are getting the best bang for our buck in that professional development team; so that they train the trainers in the team, and those trainers continue to pass on information. So we do have PD [professional development] programs e.g. LLN [language, literacy, numeracy] and inclusivity. But we are trying to build those advanced skills people, making sure that they do exist, that they do have access to the professional development and that they do pass on their expertise to their team members. (Linda, manager, Case B)

Some Case B teachers spoke highly of the professional development offerings provided to them. Loretta, for example, felt that both Case B and TAFE Queensland in general were 'brilliant' at providing professional development. Courses and workshops provided by Case B itself were provided at no cost to participants, and according to Loretta, the organisation also funded certain external development options.

They offer a lot of courses free of charge, my university was free of charge. They paid for my entire [education] degree. They paid to put me through - well the Diploma [of Training and Assessment] was run by our Educator Support team so of course I didn't pay for that. (Loretta, teacher, Case B)

Like Case A however, some of Case B's VET teachers with advanced skills were more critical of its professional development strategy. Jon, for example, felt that the professional development activities provided by the organisation were developed on an assumption that all teachers were novices, did not recognise existing skills and knowledge, and some cases, were repetitive.

It seems to me that they are using the lowest common denominator for that [professional development]. For instance, at the moment, the latest buzzword is validation and everything is around validation. And we have another training for validation. I have already attended two full day workshops on validation, and yet I have to attend another one. If you do one in April, what more can you learn in June? (Jon, teacher, Case B)

Jon also expressed frustration that opportunities offered by Case B were predominantly focused on compliance rather than on topics which might improve teaching quality.

I think it would be nice to have something else, something that can help us to further improve, not just validation or compliance, but something that is about creative teaching or inspiring. (Jon, Case B teacher)

Like Cases $A$ and $B$, Case $C$ has policies and procedures in place to manage the professional development of its VET teachers. Professional development activities are monitored and recorded through a web based platform which attributes points for each 
relevant activity undertaken. Using this system, VET teachers must accrue and record 100 points each year, with points attributed to various activities according to the time commitment required and the activity's relevance to the teacher's educational and/or industry developmental requirements. According to Case $C$ teacher, Tagen, the system as quite structured and also somewhat prescriptive in terms of the professional development activities acknowledged and supported, explaining that reporting options are limited to industry visits, industry meetings, specific professional development activities and release to industry.

There's a breakdown, and it's very descriptive. You can't guess it, so you go in and you have to actually lodge your evidence under the tabs; it actually gets checked, and then you get those points allocated. So you can anywhere from 5 to 15 points, depending on the activity. For a 3 day conference you might get 20 points. (Tagen, teacher, Case C)

As well as industry currency activities, teachers can record activities relating to 'teaching currency' using the system. These activities also contribute to the required 100 points, however Case $\mathrm{C}$ teacher Rachelle argued that it was difficult for some VET teachers to achieve points for teaching currency as the prescribed activities do not necessarily relate to their day to day teaching role and the activities that will be approved and recorded are primarily focused on compliance.

Well it's a variety of activities that we can do, and it's split between industry currency and training currency. You have to reach 100 points by the end of the year, and there's two tabs. So there's a tab for industry currency and it's broken down into industry visits, industry meetings, professional development, industry release. The other tab is teaching currency, which is more difficult to attain. The most that the majority of us can get is [participating in a] validation panel, so we nearly can only do validation panels to get training currency. (Rachelle, teacher, Case C)

The validation panel which Rachelle describes is comprised of VET teachers and those responsible for managing compliance in the organisation. It is essentially a compliance and continuous improvement focused process, in which the panel evaluates assessment activities against a range of quality criteria to ensure that assessment activities meet the requirements specified by the curriculum and other quality indicators. While participating in such a panel might enhance VET teachers' skills to develop compliant assessment, it seems unlikely to contribute much to the development of other skills required for teaching. Case $\mathrm{C}$ provides other professional development opportunities for teachers within the organisation, however 
due to its origins as a university, managers Sonya and Paul felt that the content of the internal learning and development activities were more relevant to higher education, and needed to be adapted to be more relevant to VET.

Any of the learning and teaching that comes out is designed under a HE model, and so it's up to the teachers to transpose that knowledge into their [VET] style. (Sonya, manager, Case C)

The compliance-focused professional development strategies described by VET teachers could be feasibly perceived as an instrumental or reductionist approach to VET teacher development; one which emphasises the development of a narrow range of skills and capabilities in order to meet compliance requirements and which overlooks the importance of other capabilities and qualities necessary for good VET teaching. While it is undeniably necessary for VET teachers to understand and develop the capabilities to meet their responsibilities according to the regulatory framework of the VET sector, VET teachers have suggested that it may be possible to do so while still providing opportunities for other, more diverse professional development activities which are more likely to support the development of advanced skills. Further, just as VET teachers with advanced skills exercise their existentialist freedom and responsibility by making authentic choices which guide their classroom practice, so too do they apply this when making decisions about their own ongoing personal and professional development.

Connelly and Clandinin's (1995) theory of secret, sacred and cover stories provided a useful framework for understanding the way that VET teachers manage epistemological dilemmas within their professional teaching landscape. It may also be applied to understand the way they negotiate the different places and perceptions which make up their professional and personal knowledge landscape. Perceptions of teachers' knowledge bases and the landscape they must navigate outside of the safe space of the classroom also influences the type of professional development opportunities provided to VET teachers. As the research suggests, the professional development activities proffered and prescribed to VET teachers with advanced skills are often not relevant to and not valued by them. To overcome this, they pursue their own professional and personal development activities and trajectories, creating a secret learning space for themselves which cannot be impacted upon by the sacred stories and influences outside of that space. Just as they make individual, authentic decisions about what happens in the classroom, they also exercise that judgement in the professional 
development activities that they choose to participate in. VET teachers with advanced skills still manage their compliance responsibilities however, and in this way they develop the cover stories needed to appease managers, regulators and others who need to monitor and report on such compliance. In this way, they quietly, yet determinedly and authentically maintain their resistance to external influences in order to retain their individual personhood.

This chapter has presented the project's findings, by discussing the three Assertions and revealing interesting and somewhat compelling insights about advanced skills for VET teachers and how they are developed. It has, however, also left us with a problem - what are the implications of the findings, and what should now be done? Chapter 9 will conclude the thesis by elaborating on these implications and proffering suggestions for a way forward into the future.

If the teacher agrees to submerge himself into the system, if he consents to being defined by others' views of what he is supposed to be, he gives up his freedom 'to see, to understand, and to signify' for himself. If he is immersed and impermeable, he can hardly stir others to define themselves as individuals. (Greene, 1973, p. 270) 


\section{CHAPTER 9 CONCLUSION}

The teacher as person is centrally important in teaching. A physician can concentrate entirely on treating her patients; so long as she exercises the virtues that reflect her expertise, her personal character and personality matter very little. But the teacher sets an example with her whole self- her intellect, her responsiveness, her humour, her curiosity . . . her care. (Noddings, 2003, p. 244)

Chapter 8 presented and discussed the study's key findings through its three primary assertions. This concluding chapter poses and briefly elaborates implications of these findings for Australia's VET sector and its teachers.

Conceptualisations of advanced skills impact the way in which VET teachers' performance and professional development are managed, and how 'good VET teaching' is recognised and rewarded. There is an established link between VET teaching quality and student outcomes (Braithwaite, 2018; Walker, 2012; Wheelahan \& Moodie, 2011) and the 'quality of the VET system is only as good as its teachers and trainers' (Harris, 2015, p. 16). Therefore, practices which impact upon the provision of 'good teaching' will also impact upon student achievements and perceptions of quality in the sector. The sector's current reductionist emphases, based on capability frameworks and competency based standards which seek to atomise VET teachers' capabilities into comprehensive lists of discrete skills, knowledge and behaviours, may produce tools which are useful as industrial instruments to articulate the requirements of the VET teacher's job role in an organisation. This study suggests however, that such an approach overlooks the importance of an individual teacher's moral and personal character to 'good teaching' practices, such as the relational, ethical and moral practices described by Greene (1973), Hansen (1995), Noddings (2003), and Van Manen (1991b). Conceptualisations of VET teaching derived from reductionist approaches also influence the assumptions that underpin the sector's VET teacher development strategies. They produce equally atomised, lockstep approaches to VET teachers' ongoing professional development which focus on a narrow range of skills, knowledge and capabilities relating to compliance and industry currency, while neglecting other salient aspects of the teachers' intellectual, professional and personal development.

The thesis asserts that an alternative to the reductionist approach and its consequences lies in a sectoral shift towards a more holistic conceptualisation of advanced skills for VET teachers. This shift needs to recognise: i) the responsibilities of VET teachers' 
role as being broader than what can be described in a capability framework, and ii) the importance of the unique, irreproducible qualities and characteristics of the individual teacher to good teaching. The holistic conceptualisation understands that the 'whole' of good teaching can never be unpacked or represented as the sum of its parts, and would require a change in the way that VET teachers' skills, knowledge and capabilities are observed and articulated. It would also require an approach to professional learning which supports the development of the individual teacher's 'personhood' (Hansen, 2008a, p. 13) and which acknowledges the need for VET teachers to access an expansive range of developmental opportunities.

The study's findings support the necessity to expand and potentially transform the way the VET sector understands good VET teaching and to broaden its concept of VET teacher development. The findings also however, present a problem. It would not be wise to develop VET teacher development strategies without first deciding upon what is to be achieved - the 'underlying assumptions about teaching and education' (Hansen, 2008b, p. 5), to inform such strategies. It is difficult however, to articulate these assumptions until the sector develops the language required to adequately encapsulate a more holistic conceptualisation of teaching which recognises the importance of the individual teacher, and which is underpinned by '...the easy-to-overlook truth that it is persons, rather than roles as such, who educate' (Hansen, 2017, p. 7).

The literature reveals that such a language somewhat exists, and is reflected in, for example, Nodding's (1999; 2003; 2012; 2016a) concept of 'care' and in Van Manen's (1991a; 1991b; 1994) description of a teacher's thoughtful and purposeful ethical and moral practice during 'pedagogical moments'. Adding to this vocabulary is Greene (1973), who used the term 'authentic choosing' to task teachers with a responsibility to decide and act critically, intentionally and thoughtfully according to the best interests of their students, and Hansen (2001), who deemed the word 'conduct' suitable to depict the visible, individual and morally considered actions of dedicated, committed teachers, for whom teaching is more than simply a job (p. 28). Whether this pre-existing language is relatable and meaningful to teachers within Australia's VET sector however, is a question to ask of them. The language needed is more likely to evolve from those VET teachers themselves, rather than from those who manage them, given that the study found VET managers were more likely to apply a reductionist approach to conceptualise VET teaching, while VET teachers expressed 
conceptualisations of advanced skills more holistically. The language may also, already exist, and need only to be made visible, providing the sector can find a way to listen, ask, or to provide a safe space for it to be revealed, as Clandinin and Connelly (1995) assert that the secret narratives teachers develop and tell about their teaching practice inside the safe place of the classroom may not be the same narratives they reveal to others outside of it. Certainly Brennan Kemmis \& Green (2013) suggest this to be the case.

The moral, social and personal dimensions of teaching, and the recognition of the importance of these dimensions, survive in the expressions of praxis that come from those who have day to day responsibility for their students.' (Brennan Kemmis \& Green, 2013, p. 118)

The research has supported Clandinin and Connelly's (1995) position, demonstrating that the secret, yet authentic stories of good VET teaching are constructed and enacted in the safe space behind the classroom door ${ }^{7}$. It follows then, that only those who are the active players in such practice - in that particular space and place - can know, understand and reveal these stories. While there is no doubt that the views and voices of both students and teachers have been sought to inform contemporary views on VET teaching and to develop the sector's VET teaching capability frameworks (see for example, Smith \& Yasukawa, 2017), contemporary research on good VET teaching is perhaps unsurprisingly dominated by reductionist conceptualisations. Such a position does not provide the theoretical scaffolding necessary to reflect upon the richer, more holistic stories of advanced skills and the 'good' VET teacher, such as those revealed in this study. An alternative conceptual framework will be necessary to ensure we ask the right questions, those that will yield the answers we need to understand and to develop a more holistic conceptualisation of VET teaching which recognises the importance of the teacher and his/her individual character to good teaching.

The implications I have discussed thus far have been calls for action by the sector and by those who research it or develop policies about it. I must make a final call for action however, to VET teachers themselves. VET teachers with advanced skills, the 'good' VET teachers, know that they must make decisions and choices about teaching each day. They know that they understand 'good teaching' differently to their managers and differently to others who seek to influence the way that they teach through research, policy, curriculum

\footnotetext{
${ }^{7}$ Figuratively speaking, as the classroom may not exist in a physical space, and the relationship between teacher and student may be developed from a distance.
} 
design and regulation. Despite this knowledge and the dilemmas it creates, good VET teachers still make conscious, moral, ethical and authentic choices about what to teach, how to teach and the things that must be prioritised in order to do so, even when such choices are in conflict with policy and the sacred stories of the sector and the organisation. The call to action which I make to VET teachers requires them to continue to practice authentically, ethically and morally, and to know that it is important that they continue to do so. Just as Donnelly (1999), would urge that they continue to look very hard and critically at demands for an increased emphasis on instrumentality' (p. 947) and Greene (1973) would implore them to consciously and actively resist unthinking submergence into the system, I encourage VET teachers to continue their resistance, to actively interrogate further reductionist attempts to describe their work, and to require that those who would seek to manage or shape their teaching work are compelled to remember the importance of the individual VET teacher in good VET teaching - 'that it is persons rather than roles who educate' (Hansen, 2017, p.9).

To conclude this thesis, I will relate the story of 'The Twenty-Foot Fifoot' (Witsenhuysen, 2017), a larger than life streetscape mural of teacher, Bob Fifoot, painted by artist Claire Foxton on the wall of a concrete building in the small rural town of Gatton where I grew up. Mr Fifoot taught mathematics at Lockyer District High School for 49 years, and while this is an impressive tenure, it was not the inspiration for the mural. Mr Fifoot was a legendary teacher with a unique identity, a sense of humour and a genuine care for and connection with his students. Upon his retirement in 2013, students left tributes to Bob on social media and YouTube, relating their memories of his unique and sometimes absurd sense of humour with quotes of his favourite sayings, such as 'rhubarb, rhubarb, rhubarb'. They also remembered the influence that he had on their lives and their future. I am sure that Bob did not always comply with the sacred stories of the education system and the school during his career - another of his favourite sayings was '2,4,6,8, we don't want to integrate' - but his words and actions spoke of a genuine concern for his students and their success:

I did teach for 49 years at Lockyer High and made sure I did everything I could to help all of my students flourish over the years. (Mr Bob Fifoot, as reported by Witsenhuysen, 2017)

The 'Twenty-Foot Fifoot' mural is not only a tribute to teacher Bob Fifoot, but a visual reminder of the importance of the unique personality, and the individual moral and ethical character of the person who fulfils the role of teacher. There are many teachers like Bob Fifoot, and they are quietly and individually influencing the lives of students from all sectors 
of education, including VET. To recognise such teachers, and to ensure that there will be more like Bob Fifoot to ensure the success of future generations, we must find a way to identify, describe and develop such individuals, and to understand that to conceptualise good VET teaching, and good teaching in all sectors, we must first understand that the whole is quite likely to be more than that which can be measured by the sum of its parts. 


\section{REFERENCES}

Anderson, D. (1997). Competition and market reform in the Australian VET sector: Review of research. Adelaide: NCVER.

Anderson, D. (1998). Refocusing market reform. In C. Robinson \& R. Kenyon (Eds.), The market for vocational education and training (pp. 307-322). Adelaide: NCVER.

Anderson, D. (2005). Trading places: the impact and outcomes of market reform in vocational education and training. Adelaide: NCVER.

Anderson, D., Brown, M., \& Rushbrook, P. (2004). Vocational Education and Training. In G. Foley (Ed.), Dimensions of adult learning: Adult education and training in a global era (pp. 234-250). Maidenhead, England: Open University Press.

Arnold, I. (2011). [Review of the book, Visible learning: A synthesis of over 800 metaanalyses relating to achievement by J. Hattie] (Vol. 57) pp. 219-221. Dordrecht, Netherlands: Springer.

Atkins, L. (2010). Opportunity and aspiration, or the great deception? The case of 14-19 Vocational Education. Power and Education, 2(3), 253-265.

doi:10.2304/power.2010.2.3.253

Atkins, L., \& Tummons, J. (2017). Professionalism in vocational education: International perspectives. Research in Post-Compulsory Education, 22(3), 355-369. doi:10.1080/13596748.2017.1358517

Australian Committee on Technical and Further Education \& Kangan, M. (1974). TAFE in Australia: Report on needs in technical and further education, April 1974 (Kangan report). Canberra, Australia: Retrieved July 17, 2018, from http://hdl.handle.net/11343/115331

Australian Institute for Teaching and School Leadership. (2011). Australian Professional Standards for Teaching. Carlton, VIC: Education Services Australia.

Australian National Training Authority. (1997). Research reports into professional development. Brisbane: ANTA. 
Australian Skills Quality Authority. (2017). User's guide to the Standards for Registered Training Organisations Version 2.0. Canberra: Australian Government, Retrieved 8 July, 2018, from www.asqa.gov.au

Australian Skills Quality Authority. (2018). How does ASQA regulate? Canberra: Australian Government, Retrieved 8 July, 2018, from https://www.asqa.gov.au/about/howdoes-asqa-regulate

Ball, S. J. (1994). Education reform: A critical and post-structural approach. Philadelphia: Open University Press.

Bassey, M. (1999). Case study research in educational settings. Buckingham, England: Open University Press.

Bathmaker, A. (2000). Standardising teaching: The introduction of the national standards for teaching and supporting learning in further education in England and Wales. Journal of In-Service Education, 26(1), 9-23. doi:10.1080/13674580000200101

Bazeley, P., \& Jackson, K. (2013). Qualitative data analysis with NVivo (2nd ed.). London: SAGE.

Berger, P. L., \& Luckmann, T. (1966). The social construction of reality: A treatise in the sociology of knowledge (1st ed.). New York: Doubleday.

Biesta, G. (2009). Good education in an age of measurement: on the need to reconnect with the question of purpose in education. Educational Assessment, Evaluation and Accountability, 21(1), 33-46. doi:10.1007/s11092-008-9064-9

Billett, S. (2014). The standing of vocational education: sources of its societal esteem and implications for its enactment. Journal of Vocational Education and Training, 66(1), 1-21. doi:10.1080/13636820.2013.867525

Billett, S., Choy, S., \& Smith, R. (2013). Evaluation of continuing professional development programs provided by the VET Development Centre. Melbourne: VET Development Centre. 
Billett, S., McKavanagh, C., Beven, F., Angus, L., Seddon, T., Gough, J., Hayes, S., \& Robertson, I. (1999). The CBT decade: Teaching for flexibility and adaptability. Adelaide: NCVER.

Bogdan, R., \& Biklen, S. K. (2007). Qualitative research for education: An introduction to theories and methods (5th ed). Boston: Pearson.

Borer, M. I., \& Fontana, A. (2012). Postmodern trends: Expanding the horizons of interviewing practices and epistemologies. In J. F. Gubrium, J. A. Holstein, A. B. Marvasti, \& K. D. McKinney (Eds.), The SAGE handbook of interview research: The complexity of the craft (2nd ed.) (pp. $45-60)$. Thousand Oaks: SAGE.

Boyatzis, R. E. (1998). Transforming qualitative information: Thematic analysis and code development. Thousand Oaks: SAGE.

Braddock, G. (2006). Sartre on atheism, freedom, and morality in the humanism of existentialism. In C. Daigle (Ed.), Existentialist thinkers and ethics (pp. 91-106). Montreal: McGill-Queen's University Press.

Braithwaite, V. (2018). All eyes on quality: Review of the National Vocational Education and Training Regulator Act 2011 report. Canberra: Australian Government.

Braun, V., \& Clarke, V. (2006). Using thematic analysis in psychology. Qualitative Research in Psychology, 3(2), 77-101. doi:10.1191/1478088706qp063oa

Brennan Kemmis, R., \& Green, A. (2013). Vocational education and training teachers' conceptions of their pedagogy. International Journal of Training Research, 11(2), 101-121. doi:10.5172/ijtr.2013.11.2.101

Brookfield, S. D. (1995). Becoming a critically reflective teacher. San Francisco: Jossey Bass.

Brown, J. S., Collins, A., \& Duguid, P. (1989). Situated cognition and the culture of learning. Educational Researcher, 18(1), 32-42.

Buchanan, J. (2012). Beyond the fragments: Reflections on the recent Victorian VET reform. Australian TAFE Teacher, 46(Spring), 16-17. 
Chappell, C., Gonczi, A. \& Hager, P. (1994). Kangan and development of TAFE teacher education. In H. Kearns \& W. Hall (Eds.), Kangan 20 years on: A commemmoration TAFE 1974 - 1994 (pp. 183-192). Adelaide: NCVER.

Chappell, C., \& Johnston, R. (2003). Changing work: Changing roles for vocational education and training teachers and trainers, Adelaide: NCVER.

Chase, S. E. (2011). Narrative inquiry: still a field in the making. In N. K. Denzin \& Y. S. Lincoln (Eds.), The SAGE handbook of qualitative research (4th ed.). (pp. 421-434). Thousand Oaks: SAGE.

Clandinin, D. J., \& Connelly, F. M. (1996). Teachers' professional knowledge landscapes: Teacher stories-stories of teachers-school stories-stories of schools. Educational Researcher, 25(3), 24-30. doi:10.2307/1176665

Clandinin, D. J., \& Connelly, F. M. (2000). Narrative inquiry: Experience and story in qualitative research (Vol. 1). San Francisco: Jossey-Bass.

Clayton, B., Jonas, P., Harding, R., Harris, M., \& Toze, M. (2013). Industry currency and professional obsolescence: What can industry tell us? Adelaide: NCVER.

Clayton, B., Meyers, D., Bateman, A., \& Bluer, R. (2010). Practitioner expectations and experiences with the Certificate IV in Training and Assessment (TAA40104). Adelaide: NCVER.

Commonwealth Government of Australia: Department of Education and Training. (2015). Standards for Registered Training Organisations (RTOs) 2015. Canberra: Australia, retrieved on 30 March, 2018 from

\section{https://www.legislation.gov.au/Details/F2017C00663}

Connelly, F. M., \& Clandinin, D. J. (1988). Teachers as curriculum planners: Narratives of experience. New York: Teachers College Press.

Connelly, F. M., \& Clandinin, D. J. (1995). Teachers' Professional Knowledge Landscapes: Secret, Sacred, and Cover Stories, In D. J. Clandinin \& F. M. Connelly (Eds.), Teachers' professional knowledge landscapes (pp. 3-15). New York: Teachers College Press. 
Connelly, F. M., \& Clandinin, D. J. (1999). Shaping a professional identity: Stories of educational practice. New York: Teachers College Press.

Corbel, C., Wheelahan, L., Forward, P., \& Darwin, S. (2014). Building future capabilities for vocational education: Why high-level teaching qualifications matter for TAFE teachers. Southbank: Australian Education Union.

Corben, H., \& Thomson, K. (2001). What makes a great teacher? Attributes of excellence in VET. Paper presented at the TAFE Educational Services Research Conference held October, 2001 in Sydney, Australia.

Council of Australian Governments. (2008). Council of Australian Governments Meeting Communique: 29th November 2008. Canberra, Australia. Retrieved $15^{\text {th }}$ July, 2018, from https://www.coag.gov.au/meeting-outcomes/coag-meeting-communiqué-29november-2008

Cousin, G. (2010). Positioning positionality: The reflexive turn. In M. Savin-Baden \& C. H. Major (Eds.), New approaches to qualitative research: Wisdom and uncertainty (pp. 9-18). New York: Routledge.

Creswell, J. W. (2009). Research design: qualitative, quantitative, and mixed methods approaches (3rd ed.). Thousand Oaks: SAGE

Creswell, J. W. (2013). Qualitative inquiry and research design: Choosing among five approaches (3rd ed.). Thousand Oaks: SAGE

Creswell, J. W., \& Plano Clark, V. L. (2018). Designing and conducting mixed methods research (3rd ed.). Thousand Oaks: SAGE.

Crotty, M. (1998). The foundations of social research: Meaning and perspective in the research process. St Leonards, NSW: Allen \& Unwin.

Daigle, C. (2006). Existentialist thinkers and ethics. Montreal: McGill-Queen's University Press.

Darwin, S. (2007). The changing contexts of vocational education: Implications for institutional vocational learning. International Journal of Training Research, 5(1), 5571. doi:10.5172/ijtr.5.1.55 
Dawkins, J. (1988). Industry training in Australia: The need for change [Dawkins report]. Canberra: Australian Government Publishing Service.

Day, C. (2004). Passion for teaching. London: Routledge Falmer.

Denzin, N. K., \& Lincoln, Y. S. (2011). The SAGE handbook of qualitative research (4th ed.). Thousand Oaks: SAGE.

Dewey, J. (1966). Democracy and education: An introduction to the philosophy of education. New York: Free Press.

Dickie, M., Eccles, C., FitzGerald, I., McDonald, R., Cully, M., Blythe, A., Stanwick, J., \& Brooks, L. (2004). Enhancing the capability of VET professionals project: Final report (incorporating data analysis and literature review). Brisbane: ANTA.

Donnelly, J. (1999). Schooling Heidegger: On being in teaching. Teaching and Teacher Education, 15(8), 933-949.

Duckworth, V., \& Smith, R. (2018). Women, adult literacy education and transformative bonds of care. Australian Journal of Adult Learning, 58(2), 157-183.

Duncan, M., \& Watson, R. (2010). Taking a stance: Socially responsible ethics and informed consent. In M. Savin-Baden \& C. H. Major (Eds.), New approaches to qualitative research: wisdom and uncertainty (pp. 49-58). New York: Routledge.

Eisenhardt, K. M. (1989). Building theories from case study research. The Academy of Management Review, 14(4), 532-550. doi:10.2307/258557

Eisenhardt, K. M., \& Graebner, M. E. (2007). Theory building from cases: Opportunities and challenges. The Academy of Management Journal, 50(1), 25-32. doi:10.5465/AMJ.2007.24160888

Eisner, E. W. (1991). The enlightened eye: Qualitative inquiry and the enhancement of educational practice. New York: Macmillan

Eisner, E. W. (1994). The educational imagination: On the design and evaluation of school programs (3rd ed.). New York: Macmillan. 
Elliott, G. (2017). Preface to M. Daley, K. Orr, \& J. Petrie (Eds.), The Principal: Power and professionalism in FE, (pp. xxiii - xxvi). London: loE Press.

Fleming, P., \& Tertiary Education Council. (1978). Formal preparation of TAFE teachers in Australia: a report to the Council by the Staff Development Advisory Committee [Fleming report]. Canberra: Australian Government Publishing Service.

Flyvbjerg, B. (2006). Five misunderstandings about case-study research. Qualitative Inquiry, 12, 219-245. doi:10.1177/1077800405284363

Freire, P. (1972). Pedagogy of the oppressed. Harmondsworth: Penguin Education.

Gage, N. L. (1989). The Paradigm Wars and Their Aftermath: An "Historical" Sketch of Research on Teaching since 1989. Educational Researcher, 18(7), 4-10. doi:10.2307/1177163

Gage, N. L., \& Travers, R. M. W. (1973). Second handbook of research on teaching: A project of the American Educational Research Association. Chicago: Rand McNally.

Gall, M. D., Gall, J. P., \& Borg, W. R. (2007). Educational research: An introduction (8 ${ }^{\text {th }}$ Vol.). Boston: Pearson, Allyn \& Bacon.

Gibbs, G. (2002). Qualitative data analysis: Explorations with NVivo. Buckingham: Open University Press.

Giroux, H. A. (1992). Border crossings: Cultural workers and the politics of education. London: Routledge.

Giroux, H. A. (1997). Pedagogy and the politics of hope: Theory, culture, and schooling : a critical reader. Boulder: Westview Press.

Goozee, G. (2001). The development of TAFE in Australia. Adelaide: NCVER.

Grbich, C. (2013). Qualitative data analysis: an introduction (2nd ed.). Thousand Oaks: SAGE.

Greene, M. (1973). Teacher as stranger: Educational philosophy for the modern age. Belmont: Wadsworth.

Greene, M. (1988). Quality in teacher education. Educational Policy, 2(3), 235-250. doi:10.1177/0895904888002003001 
Griffin, T. (2017). Are we all speaking the same language? Understanding 'quality' in the VET sector. Adelaide: NCVER.

Grubb, W. N. (1996). The 'new vocationalism' in the United States: Returning to John Dewey. Educational Philosophy and Theory, 28(1), 1-23. doi:10.1111/j.14695812.1996.tb00229.x

Guba, E. G., \& Lincoln, Y. S. (1981). Effective evaluation. San Francisco: Jossey-Bass

Gubrium, J. F., \& Holstein, J. A. (2012). Narrative practice and the transformation of interview subjectivity. In J. F. Gubrium, J. A. Holstein, A. B. Marvasti, \& K. D. McKinney (Eds.), The SAGE handbook of interview research: The complexity of the craft (2nd ed.). (pp. $27-44)$. Thousand Oaks: SAGE.

Guthrie, H. (2010). Professional development in the Vocational Education and Training workforce. Adelaide: NCVER.

Guthrie, H., \& Clayton, B. (2012). An association for VET's professionals: What's the story? Paper presented at The value and voice of VET research for individuals, industry,community and the nation: The 15th Australian Vocational Education and Training Research Association Conference, held 12-13 ${ }^{\text {th }}$ April 2012 at Capital Hill, ACT.

Guthrie, H., McNaughton, A., \& Gamlin, T. (2011). Initial training for VET teachers: A portrait within a larger canvas. Adelaide: NCVER.

Guthrie, H., Smith, E., Burt, S., \& Every, P. (2014). Review of the effects of funding approaches on Service Skills qualifications and delivery in Victoria. Melbourne: Victoria University.

Hall, W., Hayton, G., Mageean, P., \& Scarfe, J. (1990). National review of TAFE teacher preparation and development: Stages $1 A$ and $1 B$, skills and competencies. Adelaide: TAFE National Centre for Research and Development.

Hansen, D. T. (1994). Teaching and the sense of vocation. Educational theory, 44(3), 259275.

Hansen, D. T. (1995). The call to teach. New York: Teachers College Press. 
Hansen, D. T. (1998). The moral is in the practice. Teaching and Teacher Education, 14(6), 643-655. doi:10.1016/S0742-051X(98)00014-6

Hansen, D. T. (2001). Exploring the moral heart of teaching: toward a teacher's creed. New York: Teachers College Press.

Hansen, D. T. (2008a). Values and purpose in teacher education. In M. Cochran-Smith, S. Feiman-Nemser, J. McIntyre, \& K. Denmers (Eds.), Handbook of research on teacher education: Enduring questions in changing contexts (3rd ed.), (pp. 10-26). New York: Routledge.

Hansen, D. T. (2008b). Why educate teachers? In M. Cochran-Smith, S. Feiman-Nemser, J. McIntyre, \& K. Denmers (Eds.), Handbook of research on teacher education: Enduring questions in changing contexts (3rd ed.), (pp. 10-26). New York: Routledge.

Hansen, D. T. (2017). Bearing witness to teaching and teachers. Journal of Curriculum Studies, 49(1), 7 - 23. doi:10.1080/00220272.2016.1205137

Hargreaves, D. (1993). A common-sense model of the professional development of teachers. In J. Elliott (Ed.), Reconstructing teacher education: Teacher development (pp. 86-92). London: Falmer Press.

Harris, R. (2015). Quality in the Australian VET sector: What has been happening? International Journal of Training Research, 13(1), 16-34.

Harris, R. (2017). What do we learn from 40 years of history? Issues in VET teacher education from Kangan to today. International Journal of Training Research, 15(1), 4-22. doi:10.1080/14480220.2017.1321158

Harris, R., \& Hodge, S. (2009). A quarter of a century of CBT: The vicissitudes of an idea. International Journal of Training Research, 7(2), 122-133. doi:10.5172/ijtr.7.2.122

Harris, R., Simons, M., \& Clayton, B. (2005). Shifting mindsets: The changing work roles of vocational education and training practitioners. Adelaide: NCVER.

Harris, R., Simons, M., Hill, D., Smith, E., Pearce, R., Blakeley, J., Choy, S., \& Snewin, D. (2001). The changing role of staff development for teachers and trainers in vocational education and training. Adelaide: NCVER. 
Harris, R. M. (1995). Competency-based education and training: Between a rock and a whirlpool. South Melbourne: Macmillan

Hattie, J. (2012). Visible learning for teachers: Maximizing impact on learning. London: Routledge.

Heidegger, M. (1962). Being and time (1st English ed.). New York: Harper.

Henry, J. (2001). Work based learning and professional development in the VET sector of Australia. Adelaide: Reframing the Future

Hetherington, D., \& Rust, J. (2014). Training days: Models of vocational training provision: lessons from the Victorian experience. Fine Print, 37(1), 8-20.

Highet, G. (1951). The art of teaching. Quarterly Journal of Speech, 37(1), 53-54. doi:10.1080/00335635109381635

Hodge, S. (2014). Interpreting competencies in Australian vocational education and training: Practices and issues. Adelaide: NCVER.

Hodge, S. (2015). Martin Heidegger: Challenge to education. Switzerland: Springer.

Hodge, S. (2016). After competency-based training: Deepening critique, imagining alternatives. International Journal of Training Research, 14(3), 171-179. doi:10.1080/14480220.2016.1261432

Hodge, S., \& Harris, R. (2012). Discipline, governmentality and 25 years of competencybased training. Studies in the Education of Adults, 44(2), 155-170. doi:10.1080/02660830.2012.11661630

Hodgson, A., \& Spours, K. (2015). The future for FE colleges in England: The case for a new post-incorporation model. In A. Hodgson (Ed.), The Coming of Age for FE? Reflections on the past and Future Role of Further Education Colleges in the UK. (pp. 199-219). London: Institute for Education.

hooks, B. (1994). Teaching to transgress: Education as the practice of freedom, New York: Routledge.

hooks, B. (2009). Teaching critical thinking: Practical wisdom. New York: Routledge 
Innovation and Business Skills Australia. (2013). VET Capability Framework Implementation Guide. Canberra: Department of Industry, Innovation, Climate Change, Sicence, Rsearch and Tertiary Education, Retrieved on 14 July, 2015 from https://www.ibsa.org.au/sites/default/files/media/VET\%20Capability\%20Framework \%20Implementation\%20Guide.pdf.

Jackson, P. W. (1992). Untaught lessons, New York:Teachers College Press.

Jones, A., Pitard, J., \& McClusky, T. (2011). Pathways for VET educators: Higher level VET education qualifications and higher education articulation framework. East Melbourne: IBSA.

Kearns, P., \& Hall, W. (1994). Introduction to Kangan 20 years on: A commemoration. In P. Kearns \& W. Hall (Eds.), Kangan 20 years on: A commemoration: TAFE 1974-1994. (pp. 1-8) Adelaide: NCVER.

Kvale, S., \& Brinkmann, S. (2015). Interviews: Learning the craft of qualitative research interviewing ( $3^{\text {rd }}$ Vol.). Los Angeles: SAGE.

Laursen, P. F. (2005). The authentic teacher. In M. P. C. Beijaard D., Morine-Dershimer G., Tillema H. (Ed.), Teacher professional development in changing conditions (pp. 199212). Netherlands: Springer.

Lave, J., \& Wenger, E. (1991). Situated learning: Legitimate peripheral participation. Cambridge: Cambridge University Press.

Leavy, P. (2017). Research design: Quantitative, qualitative, mixed methods, arts-based, and community-based participatory research approaches. New York: Guilford.

LH Martin Institute. (2016). Draft: Overview of the VET Teaching Capability Framework. Melbourne: University of Melbourne. Retrieved on 17 March, 2017 from http://www.Ihmartininstitute.edu.au/userfiles/files/Projects/VET\%20quality\%20of\% 20teaching/DRAFT\%20\%20-\%20Capability\%20Framework\%2019022016(v2).pdf.

Lifelong Learning UK. (2007). New overarching professional standards for teachers, tutors and trainers in the lifelong learning sector. London: Lifelong Learning UK.

Lincoln, Y. S., \& Guba, E. G. (1985). Naturalistic inquiry. Newbury Park: SAGE. 
Lincoln, Y. S., \& Guba, E. G. (1990). Judging the quality of case study reports. International Journal of Qualitative Studies in Education, 3(1), 53-59.

doi:10.1080/0951839900030105

Lincoln, Y. S., Lynham, S. A., \& Guba, E. G. (2011). Paradigmatic controversies, contradictions, and emerging confluences, revisited. In N. K. Denzin \& Y. S. Lincoln (Eds.), The SAGE Handbook of Qualitative Research (4th ed.). (pp. 97 - 128). Thousand Oaks: SAGE

Lortie, D. (2002). Schoolteacher: A sociological study. Chicago: University of Chicago Press.

Lowrie, T., Smith, E., \& Hill, D. (1999). Competency-Based Training: A staff development perspective. Adelaide: NCVER.

Lucas, N. (2002). The introduction of national standards and compulsory teacher education for further education college teachers in England: Issues and challenges. Teacher Development, 6(3), 459-476. doi:10.1080/13664530200200178

Macmurray, J. (1964). Teachers and Pupils. The Educational Forum, 29(1), 17-24. doi:10.1080/00131726409339304

Maxted, R. (2015). Critical Pedagogy in FE. In M. Daley, K. Orr, \& J. Petrie (Eds.) Further education and the twelve dancing princesses. London: IoE Press.

Maxwell, J. A. (2005). Qualitative research design: An interactive approach (2nd ed.). Thousand Oaks: SAGE.

Maykut, P. S., \& Morehouse, R. (1994). Beginning qualitative research: A philosophic and practical guide. London: Falmer Press.

McDonald, R. (2011). No substitute for the real thing: A discussion on the nature of vocational education and training. Melbourne: National Quality Council.

Merriam, S. B. (2009). Qualitative research: A guide to design and implementation. San Francisco: Jossey-Bass.

Miles, M. B., \& Huberman, A. M. (1994). Qualitative data analysis: An expanded sourcebook (2nd ed.). Thousand Oaks: SAGE 
Mishler, E. G. (1986). Research interviewing: Context and narrative. Cambridge: Harvard University Press.

Misko, J. (1999). Competency-based training. Adelaide: NCVER.

Mitchell, J. (2008). Capabilities of the emerging 'advanced VET practitioner'. Paper presented at VET in context, the 11th Conference of the Australian VET Research Association in Adelaide, South Australia

Mitchell, J., Chappell, C., Bateman, A., \& Roy, S. (2006). Quality is the key: Critical issues in teaching, learning and assessment in vocational education and training. Adelaide: NCVER.

Mitchell, J., \& Ward, J. (2010). The JMA Analytics Model of VET Capability Development: A report on the national survey of Vocational Education and Training (VET) practitioner skills, conducted October-November 2009. Sydney: John Mitchell and Associates.

Mulcahy, D. (2003). Teaching standards and professionalism in TAFE: Prospects, possibilities and pitfalls. Paper presented at The changing face of VET, the sixth Australian VET Research Association conference on 9-11 April, 2003 at Eveleigh, NSW.

Mulcahy, D. (2011). Assembling the 'accomplished' teacher: The performativity and politics of professional teaching standards. Educational Philosophy and Theory, 43(1), 94113. doi:10.1111/j.1469-5812.2009.00617.x

Nakar, S., Bagnall, R. G., \& Hodge, S. (2018). A reflective account of the VET FEE-HELP initiative as a driver of ethical dilemmas for vocational education teachers in Australia. The Australian Educational Researcher, 45(3), 383-400. doi:10.1007/s13384-018-0257-z

National Health and Medical Research Council, Australian Research Council, \& Universities Australia. (2007). National Statement on Ethical Conduct in Human Research 2007 Canberra: Commonwealth of Australia.

National Skills Standards Council. (2013). Improving vocational education and training: The case for a new system. Canberra: Commonwealth of Australia. 
National VET Equity Advisory Council. (2011). Equity blueprint 2011-2016. Creating futures: Achieving potential through VET. Technical and Vocational Education and Training Australia Limited (TVET): Melbourne.

Noddings, N. (1999). Caring and competence. In G. A. Griffin (Ed.), The education of teachers. (pp. 205 - 220). Chicago: University of Chicago Press

Noddings, N. (2003). Is teaching a practice? Journal of Philosophy of Education, 37(2), 241251. doi:10.1111/1467-9752.00323

Noddings, N. (2012). The caring relation in teaching. Oxford Review of Education, 38(6), 771781. doi:10.1080/03054985.2012.745047

Noddings, N. (2016a). Moral life and education. Action in Teacher Education, 38(3), 212-216. doi:10.1080/01626620.2016.1194783

Noddings, N. (2016b). Philosophy of education (4th ed.). Boulder: Westview Press.

Palmieri, P. (2004). Approaches to the idea of the 'good teacher' in vocational education and training. Paper presented at Doing the public good: positioning education research, Annual conference of AARE, held in Melbourne, Victoria.

Patton, M. Q. (2002). Qualitative research and evaluation methods (3 ed.). Thousand Oaks: SAGE.

Peoples, K. (1998). A market for all. In C. Robinson \& R. Kenyon (Eds.), The market for vocational education and training (pp. 200-207). Adelaide: NCVER.

Piccardi, K. (2013). The emerging role of enterprise learning consultants. Adelaide: NCVER.

Polesel, J. (2010). Vocational education and training (VET) and young people: The pathway of the poor? Education and Training, 52(5), 415-426. doi:10.1108/00400911011058352

Preskill, S. (1998). Narratives of teaching and the quest for the second self. Journal of Teacher Education, 49(5), 344-357. doi:10.1177/0022487198049005004

Pring, R. (2004). The skills revolution. Oxford Review of Education, 30(1), 105-116. doi:10.1080/0305498042000190078 
Productivity Commission. (2011). Vocational education and training workforce. Melbourne: Commonwealth of Australia.

PWC's Skills for Australia. (2017). TAE Training and Education Training Package Release 2.1. Canberra: Commonwealth of Australia.

Queensland College of Teachers. (2015). Draft professional standards for vocational education and training practitioners. Brisbane: Queensland College of Teachers, Retrieved $12^{\text {th }}$ May, 2016, from http://fet.qct.edu.au

Queensland Government. (2008). TAFE Qld governance consultation paper. Brisbane: Department of Education, Training and the Arts.

Queensland Industrial Relations Commission. (2016). TAFE Queensland Educators Certified Agreement 2016. Brisbane: QIRC, Retrieved $14^{\text {th }}$ May, 2017 from http://www.qirc.qld.gov.au/qirc/resources/pdf/certified_agreements/cert_agreeme nts/2016/ca213_2016.pdf.

Queensland VET Development Centre. (2012). Queensland vocational education and training (VET) continuous professional learning strategy: 2012-2015. Brisbane: Department of Education, Training and Employment.

Rancière, J. (1991). The ignorant schoolmaster. California: Stanford University Press.

Rasmussen, C. (2016). Improving the quality, capability and status of the VET teacher workforce. Victoria: Department of Education and Training:

Reframing the Future. (2008). Reframing the Future: Developing Australia's VET workforce to implement the national training system. Reframing the Future: Retrieved on $18^{\text {th }}$ August, 2018, from http://pandora.nla.gov.au/pan/125081/201102110948/www.reframingthefuture.net/Default.html

Riessman, C. K. (1993). Narrative analysis. Newbury Park: SAGE

Robertson, I. (2008). VET teachers' knowledge and expertise. International Journal of Training Research, 6(1), 1-22. 
Robinson, C. (1998). The VET product and the development of the training market. In C. Robinson \& R. Kenyon (Eds.), The market for vocational education and training (pp. 102-124). Adelaide: NCVER.

Robinson, C., \& Kenyon, R. (Eds.). (1998). The market for vocational education and training. Adelaide: NCVER.

Rushbrook, P., \& Mackinnon, R. (1998). Technocrat or visionary? Reflections on the Kangan legacy. In F. Ferrier \& D. Anderson (Eds.), Different drums, one beat? Economic and social goals in education and training. (pp 159 - 164). Adelaide: NCVER.

Sartre, J. (1977). Essays in existentialism. In W. Baskin (Ed.). Seacaucus: Citadel Press.

Schmidt, T. (2016). Excellence in VET teaching: How does context influence the understanding and recognition of advanced skills in the VET sector? Paper presented at Policy \& Teaching Practice: building connections, the 2nd Annual National ACDEVEG Conference on VET Teaching and VET Teacher Education Research held on the $8^{\text {th }}-9^{\text {th }}$ December at University of Technology, Sydney.

Schmidt, T. (2017a). Capabilities and context: What are advanced skills for VET practitioners? Paper presented at Renovate or rebuild: Exploring the architecture of VET, the 20th Annual AVETRA Conference on $28^{\text {th }}-20^{\text {th }}$ April, 2017, at William Angliss Institute of TAFE, Melbourne.

Schmidt, T. (2017b). Context and capabilities: tensions between managers' and teachers' views of advanced skills in VET. International Journal of Training Research, 15(1), 4154. doi:10.1080/14480220.2017.1331862

Schmidt, T. (2017c). Developing a dual identity: Does maintaining industry currency hinder the development of advanced teaching skills for VET teachers? Paper presented at the ACDEVEG 3rd Annual Conference, Driving the Future Quality of VET Teaching in Australia, on $7^{\text {th }}$ and $8^{\text {th }}$ December, 2017 at TAFE Queensland South Bank Campus, Brisbane.

Schmidt, T. (2018). Is the sum of the parts equal to the whole? Alternatives for a more holistic conceptualisation of the 'good' VET teacher. Paper presented at the 
Australian Vocational Education and Training Research Association Research Forum on $26^{\text {th }}$ October, at Canberra Institute of Technology.

Schmidt, T. (2019 in print). Industry currency and vocational teachers in Australia: what is the impact of contemporary policy and practice on their professional development? Research in Post Compulsory Education. doi:10.1080/13596748.2019.1584431

Schön, D. A. (1983). The reflective practitioner: How professionals think in action. New York: Basic Books

Schubert, R. (2017). Putting a stake in the ground: Quality teaching in VET. Paper presented at the 19th Annual Australian Vocational Education and Training Research Association Conference on 21-22 April, 2017, at TAFE Northern Sydney campus.

Seddon, T. (2001). Exploring capacity-building: From functionalist to political analysis. Australian and New Zealand Journal of Vocational Education Research, 9(2), 61-86.

Shulman, L. (1987). Knowledge and teaching: Foundations of the new reform. Harvard Educational Review, 57(1), 1-23.

Simons, M., \& Harris, R. (2001). Differing realities: Staff development in public and private providers of VET. Paper presented at Research to reality: Putting VET research to work, AVETRA conference held on $28^{\text {th }}-30^{\text {th }}$ March, 2001, at Victoria Square, Adelaide.

Simons, M., Harris, R., Pudney, V., \& Clayton, B. (2009). Careers in Vocational Education and Training: What Are They Really Like? Adelaide: NCVER.

Simons, M., \& Smith, E. (2008). The understandings about learners and learning that are imparted in Certificate IV level courses for VET teachers and trainers. International Journal of Training Research, 6(1), 23-43. doi:10.5172/ijtr.6.1.23

Skilbeck, M., Connell, H., Lowe, N., \& Tait, K. (1994). The vocational quest: New directions in education and training. London: Routledge.

Skills Australia. (2010). Creating a future direction for Australian vocational education and training: A discussion paper on the future of the VET system. Canberra: Commonwealth of Australia. 
Skills Australia. (2011). Skills for prosperity: A roadmap for vocational education and training. Canberra: Skills Australia.

Smith, E. (2000). Dinosaurs or horses to water? Engagement in staff development by teachers in further and higher education. In F. Beven, C. Kanes, \& D. Roebuck (Eds.), Learning together, working together: building communities in the 21st century: Proceedings of the 8th Annual International Conference on Post-Compulsory Education and Training: volume one. (pp.174-182). Brisbane: Australian Academic Press.

Smith, E. (2009). Teachers, instructors and trainers: An Australian focus. In R. Maclean, D. Wilson, \& C. Chinien (Eds.), International Handbook of Education for the Changing World of Work (pp. 1203 - 1217). Dordrecht: Springer.

Smith, E., \& Grace, L. (2011). Vocational educators' qualifications: A pedagogical poor relation? International Journal of Training Research, 9(3), 204-217.

Smith, E., \& Keating, J. (2003). From training reform to training packages. Tuggerah: Social Science Press.

Smith, E., Smith, A., Hampson, I., \& Junor, A. (2015). How closely do Australian Training Package qualifications reflect the skills in occupations? An empirical investigation of seven qualifications. International Journal of Training Research, 13(1), 49-63. doi:10.1080/14480220.2015.1051351

Smith, E., \& Yasukawa, K. (2016). Views of VET teachers, managers and students about VET teacher qualifications. Paper presented at Putting VET research to work: Collaboration, Innovation, Prosperity. 19th Annual Australian Vocational Education and Training Research Association Conference on the $20^{\text {th }}-22^{\text {nd }}$ April, 2016 at TAFE NSW Northern Sydney Institute.

Smith, E., \& Yasukawa, K. (2017). What makes a good VET teacher? Views of Australian VET teachers and students. International Journal of Training Research, 15(1), 23-40. doi:10.1080/14480220.2017.1355301

Squires, G. (1999). Teaching as a professional discipline. London: Falmer Press. 
Stake, R. E. (1978). The Case Study Method in Social Inquiry. Educational Researcher, 7(2), 58. doi:10.3102/0013189X007002005

Stake, R. E. (1995). The art of case study research. Thousand Oaks: SAGE.

Stake, R. E. (2006). Multiple case study analysis. New York: The Guilford Press.

Stake, R. E. (2010). Qualitative research: Studying how things work. New York: Guilford Press.

TAFE Queensland. (2016). Educator Capability Framework (Version 5). Brisbane: TAFE Queensland.

Tom, A. R. (1980). Teaching as a moral craft: A metaphor for teaching and teacher education. Curriculum Inquiry, 10(3), 317-323. doi:10.1080/03626784.1980.11075226

Tomlinson, S. (1997) Education 14-19: divided and divisive, in S. Tomlinson (Ed.). Education 14-19: Critical perspectives. London: Athlone Press

Toner, P. (2014). Contracting out publicly funded vocational education: A transaction cost critique. The Economic and Labour Relations Review, 25(2), 222-239.

Toner, P. (2018). How economics explains failure of the publicly funded privately delivered training market. Melbourne: University of Melbourne, Retrieved on 7 July, 2018 from https://melbourne-cshe.unimelb.edu.au/lh-martininstitute/resources/resources/innovation/role-of-tafe-vet

Toze, M., \& Tierney, S. (2010). Keeping it real: Industry currency of trainers in Queensland. Brisbane: Department of Education and Training.

Tummons, J. (2014). Professional standards in teacher education: Tracing discourses of professionalism through the analysis of textbooks. Research in Post-Compulsory Education, 19(4), 417-432. doi:10.1080/13596748.2014.955634

Turner-Bisset, R. (2001). Expert teaching: Knowledge and pedagogy to lead the profession. Oxfordshire: Routledge. 
Tyler, M., \& Dymock, D. (2017). Continuing professional development for a diverse VET practitioner workforce. Adelaide: NCVER.

Van Maanen, J. (1983). Reclaiming qualitative methods for organisational research: A preface. Administrative Science Quarterly, 24(4), 520 - 526.

Van Manen, M. (1991a). Reflectivity and the pedagogical moment: The normativity of pedagogical thinking and acting. Journal of Curriculum Studies, 23(6), 507-536. doi:10.1080/0022027910230602

Van Manen, M. (1991b). The tact of teaching: The meaning of pedagogical thoughtfulness. Albany: State University of New York Press.

Van Manen, M. (1994). Pedagogy, virtue, and narrative identity in teaching. Curriculum Inquiry, 24(2), 135-170.

Velg Training (2018). Velg Training. Retrieved on $17^{\text {th }}$ July, 2018, from https://www.velgtraining.com

VET Development Centre. (2016). VET Development Centre: About us. Melbourne: VET Development Centre, Retrieved on $17^{\text {th }}$ July, 2018, from https://vdc.edu.au/aboutus/

Walker, R. (2012). A quality VET teaching and learning framework for community colleges. Paper presented at The value and voice of VET research for individuals, industry, community and the nation, 15th Annual AVETRA Conference, held on the $12^{\text {th }}$ and $13^{\text {th }}$ April, 2012 at Capital Hill, ACT.

Wellington, J. J. (2000). Educational research: Contemporary issues and practical approaches. London: Continuum.

Wheelahan, L. (2017). How competency-based training locks the working class out of powerful knowledge: A modified Bernsteinian analysis'. British Journal of Sociaology of Education, 28(5), $637-651$.

Wheelahan, L., \& Moodie, G. (2011). The quality of teaching in VET: Final report and recommendations. Australian Government. Retrieved $5^{\text {th }}$ August, 2013, from http://austcolled.com.au/sites/default/files/quality vetteaching final report1.pdf 
Whitelock, D. (1974). The great tradition: A history of adult education in Australia. Brisbane: University of Queensland Press.

Williams, K. M. (2010). Examining education qualifications for Australian vocational education practitioners. Journal of Vocational Education and Training, 62(2), 183194. doi:10.1080/13636821003797648

Witsenhuysen, F. (2017, July 3). Twenty Foot Fifoot. The Gatton Star. Retrieved 20 February, 2019 from https://www.gattonstar.com.au/news/twenty-foot-fifoot/3196279/

Wolcott, H. F. (1994). Transforming qualitative data: Description, analysis, and interpretation. Thousand Oaks: SAGE.

Wolcott, H. F. (2009). Writing up qualitative research (3rd ed.). Los Angeles: SAGE.

Yin, R. K. (2014). Case study research: Design and methods (5th ed.). Los Angeles: SAGE. 


\section{APPENDICES}

List of Appendices

Appendix A: Plain Language Information Statement and Informed Consent

Appendix B: Interview Schedule for VET Managers

Appendix C: Interview Schedule for VET Teachers

Appendix D: Cross Case Analysis Worksheets (Tables 1,2,3 and 4) 
Appendix A: Plain Language Information Statement and Informed Consent 


\section{What are advanced skills for VET teachers and how are they developed? INFORMATION SHEET}

\begin{tabular}{|l|l|}
\hline $\begin{array}{l}\text { Who is conducting the } \\
\text { research }\end{array}$ & $\begin{array}{l}\text { Teressa Schmidt (Student Researcher) } \\
\text { School of Education and Professional Studies } \\
\text { Phone: 0434 175 658 } \\
\text { Email: teressa.schmidt@griffith.edu.au }\end{array}$ \\
& Steven Hodge (Research Supervisor) \\
& School of Education and Professional Studies \\
& Phone: (07) 373 55712 \\
& Mobile: 0421 22 44 74 \\
& Email: s.hodge@griffith.edu.au \\
& \\
\hline
\end{tabular}

You are invited to participate in a research project which will investigate how Advanced Vocational Education and Training (VET) teachers develop their expertise. While the term 'Advanced VET Practitioner' is frequently used in the VET sector to describe VET teachers with advanced skills, the nature of these skills and how they are developed has not been established. In this study, data will be collected from interviews with VET managers and VET teachers with advanced skills. Interviews will be conducted in 3 large Registered Training Organisations based in Queensland. A case study on each organisation will be developed from the interview data and an analysis of the case studies will be used to answer the following research questions:

- How are advanced skills for VET teachers understood?

- How do VET teachers develop advanced skills?

It is envisaged that the research findings may inform the design of future learning and development programs for VET teachers.

The principal researcher ( $\mathrm{Dr}$ Steven Hodge) is a Lecturer and experienced researcher from the School of Education and Professional Studies, Griffith University. Teressa Schmidt is a PhD student at the School of Education and Professional Studies, Griffith University, and this research is being undertaken for preparation of a PhD thesis. Teressa has extensive experience in Vocational Education and Training as both a manager and VET teacher at a Queensland TAFE Institute, but is now self-employed as a developer of learning and assessment resources.

The purpose of this Information Sheet is to explain the research project, to provide you with details of what you will be required to do if you agree to participate, and to inform you of the expected time commitment required. Participation is voluntary, and you can choose to withdraw consent and discontinue participation in the research project at any time, and without explanation. 
You will be asked to undertake the following activities:

A principal interview will be conducted of approximately 60 - 90 minutes duration. If required, there may be a follow up interview of 30-60 minutes duration. Interviews will be audiotaped, and a transcript of each interview will be sent to participants for review. The interviews will be semi-structured, and the researcher may ask the participant specific questions relating to the research topic. The participant can choose not to answer any particular question.

The project uses a multiple case study methodology, and case studies will be developed for three large Registered Training Organisations. Data collected from participants will be used to develop the case studies. Pseudonyms will be used to protect the identity of participants, but due to the small sample size, identification may be possible. Transcripts, audiotapes and copies of documents will be stored in a locked filing cabinet and only available to the researcher. All transcripts, audiotapes and copies of documents will be destroyed 5 years after the thesis is published. Electronic files will be retained on a password protected computer, and deleted 5 years after publishing. Only the researchers named in this letter will have access to the data.

At the conclusion of the project, a thesis will be published. Participants will receive a copy of the thesis if requested, or a summary of the findings and recommendations. Results of the research project will be presented at research conferences, and published in relevant journals. These publications will not include any direct or indirect references to you.

While it is considered that the project presents no more than everyday risk to participants, in the unlikely event that distress may be caused in reflecting on previous unhappy educational experiences, participants will be encouraged to seek the services of Lifeline. Lifeline provides telephone counselling services 24 hours a day, 7 days per week.

The telephone number for Lifeline is: 131114

If you have any questions, or you would like further information regarding the project titled 'From novice to expert - how do VET practitioners develop advanced skills', please contact the Research Supervisor, Steven Hodge of the School of Education and Professional Studies using the following contact details:

Phone: (07) 37355712

Mobile: 0421224474

Email: s.hodge@griffith.edu.au

Should you (i.e. the participant) have any concerns about the ethical conduct of this research project, please contact Manager, Research Ethics, at Griffith University Human Research Ethics Committee on 37354375 (or research-ethics@griffith.edu.au) 


\title{
What are advanced skills for VET teachers and how are they developed? CONSENT FORM
}

\author{
Research Team Teressa Schmidt (Student Researcher) \\ School of Education and Professional Studies \\ Phone: 0434175658 \\ Email: teressa.schmidt@griffith.edu.au \\ Steven Hodge (Research Supervisor) \\ School of Education and Professional Studies \\ Phone: (07) 37355712 \\ Mobile: 0421224474 \\ Email: s.hodge@griffith.edu.au
}

By signing below, I confirm that I have read and understood the information package and in particular have noted that:

- I understand that my involvement in this research will include (the completion of one interview of $60-90$ minutes duration, and a possible follow up interview of 30 -60 minutes duration);

- I have had any questions answered to my satisfaction;

- I understand the risks involved;

- I understand that there will be no direct benefit to me from my participation in this research;

- I understand that my participation in this research is voluntary;

- I understand that if I have any additional questions I can contact the research team;

- I understand that I am free to withdraw at any time, without explanation or penalty;

- I understand that I can contact the Manager, Research Ethics, at Griffith University Human Research Ethics Committee on 37354375 (or research-

ethics@griffith.edu.au) if I have any concerns about the ethical conduct of the project; and

- I agree to participate in the project.

$\square$ I agree to participate in the project.

I agree to inclusion of my personal information in publications or reporting of the results from this research.

\begin{tabular}{|l|l|}
\hline Name & \\
\hline Signature & \\
\hline Date & \\
\hline
\end{tabular}


Appendix B: Interview Schedule VET Managers 


\title{
What are advanced skills for VET teachers and how are they developed? \\ INTERVIEW SCHEDULE - VET managers
}

\author{
Research Team Teressa Schmidt (Student Researcher) \\ School of Education and Professional Studies \\ Phone: 0434175658 \\ Email: teressa.schmidt@griffith.edu.au \\ Steven Hodge (Research Supervisor) \\ School of Education and Professional Studies \\ Phone: (07) 37355712 \\ Mobile: 0421224474 \\ Email: s.hodge@griffith.edu.au
}

\section{GU Ref No: $\quad$ EDN/64/15/HREC}

Interview Schedule: Primary Interview for managers of Registered Training Organisation (those responsible for the design and/or approval of professional development activities for VET Teachers)

1. Tell me about your experience in the VET sector

2. Are there VET teachers with advanced skills in this organisation?

3. How do you know that these teachers have advanced skills?

4. What is it that VET teachers with advanced skills do that is different to those who do not have advanced skills?

5. How do VET teachers develop advanced skills?

6. How does this organisation support the development of advanced skills? 
Appendix C: Interview Schedule VET Teachers 


\section{From novice to expert - how do VET teachers develop advanced skills? INTERVIEW SCHEDULE - VET teachers}

$\begin{array}{ll}\text { Research Team } & \text { Teressa Schmidt (Student Researcher) } \\ & \text { School of Education and Professional Studies } \\ & \text { Phone: } 0434175658 \\ & \text { Email: teressa.schmidt@griffith.edu.au } \\ & \text { Steven Hodge (Research Supervisor) } \\ & \text { School of Education and Professional Studies } \\ & \text { Phone: (07) 373 55712 } \\ & \text { Mobile: 0421 22 44 74 } \\ & \text { Email: } \underline{\text { s.hodge@griffith.edu.au }}\end{array}$

\section{GU Ref No: $\quad$ EDN/64/15/HREC}

Interview Schedule: Primary Interview for VET Teachers

1. Participants will be asked to firstly reflect upon their first week as a VET teacher before being asked:

a) How did you feel on the first day?

b) What were the challenges?

c) What were the memorable moments?

d) How well prepared did you feel when commencing as a VET teacher? i.e. Do you feel that you had the skills and knowledge necessary to do the job?

2. What are advanced skills for VET teachers?

3. How did you develop these skills and how long did it take?

4. For each of the following VET practitioner activities, describe how your practice as a practitioner with advanced skills would be different to that of a novice teacher?

(a) Designing learning experiences

(b) Delivering learning experiences - learning styles, managing the group, delivery in different settings and contexts (including blended learning)

(c) Using, understanding and unpacking training packages

(d) Designing and validating assessment

(e) Reporting, compliance, continuous improvement activities 
(f) Working with industry: networking; workplace delivery; managing commercial contracts

5. How did you develop your skills and knowledge in each of the following VET teacher activities? (Participants will be reminded that all learning activities - whether formal or informal - are significant.

(a) Designing learning experiences

(b) Delivering learning experiences - learning styles, managing the group, delivery in different settings and contexts (including blended learning)

(c) Using, understanding and unpacking training packages

(d) Designing and validating assessment

(e) Reporting, compliance, continuous improvement activities

(f) Working with industry: networking; workplace delivery; managing commercial contracts

6. Participants will be asked to reflect upon their professional development activities (formal and informal)

(a) How do you plan and manage your professional development?

(b) Which activities do you enjoy the most? Why?

(c) Which activities do you feel you gain the most benefit from? Why?

7. How do you remain current and upgrade your industry skills and knowledge? 
Appendix D: Cross Case Analysis Worksheets 
TABLE 1: Expected Utility of Cases for Each Theme

Adapted from Stake (2006, p. 43)

\section{Themes}

\begin{tabular}{|l|}
\hline 1 \\
\hline 2 \\
\hline 3 \\
\hline 4 \\
\hline 5
\end{tabular}

Can advanced skills be described as a list of skills, knowledge and capabilities?

Is there an aspect of advanced skills which is related to the individual character of the teacher?

Are there differences between the way that managers and teachers understand advanced skills?

What factors contribute to the development of advanced skills?

What are the barriers to the development of advanced skills?

\begin{tabular}{|c|c|c|}
\hline \multicolumn{3}{|c|}{$\begin{array}{l}\text { Utility of Cases for each theme } \\
H=\text { high utility } \\
M=\text { moderate utility } \\
L=\text { low utility }\end{array}$} \\
\hline Case A & Case B & Case C \\
\hline $\mathrm{M}$ & $\mathrm{M}$ & $\mathrm{L}$ \\
\hline $\mathrm{H}$ & $\mathrm{H}$ & $\mathrm{H}$ \\
\hline$M$ & $\mathrm{H}$ & $M$ \\
\hline $\mathrm{H}$ & $\mathrm{H}$ & $M$ \\
\hline $\mathrm{H}$ & $\mathrm{L}$ & $\mathrm{H}$ \\
\hline
\end{tabular}




\begin{tabular}{|c|c|c|c|c|c|}
\hline \multicolumn{5}{|l|}{ TABLE 2: Case Findings and Importance to Themes } & \\
\hline \multirow[t]{2}{*}{$\begin{array}{l}\text { CASE FINDINGS } \\
\text { CASE A }\end{array}$} & \multicolumn{5}{|c|}{$\begin{array}{l}\text { Ranking of importance to theme } \\
H=\text { high importance } \\
M=\text { moderate importance } \\
L=\text { low importance }\end{array}$} \\
\hline & 1 & 2 & 3 & 4 & 5 \\
\hline F1: VET teachers with advanced skills understand the curriculum and compliance requirements. & M & & & & \\
\hline F2: A person with advanced industry skills is not necessarily a VET teacher with advanced skills. & $\mathrm{L}$ & & & & \\
\hline $\begin{array}{l}\text { F3: To be a VET teacher with advanced skills, a teacher must also have the skills and knowledge to meet } \\
\text { the requirements of the job role. }\end{array}$ & $\mathrm{M}$ & & & & \\
\hline $\begin{array}{l}\text { F4: Teachers with advanced skills have interpersonal skills to connect and engage with students, to } \\
\text { identify and meet their needs in relation to learning. }\end{array}$ & & $\mathrm{H}$ & & & \\
\hline F5: Teachers with advanced skills have an enthusiasm and passion for teaching. & & $\mathrm{H}$ & & & \\
\hline F6: Teachers with advanced skills can engage with students when teaching in any mode/format. & & $\mathrm{L}$ & & & \\
\hline F7: Teachers with advanced skills use reflection to improve their teaching. & & $\mathrm{L}$ & & $\mathrm{L}$ & \\
\hline $\begin{array}{l}\text { F8: Managers are more likely than teachers to believe that teachers with advanced skills are those who } \\
\text { have the business skills to maintain the organisation's market competitiveness. }\end{array}$ & & & M & & \\
\hline $\begin{array}{l}\text { F9: Managers regard leadership and communication skills as advanced skills, but teachers place a higher } \\
\text { value on teaching. }\end{array}$ & & & M & & \\
\hline $\begin{array}{l}\text { F10: Tensions develop due to the divergent views of managers and teachers about advanced skills and } \\
\text { how they are developed. }\end{array}$ & & & M & & \\
\hline F11: Teachers with advanced skills demonstrate a commitment to their own learning and development. & & & & $\mathrm{L}$ & \\
\hline F12: Higher Education contributes to the development of advanced skills. & & & & $\mathrm{L}$ & \\
\hline $\begin{array}{l}\text { F13: The opportunity to learn from others contributes to the development of advanced skills (e.g. } \\
\text { mentoring, coaching, networks). }\end{array}$ & & & & $\mathrm{H}$ & \\
\hline F14: Advanced skills are learned through experience. & & & & $\mathrm{L}$ & \\
\hline $\begin{array}{l}\text { F15: The learning and development needs of teachers with advanced skills are different to those of } \\
\text { novice teachers. }\end{array}$ & & & & M & $\mathrm{L}$ \\
\hline $\begin{array}{l}\text { F16: Insufficient time and money to participate in learning opportunities are constraints which may } \\
\text { impact upon the development of advanced skills. }\end{array}$ & & & & & M \\
\hline
\end{tabular}




\begin{tabular}{|c|c|c|c|c|c|}
\hline $\begin{array}{l}\text { F17: Additional support and academic skills may be required by VET teachers to undertake higher level } \\
\text { study. }\end{array}$ & & & & & $\mathrm{L}$ \\
\hline CASE B & 1 & 2 & 3 & 4 & 5 \\
\hline $\begin{array}{l}\text { F1: VET teachers with advanced skills are more likely to be specialists in some areas, not advanced in } \\
\text { everything. }\end{array}$ & M & & & & \\
\hline $\begin{array}{l}\text { F2: Teachers with advanced skills have an intrinsic ability to be good teachers - it comes naturally to } \\
\text { them. }\end{array}$ & & M & & & \\
\hline F3: Teachers with advanced skills use personal skills of creativity, critical thinking and flexibility. & & M & & & \\
\hline $\begin{array}{l}\text { F4: Teachers with advanced skills have personal attributes and interpersonal skills which help them to } \\
\text { engage closely with students. }\end{array}$ & & $\mathrm{H}$ & & & \\
\hline F5: Teachers with advanced skills have a passion for teaching - it is more than a job. & & $\mathrm{H}$ & & & \\
\hline $\begin{array}{l}\text { F6: Managers are more likely to value skills relating to the use of technology to attain efficiencies and to } \\
\text { meet perceived student demands for flexible learning options. }\end{array}$ & & & $\mathrm{H}$ & & \\
\hline $\begin{array}{l}\text { F7: Managers are more likely to regard teachers with advanced skills as those who help the organisation } \\
\text { meet its business goals (e.g business skills and knowledge of the organisation's goals) . }\end{array}$ & & & $\mathrm{H}$ & & \\
\hline $\begin{array}{l}\text { F8: Managers are more likely to regard teachers with advanced skills as those who are good at } \\
\text { compliance and assessment. }\end{array}$ & & & $\mathrm{H}$ & & \\
\hline F9: Tensions develop due to the divergent views of managers and teachers about advanced skills. & & & M & & \\
\hline F10: Teachers with advanced skills take responsibility for their own learning and development. & & & & $\mathrm{H}$ & \\
\hline F11: The opportunity to learn from others contributes to the development of advanced skills. & & & & M & \\
\hline $\begin{array}{l}\text { F12: The professional development needs of teachers with advanced skills are different to those of } \\
\text { beginning teachers. }\end{array}$ & & & & M & \\
\hline F13: Studying higher level educational qualifications contributes to the development of advanced skills. & & & & M & \\
\hline F14: Experience contributes to the development of advanced skills. & & & & M & \\
\hline $\begin{array}{l}\text { F15: Learning and development offered by the organisation is often too narrowly focused on the skills } \\
\text { and knowledge needed for compliance rather than providing the opportunity to develop advanced skills } \\
\text { for teaching. }\end{array}$ & & & & & $\mathrm{L}$ \\
\hline $\begin{array}{l}\text { F16: Financial constraints, including the cost of replacement teachers, are a barrier to participation in } \\
\text { professional development activities and the development of advanced skills. }\end{array}$ & & & & & $\mathrm{L}$ \\
\hline
\end{tabular}




\begin{tabular}{|c|c|c|c|c|c|}
\hline $\begin{array}{l}\text { F17: An emphasis on industry currency requirements may create an unbalanced approach to professional } \\
\text { development and impact negatively on the development of teaching skills. }\end{array}$ & & & & & $\mathrm{H}$ \\
\hline CASE C & 1 & 2 & 3 & 4 & 5 \\
\hline $\begin{array}{l}\text { F1: VET teachers require current industry skills, but high levels of industry skills do not guarantee 'good } \\
\text { teaching'. }\end{array}$ & M & & & & \\
\hline $\begin{array}{l}\text { F2: VET teachers may have advanced skills even though they are not advanced in all aspects of the job } \\
\text { role. }\end{array}$ & $M$ & & & & \\
\hline $\begin{array}{l}\text { F3: Teachers with advanced skills have a passion for teaching, and gain enjoyment and satisfaction from } \\
\text { teaching. }\end{array}$ & & $\mathrm{H}$ & & & \\
\hline $\begin{array}{l}\text { F4: Teachers with advanced skills engage and connect easily with students to develop productive } \\
\text { relationships for learning. }\end{array}$ & & $\mathrm{H}$ & & & \\
\hline $\begin{array}{l}\text { F5: Managers are more likely to value and reward skills relating to compliance than outcomes of good } \\
\text { teaching. }\end{array}$ & & & $M$ & & \\
\hline $\begin{array}{l}\text { F6: Managers are more likely to see teaching skills as core to the VET teachers' job role, and advanced } \\
\text { skills as additional skills (such as business skills) which contribute to the organisation's goals. }\end{array}$ & & & $\mathrm{H}$ & & \\
\hline $\begin{array}{l}\text { F7: Tensions develop due to the divergent views of managers and teachers about advanced skills and } \\
\text { how they are developed. }\end{array}$ & & & $M$ & & \\
\hline F8: VET teachers with advanced skills take responsibility for their own learning and development. & & & & M & \\
\hline $\begin{array}{l}\text { F9: VET teachers need access to a wide range of developmental activities, and also the time to } \\
\text { participate in them. }\end{array}$ & & & & $M$ & \\
\hline $\begin{array}{l}\text { F10: Learning from others (e.g. mentoring, coaching, networking) is an effective means of developing } \\
\text { advanced skills. }\end{array}$ & & & & $\mathrm{H}$ & \\
\hline F11: An emphasis on maintaining industry currency may compromise the development of teaching skills. & & & & & $\mathrm{H}$ \\
\hline $\begin{array}{l}\text { F12: The administrative burden associated with compliance creates time constraints which is a barrier to } \\
\text { developing advanced skills. }\end{array}$ & & & & & $\mathrm{H}$ \\
\hline
\end{tabular}




\section{TABLE 3 - Merged Findings and Importance Rankings}

\begin{tabular}{|c|c|c|c|c|c|c|}
\hline \multicolumn{2}{|l|}{ Table adapted from Stake (2006, p. 59) } & \multicolumn{5}{|c|}{$\begin{array}{l}\text { Importance of Finding to Themes: } \\
H=\text { high importance } \\
M=\text { medium importance } \\
L=\text { Low importance }\end{array}$} \\
\hline Merged Findings & From which Cases? & 1 & 2 & 3 & 4 & 5 \\
\hline $\begin{array}{l}\text { MF1: A VET teacher requires advanced industry/vocational skills and knowledge, } \\
\text { but this does not necessarily lead to advanced teaching skills. }\end{array}$ & $A, C$ & $\mathrm{M}$ & & & & \\
\hline $\begin{array}{l}\text { MF2: Teachers with advanced skills must have certain skills and knowledge to do } \\
\text { the job, but are more likely to be specialists in some areas, not advanced in all. }\end{array}$ & $A, B, C$ & $\mathrm{H}$ & & & & \\
\hline $\begin{array}{l}\text { MF3: Teachers with advanced skills have personal attributes and interpersonal } \\
\text { skills to connect and engage authentically and meaningfully with students. }\end{array}$ & $A, B, C$ & & $\mathrm{H}$ & & & \\
\hline $\begin{array}{l}\text { MF4: Teachers with advanced skills have a passion and enthusiasm for teaching, } \\
\text { express a genuine commitment to successful outcomes for students, gain } \\
\text { satisfaction and enjoyment from teaching and a somewhat 'natural ability to } \\
\text { teach'. }\end{array}$ & $A, B, C$ & & $\mathrm{H}$ & & & \\
\hline $\begin{array}{l}\text { MF5: Managers' conceptualisations of advanced skills are more likely to be } \\
\text { contextual and related to the skills needed to contribute to the organisation's } \\
\text { business goals. }\end{array}$ & $A, B, C$ & & & $\mathrm{H}$ & & \\
\hline $\begin{array}{l}\text { MF6: Managers are more likely to regard teachers with advanced skills as those } \\
\text { who understand the curriculum and are good at compliance and assessment. }\end{array}$ & $\begin{array}{l}A, B, C \text { (stronger for } B \\
\& C)\end{array}$ & & & $\mathrm{H}$ & & \\
\hline $\begin{array}{l}\text { MF7: Tensions may develop due to the divergent views of managers and } \\
\text { teachers about advanced skills and how they are developed. }\end{array}$ & $A, B, C$ & & & $\mathrm{H}$ & & \\
\hline
\end{tabular}




\begin{tabular}{|c|c|c|c|c|c|c|}
\hline $\begin{array}{l}\text { MF8: Studying education at a higher level than the Certificate IV TAE (e.g. } \\
\text { Diploma, Bachelor and Postgraduate) contributes to the development of } \\
\text { advanced skills by improving pedagogical skills and knowledge and by allowing } \\
\text { teachers to experience the role of learner. }\end{array}$ & $A, B, C$ & & & & M & \\
\hline $\begin{array}{l}\text { MF9: The opportunity to learn from others (e.g. mentoring, coaching and } \\
\text { networking) contributes to the development of advanced skills. }\end{array}$ & $A, B, C$ & & & & $\mathrm{H}$ & \\
\hline MF10: Advanced skills are developed through time and experience. & $A, B, C$ & & & & M & \\
\hline $\begin{array}{l}\text { MF11: Teachers with advanced skills are likely to be lifelong learners who } \\
\text { demonstrate a commitment to their own learning and development and who } \\
\text { reflect on their own teaching to make improvements. }\end{array}$ & $A, B, C$ & & & & $\mathrm{H}$ & \\
\hline $\begin{array}{l}\text { MF12: Teachers with advanced skills have different learning and development } \\
\text { needs to beginning/novice teachers. }\end{array}$ & $A, B$ & & & & M & \\
\hline $\begin{array}{l}\text { MF13: Teachers require a wide range of developmental activities to develop } \\
\text { advanced skills. }\end{array}$ & $\mathrm{B}, \mathrm{C}$ & & & & $\mathrm{H}$ & $\mathrm{H}$ \\
\hline $\begin{array}{l}\text { MF14: Insufficient time and money to participate in learning opportunities are } \\
\text { constraints which may impact upon the development of advanced skills. } \\
\text { - Financial constraints include the cost of replacement teachers to enable } \\
\text { participation. } \\
\text { - The administrative burden associated with compliance takes time which } \\
\text { could be used for learning and development. }\end{array}$ & $A, B, C$ & & & & & $\mathrm{H}$ \\
\hline $\begin{array}{l}\text { MF15: An emphasis on industry currency requirements may impact upon the } \\
\text { development of teaching skills. }\end{array}$ & $\mathrm{B}, \mathrm{C}$ & & & & & $\mathrm{H}$ \\
\hline Special Findings (Case specific) & Case & 1 & 2 & 3 & 4 & 5 \\
\hline SF1: Managers regard leadership and communication skills as advanced skills. & A & & & $\mathrm{H}$ & & \\
\hline $\begin{array}{l}\text { SF2: Managers are more likely to regard those with high technological skills as } \\
\text { advanced. }\end{array}$ & B & & & $\mathrm{H}$ & & \\
\hline
\end{tabular}




\section{TABLE 4: Assertions}

\section{Assertion}

1. Teachers with advanced skills are more likely to conceptualise these holistically and recognise the importance of the teacher's individual qualities, while managers are more likely to express an atomised and contextual interpretation of advanced skills.

2. Teachers develop advanced skills through a variety of activities and advanced skills teachers take personal responsibility for their own continued learning and development.

3. The development of advanced skills may be negatively affected by insufficient resources and an unbalanced approach to professional development.

Relevant Merged Findings

MF 1,2,3,4,5,6,7

(Also relevant to Case Specific

Special Findings, SF1 and SF2)

MF $8,9,10,11,12,13$

MF13,14,15 
This page intentionally left blank 